\title{
Seismic Response Analysis of a 13-story Steel Moment-framed Building in Alhambra, California
}

\author{
By Janise E. Rodgers ${ }^{1}$, Ahmet K. Sanli ${ }^{2}$, and Mehmet Çelebi ${ }^{1}$
}

\section{Open-File Report 2004-1338}

\section{U.S. Department of the Interior} U.S. Geological Survey

\footnotetext{
${ }^{1}$ U.S. Geological Survey, Menlo Park, California

${ }^{2}$ Uzun and Case Engineers, 1180 West Peachtree Street, NE, Suite 1200, Atlanta, Georgia 30309
} 


\section{Table of Contents}

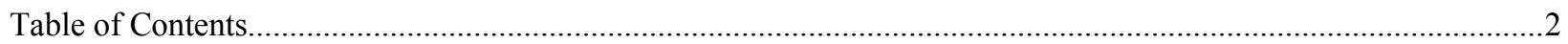

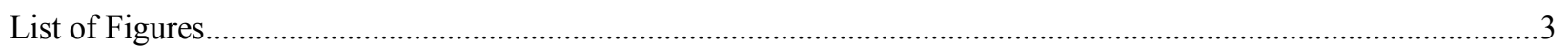

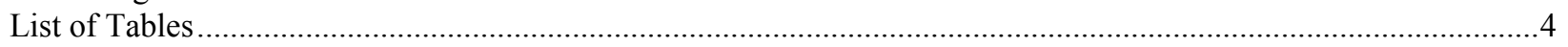

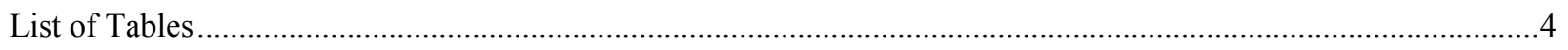

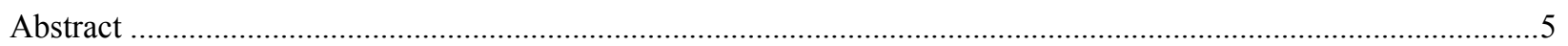

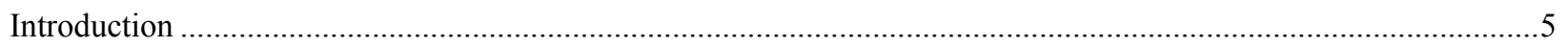

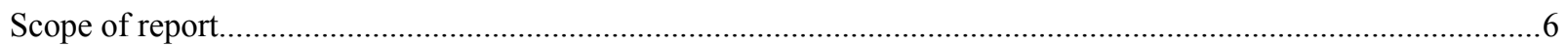

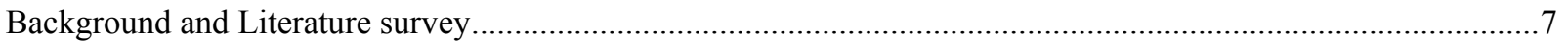

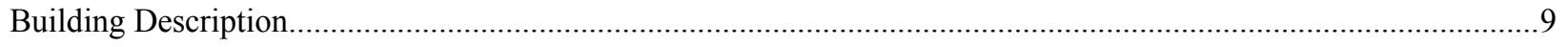

Structural system

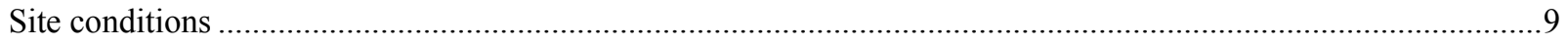

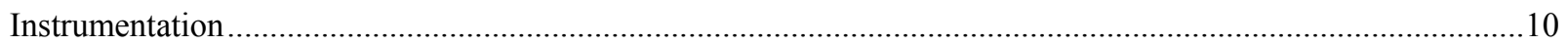

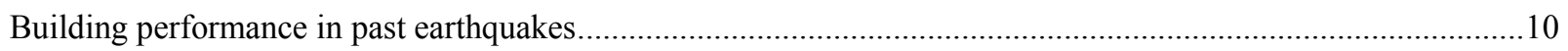

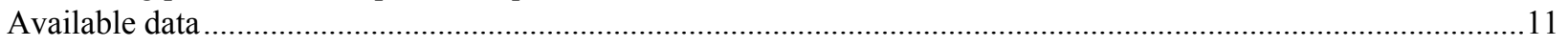

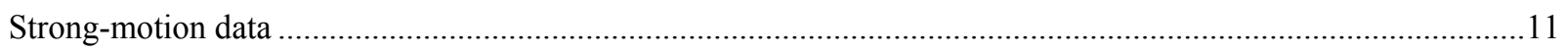

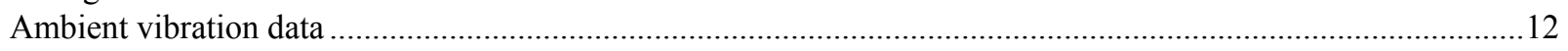

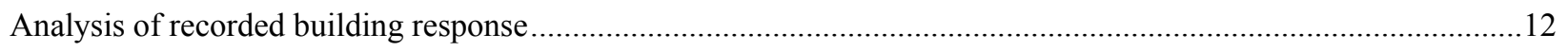

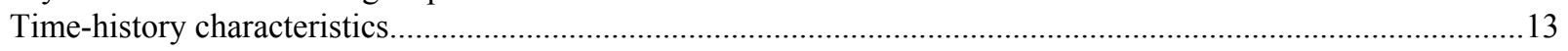

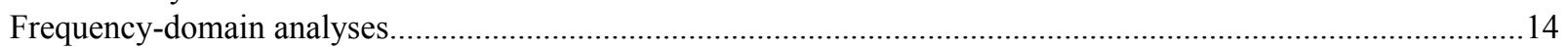

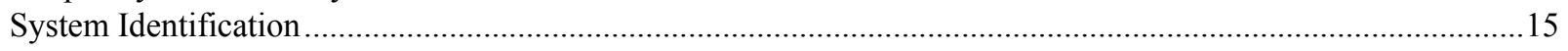

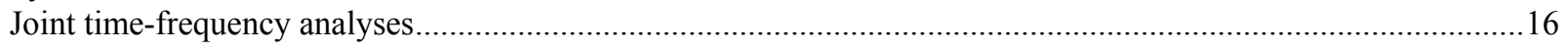

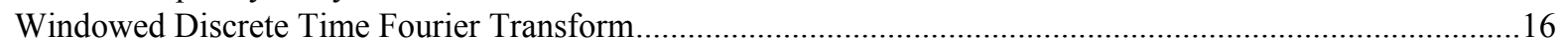

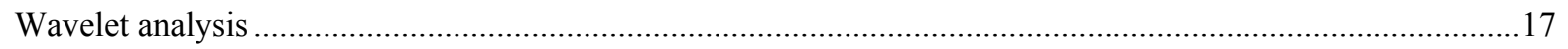

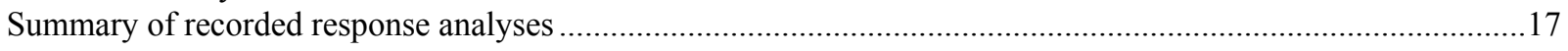

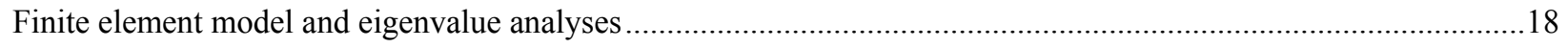

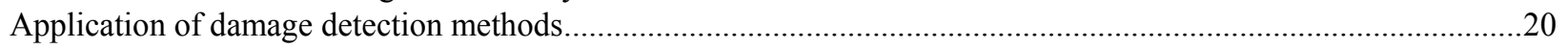

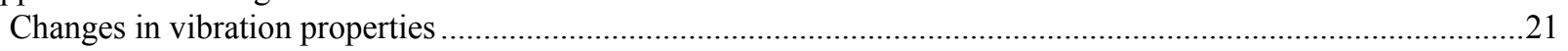

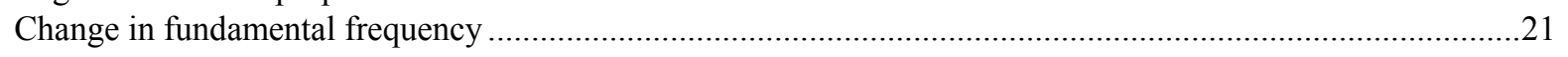

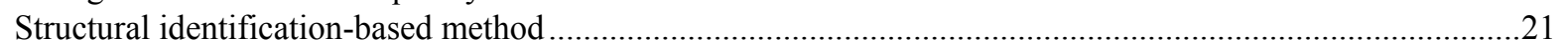

Methods based on changes in particular structural response quantities............................................................25

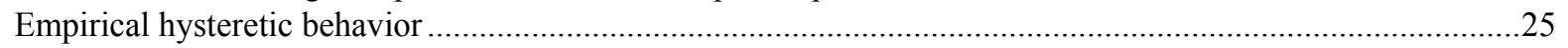

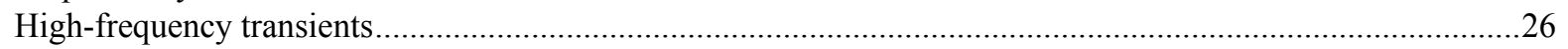

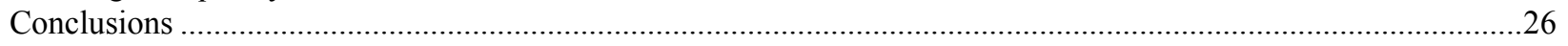

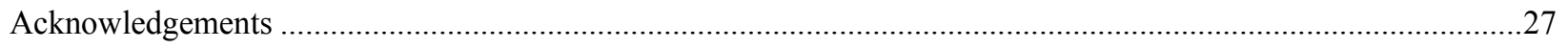

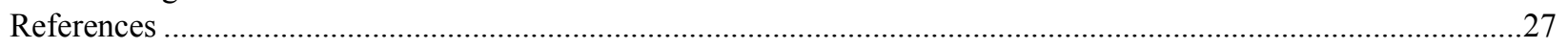

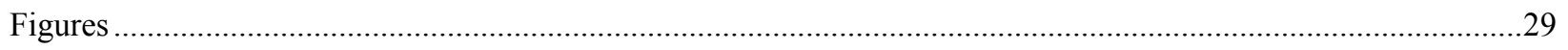




\section{List of Figures}

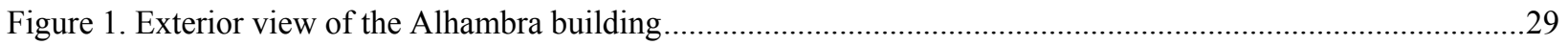

Figure 2. Location of Alhambra Building and epicenters of earthquakes with strong-motion data recorded ..............30

Figure 3. Location of Alhambra building with respect to mapped surface traces of major faults. The map location is

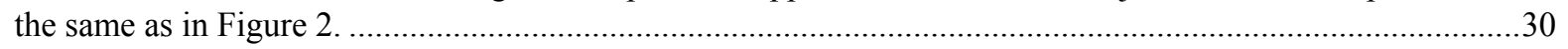

Figure 4. Massive concrete piers at the base of the building, extending from the ground floor to the second floor. The steel moment frame begins at the large black band (plate girder) directly above the piers. .................................31

Figure 5. Structural framing for a typical floor (plan view) ................................................................................

Figure 6. Code-recommended (left) and extensive (right) instrumentation configurations with channel numbering used elsewhere in report. Red arrows indicate the location and direction of each accelerometer. .....................32

Figure 7. Nominal torsional accelerations obtained by differencing the two parallel E-W channels at the $2^{\text {nd }}, 6^{\text {th }}$, and

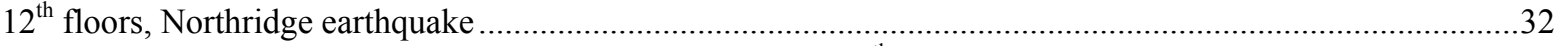

Figure 8. Acceleration, velocity and displacement time histories, $12^{\text {th }}$ floor E-W (Ch.2), Northridge earthquake ......33

Figure 9. Particle motion for San Fernando, Whittier Narrows, Landers, and Northridge earthquakes (full time

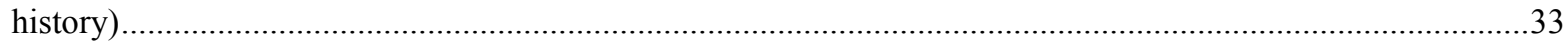

Figure 10. Ratios of measured response quantities versus peak base acceleration .....................................................34

Figure 11. Variation in first mode period with time (left) and peak base acceleration amplitude (right). Error bars

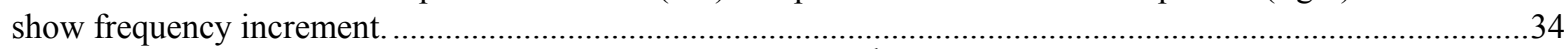

Figure 12. Comparison of 1 st mode frequency determined from $12^{\text {th }}$ floor N-S records from Fourier amplitude spectra (Sx), and autospectra with window lengths $k$ of half the record (Sxx k n/2) and the full record (Sxx $\mathrm{k} \sim \mathrm{n})$.

Figure 13. Comparison of 1 st mode frequency determined from $12^{\text {th }}$ floor E-W records from Fourier amplitude spectra (Sx), and autospectra with window lengths $k$ of half the record (Sxx k n/2) and the full record (Sxx $\mathrm{k} \sim \mathrm{n})$.

ure 14. Normalized translational Fourier amplitude spectra, $12^{\text {th }}$ floor N-S, high-amplitude (left) and lowamplitude (right) motions ..................................................................................................................... 36

Figure 15. Normalized torsional Fourier amplitude spectra, $12^{\text {th }}$ floor, high-amplitude (left) and low-amplitude

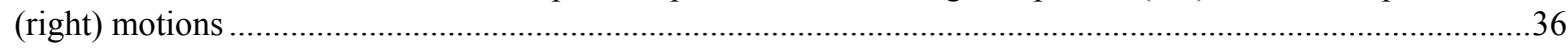

Figure 16. Ratios of translational Fourier amplitude spectra, Northridge earthquake ...............................................37

Figure 17. Ratios of torsional Fourier amplitude spectra, Northridge earthquake...................................................37

Figure 18. Spectral analysis of $2^{\text {nd }}, 6^{\text {th }}$, and $12^{\text {th }}$ floor accelerations, E-W channel pairs, Northridge earthquake........38 Figure 19. Results of system identification using the ARX method, Whittier Narrows earthquake, N-S direction. Excellent agreement between the recorded and computed responses at the $12^{\text {th }}$ floor was obtained...................39

Figure 20. System identification, Whittier Narrows earthquake, E-W direction. Excellent agreement between the

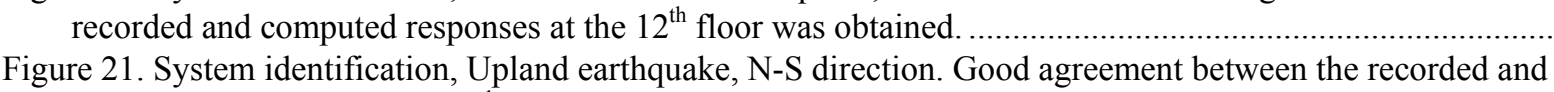
computed responses at the $12^{\text {th }}$ floor was obtained, despite the very low amplitude basement input motions, which are approaching the digitization resolution for the last 50 seconds of the record.

Figure 22. System identification, Upland earthquake, E-W direction. Good agreement between the recorded and computed responses at the $12^{\text {th }}$ floor was obtained, despite the very low amplitude basement input motions, which are approaching the digitization resolution for the last 50 seconds of the record.

Figure 23. System identification, Northridge earthquake, N-S direction. Excellent agreement between the recorded and computed responses at the $12^{\text {th }}$ floor was obtained.

Figure 24. System identification, Northridge earthquake, E-W direction. Excellent agreement between the recorded

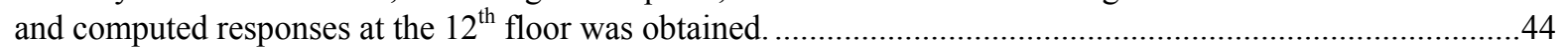

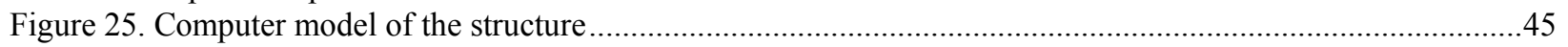

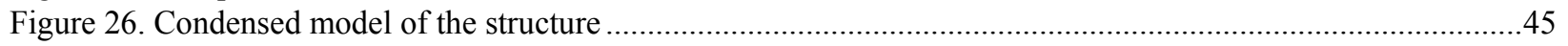

Figure 27. Approximate empirical hysteretic loops: recorded acceleration and computed displacement ...................46

Figure 28. Empirical hysteresis loops with forces estimated using linear interpolation of accelerations at intermediate floors (top) and cubic spline interpolation of displacements at intermediate floors, which are then double differentiated and low-pass filtered to obtain accelerations (bottom). Base shear is calculated by summing mass times acceleration at all floor levels.. 


\section{List of Tables}

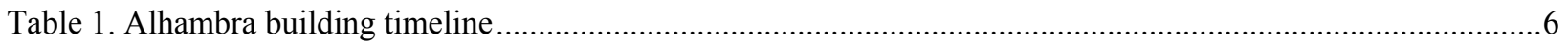

Table 2. Summary of Alhambra building studies to date ...................................................................................

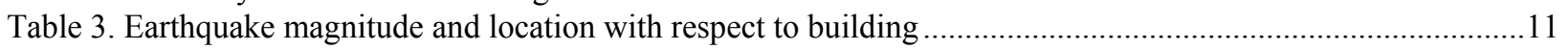

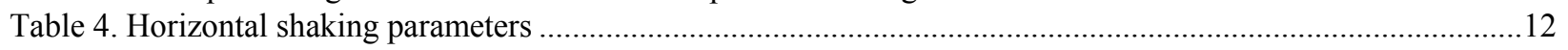

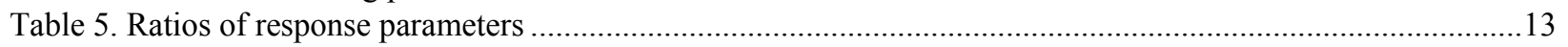

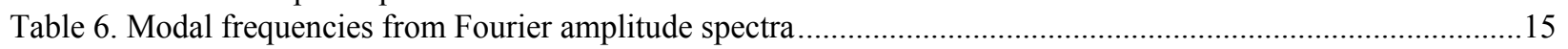

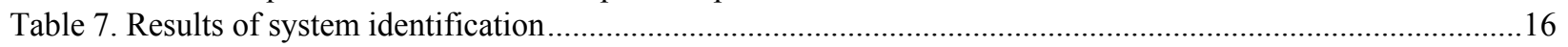

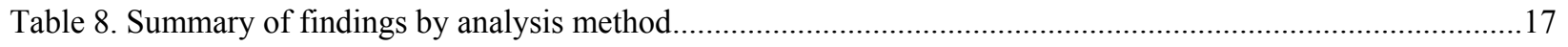

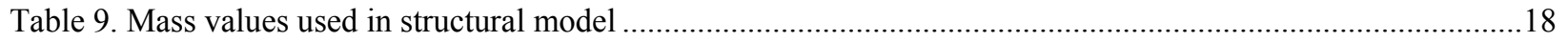

Table 10. Natural frequencies and mode shapes from eigenvalue analysis ........................................................19

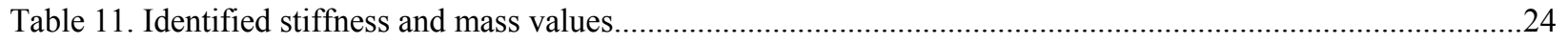

Table 12. Frequencies obtained from the earthquake records..................................................................................24

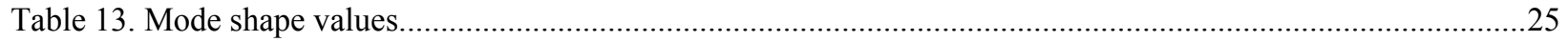




\title{
Seismic Response Analysis of a 13-story Steel Moment-framed Building in Alhambra, California
}

\author{
By Janise E. Rodgers ${ }^{1}$ Ahmet K. Sanli ${ }^{2}$, and Mehmet Çelebi ${ }^{1}$ \\ ${ }^{1}$ U.S. Geological Survey, Menlo Park, California \\ ${ }^{2}$ Uzun and Case Engineers, 1180 West Peachtree Street, NE, Suite 1200, Atlanta, Georgia 30309
}

\begin{abstract}
The seismic performance of steel moment-framed buildings has been of particular interest since brittle fractures were discovered at the beam-column connections of some frames following the M6.7 1994 Northridge earthquake. This report presents an investigation of the seismic behavior of an instrumented 13-story steel moment frame building located in the greater Los Angeles area of California. An extensive strong motion dataset, ambient vibration data, engineering drawings and earthquake damage reports are available for this building. The data are described and subsequently analyzed.
\end{abstract}

The results of the analyses show that the building response is more complex than would be expected from its highly symmetrical geometry. The building's response is characterized by low damping in the fundamental mode, larger peak accelerations in the intermediate stories than at the roof, extended periods of vibration after the cessation of strong input shaking, beating in the response, and significant torsion during strong shaking at the top of the concrete piers which extend from the basement to the second floor. The analyses of the data and all damage detection methods employed except one method based on system identification indicate that the response of the structure was elastic in all recorded earthquakes. These findings are in general agreement with the results of intrusive inspections (meaning fireproofing and architectural finishes were removed) conducted on approximately $5 \%$ of the moment connections following the Northridge earthquake, which found no earthquake damage.

\section{Introduction}

The Los Angeles County Public Works Headquarters is a 13-story steel moment-resisting frame office building located at 900 South Fremont Avenue, approximately $8 \mathrm{~km}$ ENE of downtown Los Angeles. For the sake of brevity, the building will hereafter be referred to as the Alhambra building. The building was designed in 1969 according to the 1967 Uniform Building Code (ICBO, 1967) and constructed in 1970. An exterior view of the building is shown in Figure 1. 
Due to the building's height, seismic instrumentation was required by the building code ${ }^{1}$. Since its instrumentation in 1971, the building has been shaken by numerous earthquakes of various magnitudes and epicentral distances, which are shown in Figure 2. The tectonic setting of the building and its proximity to major faults are shown in Figure 3. Records from all events which triggered the instruments have been digitized (if original records were from analog instruments) and processed, so an extensive strong motion dataset is now available. Ambient vibration tests have been performed on the building, and this data is available as well. Both datasets are described in this report. Due to the large amount of chronological information, a timeline of earthquakes, instrumentation changes, and ambient vibration testing is shown in Table 1. Further details are located in Appendix A.

Table 1. Alhambra building timeline

\begin{tabular}{|l|l|}
\hline Year & Event(s) \\
\hline 1969 & Designed in accordance with 1967 Uniform Building Code \\
\hline 1970 & Constructed \\
\hline 1971 & $\begin{array}{l}\text { Instrumented with code-mandated tri-axial accelerometers at basement, } 6^{\text {th }} \text {, and } 12^{\text {th }} \text { floors } \\
\mathrm{M}_{\mathrm{w}} \text { 6.6 San Fernando earthquake }\end{array}$ \\
\hline 1973 & $\mathrm{M}_{\mathrm{w}}$ 5.3 Point Mugu earthquake \\
\hline 1987 & $\mathrm{M}_{\mathrm{w}}$ 6.1 Whittier Narrows earthquake \\
$\mathrm{M}_{\mathrm{l}} 5.3$ Whittier Narrows aftershock of 10/4/1987
\end{tabular}

\section{Scope of report}

This report summarizes the significant amount of research conducted on the Alhambra building and its associated data sets by USGS researchers over the past several years. This report includes a description of the Alhambra building itself, including its performance during earthquakes, and of the recorded strong-motion and ambient vibration datasets available. These data are then analyzed using time domain, frequency domain, joint timefrequency, wavelet, and system identification methods, and results are presented. A finite element model of the building is presented, along with results of eigenvalue analyses conducted using the model. Several damage

\footnotetext{
${ }^{1}$ At the time, L.A. County mandated the UBC (ICBO, 1967) recommendations for tri-axial instruments at the roof, mid-height, and base of buildings 6 stories and higher with floor area greater than 60,000 square feet, and all buildings 10 stories and higher. After 1982, only a single tri-axial instrument at the roof was required.
} 
detection methods are also applied to the building data, and their ability to detect the observed earthquake damage is evaluated. The results are then synthesized and conclusions are presented regarding the building's dynamic behavior and performance in past earthquakes.

\section{Background and Literature survey}

The Alhambra Building has been the subject of or has been included in various studies to date. These studies include nonlinear dynamic analyses of a computer model of the building (Cohen 1996), evaluation of a damage detection method (Sanli and Çelebi 2002), system identification (Goel and Chopra 1997, Çelebi, unpublished), and ambient vibration tests (Çelebi and Liu, unpublished, Dunand et al. 2004). Building response was deemed to be essentially elastic (Cohen 1996) for earthquakes up to and including Whittier Narrows. Stiffness degradation of approximately ten percent was deemed to occur in both directions (Sanli and Çelebi 2002) between the 1987 Whittier Narrows and 1999 Hector Mine earthquakes.

Several interesting aspects of the building's behavior were noted by prior investigators. These aspects include lengthy vibration duration after the cessation of strong motion input (Cohen 1996, Sanli and Celebi 2002), very low damping (Cohen 1996, Goel and Chopra 1997), beating (Sanli and Çelebi 2002), a tendency for the highest accelerations to occur at intermediate floors rather than the roof (Cohen 1996, Sanli and Çelebi 2002), and difficulty in determining the second mode frequency due to the presence of several peaks on a swollen baseline in the Fourier amplitude spectra (Sanli and Çelebi 2002). All prior studies agree that the fundamental period of the structure is approximately 2.0 seconds in both the N-S and E-W directions.

These observations show that the response of the building to strong shaking is significantly more complex than what would be anticipated from the building's regular geometry. Basic observations by each investigator are summarized in Table 2 below.

Table 2. Summary of Alhambra building studies to date

\begin{tabular}{|c|c|}
\hline Study & Scope and summary of observations \\
\hline Cohen, 1996 & $\begin{array}{l}\text { Examined records from } 1971 \text { San Fernando and } 1987 \text { Whittier Narrows (WN) earthquakes } \\
\text { only; nonlinear dynamic analysis performed using DRAIN-2DX (public domain software, } \\
\text { U.C. Berkeley) and the } 1994 \text { Northridge Newhall record. } \\
\text { - Damping estimated at } 1.84 \% \text { from logarithmic decrement of WN record } \\
\text { - States report (source uncited) of structural damage to at least one corner in WN } \\
\text { - Reports anecdotal evidence (source uncited) of extended vibration }(\sim 2 \text { min) during } \\
\text { the WN event, causing panic in occupants and refusal to return to work } \\
\text { - Analysis predicted interstory drift ratios from } 0.88 \% \text { in the second story to } 1.66 \% \\
\text { in the } 10^{\text {th }} \text { story for Newhall record } \\
\text { - Analysis did not predict significantly higher accelerations for the } 2^{\text {nd }} \text { floor } \\
\text { - Analysis predicted beam end plastic rotation demands of } 0.4 \% \text { in } 2^{\text {nd }} \text { floor and } \\
1.4 \% \text { in the } 11^{\text {th }} \text { floor for Newhall record }\end{array}$ \\
\hline $\begin{array}{l}\text { Çelebi \& Liu, } \\
\text { unpublished, } 1996\end{array}$ & $\begin{array}{l}\text { Spectral analysis was performed on ambient data [Note: channel numbering differs from } \\
\text { that in this report (Roof NS is Ch.4, Roof EW is Ch.5, Roof NS is Ch.6)]. } \\
\text { - From roof response three frequencies were observed in both sets at approximately } \\
\text { 0.57, } 0.87 \text {, and } 1.58 \mathrm{~Hz} \text {. These are a bit higher than the first translational } \\
\text { frequency, first torsional frequency and second translational frequency (about } 0.5 \text {, } \\
0.8 \text {, and } 1.3 \mathrm{~Hz} \text { typically) obtained from spectral analysis of ground motions. }\end{array}$ \\
\hline
\end{tabular}




\begin{tabular}{|c|c|}
\hline Study & Scope and summary of observations \\
\hline $\begin{array}{l}\text { Goel \& Chopra, } \\
1997\end{array}$ & $\begin{array}{l}\text { System identification methods including the transfer function, modal minimization, and } \\
\text { autoregressive with extra input (ARX) methods were applied to a number of buildings with } \\
\text { strong-motion recordings. Period, damping, participation and contribution factors, initial } \\
\text { displacement, and initial velocity were determined for } 4 \text { modes in the E-W direction and } 6 \\
\text { modes in the N-S direction. } \\
\text { - Modal frequencies are determined, but have large errors especially for low } \\
\text { frequencies - it is unclear if errors are the same for each mode. } \\
\text { - First mode frequencies were determined to be } 0.465 \mathrm{~Hz}(\mathrm{EW}) \text { and } 0.450 \mathrm{~Hz}(\mathrm{NS}) \text {. } \\
\text { - Second mode frequencies were found to be } 1.305 \mathrm{~Hz}(\mathrm{EW}) \text { and } 1.273 \mathrm{~Hz}(\mathrm{NS}) \text {. } \\
\text { - Torsional modes were not explicitly identified } \\
\text { - First mode damping values were found to be } 1.19 \%(\mathrm{EW}) \text { and } 1.94 \%(\mathrm{NS}) \text {. }\end{array}$ \\
\hline $\begin{array}{l}\text { Post-Northridge } \\
\text { inspections, } \\
\text { unpublished, } 1997\end{array}$ & $\begin{array}{l}\text { Inspections performed by the County of Los Angeles and by a consulting engineering } \\
\text { firm. } \\
\text { - Small cracks (all FEMA designation W1 or smaller) at beam-column connections } \\
\text { were observed with ultrasonic testing (UT) following the } 1994 \text { Northridge } \\
\text { earthquake - no full separation of welds or girder flanges was noted. } \\
\text { - Approximately } 50 \text { connections ( } ~ 5 \% \text { of total) had inspections using UT with } \\
\text { backing bars removed } \\
\text { - Several core samples revealed slag inclusions and zones of incomplete fusion, } \\
\text { indicating poor weld quality } \\
\text { - No other structural damage was noted, but some nonstructural damage was } \\
\text { observed } \\
\text { - In the opinion of the consulting engineer, the W1 indications were weld defects not } \\
\text { discovered at the time of original construction, not earthquake damage }\end{array}$ \\
\hline $\begin{array}{l}\text { Sanli \& Çelebi, } 2003 \\
\text { (see also section on } \\
\text { application of } \\
\text { damage detection } \\
\text { methods) }\end{array}$ & $\begin{array}{l}\text { Records from the } 1987 \text { Whittier Narrows, } 1990 \text { Upland, } 1994 \text { Northridge, and } 1999 \text { Hector } \\
\text { Mine earthquakes were used along with modal identification and 'bug colony' optimization } \\
\text { techniques (based on the ant colony method by Dorigo et al. (1995)) to determine modal } \\
\text { properties and change in stiffness due to the different earthquakes. The } 1987 \text { Whittier } \\
\text { Narrows record was used as a baseline. } \\
\text { - Stiffness loss between the } 1987 \text { Whittier Narrows and } 1999 \text { Hector Mine } \\
\text { earthquakes was about } 10 \% \text { in both directions } \\
\text { - The E-W direction was affected more than the N-S direction during Northridge, } \\
\text { particularly in the lower half of the building } \\
\text { - Stiffness loss in the N-S direction due to Hector Mine brought total loss to } \sim 10 \% \\
\text { Second mode period was difficult to determine due to multiple peaks; issue } \\
\text { resolved by using period of mode determined by modal identification to have zero } \\
\text { basement motion. }\end{array}$ \\
\hline $\begin{array}{l}\text { Dunand et al., } 2004 \\
\text { and Dunand, } \\
\text { unpublished data }\end{array}$ & $\begin{array}{l}\text { Ambient vibration data were collected using velocimeters (velocity transducers) and } \\
\text { subsequently analyzed. } \\
\text { - First mode frequency and damping ratio were } 0.58 \mathrm{~Hz} \text { and } 3.6 \% \\
\text { - Second mode frequency and damping ratio were } 1.64 \mathrm{~Hz} \text { and } 4.6 \%\end{array}$ \\
\hline
\end{tabular}




\section{Building Description}

\section{Structural system}

The lateral force-resisting system of the Alhambra building consists of perimeter welded steel moment frames (WSMFs) with pre-Northridge connections above the second floor, and massive reinforced concrete piers (shown in Figure 4 below the second floor. The floor plan is square with near-perfect symmetry (the only asymmetry being in core services) as shown in Figure 5, with floor framing consisting of lightweight concrete over metal decking

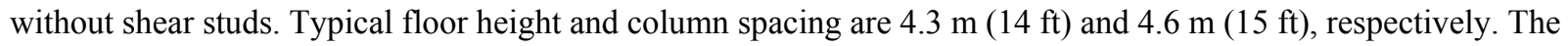
moment-resisting frames are constructed of built up beam and column sections and are nominally identical in both directions except for the connections at the corner columns, which are pinned in the East-West direction. In addition, there are several small moment frames in the E-W direction in the interior core (16 connections total), and an equal number of semi-rigid connections in the NS direction which resist negative bending moment.

Typical perimeter moment frame beam sizes range from 30PG109 (meaning a $30 \mathrm{in}$. (760 mm) deep plate girder weighing 109 pounds $(0.485 \mathrm{kN})$ per linear foot) at the third floor to $24 \mathrm{PG} 45$ at the roof. Built-up columns are 430 $\mathrm{mm}$ (17 in.) deep, and have flanges $200 \mathrm{~mm}$ ( 8 in.) wide. Perimeter moment frames are constructed of A36 steel, while interior frames are A572, with Fy $=66 \mathrm{ksi}(0.455 \mathrm{GPa})$ specified on the construction drawings. The moment

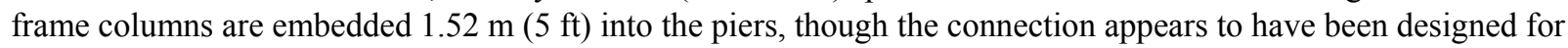
shear only. Large plate girders (57PG201) at the top of the piers transfer loads from non-continuous perimeter columns.

The perimeter moment connections differ in two ways from the standard pre-Northridge detail: (a) the web was welded rather than bolted, and (b) vertical column flange stiffeners were used instead of continuity plates. The welded web was presumed by the consulting engineer to make fracture slightly less likely (Black \& Veatch, unpublished report, 1997), while the effect of the vertical stiffeners was deemed unclear. However, the poor quality of welds found during the inspection and the use of the low notch toughness E70-T4 welding electrode was deemed to make fracture more likely.

Below the second floor, lateral force resistance is provided by large 2-story high reinforced concrete piers that extend from the ground floor to the second floor. These piers are significantly stiffer than the moment frame, despite their two-story height. The piers are constructed integrally with concrete columns which extend from the ground floor through the basement to the foundation. The foundation type is reinforced concrete spread footings, with strip footings under the basement walls. The moment frame columns are embedded 5 feet into these piers, and the moment frame then extends from the second floor to the roof. Large plate girders (57PG201) at the top of the piers transfer loads from non-continuous perimeter columns. These large plate girders are also visible in Figure 4. Cohen (1996) provides detailed information on the structural system of the building as well as a summary of the original design assumptions and calculations.

Due to the age of the building, the moment frames were not designed in accordance with several key provisions of more modern codes, such as drift limits and criteria for strong column-weak girder behavior. However, the resulting design shear at the base of the moment frame (equal to $0.0324 \mathrm{~W}_{\text {tower }}$ ) was multiplied by 3 to control drift, giving a base shear coefficient of nearly 0.1 . Cohen (1996) states that no rationale for this multiplier was given. Using masses from an existing analytical model (Sanli and Çelebi 2002) gives a design shear at the base of the moment frame (at the second story) of $3 * 0.0324 \mathrm{Ws}=10680 \mathrm{kN}$ (2400 kips). Based on the as-built drawings, the total base shear is the moment frame base shear plus the pier $\left(0.1\left(\mathrm{~W}_{2 n d \text { floor }}+\mathrm{W}_{\text {ground floor }}\right)\right)$ and mezzanine $\left(0.2 \mathrm{~W}_{\text {mezzanine }}\right)$ shears. The total shear computed using the same mass values is $13100 \mathrm{kN}$ (2940 kips).

\section{Site conditions}

The building is located on alluvium in the Los Angeles basin, a deep sedimentary basin. Due to the complex geology of the Los Angeles area, the site is in close proximity to a number of faults, as shown in Figure 3. The site has been 
affected by significant earthquakes on faults at distances of up to $325 \mathrm{~km}$. It is likely that most sizeable future Southern California earthquakes will affect the site, though the level of motion may be small for distant events.

\section{Instrumentation}

The Alhambra building has had two different instrumentation configurations, as shown in Figure 6. The building was initially instrumented in early 1971 with code-recommended tri-axial accelerometers (Kinemetrics SMA-1) ${ }^{*}$ at the basement, $6^{\text {th }}$ and $12^{\text {th }}$ floor levels. The instrumentation was improved to a twelve channel structural array with a Kinemetrics CRA- ${ }^{*}$ recorder in 1989. The sensors used in the array were three uni-axial force balance accelerometers (FBAs) per floor at the $2^{\text {nd }}, 6^{\text {th }}$, and $12^{\text {th }}$ floors, and a tri-axial accelerometer in the basement. The FBAs at the $2^{\text {nd }}, 6^{\text {th }}$ and $12^{\text {th }}$ floors were deployed in a manner permitting both translational and torsion measurements. Additional changes to the instrumentation occurred in 1996 when the recorder was upgraded to a digital Kinemetrics $\mathrm{K}^{*}$, and in 1998 when a tri-axial instrument was deployed in the free-field on building grounds. Further information on changes to the instrumentation, trigger levels, and instrument characteristics is located in Appendix A.

\section{Building performance in past earthquakes}

The building has experienced a variety of shaking levels during past earthquakes. Peak base accelerations were greater than 10\% g in the 1971 San Fernando, 1987 Whittier Narrows, 10/4/1987 Whittier Narrows aftershock, 1991 Sierra Madre, and 1994 Northridge earthquakes. Of these earthquakes, the Whittier Narrows and Northridge earthquakes caused the strongest shaking, and thus had the greatest potential for damaging the structure. Anecdotal evidence (Cohen 1996) indicates that some structural damage may have resulted from the 1987 Whittier Narrows earthquake.

After the Northridge earthquake, intrusive inspections detected small cracks with FEMA designation W1 (FEMA 1995) or smaller in some moment connections. No other structural damage was found, though some nonstructural damage was noted. Approximately 20 connections were inspected with ultrasonic testing (UT) by the county. At this point, the W1s in the connections considered to be Northridge earthquake damage. Further inspections of approximately 30 additional connections, and re-inspection of the 20 originally inspected connections were performed by consulting engineers (Black \& Veatch, unpublished report, 1997) to comply with FEMA 267 requirements (FEMA 1995). Backing bars were removed at all inspected connections during this second round of inspections, and several core samples were examined. Numerous instances of poor weld quality were observed, including slag inclusions and areas of incomplete fusion. The inspected connections represented approximately 5\% of the total number of moment connections, and were selected based on the results of elastic dynamic analyses which were intended to predict which connections had the highest stresses. After the second phase of inspection, it was the opinion of the consulting engineers that the W1s were weld defects dating from the original construction, rather than earthquake damage. Cracks with designation W1 are now considered by many engineers to be preexisting conditions rather than earthquake damage (Paret 2000).

Despite the fact that inspections did not turn up significant damage (or any damage at all, depending on how W1s are interpreted), the possibility exists that a small amount of damage went undetected because of the low inspection rate. It was the general consensus of researchers with the SAC Joint Venture (SAC 1995) that analysis cannot reliably predict specific fracture locations, due to the numerous factors involved and the randomness inherent in some factors. For this reason, some connections which were more likely to fracture (due to a large weld defect, for instance) may not have been inspected. It is also important to point out that the ground motions at the base of the structure were approximately twice as large in the Whittier Narrows earthquake than in the Northridge earthquake. Therefore, it is possible that limited moment frame fracture damage occurred during the Whittier Narrows earthquake, and were not detected immediately afterward (because inspectors were not looking for fractures at that time), or after the Northridge earthquake (since a relatively small percentage of connections were inspected).

\footnotetext{
${ }^{*}$ Use of trade, firm, or product names does not imply endorsement by the U.S. Government or the authors.
} 
However, the amount of undetected damage is presumably small, if any, since the inspections satisfied the requirements of FEMA-267 (FEMA 1995), which were designed to uncover major or widespread damage.

Numerous smaller or distant earthquakes have also shaken the building. Due to the low level of ground motion in these earthquakes, the building response was elastic. However, extended periods of vibration occurred in a number of cases, most notably in the 1990 Upland, 1992 Landers, 1992 Big Bear, and 2003 San Simeon earthquakes. Extended response may have occurred for the 1999 Hector Mine earthquake as well, but was not captured due to premature de-triggering of the instruments.

\section{Available data}

\section{Strong-motion data}

The instruments in the Alhambra building have recorded nearly every major Southern California earthquake since 1971, as well as aftershocks and smaller, local events. Earthquake records available at the time of publication are listed in Table 3. Amplitude and duration characteristics for each record are summarized in Table 4. The structure has experienced peak base accelerations ranging from $0.02 \mathrm{~g}$ to nearly $0.3 \mathrm{~g}$, and durations between approximately 7 and 115 seconds. Duration is measured using $D_{5-95}$, which is defined as the time between when $5 \%$ and $95 \%$ of the total cumulative energy (acceleration squared) occurs (Trifunac and Brady 1975, Novikava and Trifunac 1994). All records from earthquakes prior to 1996 were recorded on analog film and subsequently digitized. Detailed information for each earthquake record in the dataset, including data availability, is located in Appendix A.

Table 3. Earthquake magnitude and location with respect to building

\begin{tabular}{|c|c|c|c|c|c|c|c|c|}
\hline \multirow[t]{2}{*}{ Earthquake } & \multirow{2}{*}{$\begin{array}{c}\text { Date } \\
\text { (mo/day/yr) }\end{array}$} & \multirow[t]{2}{*}{ Abbrev. } & \multirow[t]{2}{*}{$\mathrm{M}$} & \multicolumn{2}{|c|}{ Epicenter (deg) } & \multirow{2}{*}{$\begin{array}{c}\text { Depth } \\
(\mathrm{km})\end{array}$} & \multirow{2}{*}{$\begin{array}{l}\text { Azimuth } \\
\text { (deg) }\end{array}$} & \multirow{2}{*}{$\begin{array}{r}D_{\text {epi }} \\
(\mathrm{km})\end{array}$} \\
\hline & & & & Latitude & Longitude & & & \\
\hline 1971 San Fernando & $2 / 9 / 1971$ & SFD & 6.6 & 34.40 & -118.41 & 9 & 325.6 & 42 \\
\hline 1973 Point Mugu & $2 / 21 / 1973$ & PM & 5.3 & 34.065 & -119.035 & 10 & 268.4 & 82 \\
\hline 1987 Whittier Narrows & $10 / 1 / 1987$ & $\mathrm{WN}$ & 6.1 & 34.06 & -118.08 & 10 & 113.6 & 7 \\
\hline W. N. Aftershock 1 & $10 / 4 / 1987$ & WNA1 & $5.3 *$ & 34.07 & -118.10 & 8 & 110.3 & 5 \\
\hline W. N. Aftershock 2 & $2 / 11 / 1988$ & WNA2 & $5.0^{*}$ & 34.08 & -118.05 & 13 & 93.5 & 10 \\
\hline 1990 Upland & $2 / 28 / 1990$ & UP & 5.2 & 34.14 & -117.70 & 4 & 81.6 & 42 \\
\hline 1991 Sierra Madre & $6 / 28 / 1991$ & SM & 5.8 & 34.26 & -118.00 & 9 & 35.2 & 24 \\
\hline 1992 Landers & 6/28/1992 & $\mathrm{LN}$ & 7.3 & 34.20 & -116.44 & 1 & 85.4 & 158 \\
\hline 1992 Big Bear & $6 / 28 / 1992$ & $\mathrm{BB}$ & 6.5 & 34.20 & -116.83 & 5 & 84.0 & 123 \\
\hline 1994 Northridge & $1 / 17 / 1994$ & NR & 6.7 & 34.21 & -118.54 & 18 & 291.1 & 38 \\
\hline Northridge Aftershock & $3 / 20 / 1994$ & NRA & 5.2 & 34.23 & -118.47 & 13 & 298.6 & 34 \\
\hline 1999 Hector Mine & $10 / 16 / 1999$ & $\mathrm{HM}$ & 7.1 & 34.59 & -116.27 & $<1$ & 72.0 & 182 \\
\hline 2001 West Hollywood & 9/9/2001 & $\mathrm{WH}$ & $4.2^{*}$ & 34.075 & -118.379 & 8 & 267.0 & 21 \\
\hline 2001 Compton & $10 / 28 / 2001$ & $\mathrm{CP}$ & $4.0^{*}$ & 33.922 & -118.270 & 21 & 211.6 & 20 \\
\hline 2003 Big Bear City & $2 / 22 / 2003$ & $\mathrm{BBC}$ & $5.4 *$ & 34.310 & -116.848 & 1 & 78.2 & 122 \\
\hline 2003 San Simeon & $12 / 22 / 2003$ & SS & 6.5 & 35.71 & -121.10 & 8 & 303.9 & 324 \\
\hline
\end{tabular}

Azimuths are measured from the rhumb line rather than the great circle.

* Local magnitude $\left(\mathrm{M}_{\mathrm{l}}\right)$ is used for these events, with moment magnitude $\left(\mathrm{M}_{\mathrm{w}}\right)$ used otherwise. 
Table 4. Horizontal shaking parameters

\begin{tabular}{|c|c|c|c|c|c|c|c|c|c|}
\hline \multirow[t]{2}{*}{ Earthquake } & \multirow[t]{2}{*}{$\mathrm{M}$} & \multirow{2}{*}{\begin{tabular}{|c|}
$A_{\text {base max }}$ \\
$(g)$
\end{tabular}} & \multirow{2}{*}{$\frac{A_{12 \max }}{(\mathrm{g})}$} & \multicolumn{2}{|c|}{$\mathrm{A}_{\text {structure } \max }$} & \multirow{2}{*}{$\begin{array}{c}\text { Max base } \\
\mathrm{D}_{5-95}(\mathrm{~s})\end{array}$} & \multirow{2}{*}{$\begin{array}{c}\text { Max struct. } \\
\mathrm{D}_{5-95}(\mathrm{~s})\end{array}$} & \multirow{2}{*}{$\frac{\mathrm{d}_{\text {base max }}}{(\mathrm{cm})}$} & \multirow{2}{*}{$\begin{array}{c}\frac{\mathrm{d}_{12 \max }}{(\mathrm{cm})} \\
\end{array}$} \\
\hline & & & & $(\mathrm{g})$ & Comp. & & & & \\
\hline 1971 San Fernando & 6.6 & 0.12 & 0.18 & 0.18 & $12 \mathrm{EW}$ & 16.08 & 27.6 & 7.7 & 19.3 \\
\hline 1973 Point Mugu & 5.3 & 0.02 & 0.02 & 0.03 & $6 \mathrm{NS}$ & 15.32 & 15.66 & 0.2 & 0.7 \\
\hline 1987 Whittier Narrows & 6.1 & 0.29 & 0.27 & 0.47 & $6 \mathrm{EW}$ & 6.84 & $>20.26 * *$ & 2.4 & 7.5 \\
\hline W. N. Aftershock 1 & $5.3^{*}$ & 0.14 & 0.18 & 0.24 & $6 \mathrm{EW}$ & 8.04 & 14.04 & 0.5 & 1.7 \\
\hline W. N. Aftershock 2 & $5.0^{*}$ & 0.04 & 0.03 & 0.05 & $6 \mathrm{EW}$ & 8.86 & 9.79 & 0.1 & 0.2 \\
\hline 1990 Upland & 5.2 & 0.02 & 0.03 & 0.05 & $2 \mathrm{EW}$ & 40.85 & 65.57 & 0.3 & 1.9 \\
\hline 1991 Sierra Madre & 5.8 & 0.13 & 0.15 & 0.28 & $2 \mathrm{EW}$ & 12.00 & 50.02 & 1.8 & 6.5 \\
\hline 1992 Landers & 7.3 & 0.03 & 0.12 & 0.12 & $12 \mathrm{EW}$ & 58.64 & 68.68 & 7.5 & 13.3 \\
\hline 1992 Big Bear & 6.5 & 0.02 & 0.06 & 0.06 & $12 \mathrm{NS}$ & 46.92 & 76.07 & 1.1 & 5.0 \\
\hline 1994 Northridge & 6.7 & 0.16 & 0.14 & 0.54 & $2 \mathrm{EW}$ & 19.50 & 80.54 & 1.7 & 12.4 \\
\hline Northridge Aftershock & 5.3 & 0.03 & 0.02 & 0.09 & $2 \mathrm{NS}$ & 23.02 & 56.11 & 0.1 & 0.5 \\
\hline 1999 Hector Mine & 7.1 & 0.04 & 0.10 & 0.10 & $12 \mathrm{EW}$ & 30.80 & $>35.90 * *$ & 12.2 & 16.9 \\
\hline 2001 West Hollywood & $4.2 *$ & 0.02 & 0.008 & 0.05 & $2 \mathrm{NS}$ & 13.13 & 22.37 & $<0.1$ & 0.2 \\
\hline 2001 Compton & $4.0^{*}$ & 0.008 & 0.003 & 0.02 & $2 \mathrm{~N})$ & 13.54 & 31.03 & $<0.1$ & $<0.1$ \\
\hline 2003 Big Bear City & $5.4^{*}$ & 0.004 & 0.006 & 0.01 & $2 \mathrm{NS}$ & 28.14 & 37.20 & $<0.1$ & 0.1 \\
\hline 2003 San Simeon & 6.5 & 0.004 & 0.03 & 0.03 & $12 \mathrm{EW}$ & 113.54 & 116.04 & 0.6 & 3.2 \\
\hline
\end{tabular}

$\mathrm{A}_{12}$ and $\mathrm{d}_{12}$ refer to acceleration and displacement at the $12^{\text {th }}$ floor, respectively.

Values of maximum acceleration and $\mathrm{D}_{5-95}$ are for horizontal components only.

* Local magnitude $\left(\mathrm{M}_{1}\right)$ is used for these events, with moment magnitude used otherwise.

** Records truncated by premature de-triggering

\section{Ambient vibration data}

Ambient vibration tests have been performed on the building by Çelebi and Liu (1996, unpublished) and Dunand et al. (2004). The Celebi and Liu study utilized accelerometers to measure ambient vibrations. The later study utilized 3-component Lennartz LE-3D* velocimeters (i.e. velocity transducers) and CityShark ${ }^{\mathrm{TM}^{*}}$ data recorders (Chatelain, 2000).

\section{Analysis of recorded building response}

Records from the earthquakes listed in Table 3 were analyzed using direct inspection in the time domain, frequency domain methods, and joint time-frequency methods. Behavioral observations were made from the acceleration, velocity, and displacement time histories, as well as from various derived quantities. Plots of the acceleration, velocity, and displacement time series for all records in the strong motion dataset are located in chronological order in Appendix B. Observations about the frequency response of the structure were made using Fourier amplitude spectra, auto-spectra, cross-spectra, phase spectra and coherence spectra. Fourier amplitude spectra are located in Appendix C, and spectral analysis results for channel pairs are located in Appendix D. Joint time-frequency analysis was used to evaluate the changes in frequency response during selected earthquakes, with plots located in Appendix E. A summary of maxima of selected horizontal shaking parameters for the data set is provided in Table 4. Ratios of these parameters are tabulated in Table 5.

\footnotetext{
${ }^{*}$ Use of trade, firm, or product names does not imply endorsement by the U.S. Government or the authors.
} 
Table 5. Ratios of response parameters

\begin{tabular}{|l|c|c|c|c|c|c|}
\hline Earthquake & $\mathrm{M}_{\mathrm{w}}$ & $\begin{array}{c}\mathrm{A}_{\text {structmax }} / \\
\mathrm{A}_{\text {basemax }}\end{array}$ & $\begin{array}{c}\mathrm{A}_{12 \max } / \\
\mathrm{A}_{\text {basemax }}\end{array}$ & $\begin{array}{c}\mathrm{A}_{\text {structmax }} / \\
\mathrm{A}_{12 \max }\end{array}$ & $\begin{array}{c}\mathrm{D}_{5-95 \text { _truct }} / \\
\mathrm{D}_{5-95 \text { base }}\end{array}$ & $\begin{array}{c}\mathrm{D}_{12 \_\max } / \\
\mathrm{D}_{\text {base } \max }\end{array}$ \\
\hline 1971 San Fernando & 6.6 & 1.50 & 1.50 & 1.00 & 1.72 & 2.51 \\
\hline 1973 Point Mugu & 5.3 & 1.27 & 0.72 & 1.77 & 1.02 & 3.30 \\
\hline 1987 Whittier Narrows & 6.1 & 1.62 & 0.93 & 1.74 & $>2.96^{* *}$ & 3.17 \\
\hline W. N. Aftershock 1 & $5.3^{*}$ & 1.71 & 1.29 & 1.33 & 1.75 & 3.46 \\
\hline W. N. Aftershock 2 & $5.0^{*}$ & 1.22 & 0.70 & 1.75 & 1.11 & 2.09 \\
\hline 1990 Upland & 5.2 & 2.22 & 1.32 & 1.68 & 1.61 & 6.41 \\
\hline 1991 Sierra Madre & 5.8 & 2.15 & 1.15 & 1.87 & 4.17 & 3.62 \\
\hline 1992 Landers & 7.3 & 3.90 & 3.90 & 1.00 & 1.17 & 1.77 \\
\hline 1992 Big Bear & 6.5 & 2.39 & 2.39 & 1.00 & 1.62 & 4.45 \\
\hline 1994 Northridge & 6.7 & 3.38 & 0.88 & 3.86 & 4.13 & 7.24 \\
\hline Northridge Aftershock & 5.3 & 2.78 & 0.74 & 3.75 & 2.42 & 4.99 \\
\hline 1999 Hector Mine & 7.1 & 2.19 & 2.19 & 1.00 & $>1.17^{* *}$ & 1.39 \\
\hline 2001 West Hollywood & $4.2^{*}$ & 2.45 & 0.44 & 5.60 & 1.70 & 3.76 \\
\hline 2001 Compton & $4.0^{*}$ & 2.31 & 0.42 & 5.56 & 2.29 & 2.66 \\
\hline 2003 Big Bear City & $5.4^{*}$ & 3.16 & 1.44 & 2.19 & 1.32 & 2.56 \\
\hline 2003 San Simeon & 6.5 & 7.24 & 7.24 & 1.00 & 1.02 & 4.93 \\
\hline
\end{tabular}

$\mathrm{A}_{12}$ and $\mathrm{d}_{12}$ refer to acceleration and displacement at the $12^{\text {th }}$ floor, respectively.

Values of maximum acceleration and $\mathrm{D}_{5-95}$ are for horizontal components only

* Local magnitude $\left(\mathrm{M}_{\mathrm{l}}\right)$ is used for these events, with moment magnitude used otherwise.

** Records truncated by premature detriggering

\section{Time-history characteristics}

Visual inspection of the acceleration, velocity, and displacement time series provides many insights into the structural behavior. In the case of the Alhambra building, these time series were examined individually and selected series were plotted against one another.

Table 4 shows that maximum structural accelerations tend to occur in the E-W direction for most of the recorded ground motions. Peak response does not appear to directly depend on the azimuth of the arrivals, but the cases with maximum response in the N-S direction tend to have azimuths in the neighborhood of 90 or 270 degrees. However, several motions in this azimuthal neighborhood have maximum responses in the E-W direction.

The response measured at the second story is significantly different than that measured in the moment-framed stories above (see Figure B-28 in Appendix B, for example). The piers between the basement and second story are very stiff and transfer significant high frequency energy to the second story. Characterization of the building's first story as 'soft' would be incorrect. Also, peak accelerations at second floor are significantly larger than those at the $12^{\text {th }}$ floor (and also other levels) for a number of records, including Upland, Sierra Madre, Northridge, and the 3/20/1994 Northridge aftershock (see Figures B-16, B-19, B-28, and B-31). Torsional accelerations were significantly larger at the second story for the Northridge earthquake as well, as shown in Figure 7. Second floor accelerations (and torsional accelerations at any level) are unknown for events prior to 1989 since instruments were in the code configuration. However, $6^{\text {th }}$ floor translational accelerations are significantly larger than $12^{\text {th }}$ floor accelerations for Whittier Narrows and its first aftershock, and somewhat larger for Point Mugu (see Figures B-7, B10 , and B-4, respectively).

The response of the moment frame above the second floor is characterized by a lengthy response which includes higher modes during the strong shaking portion. Beating in the response, primarily at the $12^{\text {th }}$ floor, is apparent in the Upland, Landers, Big Bear, Northridge, Hector Mine, and San Simeon records (see Figures B-16, B-22, B-25, B28, B-34, and B-46). One of the best examples of this type of response is shown in Figure 8. The acceleration, 
velocity, and displacement time histories for the east-west direction at the center of the $12^{\text {th }}$ floor show significant beating, low damping, and a strong and lengthy response.

The displacement particle motion in Figure 9 shows an unusual, strong elliptical response after the initial strong motion in the Northridge records. The elliptical response is primarily first-mode, has a major axis oriented in the NE-SW direction, and appears to be nearly free vibration as base input motions are small. Little or no torsion was observed during this elliptical response, as shown in Figure 7, in contrast to the large torsional response during the strongest shaking. The Alhambra building shares some response characteristics with the Santa Clara County office building (Boroschek and Mahin 1991, Çelebi 1994). They both have near-perfect symmetry, low damping, and responses characterized by beating and an unexpectedly large resonant response to small input motions. However, the Alhambra building experiences virtually no torsional motion during the large response after strong input shaking subsides. In contrast, the Santa Clara County office building's resonant response was largely attributed to closely spaced lateral and torsional modes which led to a highly coupled response.

Ratios of response parameters from Table 5 are plotted versus peak base acceleration in Figure 10. The ratio of the $12^{\text {th }}$ floor acceleration to the base acceleration (A12/Abase) measures the amplification of the ground motion by the whole building. This amplification tends to be greater for smaller input motions, though there are several cases of low-amplitude motion which are not significantly amplified in the building. In the case of the other ratios, significant scatter is present and trends are difficult to identify. It is anticipated, however, that amplification ratios depend on input motion frequency content as well as amplitude. For example, distant earthquakes and small local earthquakes will have very different frequency contents, and will produce different responses in the concrete piers and the moment frame.

\section{Frequency-domain analyses}

Fourier amplitude spectra were computed for all channels for each earthquake, and plots of these spectra are located in Appendix C. In addition, a spectral analysis including the computation of auto-spectra, cross-spectra, phase and coherence was performed on selected pairs of channels for several earthquakes. Channel pairs were selected to examine both the torsion and potential rocking response, and plots of analysis results are provided in Appendix D.

First and second mode frequencies were determined from Fourier analysis for the two translational directions and torsional motion. These frequencies and the associated frequency increment of the spectra are listed in Table 6 . The first translational mode periods are similar for all earthquakes at approximately 2.0 seconds $(0.5 \mathrm{~Hz})$ in both NS and EW directions. The first torsional mode occurs at approximately 1.25 seconds $(0.8 \mathrm{~Hz})$ for all earthquakes.

Variations in first translational mode period with time and peak base acceleration are shown in Figure 11. Variations with time are further broken into E-W and N-S directions in Figure 12 and Figure 13, where frequencies are extracted from Fourier amplitude spectra and auto-spectra. Fairly low time resolution of the data for several records (due to short time series) causes large uncertainty $(>10 \%)$ in the first mode frequency obtained from the autospectra, and therefore frequencies are obtained from the zero-padded Fourier amplitude spectra. Overall, the variations in first mode period with earthquake occurrence time are moderate ( $\sim 20 \%$ maximum over 30 years $)$ and do not show a clear trend which would indicate structural damage. However, local sections of the overall record (such as 1987 Whittier Narrows through 1994 Northridge in the E-W direction), show a decrease in fundamental frequency, which could be misconstrued as structural damage if the complete record were not available. Care must therefore be exercised when interpreting changes in first mode frequency with small datasets of earthquake records.

When compared with the first mode, there is greater variation in the second mode translational frequencies, with multiple peaks in the region from about 1.2 to $1.4 \mathrm{~Hz}$ for a number of the records, as shown in Figure 14. Values in the table are for the largest peak. Second mode torsional frequencies are slightly more stable but have multiple peaks in the region of $2.2 \mathrm{~Hz}$, as illustrated by the comparison of torsional spectra in Figure 15. Examination of the spectra in Figure 15 shows significant torsional response around $0.5 \mathrm{~Hz}(2.0 \mathrm{sec})$, the neighborhood of the first translational mode. Many of the spectra also show peaks at the second translational mode. The second floor is not excited in the first torsional mode, but the torsional spectra often show a large peak at the first translational mode, particularly for Landers, Northridge, and San Simeon. 
The difference in the character of the response at the pier tops $\left(2^{\text {nd }}\right.$ floor $)$ and in the moment frame $\left(6^{\text {th }}\right.$ and $12^{\text {th }}$ floors) is very noticeable in the Fourier amplitude spectra. The spectra for the basement and second story have significantly higher frequency content than those for the $6^{\text {th }}$ and $12^{\text {th }}$ floors. The transfer of high-frequency energy by the piers is particularly notable, and is also very apparent in the ratios of Fourier amplitude spectra shown in Figure 16. This trend is less apparent in the ratios of torsional Fourier amplitude spectra in Figure 17.

Table 6. Modal frequencies from Fourier amplitude spectra

\begin{tabular}{|c|c|c|c|c|c|c|c|c|c|c|c|c|c|}
\hline \multirow{3}{*}{ EQ } & \multirow{3}{*}{$\begin{array}{c}\text { Frq. Resolution } \\
\text { Translation/ } \\
\text { Torsion } \\
(\mathrm{Hz})\end{array}$} & \multicolumn{4}{|c|}{ N-S Translation } & \multicolumn{4}{|c|}{ E-W Translation } & \multicolumn{4}{|c|}{ Torsion } \\
\hline & & \multicolumn{2}{|c|}{ Mode 1} & \multicolumn{2}{|c|}{ Mode 2} & \multicolumn{2}{|c|}{ Mode 1} & \multicolumn{2}{|c|}{ Mode 2} & \multicolumn{2}{|c|}{ Mode 1} & \multicolumn{2}{|c|}{ Mode 2} \\
\hline & & $\begin{array}{c}\mathrm{f} \\
(\mathrm{Hz})\end{array}$ & $\begin{array}{c}\mathrm{T} \\
(\mathrm{s})\end{array}$ & $\begin{array}{c}\mathrm{f} \\
(\mathrm{Hz})\end{array}$ & $\begin{array}{c}\mathrm{T} \\
(\mathrm{s})\end{array}$ & $\begin{array}{c}\mathrm{f} \\
(\mathrm{Hz})\end{array}$ & $\begin{array}{c}\mathrm{T} \\
(\mathrm{s})\end{array}$ & $\begin{array}{c}\mathrm{f} \\
(\mathrm{Hz})\end{array}$ & $\begin{array}{c}\mathrm{T} \\
(\mathrm{s})\end{array}$ & $\begin{array}{c}\mathrm{f} \\
(\mathrm{Hz})\end{array}$ & $\begin{array}{l}\mathrm{T} \\
(\mathrm{s})\end{array}$ & $\begin{array}{c}\mathrm{f} \\
(\mathrm{Hz})\end{array}$ & $\begin{array}{c}\mathrm{T} \\
(\mathrm{s})\end{array}$ \\
\hline SFD & .003 & .49 & 2.05 & 1.33 & .75 & .49 & 2.05 & 1.41 & .71 & - & - & - & - \\
\hline $\mathrm{PM}$ & .006 & .52 & 1.91 & 1.36 & .74 & .51 & 2.00 & 1.40 & .71 & - & - & - & - \\
\hline WN & .006 & .51 & 1.95 & 1.33 & .75 & .55 & 1.82 & 1.46 & .68 & - & - & - & - \\
\hline WNA1 & .006 & .51 & 1.95 & 1.43 & .70 & .52 & 1.91 & 1.22 & .82 & - & - & - & - \\
\hline WNA2 & .012 & .54 & 1.86 & 1.42 & .71 & .56 & 1.78 & 1.51 & .66 & - & - & - & - \\
\hline UP & $.003 / .006$ & .49 & 2.02 & 1.32 & .76 & .51 & 1.97 & 1.42 & .70 & .83 & 1.20 & 2.20 & .46 \\
\hline SM & $.003 / .006$ & .47 & 2.13 & 1.35 & .74 & .49 & 2.02 & 1.27 & .79 & .82 & 1.22 & 2.21 & .45 \\
\hline $\mathrm{LN}$ & $.003 / .006$ & .48 & 2.10 & 1.29 & .77 & .48 & 2.10 & 1.28 & .78 & .81 & 1.24 & 2.12 & .47 \\
\hline $\mathrm{BB}$ & $.003 / .006$ & .49 & 2.05 & 1.30 & .77 & .49 & 2.05 & 1.26 & .79 & .82 & 1.22 & 2.29 & .44 \\
\hline NR & $.003 / .006$ & .47 & 2.13 & 1.28 & .78 & .47 & 2.13 & 1.28 & .78 & .79 & 1.26 & 2.15 & .47 \\
\hline NRA & $.003 / .006$ & .51 & 1.97 & 1.33 & .75 & .50 & 2.00 & 1.33 & .75 & .83 & 1.20 & 2.32 & .43 \\
\hline $\mathrm{HM}$ & .003 & .46 & 2.18 & 1.29 & .78 & .49 & 2.02 & 1.34 & .74 & .79 & 1.27 & 2.08 & .48 \\
\hline WH & .003 & .51 & 1.97 & 1.29 & .78 & .51 & 1.97 & 1.57 & .64 & .84 & 1.18 & 2.33 & .43 \\
\hline $\mathrm{CP}$ & .003 & .57 & 1.74 & 1.51 & .66 & .55 & 1.82 & 1.60 & .63 & .92 & 1.09 & 2.54 & .39 \\
\hline $\mathrm{BBC}$ & .003 & .52 & 1.93 & 1.40 & .72 & .55 & 1.82 & 1.55 & .65 & .89 & 1.12 & 2.36 & .42 \\
\hline $\mathrm{SS}$ & .003 & .48 & 2.07 & 1.23 & .81 & .49 & 2.05 & 1.21 & .82 & .79 & 1.26 & 2.22 & .45 \\
\hline
\end{tabular}

A sample spectral analysis of the two parallel channels in the E-W direction on each floor is shown in Figure 18 for the Northridge earthquake. This analysis confirms that the frequencies $0.5 \mathrm{~Hz}$ and $1.3 \mathrm{~Hz}$ correspond to translation, since the phase is zero and the coherence is one at these locations. The analysis also indicates torsion at 0.8 and 2.2 $\mathrm{Hz}$.

Spectral analysis of the basement vertical and $12^{\text {th }}$ floor horizontal channels was also performed to help determine if rocking occurred in the response for the San Fernando, Whittier Narrows, Whittier Narrows Aftershock 1, Sierra Madre, and Northridge earthquakes. Potential rocking of the concrete piers was examined for the Northridge earthquake using the basement vertical and second floor horizontal channels. Figures showing the results of these analyses are located in Appendix D. These analyses indicate that rocking did not contribute significantly to the response.

\section{System Identification}

The procedures used in system identification analyses estimate a model based on observed input-output data (Ljung, 1987). Simply stated, the input is the basement or ground-floor motion and the output is the roof-level motion or one of the levels where the structural response is detectable. In most of the system identification analyses presented in this study, the ARX (acronym meaning AR for autoregressive and X for extra input) model based on the leastsquares method for single input-single output (Ljung, 1987) coded in commercially available system identification software was used (The MathWorks, 1988). The damping ratios are extracted by system identification analyses in accordance with the procedures outlined by Ghanem and Shinozuka (1995) and Shinozuka and Ghanem (1995). These procedures are demonstratively summarized by Çelebi (1998). 
System identification was performed for the Whittier Narrows, Upland, and Northridge earthquakes. Frequencies and damping ratios obtained using the methods described above are summarized in Table 7 . The damping ratios are expressed as a percentage of critical damping. Plots of the results are shown in Figure 19 through Figure 24.

Table 7. Results of system identification

\begin{tabular}{|l|c|c|c|c|c|c|c|c|}
\hline \multirow{3}{*}{ Earthquake } & \multicolumn{3}{|c|}{ North - South Direction } & \multicolumn{3}{c|}{ East - West Direction } \\
\cline { 2 - 10 } & \multicolumn{2}{|c|}{ Mode 1 } & \multicolumn{2}{c|}{ Mode 2 } & \multicolumn{3}{c|}{ Mode 1 } & \multicolumn{3}{c|}{ Mode 2 } \\
\cline { 2 - 9 } & $\mathrm{f}(\mathrm{Hz})$ & $\zeta(\%)$ & $\mathrm{f}(\mathrm{Hz})$ & $\zeta(\%)$ & $\mathrm{f}(\mathrm{Hz})$ & $\zeta(\%)$ & $\mathrm{f}(\mathrm{Hz})$ & $\zeta(\%)$ \\
\hline 1987 Whittier Narrows & 0.5 & 1.7 & - & - & 0.5 & 1.2 & - & - \\
\hline 1990 Upland & 0.5 & 2.5 & - & - & 0.5 & 2.9 & - & - \\
\hline 1994 Northridge & 0.47 & 1.5 & 1.26 & 3.8 & 0.47 & 1.5 & 1.29 & 4.2 \\
\hline
\end{tabular}

\section{Joint time-frequency analyses}

To monitor the frequency content of a record over time, both time and frequency information must be used, leading to the term "joint time-frequency analysis" (Black, 1998). The most common method involves taking the Discrete Time Fourier Transform (DTFT) of successive, fixed width portions of a record, using a common window such as the Hanning window. This method, also know as moving window analysis, provides insight into how the frequency content of the building response changes with time during the earthquake. Other methods of using both time and frequency information include wavelet analysis, plus the Wigner distribution and other such methods which lie outside the scope of this report. Plots of selected joint time-frequency analyses are located in Appendix E.

\section{Windowed Discrete Time Fourier Transform}

The results of the analysis are displayed in a graphical time vs. frequency format called a spectrogram. Spectrograms for selected channels for the Whittier Narrows and Northridge earthquakes are located in Appendix E, since these earthquakes are of particular interest. These events are the strongest experienced by the structure, any damage to the structure would be expected to occur during these events.

Several observations can be made from the Whittier Narrows and Northridge spectrograms:

- A beating effect is apparent in the low-frequency spectrogram for Northridge (see Figure E-3).

- Spectrograms for both earthquakes show significant high-frequency (but still $<25 \mathrm{~Hz}$ ) response in first 20 seconds or so of the records, but little thereafter.

- There is no burst of high frequency energy (i.e. $>10 \mathrm{~Hz}$ ) which could indicate a fracture or other sudden damage in either of these events. High frequency energy with sudden onset at 60 and $120 \mathrm{~s}$ are aftershock arrivals.

- There is no significant shift in the frequency content that would indicate damage. However, due to the Heisenberg uncertainty principle ${ }^{2}$, there is a tradeoff between time and frequency resolution. This tradeoff limits the use of the analysis in its current format (visual inspection) to detect small amounts of damage.

- Possible 'migration' of the second mode frequency was observed, and further study is being made. Caution must be used as three (or more) peaks of the Fourier amplitude spectrum typically occur in the neighborhood of the second mode even for elastic response, and change of the second mode frequency may simply be a change in which peak is largest in a given time range.

\footnotetext{
${ }^{2}$ The Heisenberg uncertainty principle states that arbitrarily high accuracy cannot be obtained in both time and frequency domains simultaneously. See the discussion in Vetterli and Kovacevic (1995) for further details.
} 
Based on these observations, time-frequency analysis was able to provide insight into the response of the structure and did not indicate any structural damage. Overall observations from time-frequency analysis are consistent with those from independent time domain and frequency domain information.

\section{Wavelet analysis}

Wavelets provide a different method of examining the changes in frequency response with time. The basics of wavelet analysis are covered elsewhere (e.g. Vetterli and Kovacevic 1995, Walker 1999) and will not be repeated here. Wavelet analysis involves taking the wavelet transform of a signal using a "mother wavelet" basis function (in contrast, the Fourier Transform uses sine and cosine basis functions). Scaling and shifting of the mother wavelet produces a multi-resolution analysis and plots of the scaling factor (which is inversely related to frequency by an equation which depends on the mother wavelet used) versus time. Several mother wavelets were used in the analysis of the Alhambra building records, but only results using the Daubechies 4 (Daub4) mother wavelet (see Walker) are presented here in the interest of space (the other selected wavelets provide similar results). The wavelet transforms of the accelerograms from Whittier Narrows and Northridge are shown as spike plots in Figures E-4 and E-5, respectively. The spikes represent the amplitudes of the wavelet coefficients at the various levels of decomposition.

While the wavelet transforms provide an interesting and detailed picture of the response, including beating (expressed by a pattern resembling amplitude modulation in the wavelet coefficients), no distinctive indication of fracture (i.e.a burst of high-frequency energy indicated by large-valued wavelet coefficients in the upper stories of the building at lower scales/higher frequencies) was found.

\section{Summary of recorded response analyses}

Several methods were employed in the analysis of the time history recordings in order to examine different features of the response. The major response features identified by each method are summarized in Table 8. Overall, the observations were consistent across the different methods.

Table 8. Summary of findings by analysis method

\begin{tabular}{|c|c|c|c|c|c|c|}
\hline \multirow[b]{2}{*}{ Observed Response } & \multicolumn{6}{|c|}{ Method } \\
\hline & $\begin{array}{c}\text { Visual } \\
\text { observation of } \\
\text { time series }\end{array}$ & $\begin{array}{l}\text { Fourier } \\
\text { analysis }\end{array}$ & $\begin{array}{l}\text { Spectral } \\
\text { analysis }\end{array}$ & $\begin{array}{c}\text { System } \\
\text { identification }\end{array}$ & $\begin{array}{l}\text { Windowed } \\
\text { DTFT } \\
\text { analysis }\end{array}$ & $\begin{array}{l}\text { Wavelet } \\
\text { analysis }\end{array}$ \\
\hline Extended vibration response & $\mathrm{x}$ & & & & $\mathrm{x}$ & $\mathrm{x}$ \\
\hline $\begin{array}{l}\text { Peak acceleration higher in intermediate } \\
\text { stories than at } 12^{\text {th }} \text { floor }\end{array}$ & $\mathrm{x}$ & & & & & \\
\hline Beating & $\mathrm{x}$ & & & & $\mathrm{x}$ & $\mathrm{x}$ \\
\hline $\begin{array}{l}\left.\text { Response at pier tops ( } 2^{\text {nd }} \text { floor }\right) \text { different } \\
\text { from moment frame }\left(6^{\text {th }} \text { and } 12^{\text {th }} \text { floors }\right)\end{array}$ & $\mathrm{x}$ & $\mathrm{x}$ & & & $\mathrm{x}$ & $\mathrm{x}$ \\
\hline $\begin{array}{l}1^{\text {st }} \text { and } 2^{\text {nd }} \text { mode translation frequencies } \\
\text { (in both directions) } \sim 0.5 \mathrm{~Hz}, 1.3 \mathrm{~Hz}\end{array}$ & & $\mathrm{x}$ & $\mathrm{x}$ & $\mathrm{x}$ & $\mathrm{x}$ & \\
\hline $\begin{array}{l}1^{\text {st }} \text { and } 2^{\text {nd }} \text { mode torsional frequencies } \\
\sim 0.8 \mathrm{~Hz}, 2.2 \mathrm{~Hz}\end{array}$ & & $\mathrm{x}$ & $\mathrm{x}$ & & & \\
\hline Elliptical particle motion & $\mathrm{x}^{*}$ & & & & & \\
\hline Low damping $\left(\sim 1.5 \%\right.$ in $1^{\text {st }}$ mode $)$ & & & & $\mathrm{x}$ & & \\
\hline $\begin{array}{l}\text { Significant torsion at } 2^{\text {nd }} \text { floor during } \\
\text { strong shaking but little thereafter }\end{array}$ & $\mathrm{x}$ & & & & & \\
\hline $\begin{array}{l}\text { Significant higher mode response during } \\
\text { strong shaking but little thereafter }\end{array}$ & $\mathrm{x}$ & & & & $\mathrm{x}$ & $\mathrm{x}$ \\
\hline $1^{\text {st }}$ mode frequency unchanged during eq. & & & & & $\mathrm{x}$ & \\
\hline
\end{tabular}

* From N-S displacement vs. E-W displacement plots 


\section{Finite element model and eigenvalue analyses}

In this portion of the study, we took advantage of and revised a 3-D computer model of the structure originally developed (in the early 1990's) by Professor James Anderson of the University of Southern California (USC) using commercially available finite element software SAP90 (Computers and Structures, Inc. 1990). The original model consisted of only the four external frames of the structure. In this study, the input data was adapted to SAP2000 (Computers and Structures, Inc. 1998), and the internal frames were added to the model. A rigid floor diaphragm model (all nodes at the same elevation constrained to move as a rigid plane) was used in order to reduce the number of degrees of freedom. Assumed mass was uniformly distributed over each floor, with floor masses given in Table 9. Two structural models were prepared, one with fixed support conditions and one with pinned support conditions at the basement level, and are shown in Figure 25.

Table 9. Mass values used in structural model

\begin{tabular}{|c|c|c|c|c|}
\hline Floor Level & $\begin{array}{c}\text { Mass } \\
(\mathrm{kg})\end{array}$ & $\begin{array}{c}\text { Mass moment of } \\
\text { inertia }\left(\mathrm{kg}-\mathrm{m}^{2}\right)\end{array}$ & $\begin{array}{c}\text { Mass } \\
(\mathrm{k-s} / \mathrm{s} / \mathrm{in})\end{array}$ & $\begin{array}{c}\text { Mass moment of } \\
\text { inertia }\left(\mathrm{k}-\mathrm{in}-\mathrm{s}^{2}\right)\end{array}$ \\
\hline Roof & $1.0403 \mathrm{E}+06$ & $2.2081 \mathrm{E}+08$ & 5.93 & $1.9510 \mathrm{E}+06$ \\
\hline 12 & $1.0175 \mathrm{E}+06$ & $2.1597 \mathrm{E}+08$ & 5.8 & $1.9082 \mathrm{E}+06$ \\
\hline 11 & $1.0175 \mathrm{E}+06$ & $2.1597 \mathrm{E}+08$ & 5.8 & $1.9082 \mathrm{E}+06$ \\
\hline 10 & $1.0175 \mathrm{E}+06$ & $2.1597 \mathrm{E}+08$ & 5.8 & $1.9082 \mathrm{E}+06$ \\
\hline 9 & $1.0175 \mathrm{E}+06$ & $2.1597 \mathrm{E}+08$ & 5.8 & $1.9082 \mathrm{E}+06$ \\
\hline 8 & $1.0175 \mathrm{E}+06$ & $2.1597 \mathrm{E}+08$ & 5.8 & $1.9082 \mathrm{E}+06$ \\
\hline 7 & $1.0175 \mathrm{E}+06$ & $2.1597 \mathrm{E}+08$ & 5.8 & $1.9082 \mathrm{E}+06$ \\
\hline 6 & $1.0175 \mathrm{E}+06$ & $2.1597 \mathrm{E}+08$ & 5.8 & $1.9082 \mathrm{E}+06$ \\
\hline 5 & $1.0175 \mathrm{E}+06$ & $2.1597 \mathrm{E}+08$ & 5.8 & $1.9082 \mathrm{E}+06$ \\
\hline 4 & $1.0175 \mathrm{E}+06$ & $2.1597 \mathrm{E}+08$ & 5.8 & $1.9082 \mathrm{E}+06$ \\
\hline 3 & $1.0175 \mathrm{E}+06$ & $2.1597 \mathrm{E}+08$ & 5.8 & $1.9082 \mathrm{E}+06$ \\
\hline 2 & $1.0175 \mathrm{E}+06$ & $2.1597 \mathrm{E}+08$ & 5.8 & $1.9082 \mathrm{E}+06$ \\
\hline 1 & $1.1578 \mathrm{E}+06$ & $2.4575 \mathrm{E}+08$ & 6.6 & $2.1714 \mathrm{E}+06$ \\
\hline
\end{tabular}

The natural frequencies resulting from eigenvalue analyses of the computer models are summarized in Table 10. The smallest natural frequency obtained from the fixed support model is $0.47 \mathrm{~Hz}$, which is related to the first translational mode shape in the North-South direction. Next is the first translational mode in the East-West direction $(0.48 \mathrm{~Hz})$, and then the first torsional mode $(0.77 \mathrm{~Hz})$. This order repeats for the second and third modes except the fourth translational mode occurs at a lower frequency than the third torsional mode. The first N-S and E-W translational and torsional modes of the pin-supported system are $0.46 \mathrm{~Hz}, 0.46 \mathrm{~Hz}$, and $0.75 \mathrm{~Hz}$ respectively. The natural frequencies of the N-S direction are slightly smaller than those of the E-W, which shows that the $\mathrm{E}-\mathrm{W}$ direction of the building has slightly larger stiffness according to the fixed-support model. 
Table 10. Natural frequencies and mode shapes from eigenvalue analysis

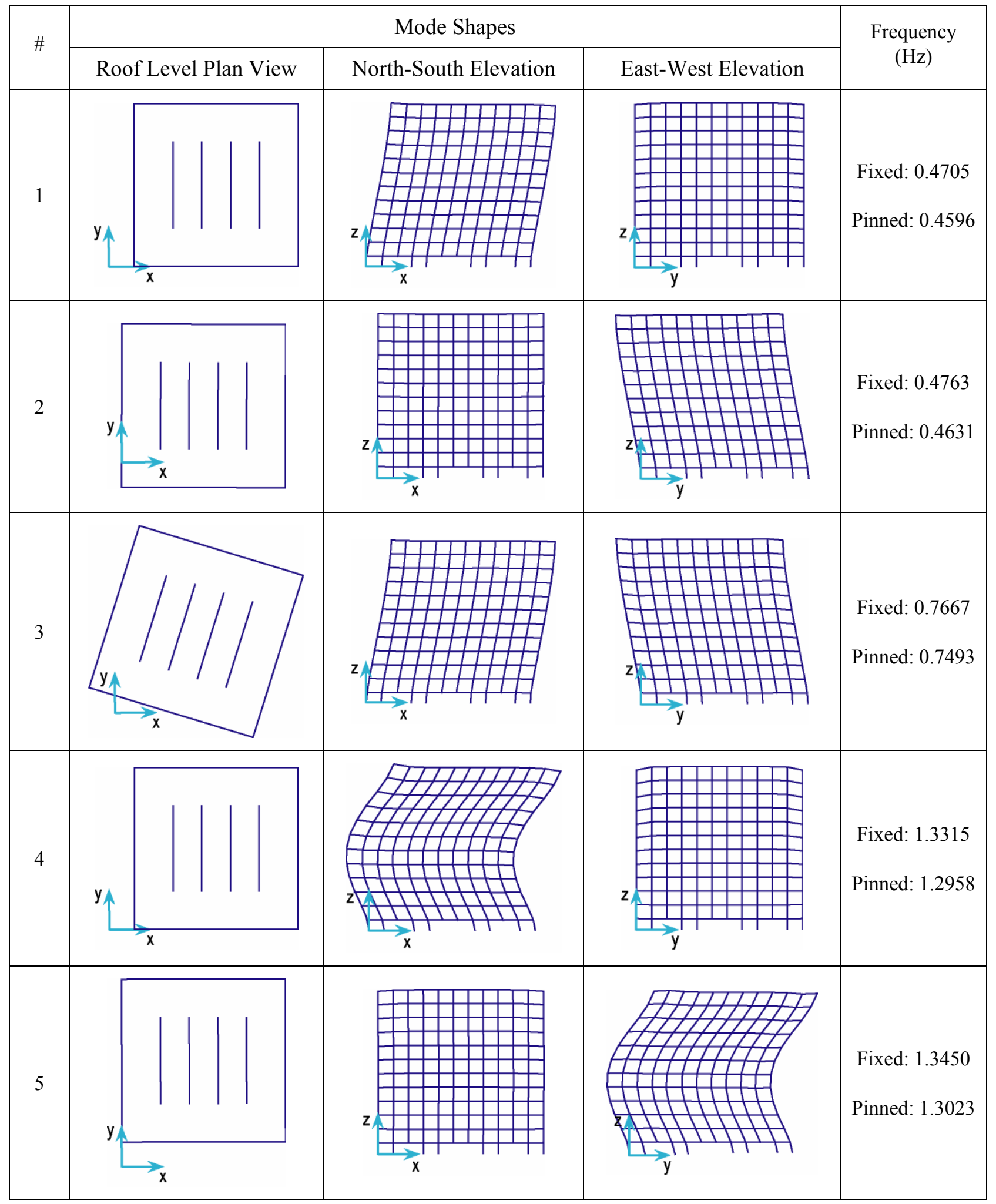




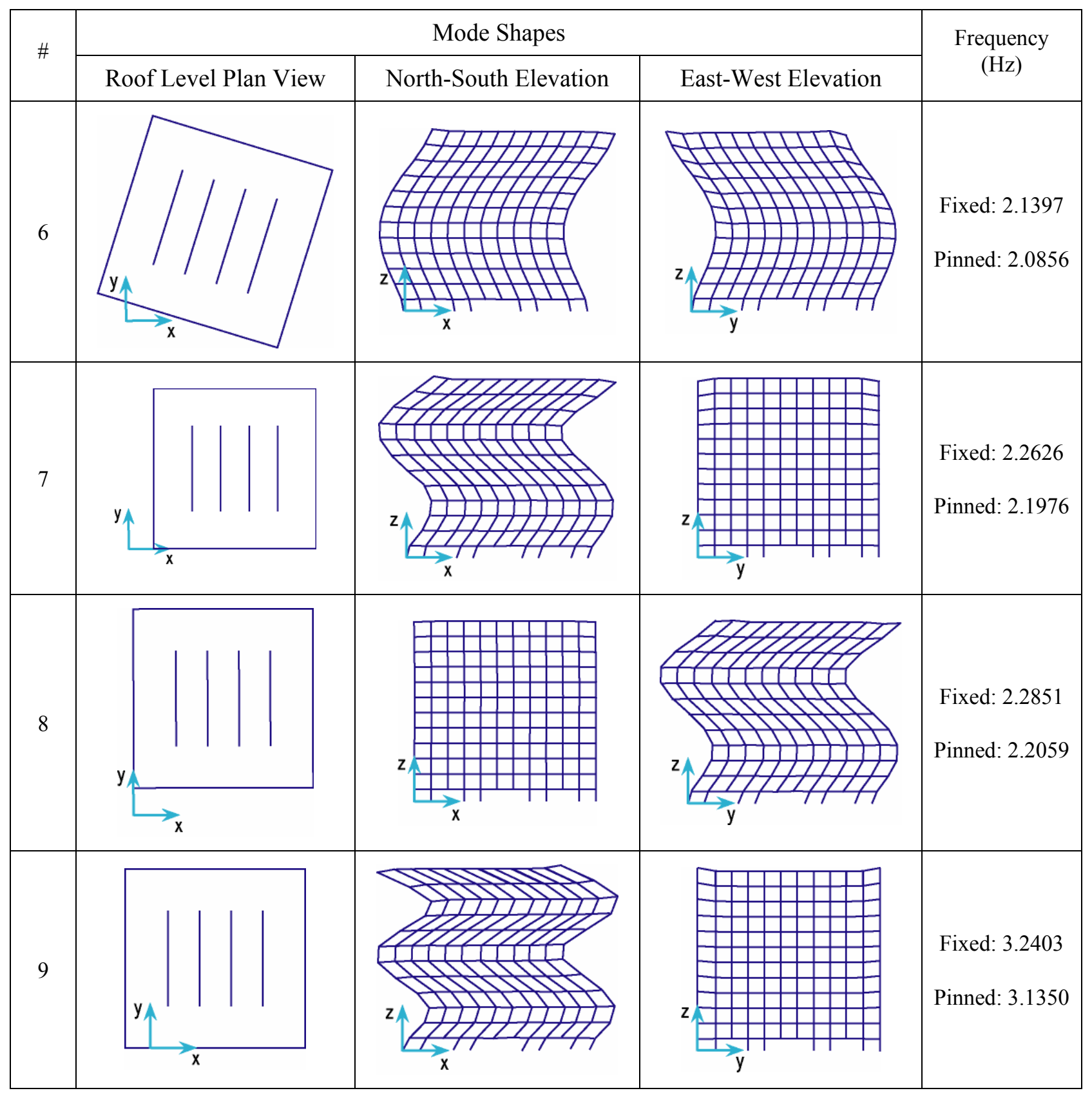

\section{Application of damage detection methods}

Knowledge of the building's performance in the earthquakes with strong motion data recorded allows the extensive data set to be used to evaluate damage detection methods. Due to the numerous damage detection methods which have been proposed in the literature (see Sohn et al. 2003 for a discussion of available methods), the size and complexity of the structural system (over 1000 moment-resisting connections), and the significant computational effort which needs to be expended in many cases, use of all the available methods lies far outside the scope of this report. Rather, a small number of methods will be utilized: (a) methods based on changes in vibration properties caused by damage, and (b) methods based on changes in particular structural response quantities caused by damage. 


\section{Changes in vibration properties}

Numerous methods for damage detection have been based on the basic idea that damage causes a change in the vibration properties of the structure. Since damage reduces the stiffness of the structure, the natural vibration frequencies will shorten (and periods will lengthen). The natural mode shapes change in response to damage as well. Two basic methods of examining the frequency response of the structure for changes, both between and within earthquakes, are examined. These methods are (a) simple observation of changes in fundamental frequency (as computed from Fourier amplitude spectra and auto-spectra) from one earthquake to the next, and (b) joint-time frequency analysis. Finally, a more computationally intensive method based on system identification concepts is described in Sanli and Çelebi (2002).

\section{Change in fundamental frequency}

While changes in the first mode frequency of a structure can be indicative of structural damage, they can also be indicative of nonlinear behavior in the soil (Luco et al. 1987; Trifunac et al. 2001), which may be misinterpreted as damage. In many cases, stiffness lost in one earthquake is later regained through soil compaction over time and due small earthquakes (Trifunac et al. 2001). Therefore, care should be exercised in interpreting small changes in fundamental frequency.

With this in mind, the fundamental frequencies of the structure in both translational directions were calculated for each of the earthquakes in the dataset and plotted versus time in Figure 12 for the N-S direction and Figure 13 for the E-W direction. The San Fernando earthquake was used as a baseline, a valid assumption since there is no evidence suggesting damage occurred in this earthquake. The changes in the building's fundamental frequency from the San Fernando earthquake to present do not follow a clear trend, except for some local sections (e.g. 1987-1994) which show a gradual decrease in frequency. Since the total variation in frequency is approximately twenty percent over the 30 year time period, it is difficult to draw conclusions about possible damage using the first mode. The second mode is not particularly useful, due to the multiple peaks present in the neighborhood of the second translational mode at $1.3 \mathrm{~Hz}$. Changes in this modal frequency are difficult to detect, and this mode is therefore unsuitable for indicating damage. Overall, no distinct indications of damage can be determined from the fundamental frequencies or the second mode frequencies.

The results of the joint-time frequency analysis described in previous sections can be used to determine changes in first mode frequency during an earthquake, as opposed to the previous method, in which changes could only be seen in successive earthquakes. Spectrograms of the earthquakes most likely to have caused undetected structural damage, Whittier Narrows and Northridge, are located in Appendix E. For both these earthquakes, no significant shift in fundamental frequency is noted.

\section{Structural identification-based method}

A structural identification-based damage detection method (Sanli and Çelebi 2002) was employed to find out the location of possible damages caused by the Whittier Narrows, Upland, Northridge, and Hector Mine earthquakes. Records from these earthquakes were used in the application of the method. In this technique, the main focus is to identify structural parameters such as stiffness and mass distribution via fundamental frequencies and modal shapes obtained from the records. Distress in civil engineering structures often has a significant affect on stiffness, but not on mass. In particular, cracks reduce stiffness without the loss of mass. In addition to this, according to the building administrator, between the Upland and Northridge earthquakes, there was no significant change of mass distribution because of changing service functions. Thus, it was assumed that mass values remained constant over the studied time period.

Though the natural frequencies and mode shapes obtained from the records of the Whittier Narrows earthquake are slightly different than the calculated values from the finite element model, the results using records from the Whittier Narrows earthquake were assumed as the original dynamic characteristics of the building. The finite element model was prepared using the original drawings. It is well known fact that the dynamic and static 
characteristics of an actual structure never entirely match with the designed structure's values. Modifications during construction, uncertainty of material characteristics, and the participation of the secondary members are the main causes of this phenomenon.

As mentioned earlier, the vibrations caused by the Whittier Narrows earthquake were recorded at the $12^{\text {th }}$ floor, $6^{\text {th }}$ floor, and basement. Therefore, in the identification work, the lumped masses of these floors and the condensed stiffness values between those floors are the quantities to be identified. Figure 26 illustrates the simplified model of the building. This model has four degrees of freedom (dof), with two at each floor because the torsional dof has not been considered. The first reason for neglecting torsion is that significant torsional motion was determined not to be present at the floors in question during the earthquakes, and eliminating torsion would provide input with a high signal-to-noise ratio. In addition, the instrumentation configuration at the time of the Whittier-Narrows earthquake (the earthquake selected to provide the original stiffness and masses) does not have sufficient instruments to resolve torsional mode shapes reliably.

Neglecting the torsional dof at each floor permits the uncoupling of the 4-dof system in to two orthogonal 2-dof systems, oriented in the N-S and E-W directions, respectively. The natural frequencies and modal shapes of a freely vibrating, undamped, 2-dof system can be obtained by solving the following eigenvalue problem:

$$
\left|K-w^{2} M\right|=\left|\begin{array}{cc}
k_{11}-w^{2} m_{1} & k_{12} \\
k_{21} & k_{22}-w^{2} m_{2}
\end{array}\right|=0
$$

where, $k_{11}, k_{12}, k_{21}$, and $k_{22}$ are the stiffness coefficients of the structure. The masses of the first and second measured floors are represented by $m_{1}$ and $m_{2}$, and $w$ is the natural circular frequency. For a set of stiffness and mass values, there are two w's that satisfy the equation. The eigenvectors of those solutions give the modal shapes.

However, in the structural identification problem, the stiffness and masses are unknown, while the natural frequencies and modal shapes are known. The problem has to be solved backward. On the other hand, the known frequencies and mode shapes are not certain. This uncertainty comes from several causes such as noise contamination in the signals, imprecise measurement, or numerical errors. Therefore, in fact, there is no exact solution that matches the obtained dynamic characteristics of the structure. To overcome this problem, optimization techniques can be used.

If $w_{1 a}$ and $w_{2 a}$ are the natural frequencies and $v_{11 a}, v_{12 a}, v_{21 a}$, and $v_{22 a}$ are the modal vector values corresponding to randomly selected stiffness and mass values, the error can be calculated as follows:

$$
E=\sqrt{\sum_{i=1}^{n}\left(p_{i a}-p_{i}\right)^{2}}
$$

where $n$ shows the number of parameters to be determined, and the $p$ 's are the parameters. The index $a$ represents any selected values of the parameters. For this problem, $P$ parameter vector is

$$
P=\left[\omega_{1}, \omega_{2}, v_{11}, v_{12}, v_{21}, v_{22}\right]
$$

The minimum point of this multi-dimensional error function can be obtained through the stiffness and mass values that are closest to the true values. The solution of this problem has a few challenges. First of all, $E$ does not have only one minimum point because it is a repeating function. All $c P_{a}$ vectors, $c=0$ to $\infty$, give the same error value. The outputs of the eigenvalue function for some stiffness and mass values are complex numbers, which have no physical meaning in this problem. Such zones constitute holes on the error function. Another main difficulty comes from almost flat zones of the error function. Because all of these reasons, conventional nonlinear equation solvers cannot easily manage the problem. Therefore, different approach, a hybrid version of bug colony and rolling marble techniques discussed in the next section, was used in this study. 


\section{A Hybrid of Bug Colony and Rolling Marble Techniques}

In order to find the minimum point of this multi-dimensional surface, a method inspired by the theory of evolution and termed the "bug colony" method was used. This method is a simplified version of the "ant colony" method (Dorigo et al. 1995), in which the ants' behaviors were also included in the technique. However, in the method used herein, the physical law governing a marble rolling down a hill was imposed on the bugs, instead of relying on the bugs' instincts. This approach gives more control to the solver through adjustment of fictitious gravitational and friction forces. Through this, bugs go to the deepest point of the hollow without jumping over the indefinite zones of the function and sliding on flats to far points.

The computer program implementing the method works as follows. The program creates a certain number of numerical bugs on random points of the error surface. Each bug is defined by its coordinate, lifetime, velocity, and acceleration in each direction. Friction force between the bugs and the surface controls the speed of the bugs. Velocity and acceleration of the bugs are zero when they are created. Then, because of the gravitational force that pulls them toward the minimum elevation, they gain velocity and acceleration depending on the slope on which they are standing. Height is not good for their health and thus decreases their lifetime. Therefore, while the bugs born at hills live very shortly, the ones in hollows can live longer. At each time step, while going toward the lower elevations, they give birth to new bugs. After a while, the bugs start gathering in hollows of the surface through natural selection as well as physical laws. However, because of local flatness of the surface, even very low speeds can lead them astray or pin them to a specific elevation. Therefore, the program occasionally stops all bugs and then lets them go again. This interference considerably decreases the convergence time of the problem. When a previously specified number of bugs stops, the average of the stopped bugs' coordinates gives the solution.

\section{Identification Results}

Below, Table 11 shows the stiffness and mass values identified using the "bug colony" method. The natural frequency and mode shapes of the structural systems produced from recently identified stiffness and masses are summarized in Table 12 and Table 13, respectively. The frequencies of the identified systems match the original frequencies fairly well. However, the relative differences between identified and measured modal coordinates reach up to $13 \%$. The stiffness degradation in the East-West direction caused by the Northridge earthquake can be clearly seen from Table 12. The decrease is about $12 \%$ for the Northridge and Hector Mine earthquakes. According to this method, stiffness in the North-South direction decreased an additional 3\% during the Hector Mine over the 7\% reduction from Northridge. It can also be seen from this result that the total condensed mass corresponding to the sixth floor movement is approximately 1.5 times larger than that of the roof. This may explain the larger energy of the sixth floor records, because the force applied to the floor is a function of the mass of the floor in question.

Unfortunately, given the constraint of the sparse instrumentation configuration, the identification algorithm was not able to point out the location of the damage or the origin of the softening with this approach. The damage is not locatable because no unique solution exists for the problem of mapping the condensed stiffness loss back to stiffness losses in individual structural elements. The actual amount of the changes may not indicate the severity of the problem either. For instance, $10 \%$ stiffness reduction as a result of this process may not mean that the whole structure lost $10 \%$ of its structural integrity, because the selection of the fundamental frequencies and modal vector values from recorded signals includes uncertainties. However, this method shows that the structure became softer, especially after the Northridge earthquake, and the problem most likely occurred in the lower half of the building. 
Table 11. Identified stiffness and mass values

\begin{tabular}{|c|c|c|c|c|}
\hline \multicolumn{3}{|c|}{ Whittier-Narrows Earthquake $\quad \mathrm{E}=0.00$} & \multicolumn{2}{|c|}{ Changes (\%) } \\
\hline \multirow[t]{2}{*}{ Parameter } & \multicolumn{2}{|c|}{ Normalized stiffness and masses } & \multicolumn{2}{|c|}{ Changes (\%) } \\
\hline & $\mathrm{N}-\mathrm{S}$ & $E-W$ & $\mathrm{~N}-\mathrm{S}$ & $E-W$ \\
\hline K11 & 4.37 & 4.80 & 0 & 0 \\
\hline $\mathrm{K} 12=\mathrm{k} 21$ & -2.74 & -3.12 & 0 & 0 \\
\hline K22 & 10.87 & 11.61 & 0 & 0 \\
\hline M1 & 1 & 1 & 0 & 0 \\
\hline M2 & 1.45 & 1.45 & 0 & 0 \\
\hline \multicolumn{5}{|c|}{ Upland Earthquake } \\
\hline Parameter & \multicolumn{2}{|c|}{ Normalized stiffness and masses } & \multicolumn{2}{|c|}{ Changes $(\%)$} \\
\hline & $\mathrm{N}-\mathrm{S}$ & $E-W$ & $\mathrm{~N}-\mathrm{S}$ & $E-W$ \\
\hline K11 & 4.37 & 4.55 & -0.1 & -5.0 \\
\hline $\mathrm{K} 12=\mathrm{k} 21$ & -2.77 & -3.00 & 0.9 & -3.6 \\
\hline K22 & 10.45 & 11.07 & -3.9 & -4.7 \\
\hline M1 & 1 & 1 & 0 & -0 \\
\hline M2 & 1.49 & 1.49 & 3.0 & 3.0 \\
\hline \multirow{2}{*}{\multicolumn{3}{|c|}{ 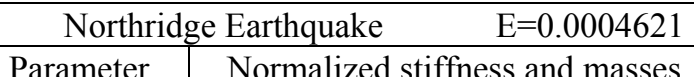 }} & & \\
\hline & & & \multicolumn{2}{|c|}{ Changes (\%) } \\
\hline & $\mathrm{N}-\mathrm{S}$ & $E-W$ & $\mathrm{~N}-\mathrm{S}$ & $E-W$ \\
\hline K11 & 4.05 & 4.34 & -7.3 & -9.5 \\
\hline $\mathrm{K} 12=\mathrm{k} 21$ & -2.57 & -2.87 & -6.3 & -8.0 \\
\hline K22 & 10.32 & 10.23 & -5.1 & -11.8 \\
\hline M1 & 1 & 1 & 0 & 0 \\
\hline M2 & 1.50 & 1.45 & 3.6 & 3.6 \\
\hline \multicolumn{5}{|c|}{ Hector Mine Earthquake } \\
\hline Parameter & \multicolumn{2}{|c|}{ Normalized stiffness and masses } & \multicolumn{2}{|c|}{ Changes (\%) } \\
\hline & $\mathrm{N}-\mathrm{S}$ & $E-W$ & $\mathrm{~N}-\mathrm{S}$ & $E-W$ \\
\hline K11 & 3.92 & 4.43 & -10.4 & -7.6 \\
\hline $\mathrm{K} 12=\mathrm{k} 21$ & -2.50 & -2.81 & -9.0 & -9.7 \\
\hline K22 & 10.03 & 10.17 & -7.8 & -12.4 \\
\hline M1 & 1 & 1 & 0 & 0 \\
\hline M2 & 1.45 & 1.45 & 0.1 & 0.1 \\
\hline
\end{tabular}

Table 12. Frequencies obtained from the earthquake records

\begin{tabular}{|c|ccccccc|}
\hline \multirow{2}{*}{ Earthquakes } & \multicolumn{2}{|c}{ North-South } & \multicolumn{2}{c|}{ East-West } & \multicolumn{2}{c|}{ Torsional } \\
& 1st & 2nd & 1st & 2nd & 1st & 2nd \\
\hline Whittier & 0.51 & 1.39 & 0.53 & 1.50 & - & - \\
\hline Upland & $\begin{array}{c}0.49 \\
(-3 \%)\end{array}$ & $\begin{array}{c}1.32 \\
(-4 \%)\end{array}$ & $\begin{array}{c}0.50 \\
(-6 \%)\end{array}$ & $\begin{array}{c}1.41 \\
(-6 \%)\end{array}$ & 0.81 & 2.14 \\
\hline Northridge & $\begin{array}{c}0.47 \\
(-8 \%)\end{array}$ & $\begin{array}{c}1.27 \\
(-8 \%)\end{array}$ & $\begin{array}{c}0.47 \\
(-13 \%)\end{array}$ & $\begin{array}{c}1.31 \\
(-13 \%)\end{array}$ & 0.77 & 2.11 \\
\hline Hector Mine & $\begin{array}{c}0.46 \\
(-10 \%)\end{array}$ & $\begin{array}{c}1.27 \\
(-8 \%)\end{array}$ & $\begin{array}{c}0.49 \\
(-9 \%)\end{array}$ & $\begin{array}{c}1.34 \\
(-11 \%)\end{array}$ & 0.78 & 2.12 \\
\hline
\end{tabular}


Table 13. Mode shape values

\begin{tabular}{|c|c|c|c|c|c|c|c|c|}
\hline \multirow{3}{*}{$v_{1}=1$} & \multirow{2}{*}{\multicolumn{2}{|c|}{ Earthquakes }} & \multicolumn{2}{|c|}{ North-South } & \multicolumn{2}{|c|}{ East-West } & \multicolumn{2}{|c|}{ Torsional } \\
\hline & & & $1 \mathrm{st}$ & 2nd & $1 \mathrm{st}$ & 2nd & $1 \mathrm{st}$ & 2nd \\
\hline & Whittier & $v_{2}$ & 0.45 & -1.58 & 0.45 & -1.49 & - & - \\
\hline & Unland & $v_{2}$ & 0.45 & -1.42 & 0.49 & -1.44 & 0.42 & -1.47 \\
\hline & & $v_{3}$ & 0.01 & -0.18 & 0.02 & -0.22 & 0.02 & -0.30 \\
\hline & Northridge & $v_{2}$ & 0.45 & -1.54 & 0.48 & -1.35 & 0.46 & -1.56 \\
\hline & NortmIIage & $v_{3}$ & 0.02 & -0.15 & 0.05 & -0.13 & 0.01 & -0.45 \\
\hline & Hector Mine & $v_{2}$ & $\begin{array}{c}- \\
000\end{array}$ & $\begin{array}{c} \\
-0\end{array}$ & 0.43 & $\begin{array}{l}-1.41 \\
\end{array}$ & 0.42 & -0.94 \\
\hline
\end{tabular}

\section{Methods based on changes in particular structural response quantities}

\section{Empirical hysteretic behavior}

In experimental research on structures or components, one of the most common methods of determining when and if nonlinear behavior is occurring is visual examination of a plot of a force quantity versus a displacement quantity, which is more commonly referred to as a hysteresis plot. Substantial damage (such as yielding or buckling) is accompanied by significant changes in the tangent slope of the force-displacement relationship. This concept can be applied to real buildings and their recorded seismic responses as well as to laboratory specimens. This idea is attractive because it permits a direct empirical estimate of the stiffness to be made at any point in the time history, and can clearly show changes in stiffness and strength that indicate damage. Local or global stiffness quantities can be estimated, depending on the force and displacement quantities chosen for plotting.

Of course, one must be able to calculate both force and displacement quantities from the recorded accelerations. Typically, both displacements corrected accelerations are provided by the data processors, and are obtained using standard processing procedures (e.g. Stephens and Boore 2004). A very approximate empirical hysteretic loop can be obtained by plotting acceleration versus displacement. This is done for the Northridge earthquake in Figure 27. Empirical hysteretic loops generated by dynamic loading are often more complex than those obtained from quasistatic tests. There are many small excursions (meaning displacement increases and then decreases, or vice versa), loops, and "squiggles" that deviate from the expected straight line even for elastic systems. Thus, a nonlinearity (such as a plateau, or leveling-off of force with increasing displacement) should be fairly large (compared to the small excursions in the remainder of the plot) to be interpreted as resulting from damage. For instance, the unusuallooking excursion near $-5 \mathrm{~cm}$ in the E-W direction at the second floor level in Figure 27 might indicate some damage occurred at that level, but it is not really large enough to be interpreted as damage with any certainty.

More refined hysteresis plots can be obtained by estimating forces from the recorded accelerations. To do this, the accelerations at every floor need to be determined. Since most structures don't have instruments at every floor, some form of interpolation is necessary. A number of investigators (e.g. Lui et al. 1990, De la Llera and Chopra 1998, Goel 2004) have used several basic techniques to estimate accelerations. The basic techniques are (1) interpolation of accelerations (generally linear), or (2) interpolation of displacements (generally using cubic splines), and then double differentiation to obtain accelerations, which are then smoothed by low-pass filtering. The second technique is more robust, since the displaced shape of the structure is typically continuous and smooth and therefore more suitable for approximation by cubic splines. The resulting accelerations at each floor are then multiplied by a lumped mass to obtain inertia forces. The sum of the inertia forces provides a good estimate of the base shear force for systems with low damping.

Both methods of interpolation were implemented for the Northridge earthquake, and the resulting base shear - roof displacement hysteresis plots are shown in Figure 28. While there are certainly local differences in the responses calculated using the two methods, both show agreement on the basic response characteristics. Hysteresis plots 
obtained using both methods provide a consistent estimate of the equivalent global stiffness and show no evidence of significant nonlinear behavior. The maximum base shear calculated using these methods is approximately 17000 $\mathrm{kN}$ (3820 kips) for linear interpolation and about $15000 \mathrm{kN}$ (3370 kips) for cubic spline interpolation. Division by the total design base shear of $13100 \mathrm{kN}$ (2940 kips) gives an upper bound estimate of the demand to nominal capacity ratio (since the nominal capacity is larger than the design base shear). Peak values of this ratio estimated by these two methods are in the range of 1.15 to 1.3. These ratio values are for short-duration "spikes" in the base shear response, and since no yield plateaus occur, these values are still compatible with the previous observation from the empirical hysteretic loop shape that there was no evidence of significant inelastic behavior, as well as with the inspections which found no significant structural damage.

\section{High-frequency transients}

Connection fractures have been observed to cause high-frequency, transient accelerations in shaking table tests of a steel moment frame specimen (Rodgers and Mahin, 2004). The possible use of the presence of high-frequency transients to detect fracture damage is being examined in a concurrent study (Rodgers et al., unpublished, 2004), which includes the Alhambra building.

Several observations from that study are included here. First, higher frequency, transient accelerations in the Northridge record at 65 seconds (see Figure 8) are from an aftershock and not due to fracture damage. This aftershock has been well documented and was observed at the Fremont School ground station not far from the site. Second, no high-frequency spikes were observed in the uncorrected or corrected accelerations derived from analog records, or in the analog records themselves, for Northridge (when the fracture damage was assumed to have occurred). This could mean that (a) no fractures capable of causing transients occurred (only W1 indications were found, and these should not cause transients), or (b) fractures occurred and generated transients, but the transients were not recorded due to instrument limitations or a large distance between the fracture and the instrument. Of these two options, (a) is more plausible given the results of the post-Northridge inspection, which should have unearthed any significant fracture damage from either Northridge or earlier earthquakes such as Whittier Narrows. A possible high-frequency transient was observed in the uncorrected (V1) Whittier Narrows record. However, an examination of a film copy of the original analog record shows no clear evidence of a transient, and the potential transient in the V1record is probably an artifact of the digitization perhaps due to relatively low resolution in the transient region and the thickness of the trace. Therefore, the transient presence cannot be established with any certainty. Thus, the high-frequency transient method is in agreement with the conclusions reached by the inspectors that no fractures occurred (W1 indications were not considered fractures).

\section{Conclusions}

Strong motion instruments in the Alhambra building have recorded sixteen earthquakes since the building was instrumented in 1971, including most of the significant Southern California earthquakes in that time period. Information about the performance of the building is available for most of these earthquakes, and ambient vibration tests have been performed on the building by several different investigators. These three types of information make up a dataset which is a valuable tool for research into both structural response and damage detection.

Overall, the studies show that the response of the building has been elastic in the majority of the earthquakes recorded at the site. Possible exceptions are the Whittier Narrows and Northridge earthquakes, where limited evidence of nonlinear behavior exists (only from the results of the system identification-based method), but no structural damage was found (if W1 indications are not considered to be earthquake damage). Despite the elastic response of the building, the observed dynamic behavior is much more complicated than one might anticipate from its very regular geometry. The building response is characterized by low damping, extended periods of vibration including an unexpected elliptical particle motion, beating, and significant higher-mode participation and torsion at the second floor during strong shaking. The very stiff concrete piers which extend to the second floor cause the response at the second floor to be much more similar in frequency content to that of the basement than to that of the moment frame above. The unexpected elliptical particle motion occurs in the moment frame during the periods of 
extended vibration after the cessation of strong shaking. The cause of this unexpected response has yet to be determined, but it has been observed at different levels of shaking, and so is likely a result of building properties rather than the characteristics of a particular earthquake.

After the Northridge earthquake, small cracks or weld defects (FEMA designation W1), were discovered in the steel moment frames as a result of intrusive inspections. It is probable that these were pre-existing conditions rather than earthquake damage, though it is extremely difficult to prove this conclusively. None of the damage detection methods used indicated any structural damage, although the identification-based method suggests that some nonlinear behavior may have occurred during the Northridge earthquake. However, due to the limited number of connections inspected $(\sim 5 \%)$ after the Northridge earthquake, it is possible that some isolated structural damage went undetected. Further research is needed to determine if soil nonlinearity may have contributed to the response.

\section{Acknowledgements}

The authors would like to express their appreciation to the following persons: Chris Stephens and Roy Tam of the USGS National Strong Motion Program Data Center, Howard Bundock of USGS, Steve Cloke and Michael Cholakian of the Los Angeles County Dept. of Public Works, Albert Chen of Black \& Veatch, Inc., and James Anderson of the University of Southern California. The authors would also like to thank the internal reviewers at USGS for their helpful suggestions which improved the manuscript.

\section{References}

Black, C.J. (1998). Dynamic analysis of civil engineering structures using joint time-frequency methods, M.A.Sc. Thesis. Department of Civil Engineering, the University of British Columbia. Vancouver.

Boroschek, R.L. and S.A. Mahin (1991). Investigation of the seismic response of a lightly-damped, torsionally-coupled building, Report No. UCB/EERC - 91/18, Earthquake Engineering Research Center, University of California, Berkeley.

Çelebi, M. (1994). Response study of a flexible building using three earthquake records, Proceedings, Structures Congress XII, Atlanta, Georgia, American Society of Civil Engineers, New York, v.2, 1220-1225.

Çelebi, M. (1998). The Loma Prieta, California, Earthquake of October 17, 1989 - Building Structures. Professional Paper 1552-C, U.S Geological Survey, Menlo Park, California.

Chatelain, J. L., Guéguen, P., Guillier, B., Fréchet, J., Bondoux, F., Serrault, J., Sulpice, P. and J.M. Neuville (2000). CityShark : A user-friendly instrument dedicated to ambient noise (microtremor) recording for site and building response studies, Seismological Research Letters, 71(6).

Cohen, J.M. (1996). Seismic vulnerability analysis of steel framing with deep spandrel beams, Professional Paper 9616, Los Angeles Tall Buildings Structural Design Council, Los Angeles, California.

Computers and Structures, Inc. (1990-2004). SAP90 and SAP2000, computer software, Berkeley, California.

De la Llera, J.C., and A.K. Chopra (1998). Evaluation of seismic code provisions using strong motion building records from the 1994 Northridge earthquake, Report No. UCB/EERC - 97/16, Earthquake Engineering Research Center, University of California, Berkeley.

Dorigo, M., Maniezzo, V., and A. Corloni (1995). The ant system: optimization by a colony of cooperating agents, IEEE Transactions on Systems, Man, and Cybernetics, 25(12).

Dunand, F., Rodgers, J.E., Acosta, A., Bard, P.-Y, and M. Çelebi (2004). Ambient vibration and earthquake strong motion data sets for selected USGS extensively instrumented buildings, Open-file Report No. 2004-xxx, (in preparation), U.S. Geological Survey, Menlo Park, California.

FEMA (1995). Interim Guidelines, Inspection, Evaluation, Repair, Upgrade and Design of Welded Moment Resisting Steel Structures, FEMA-267, prepared by the SAC Joint Venture for the Federal Emergency Management Agency, Washington, DC.

Ghanem, R. and M. Shinozuka (1995). Structural system identification: I. theory, J. of Engineering Mechanics, 121(2), 255-264. 
Goel, R.K. (2004). Evaluation of nonlinear static procedures using strong-motion building records, Proceedings, SMIP04 Seminar on Utilization of Strong-Motion Data, Sacramento, California, 61-81.

Goel, R.K. and A.K. Chopra (1997). Vibration properties of buildings determined from recorded earthquake motions, Report No. UCB/EERC - 97/14, Earthquake Engineering Research Center, University of California, Berkeley.

ICBO (1949-1997). Uniform Building Code, International Conference of Building Officials, Whittier, California. Kramer, S.L. (1996). Geotechnical earthquake engineering, Prentice Hall, Upper Saddle River, New Jersey. Ljung, L. (1987). System identification: theory for the user, Prentice-Hall, Englewood Cliffs, New Jersey.

Luco, J.E., Trifunac, M.D., and H.L. Wong (1987). On apparent changes in dynamic behavior of a nine-story reinforced concrete building, Bulletin of the Seismological Society of America, 77(6), 1961-1983.

Lui, R.R., Mahin, S.A. and J.P. Moehle (1990). Seismic response and analytical modeling of the CSULA administration building subjected to the Whittier Narrows earthquake, Proceedings, SMIP90 Seminar on Seismological and Engineering Implications of Recent Strong-Motion Data, Sacramento, California, 8.18.10.

The MathWorks (1988). MATLAB, computer software, Natick, Massachussetts.

Novikava, E.I., and M.D Trifunac, (1994). Duration of ground motion in terms of earthquake magnitude, epicentral distance, site conditions and site geometry, Earthquake Engineering and Structural Dynamics, 23, 10231043.

Paret, T.F. (2000). The W1 issue: extent of weld fracturing during Northridge earthquake, J. of Structural Engineering, 126(1), 10-18.

Rodgers, J.E., and S.A. Mahin (2004). Effects of connection hysteretic degradation on the seismic behavior of steel moment resisting frames, Report No. PEER-2003/13, Pacific Earthquake Engineering Research Center, Richmond, California

SAC (1995). Analytical and field investigations of buildings affected by the Northridge earthquake of January 17 , 1994, Report No. SAC 95-04, SAC Joint Venture, Sacramento, California.

Sanli, A.K. and M. Çelebi (2002). Earthquake damage detection of a thirteen story building using recorded responses, Proceedings, $3^{\text {rd }}$ International Workshop on Structural Health Monitoring, Stanford University, Stanford, California.

Shinozuka, M. and R. Ghanem (1995). Structural system identification II. experimental verification, J. Engng. Mech., 121(2), 265-273.

Sohn, H., Farrar, C.R., Hemez, F.M., Shunk, D.D., Stinemates, D.W., and B.R. Nadler (2003). A review of structural health monitoring literature: 1996-2001, Report No. LA-13976-MS, Los Alamos National Laboratory, Los Alamos, New Mexico.

Stephens, C.D. and D.M. Boore (2004). ANSS/NSMP strong-motion record processing and procedures, Proceedings, COSMOS Invited Workshop on Record Processing Guidelines, Consortium of Organizations for Strong Motion Observation Systems, Richmond, California.

Trifunac, M.D., and G. Brady (1975). A study of the duration of strong earthquake ground motion, Bulletin of the Seismological Society of America, 65, 581-626.

Trifunac, M.D., Ivanovic, S.S. and M.I. Todorovska (2001). Apparent periods of a building. I: Fourier analysis, J. Struct .Engng., 127(5), 517-526.

Vetterli, M. and J. Kovacevic (1995). Wavelets and subband coding, Prentice-Hall, Englewood Cliffs, New Jersey.

Walker, J.S. (1999). A primer on wavelets and their scientific applications, Chapman \& Hall/ CRC, Boca Raton, Florida. 


\section{Figures}

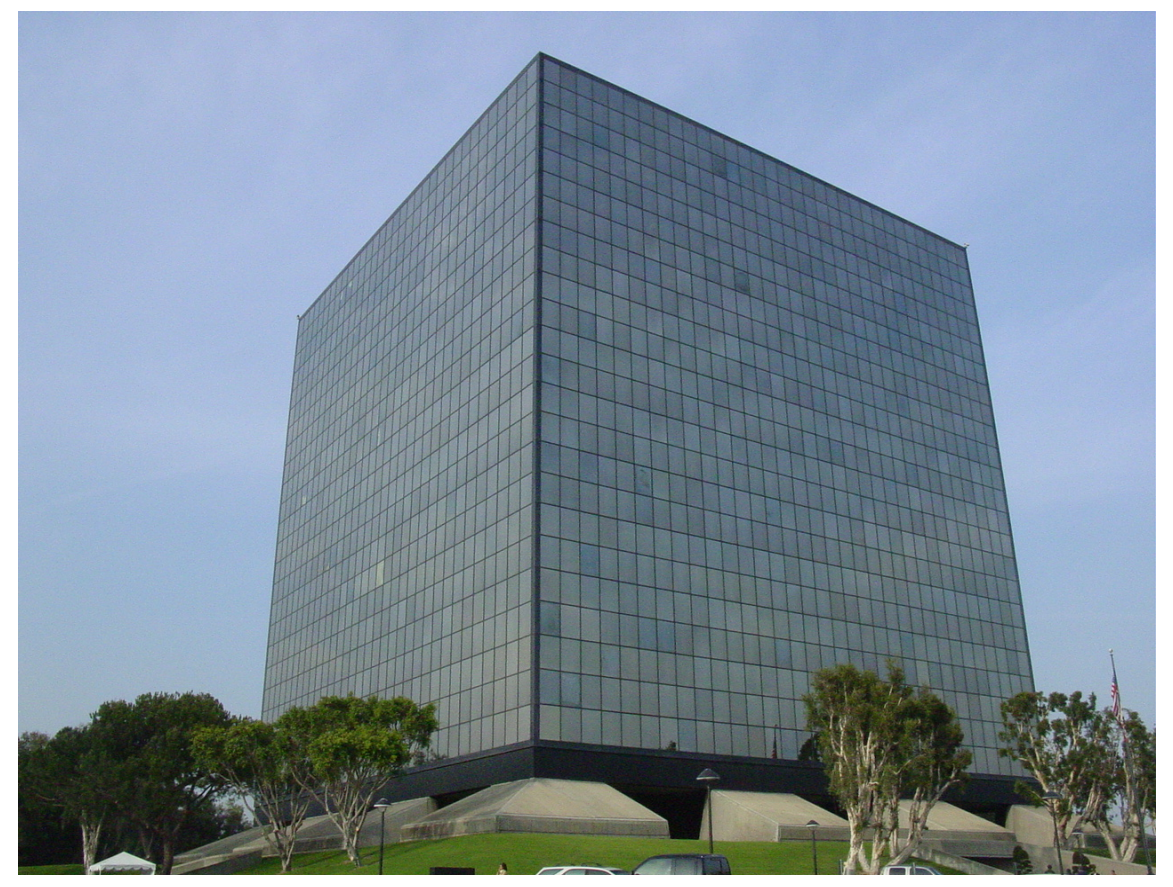

Figure 1. Exterior view of the Alhambra building 

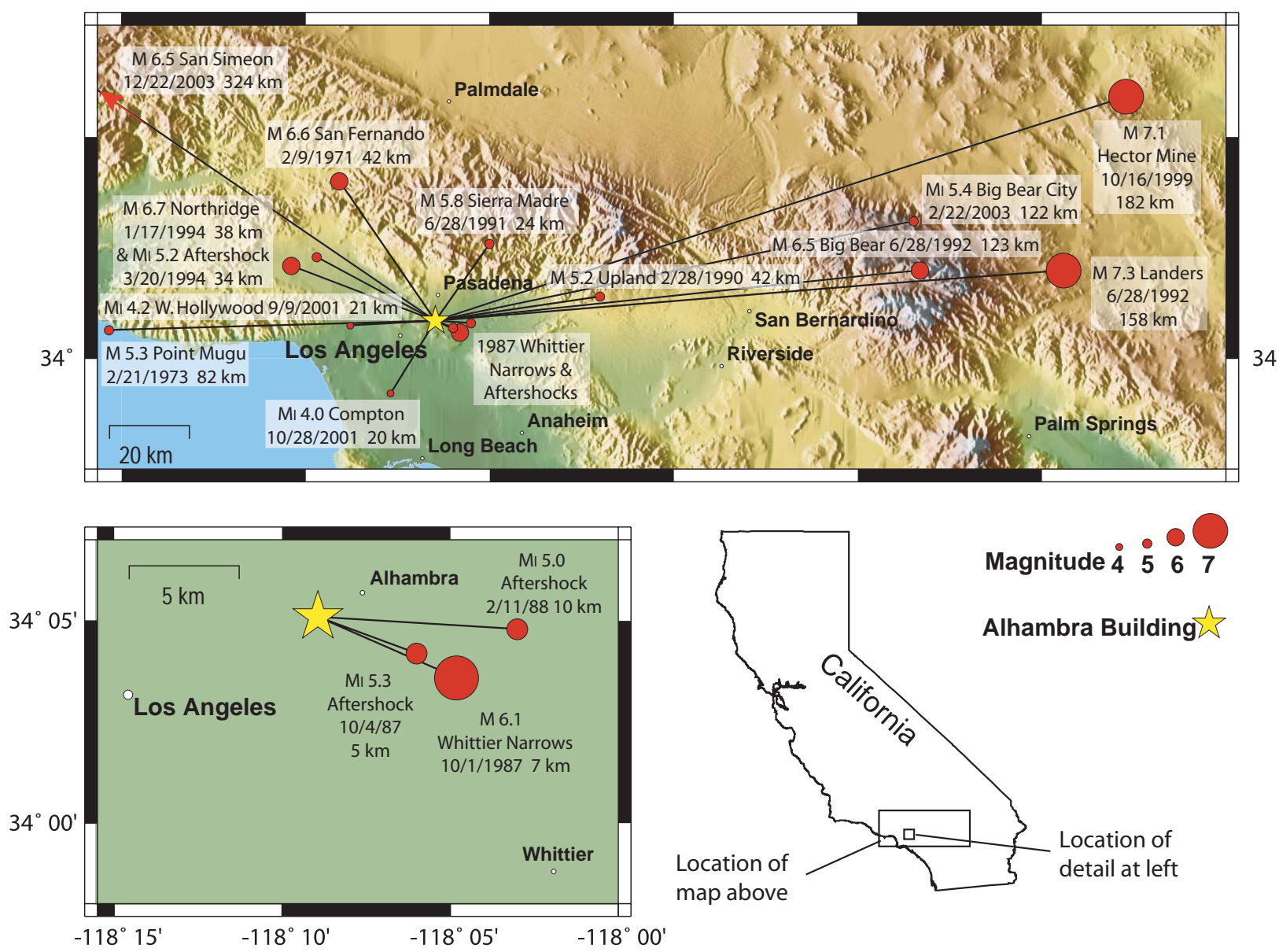

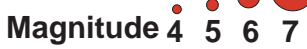

Alhambra Building $\hat{r}$

Figure 2. Location of Alhambra Building and epicenters of earthquakes with strong-motion data recorded

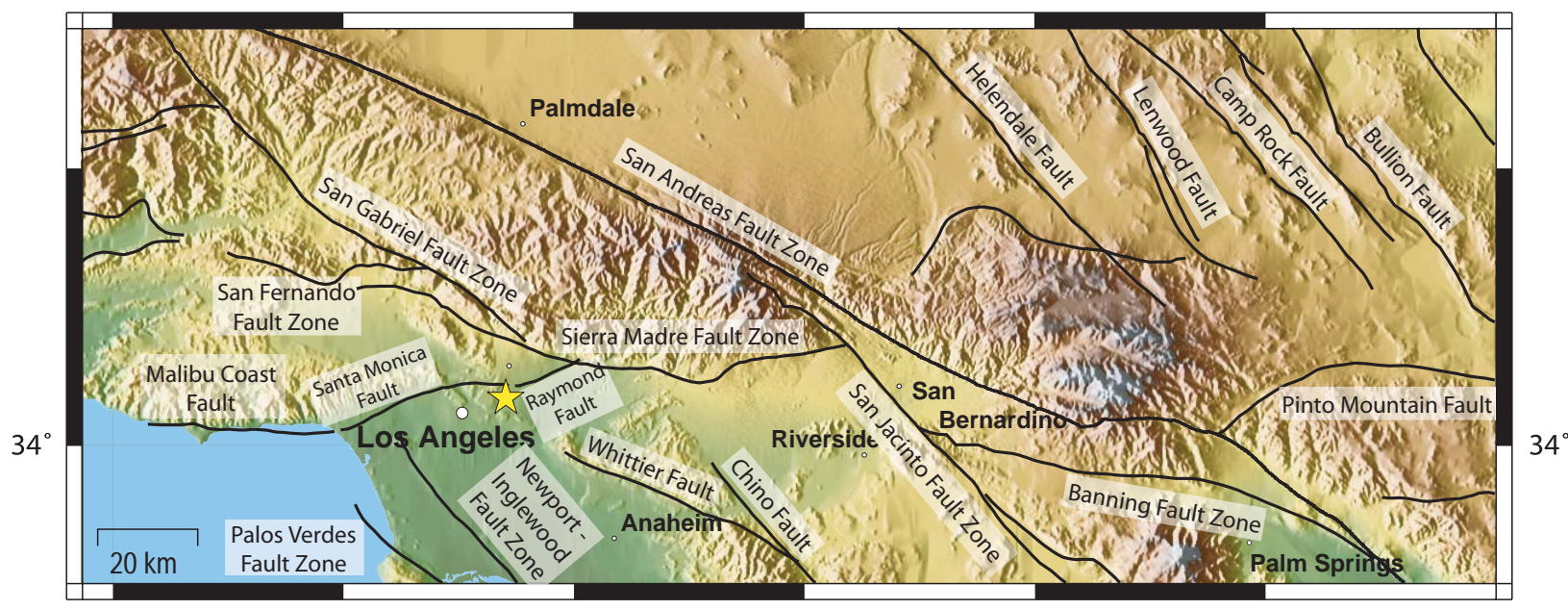

Alhambra Building $\tilde{h}$

Figure 3. Location of Alhambra building with respect to mapped surface traces of major faults. The map location is the same as in Figure 2. 


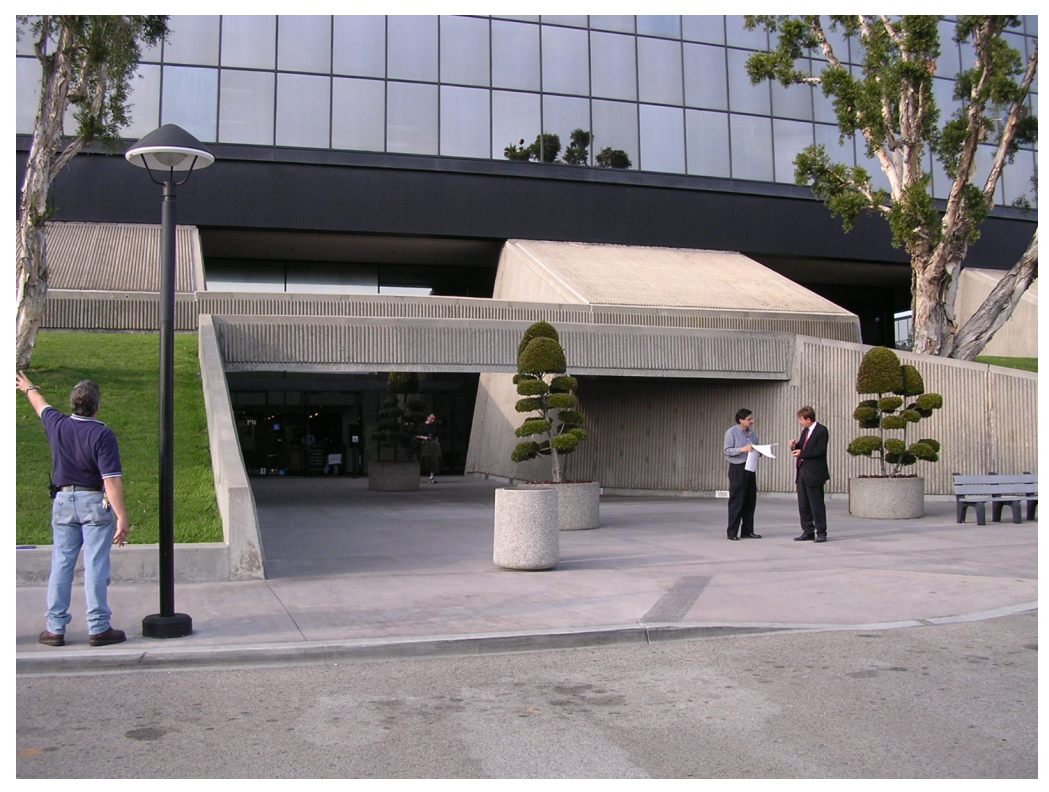

Figure 4. Massive concrete piers at the base of the building, extending from the ground floor to the second floor. The steel moment frame begins at the large black band (plate girder) directly above the piers.

(M) (L) () (1) (A) (G) (F) (E) (D) (C) (B) A

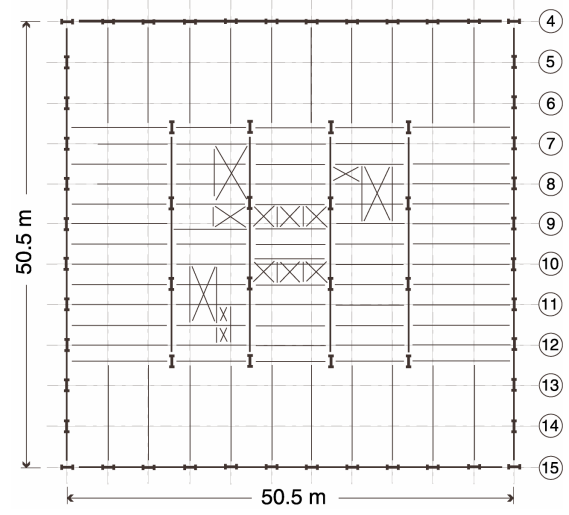

Figure 5. Structural framing for a typical floor (plan view) 

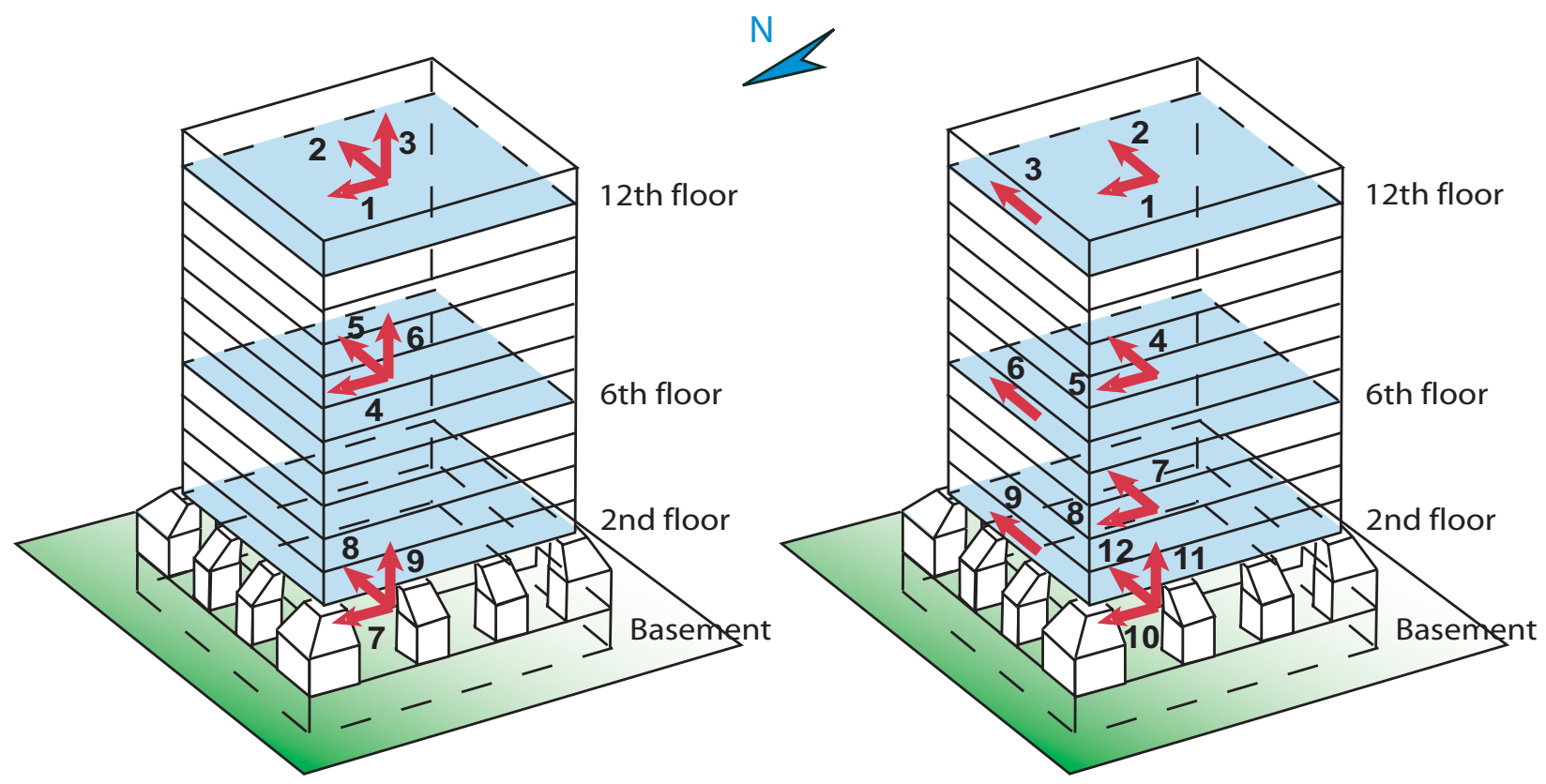

Figure 6. Code-recommended (left) and extensive (right) instrumentation configurations with channel numbering used elsewhere in report. Red arrows indicate the location and direction of each accelerometer.
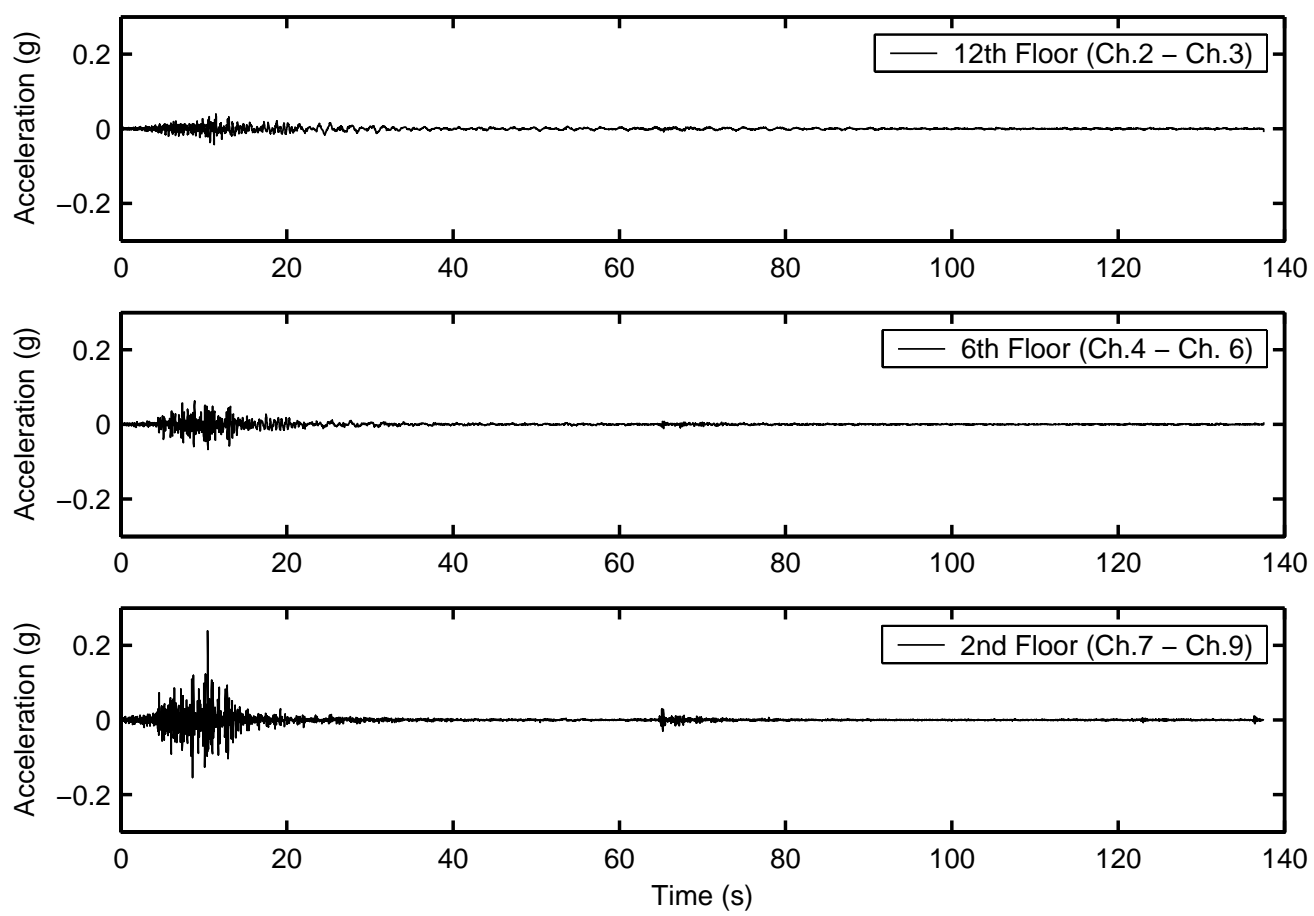

Figure 7. Nominal torsional accelerations obtained by differencing the two parallel E-W channels at the $2^{\text {nd }}, 6^{\text {th }}$, and $12^{\text {th }}$ floors, Northridge earthquake 

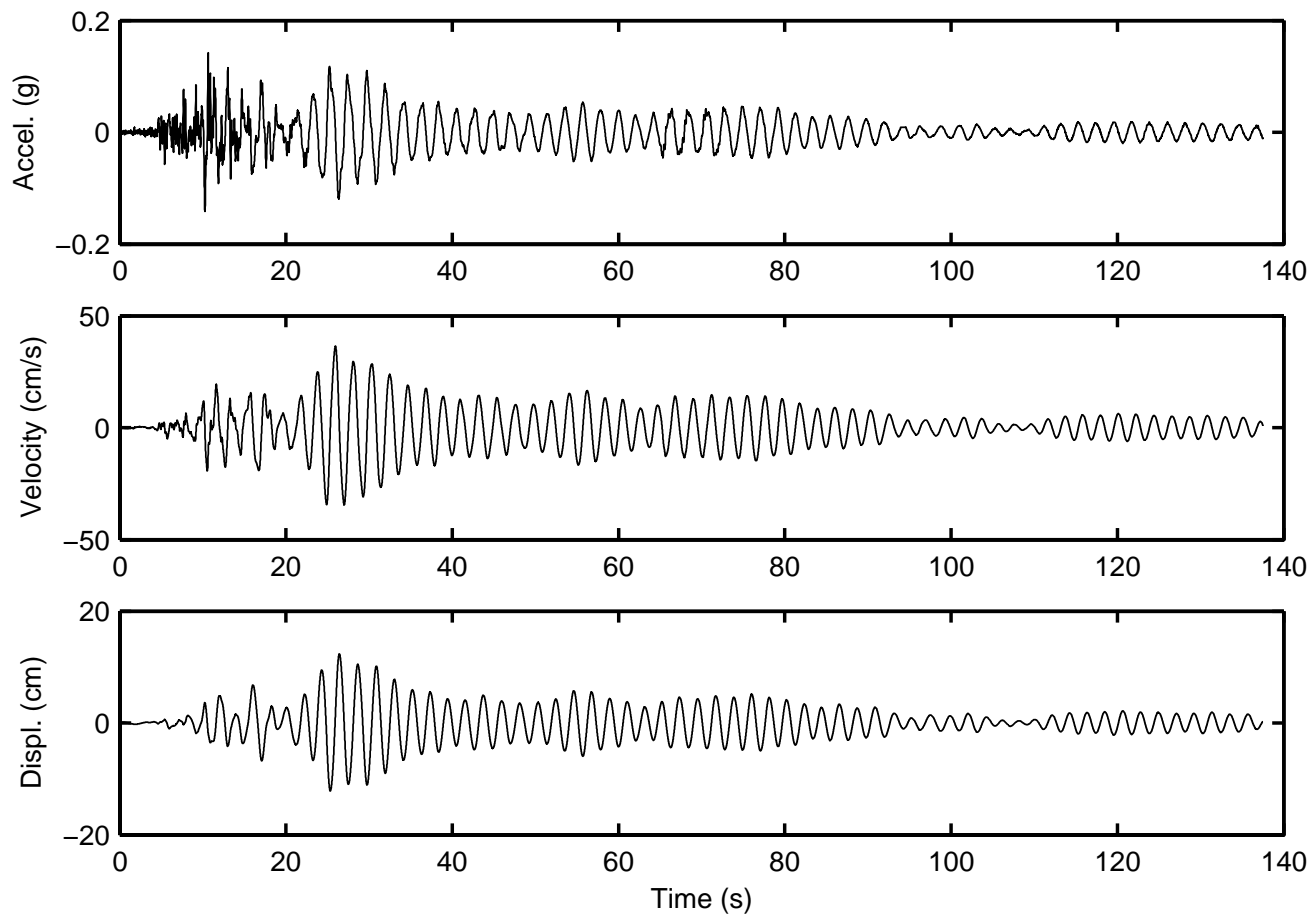

Figure 8. Acceleration, velocity and displacement time histories, $12^{\text {th }}$ floor E-W (Ch.2), Northridge earthquake
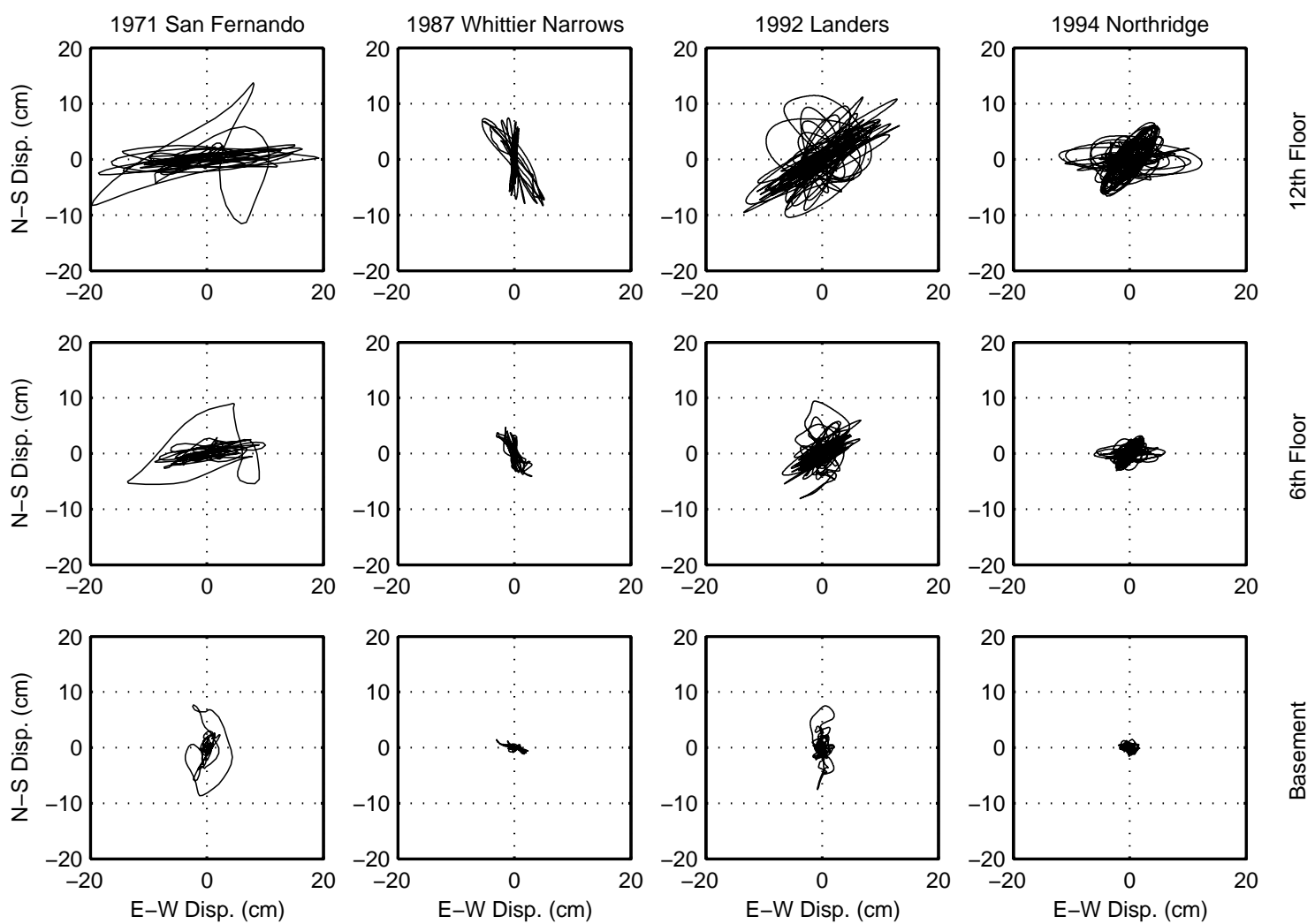

Figure 9. Particle motion for San Fernando, Whittier Narrows, Landers, and Northridge earthquakes (full time history) 


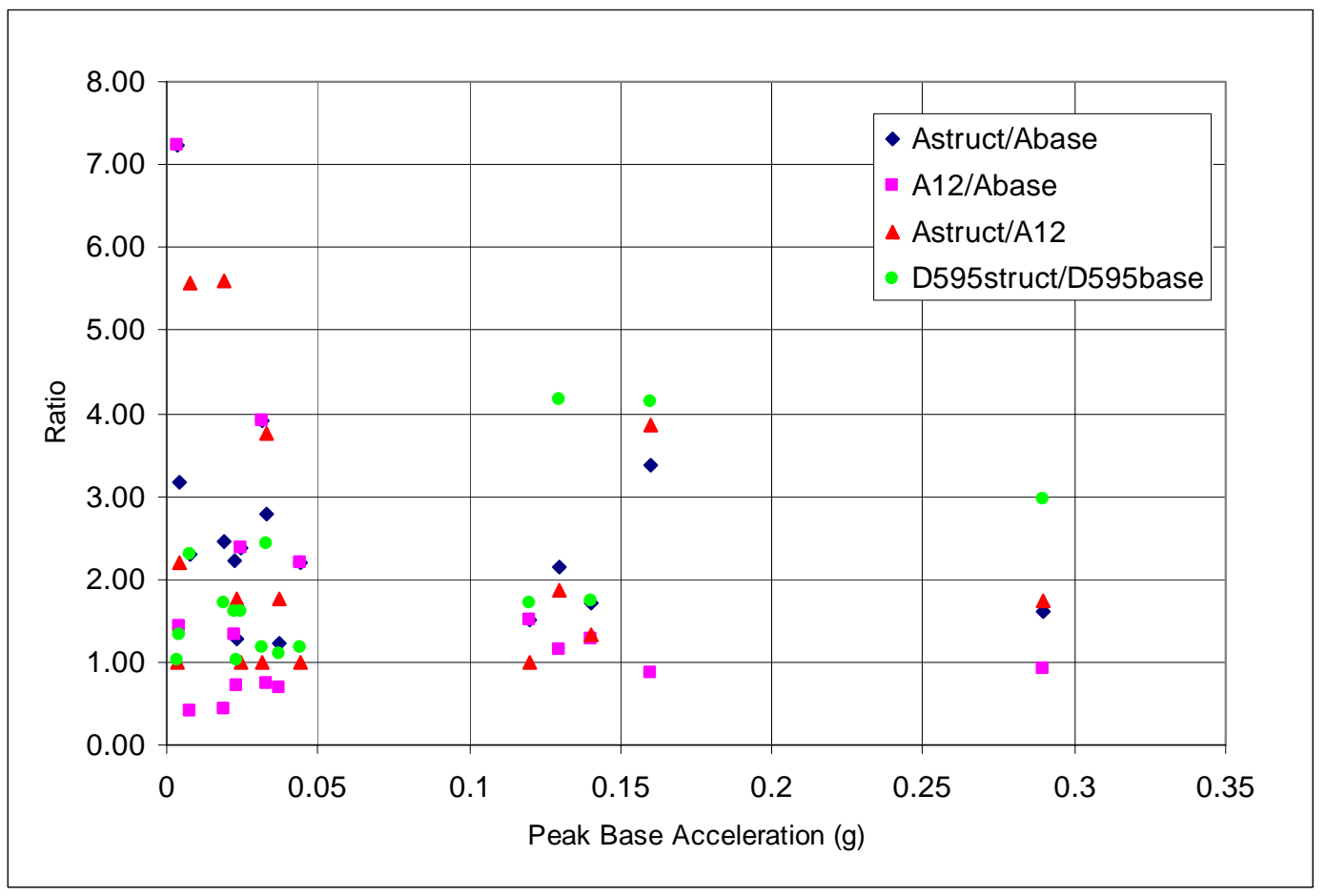

Figure 10. Ratios of measured response quantities versus peak base acceleration
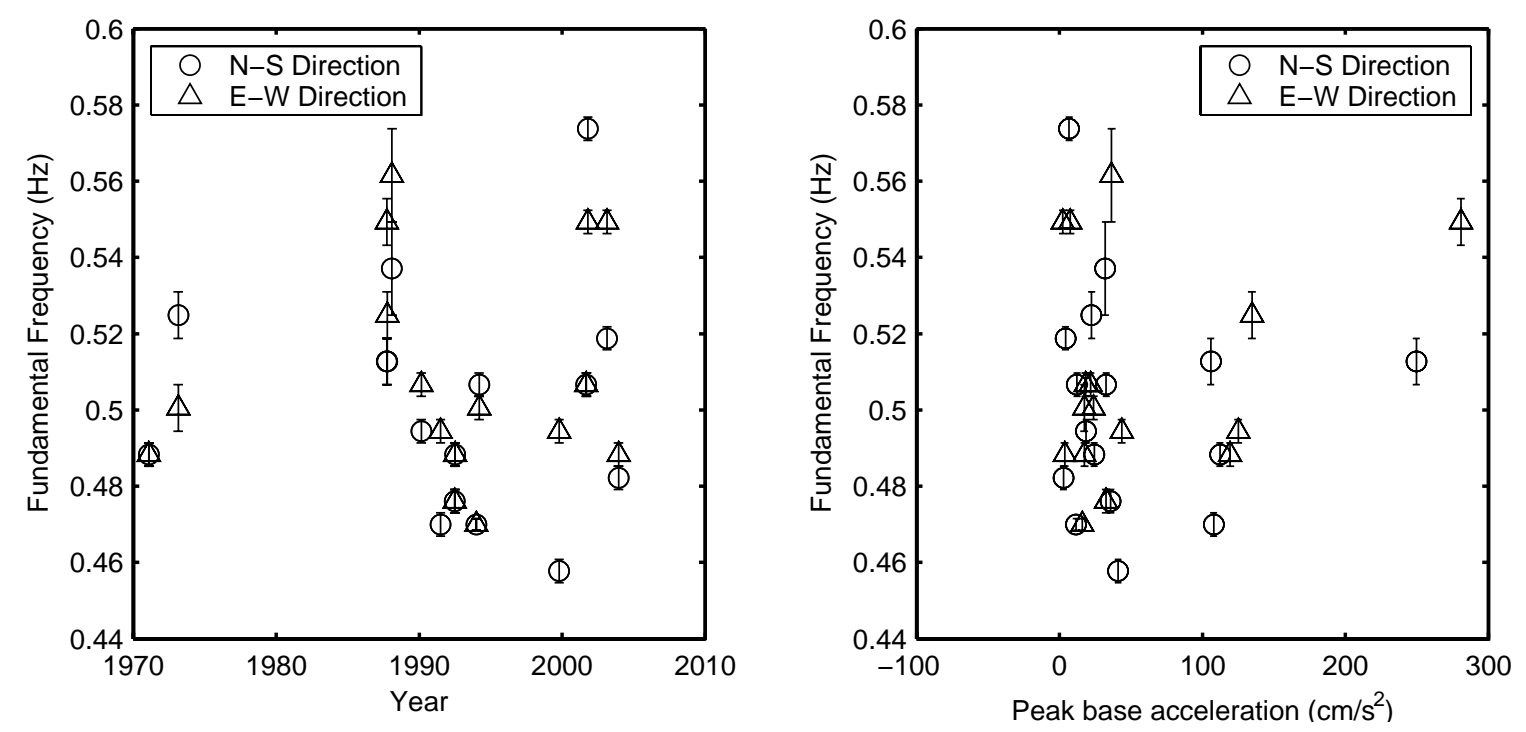

Figure 11. Variation in first mode period with time (left) and peak base acceleration amplitude (right). Error bars show frequency increment. 


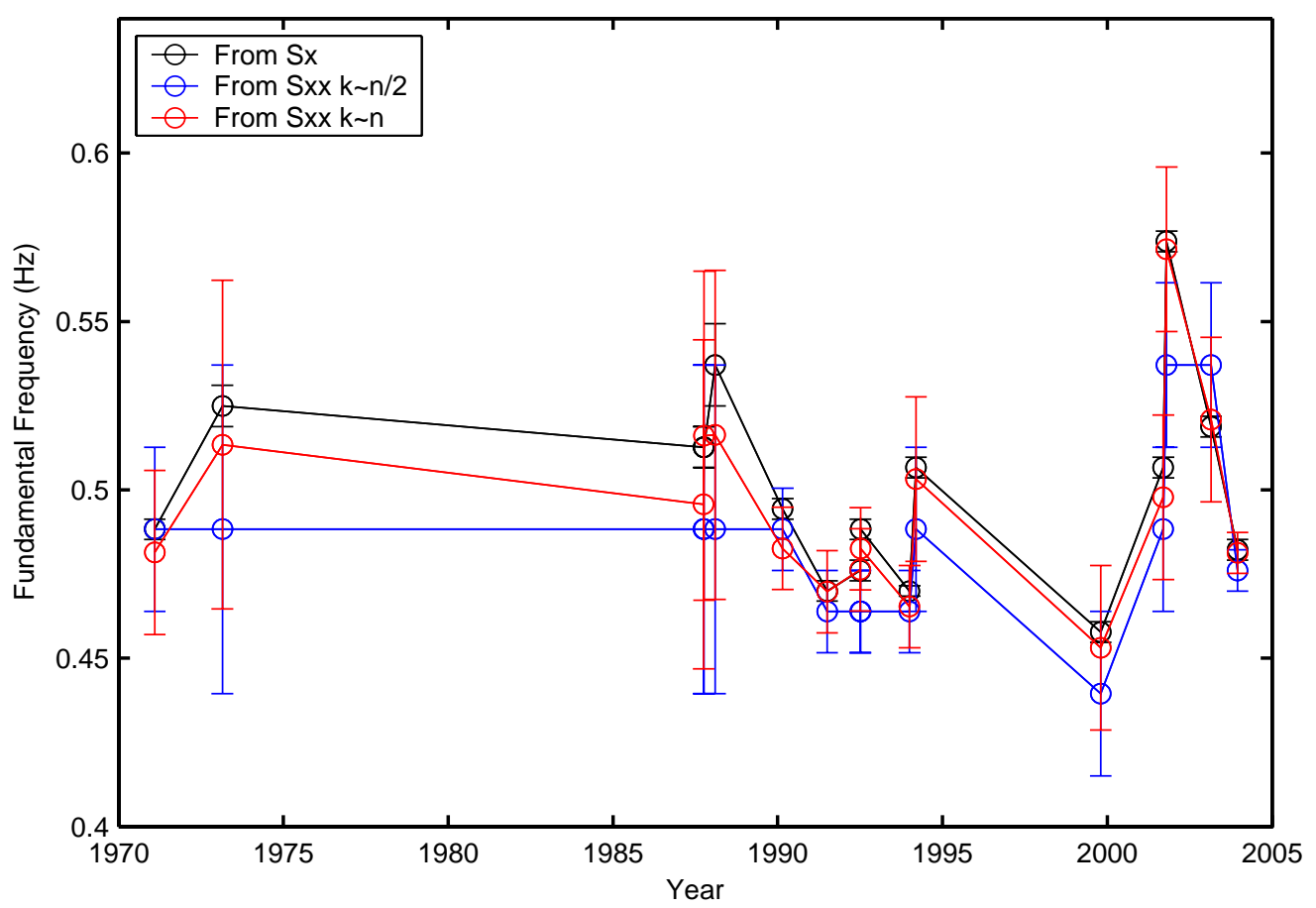

Figure 12. Comparison of 1st mode frequency determined from $12^{\text {th }}$ floor N-S records from Fourier amplitude spectra $(S x)$, and autospectra with window lengths $k$ of half the record (Sxx k n/2) and the full record (Sxx k n).

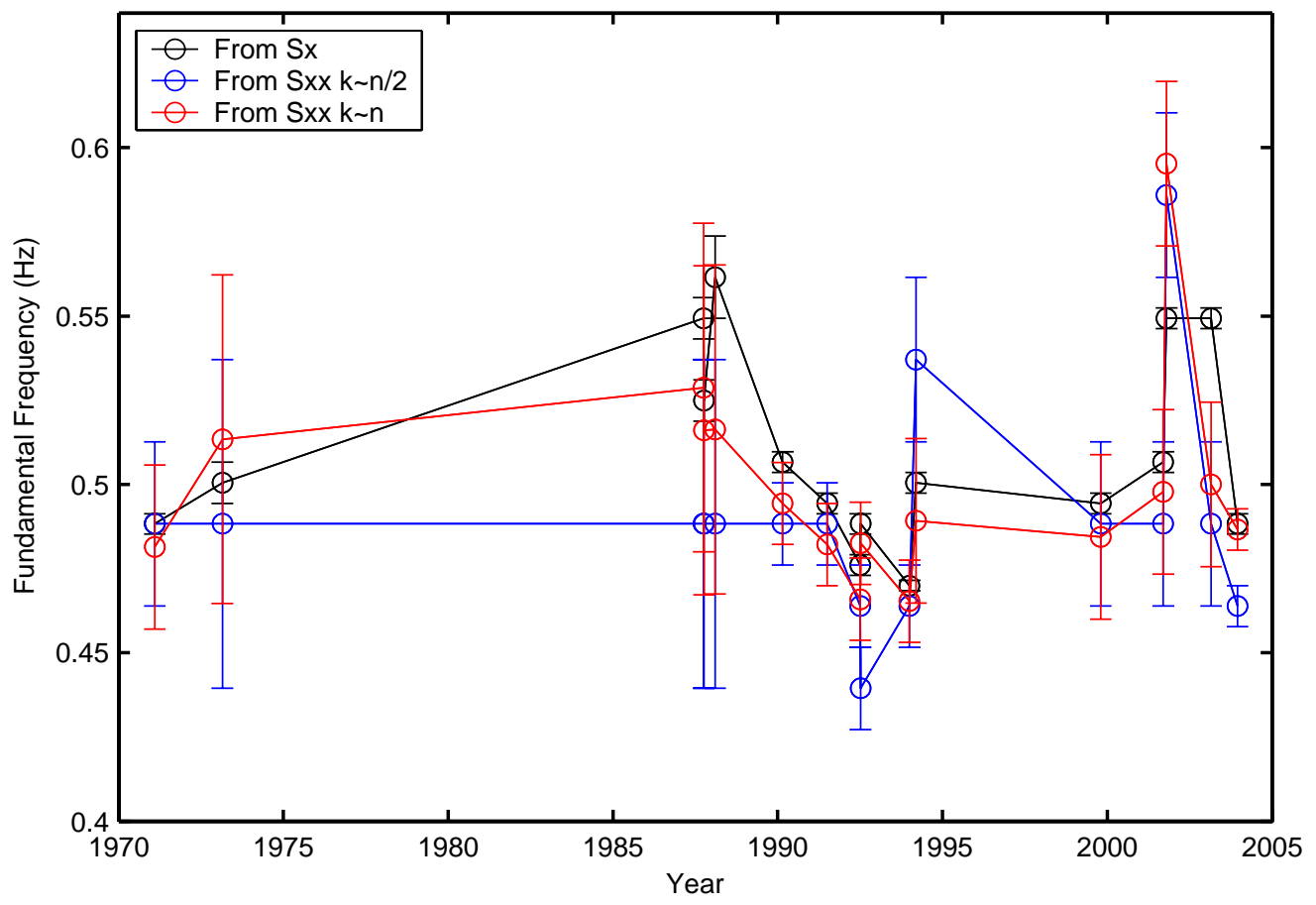

Figure 13. Comparison of 1st mode frequency determined from $12^{\text {th }}$ floor $E-W$ records from Fourier amplitude spectra $(\mathrm{Sx})$, and autospectra with window lengths $k$ of half the record (Sxx k n/2) and the full record (Sxx k n). 

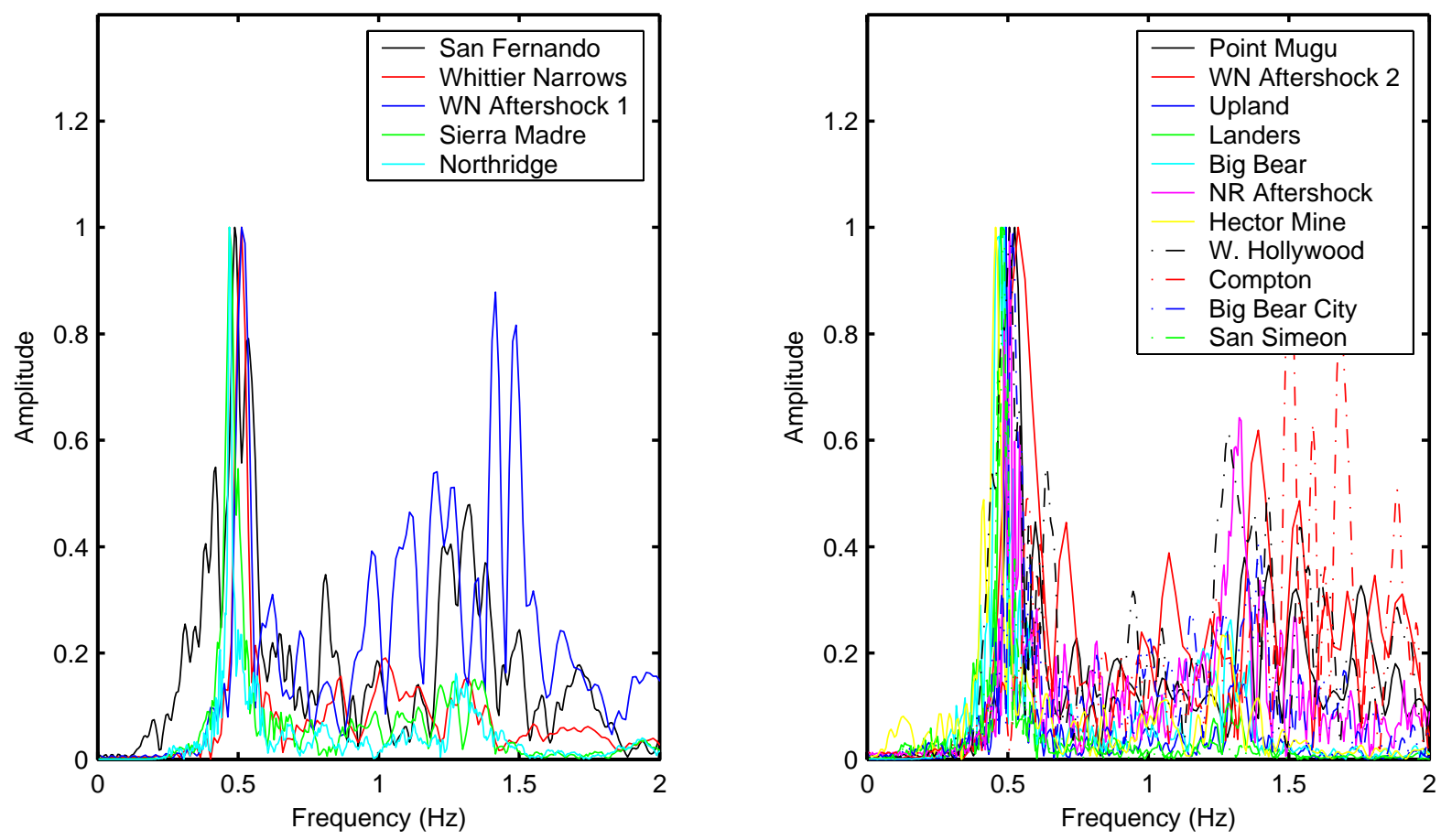

Figure 14. Normalized translational Fourier amplitude spectra, $12^{\text {th }}$ floor N-S, high-amplitude (left) and low-amplitude (right) motions
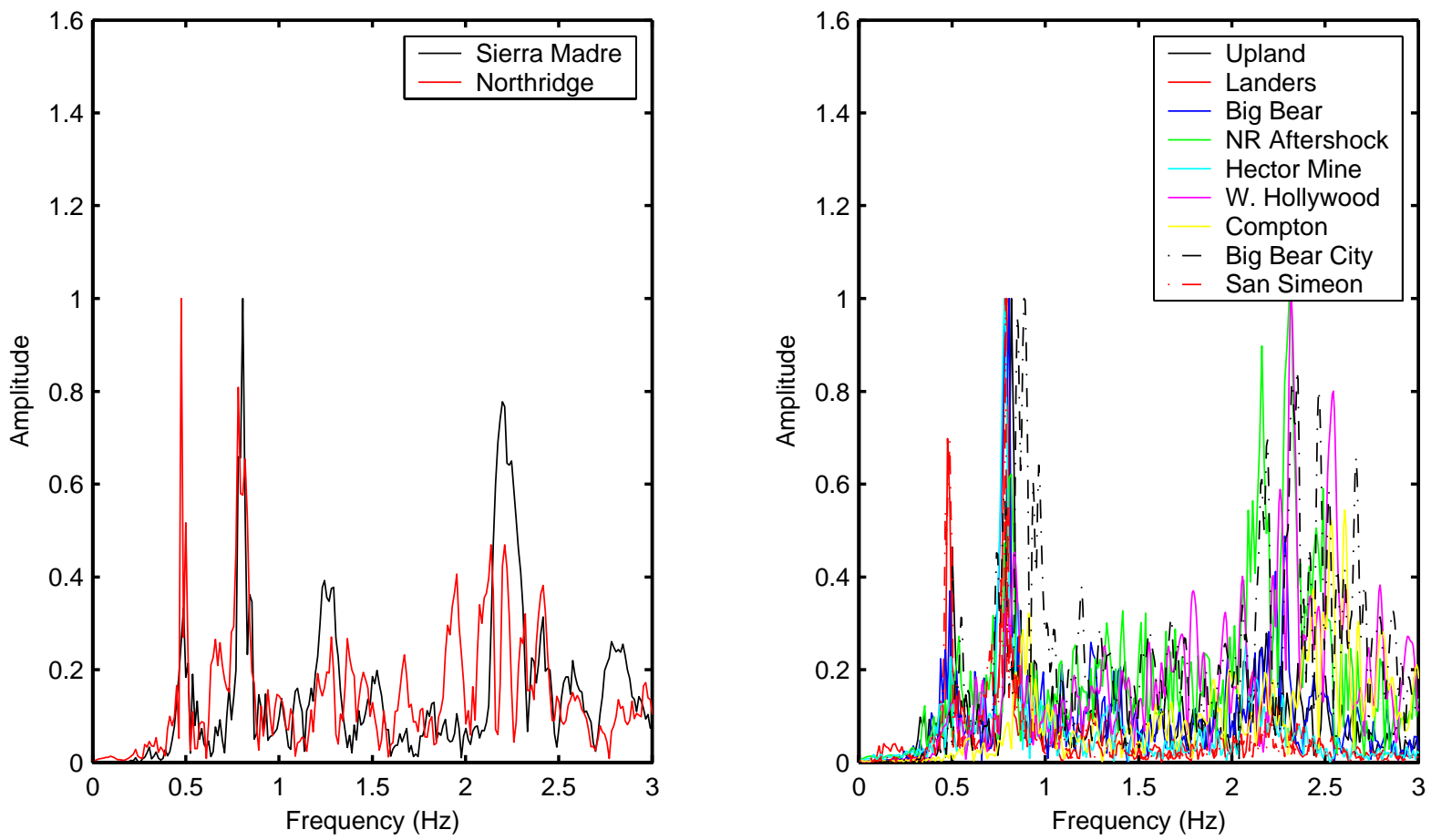

Figure 15. Normalized torsional Fourier amplitude spectra, $12^{\text {th }}$ floor, high-amplitude (left) and low-amplitude (right) motions 

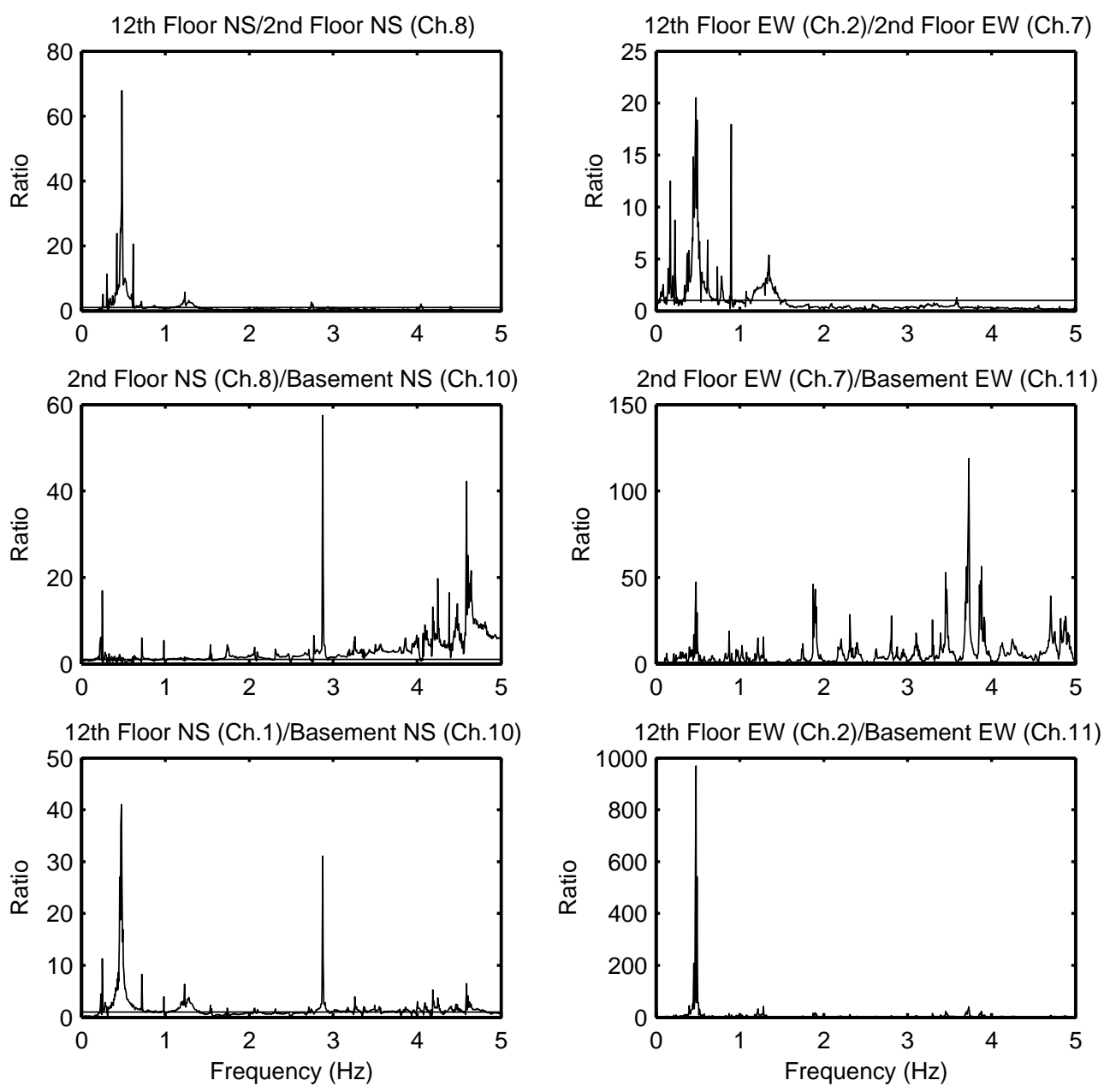

Figure 16. Ratios of translational Fourier amplitude spectra, Northridge earthquake
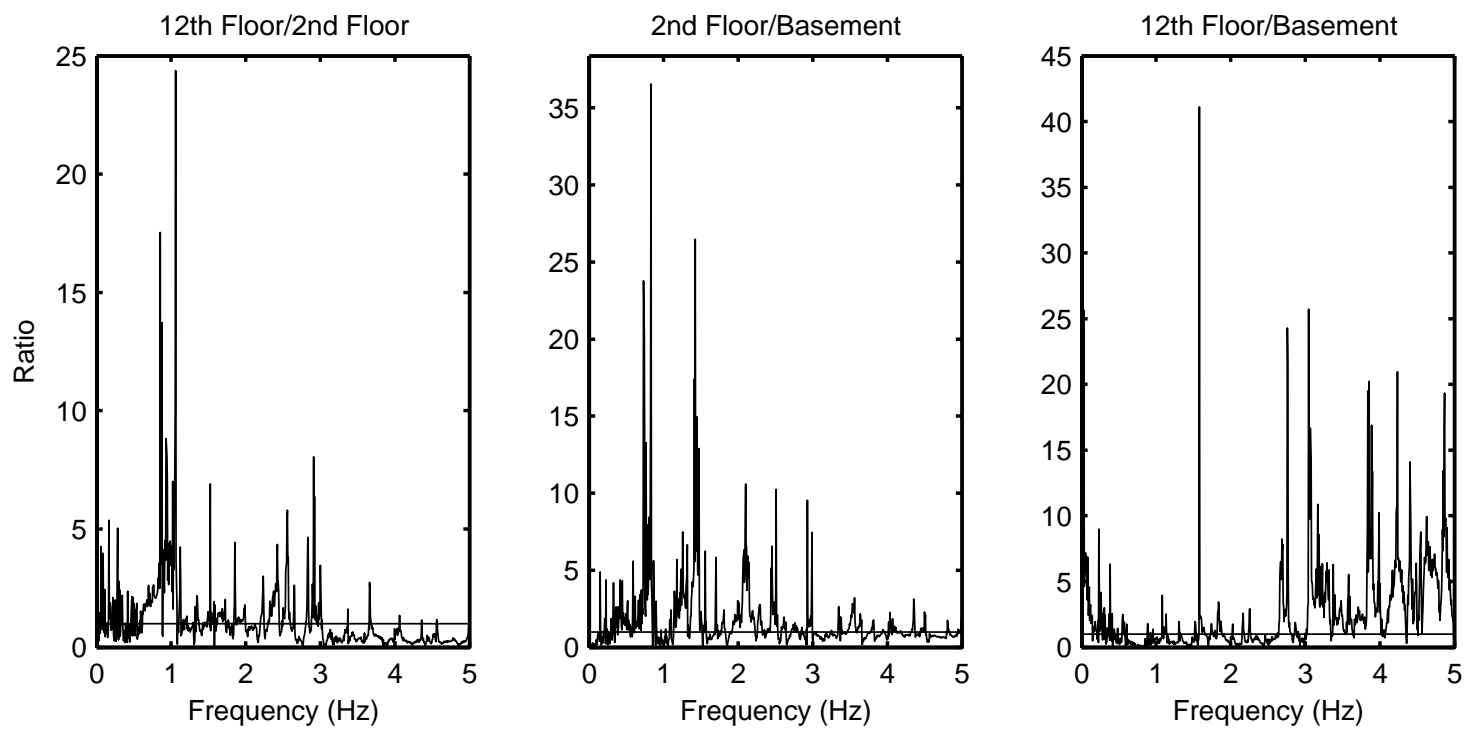

Figure 17. Ratios of torsional Fourier amplitude spectra, Northridge earthquake 

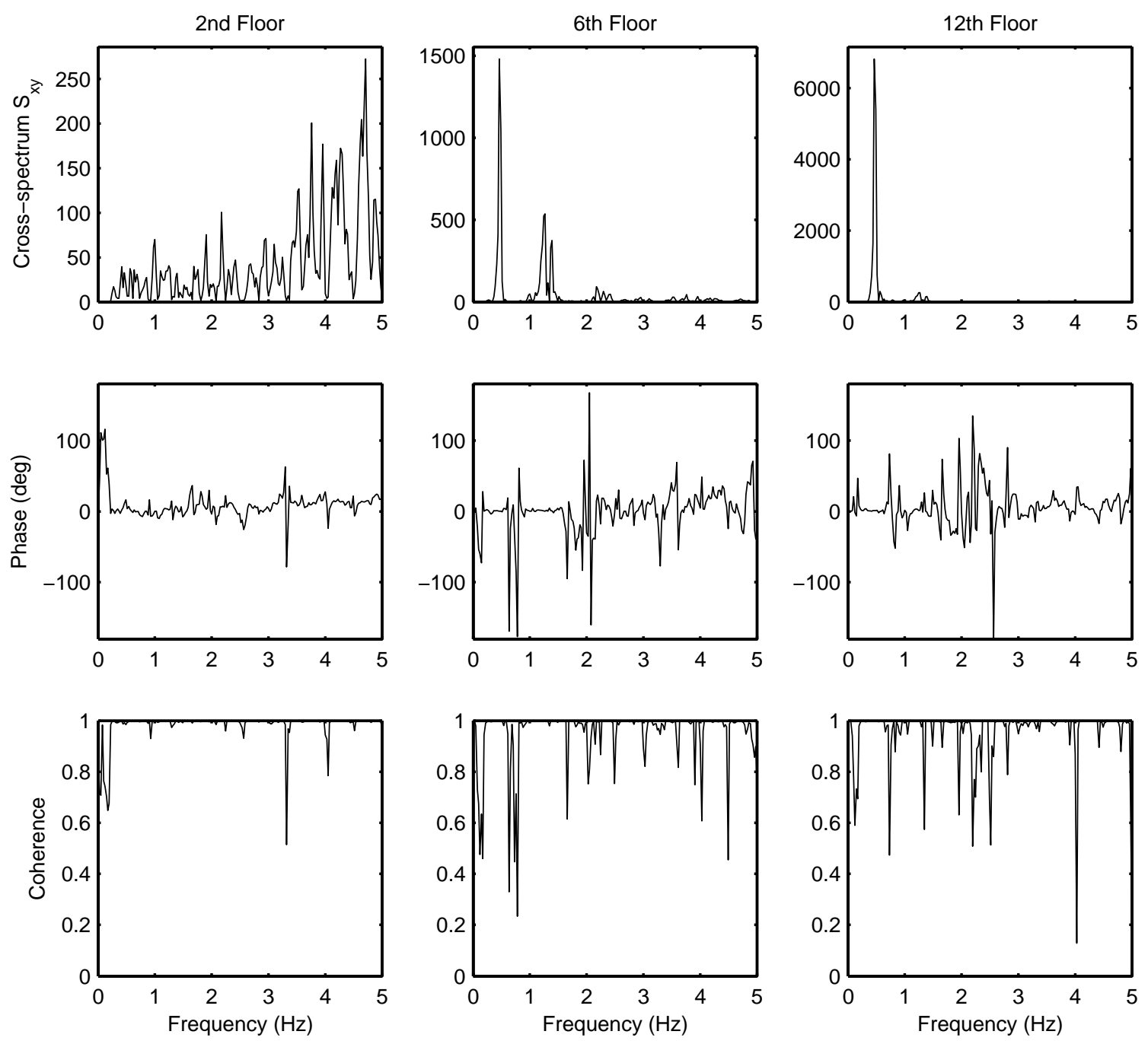

Figure 18. Spectral analysis of $2^{\text {nd }}, 6^{\text {th }}$, and $12^{\text {th }}$ floor accelerations, E-W channel pairs, Northridge earthquake 

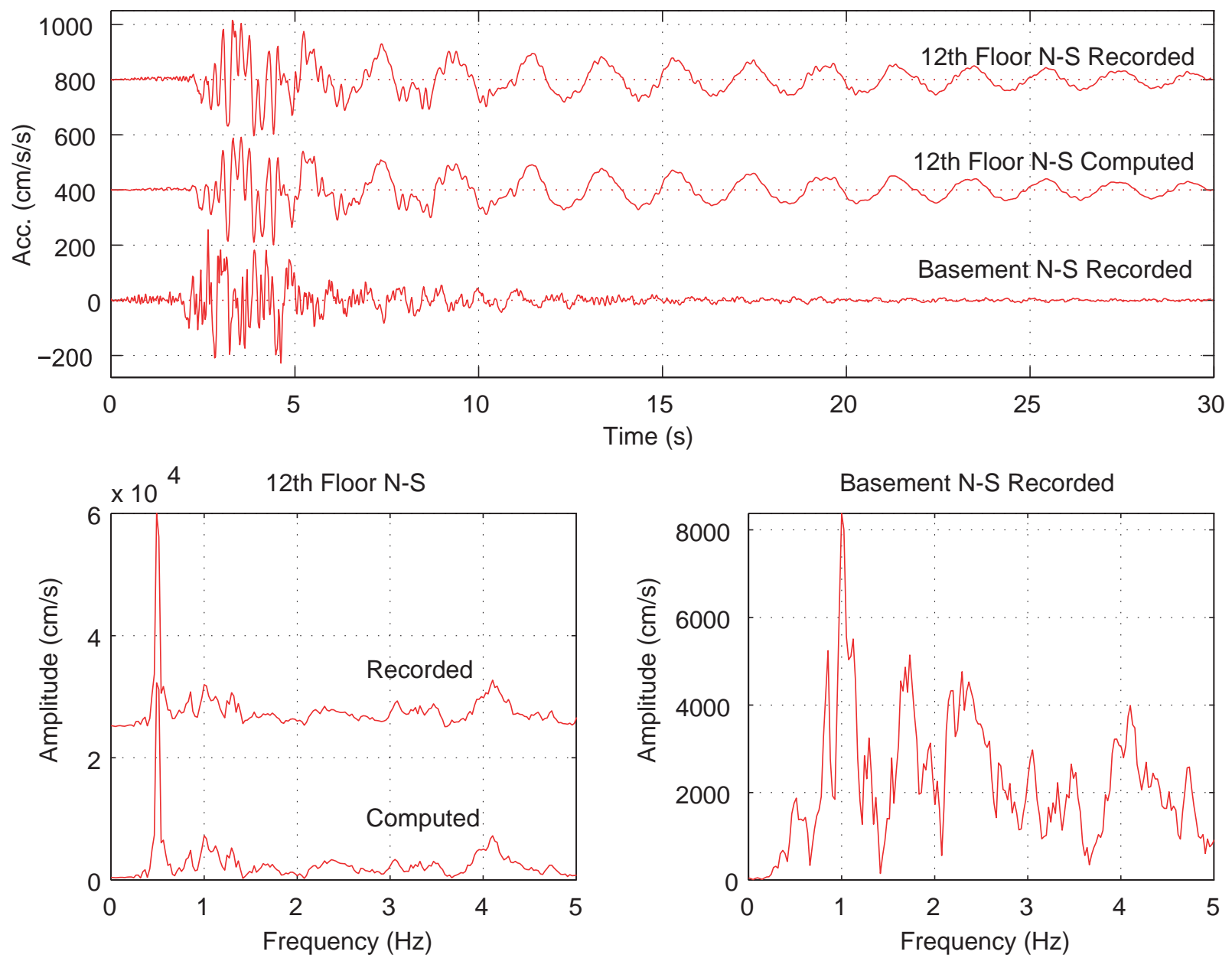

Figure 19. Results of system identification using the ARX method, Whittier Narrows earthquake, N-S direction. Excellent agreement between the recorded and computed responses at the $12^{\text {th }}$ floor was obtained. 


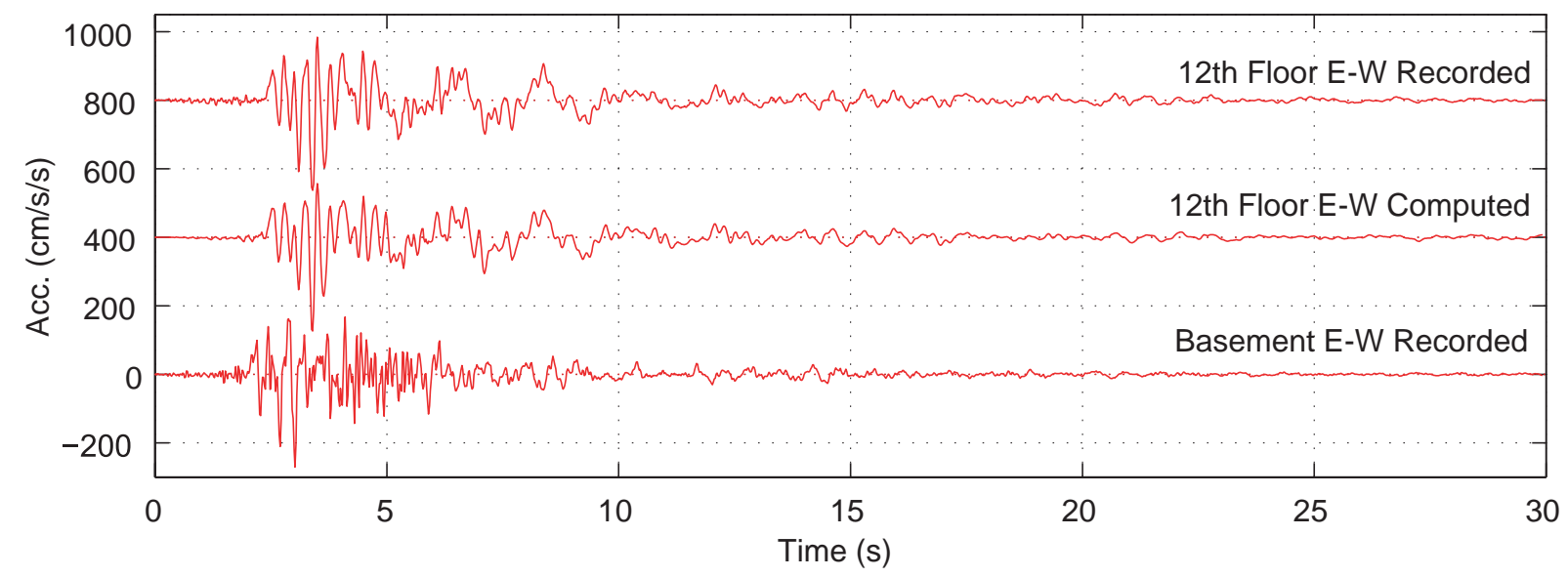

12th Floor E-W

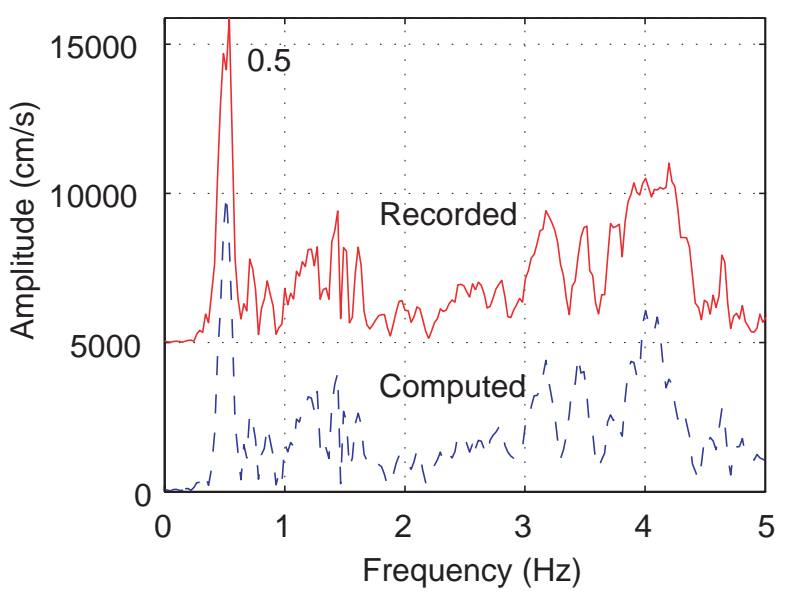

Basement E-W Recorded

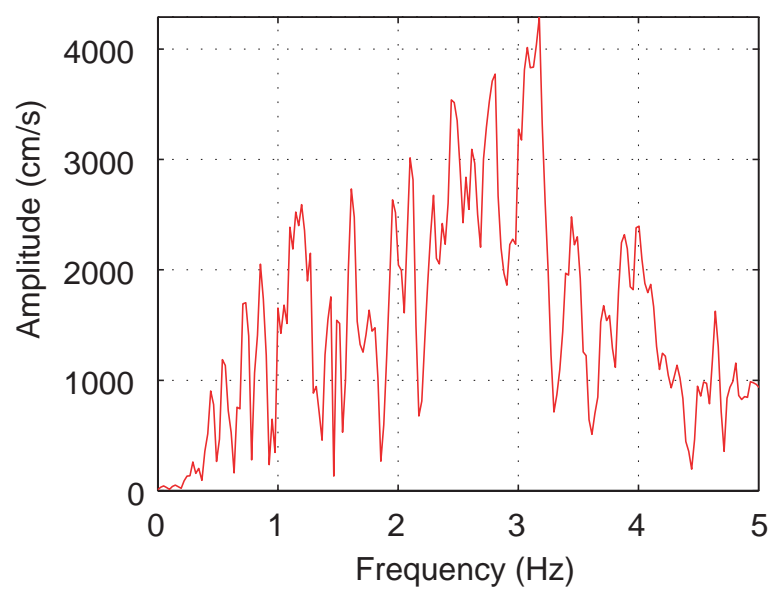

Figure 20. System identification, Whittier Narrows earthquake, E-W direction. Excellent agreement between the recorded and computed responses at the $12^{\text {th }}$ floor was obtained. 

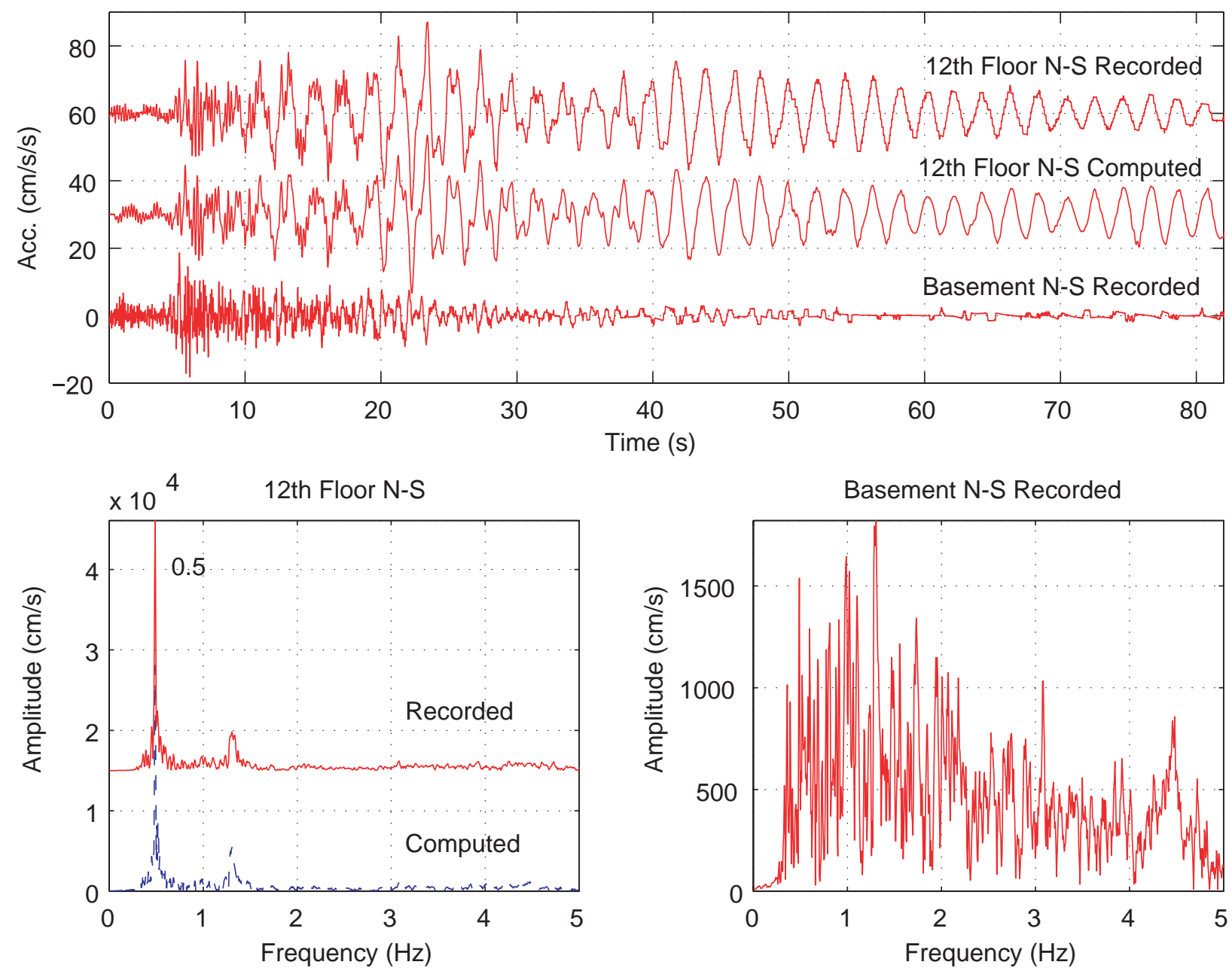

Figure 21. System identification, Upland earthquake, N-S direction. Good agreement between the recorded and computed responses at the $12^{\text {th }}$ floor was obtained, despite the very low amplitude basement input motions, which are approaching the digitization resolution for the last 50 seconds of the record. 

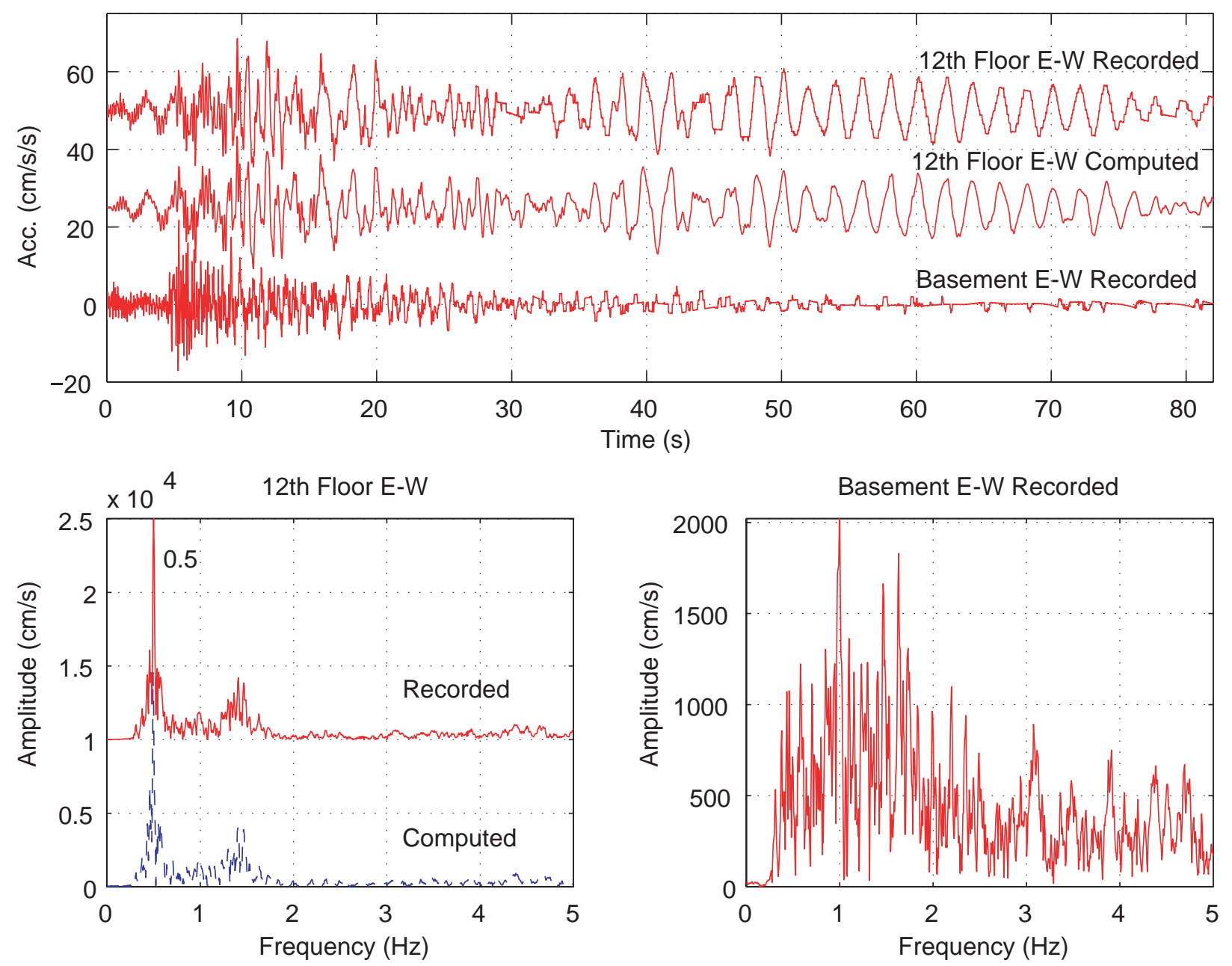

Figure 22. System identification, Upland earthquake, E-W direction. Good agreement between the recorded and computed responses at the $12^{\text {th }}$ floor was obtained, despite the very low amplitude basement input motions, which are approaching the digitization resolution for the last 50 seconds of the record. 

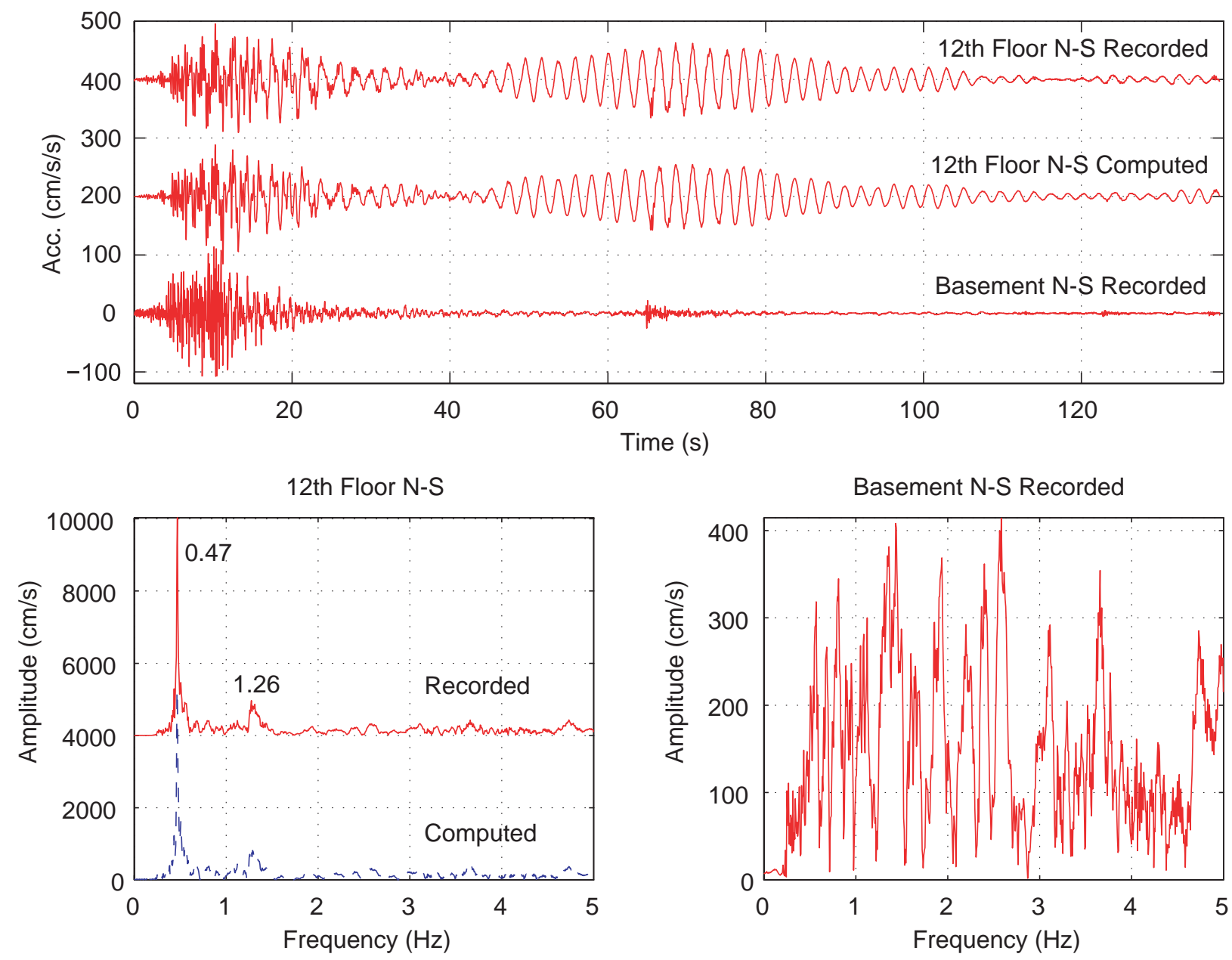

Figure 23. System identification, Northridge earthquake, N-S direction. Excellent agreement between the recorded and computed responses at the $12^{\text {th }}$ floor was obtained. 

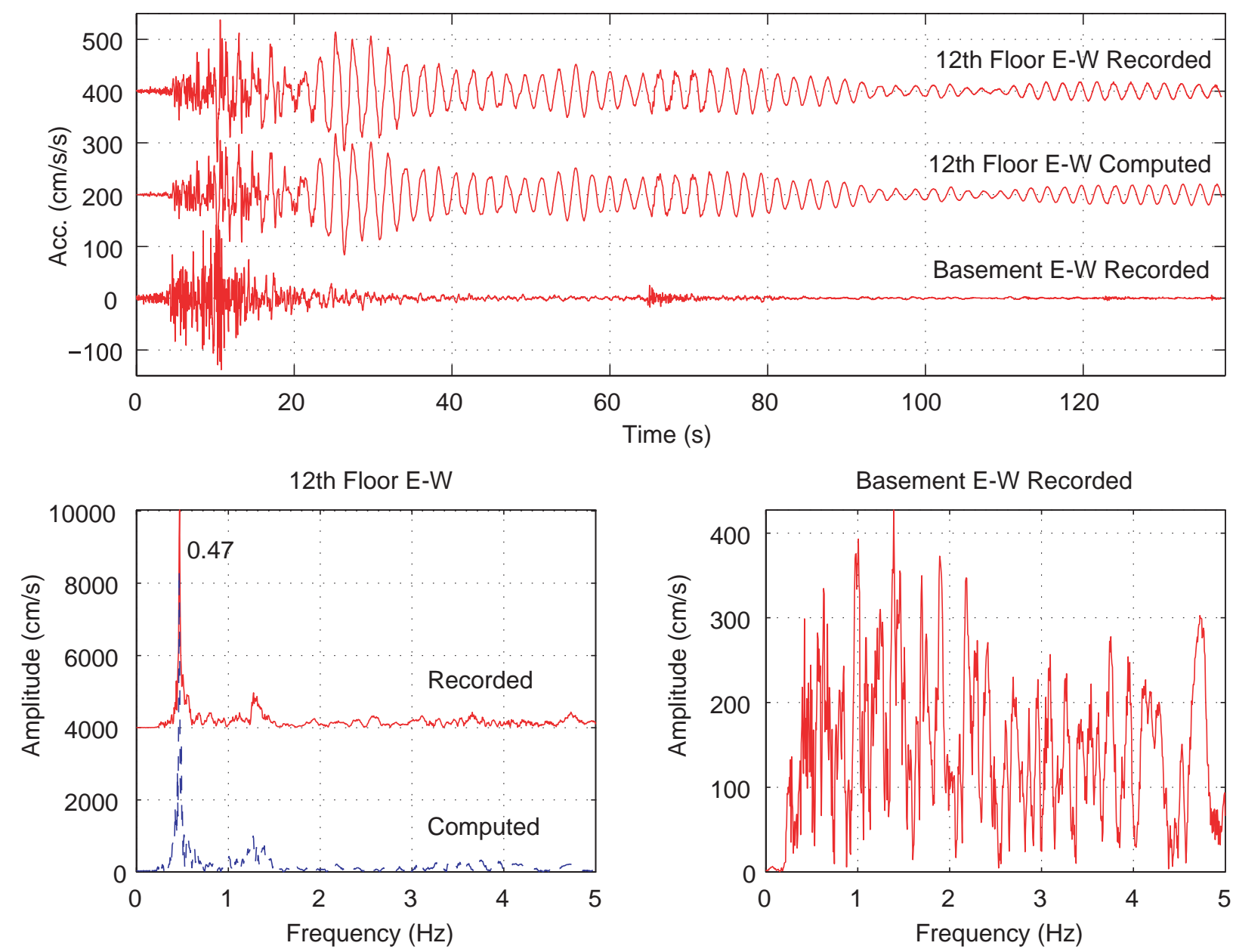

Figure 24. System identification, Northridge earthquake, E-W direction. Excellent agreement between the recorded and computed responses at the $12^{\text {th }}$ floor was obtained. 

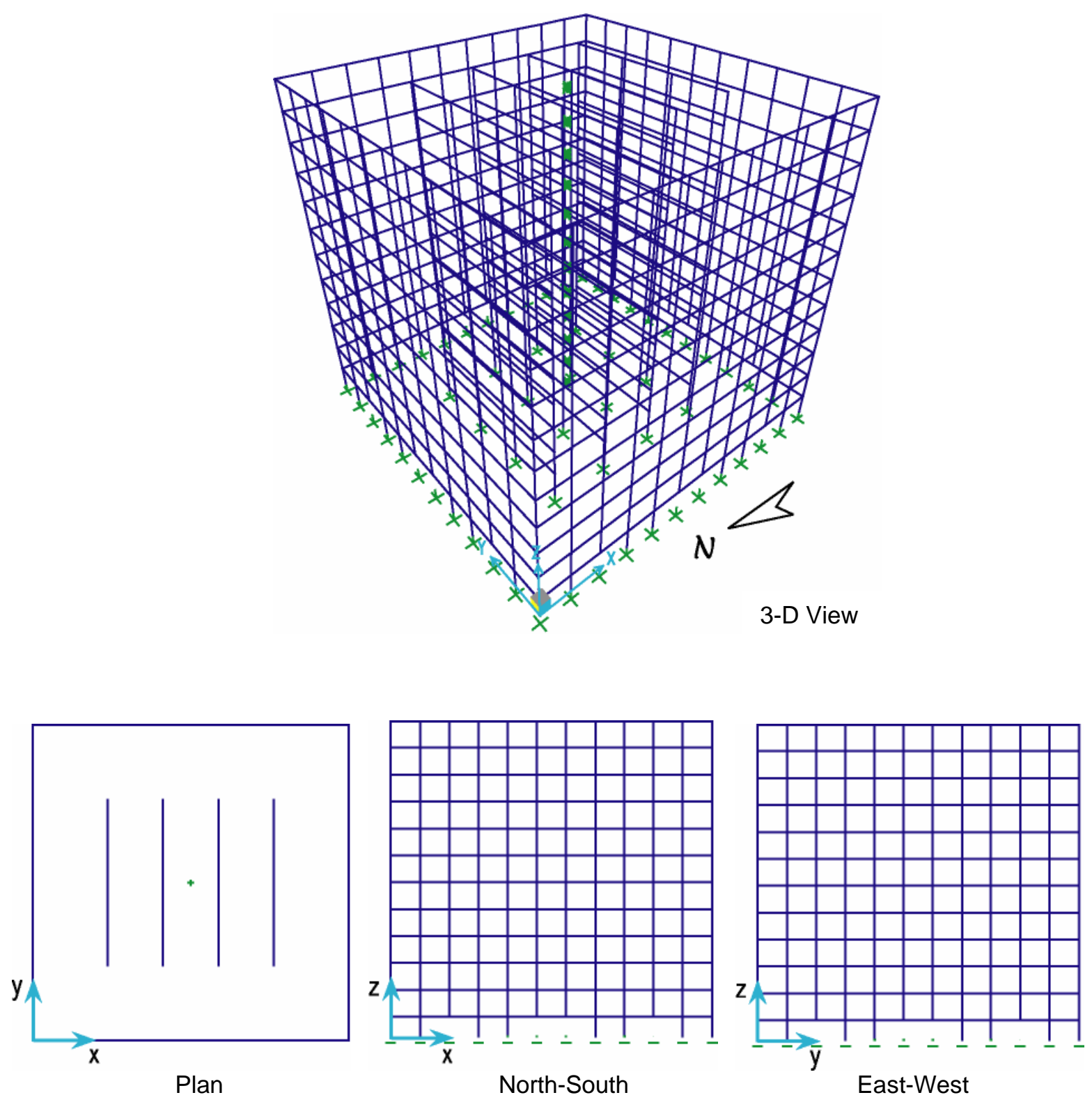

Figure 25. Computer model of the structure

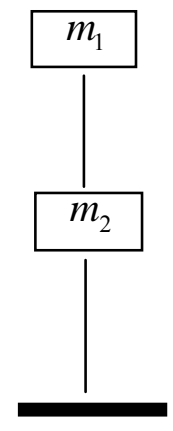

Figure 26. Condensed model of the structure 

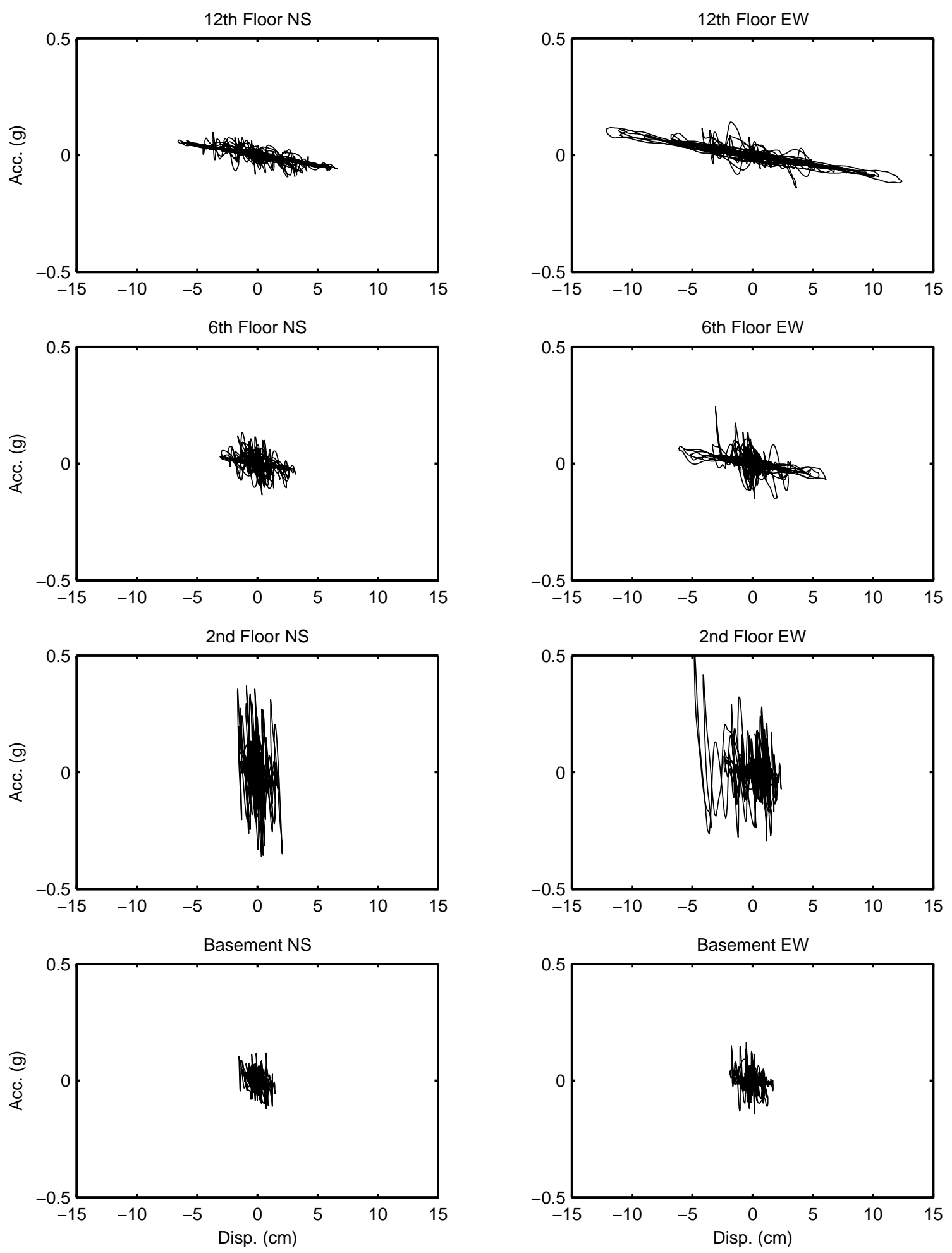

Figure 27. Approximate empirical hysteretic loops: recorded acceleration and computed displacement 

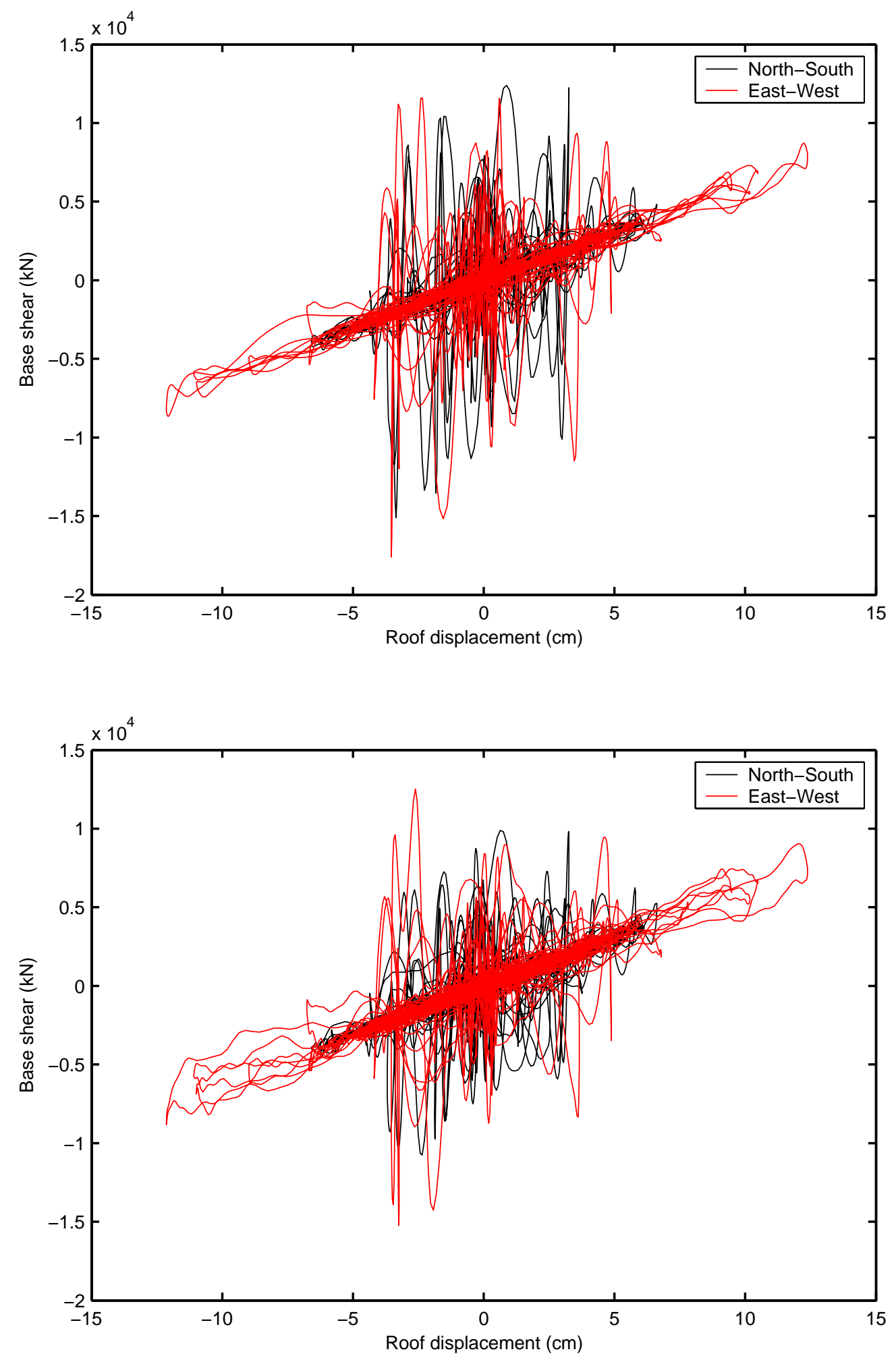

Figure 28. Empirical hysteresis loops with forces estimated using linear interpolation of accelerations at intermediate floors (top) and cubic spline interpolation of displacements at intermediate floors, which are then double differentiated and low-pass filtered to obtain accelerations (bottom). Base shear is calculated by summing mass times acceleration at all floor levels. 


\section{Appendix A - Detailed Description of Strong-Motion Data Available for the Alhambra Building}


Station no.: 482

Station owner: USGS

Address: 900 S. Fremont St., Alhambra CA

Building name: LA County Public Works Headquarters

No. stories: 12

Structural system: Welded steel moment frame (pre-Northridge connections) above 2nd floor;

massive RC piers from basement to 2 nd floor

Year designed/constructed: 1969/1970

Instrumentation history (dates in $\mathrm{mm} / \mathrm{dd} / \mathrm{yyyy}$ ):

02/05/1971 Instrumented with SMA-1 at basement (serial no. 179), 6th (187), and 12th (165) floors

9 channels total (1 triaxial at each instrumented floor)

07/28/1989 Instrumentation upgraded: 3 uniaxial FBAs on 2nd (ch 7-9), 6th (ch 4-6), and 12th (ch 1-3) floors:

2 horizontal at center, 1 horizontal at edge. Triaxial FBA in basement (ch 10-12).

CRA-1 recorder (serial no 316); 12 channels total

12/10/1996 CRA-1 upgraded to 12 channel K2 (serial no 699), existing FBAs used without changes

02/26/1998 Free field station added w/ K2; 15 channels total (12 structure +3 free-field)

Instrument trigger levels:

$0.01 \mathrm{~g}$ for analog instruments (1971-1989)

$0.0025 \mathrm{~g}$ horizontal, $0.005 \mathrm{~g}$ vertical for digital instruments (current)

Instrument orientations listed in data file headers:

90, S90W, 270 East-West

360, S00W, 180 North-South

Up,Down Vertical

Earthquakes with data recorded at this station:

1971 Mw 6.6 San Fernando

1973 Mw 5.3 Point Mugu

1987 Mw 6.1 Whittier Narrows

Ml 5.3 Aftershock 10/4/87

Ml 5.0 Aftershock 2/11/88

1990 Ml 5.2 Upland

1991 Mw 5.8 Sierra Madre

$1992 \mathrm{Mw} 7.3$ Landers

1992 Mw 6.5 Big Bear

1994 Mw 6.7 Northridge

Mw 5.3 Aftershock 3/20/94

1999 Mw 7.1 Hector Mine

2001 Ml 4.2 West Hollywood

$2001 \mathrm{Ml} 4.0$ Compton

2003 Mw 5.2 Big Bear City

2003 Mw 6.5 San Simeon

* Note: the 1988 Pasadena earthquake was not recorded at this station.

Data source and availability is noted in the data processing comments for each earthquake.

Vibration testing:

1996 Ambient vibration testing by Celebi \& Liu using existing instumentation

2004 Ambient vibration testing by Dunand, Rodgers \& Acosta using portable velocimeters at instrument locations in basement and 12th floor level 
Table A - 1. Earthquake record parameters

\begin{tabular}{|l|c|c|c|c|c|c|c|c|}
\hline Earthquake & $\begin{array}{c}\text { Date } \\
(\mathrm{mo} / \text { day/yr })\end{array}$ & $\mathbf{M}_{\mathrm{w}}$ & $\begin{array}{c}\text { Instrum. } \\
\text { System }\end{array}$ & Type & $\begin{array}{c}\text { Sampling } \\
\text { rate }(\mathrm{sps})^{\mathrm{a}}\end{array}$ & $\begin{array}{c}\text { Data } \\
\text { Points }\end{array}$ & $\begin{array}{c}\text { Duration } \\
(\mathrm{s})\end{array}$ & $\begin{array}{c}\text { Data } \\
\text { Processor }\end{array}$ \\
\hline San Fernando & $2 / 9 / 1971$ & 6.6 & 3 SMAs & Analog & $50^{\mathrm{b}}$ & 2285 & 45.7 & NGDC \\
\hline Point Mugu & $2 / 21 / 1973$ & 5.3 & 3 SMAs & Analog & 200 & 5064 & 25.32 & USGS \\
\hline Whittier Narrows & $10 / 1 / 1987$ & 6.1 & 3 SMAs & Analog & 200 & 6052 & 29.94 & NGDC \\
\hline \multicolumn{1}{|c|}{ Aftershock 1 } & $10 / 4 / 1987$ & $5.3^{\mathrm{c}}$ & 3 SMAs & Analog & 200 & 5038 & 25.19 & USGS \\
\hline \multicolumn{1}{|c|}{ Aftershock 2 } & $2 / 11 / 1988$ & $5.0^{\mathrm{c}}$ & 3 SMAs & Analog & 200 & 3099 & 15.495 & USGS \\
\hline Upland & $2 / 28 / 1990$ & 5.2 & CRA & Analog & 100 & 8496 & 84.96 & SEEC \\
\hline Sierra Madre & $6 / 28 / 1991$ & 5.8 & CRA & Analog & 200 & 16178 & 80.89 & USGS \\
\hline Landers & $6 / 28 / 1992$ & 7.3 & CRA & Analog & 200 & 19318 & 96.59 & USGS \\
\hline Big Bear & $6 / 28 / 1992$ & 6.5 & CRA & Analog & 200 & 19481 & 97.405 & USGS \\
\hline Northridge & $1 / 17 / 1994$ & 6.7 & CRA & Analog & 100 & 13754 & 137.534 & SEEC \\
\hline \multicolumn{1}{|c|}{ Aftershock } & $3 / 20 / 1994$ & 5.3 & CRA & Analog & 200 & 14310 & 71.55 & USGS \\
\hline Hector Mine & $10 / 16 / 1999$ & 7.1 & K2 & Digital & 200 & 12800 & 64.00 & USGS \\
\hline West Hollywood & $9 / 9 / 2001$ & $4.2^{\mathrm{c}}$ & K2 & Digital & 200 & 8840 & 44.20 & USGS \\
\hline Compton & $10 / 28 / 2001$ & $4.0^{\mathrm{c}}$ & K2 & Digital & 200 & 8400 & 42.00 & USGS \\
\hline Big Bear City & $2 / 22 / 2003$ & $5.4^{\mathrm{c}}$ & K2 & Digital & 200 & 9600 & 48.00 & USGS \\
\hline San Simeon & $12 / 22 / 2003$ & 6.5 & K2 & Digital & 200 & 37400 & 187.00 & USGS \\
\hline
\end{tabular}

${ }^{\mathrm{a}}$ Digital sampling rate for processed data

${ }^{\mathrm{b}}$ Values for acceleration data; lower values for velocity (25 sps, 1142 points) and displacement (10 sps, 457 points)

${ }^{\mathrm{c}}$ Local magnitude; moment magnitude used otherwise

Table A - 2. Peak accelerations

\begin{tabular}{|c|c|c|c|c|c|c|c|c|c|c|c|c|}
\hline \multirow{3}{*}{ Earthquake } & \multicolumn{3}{|c|}{ Basement } & \multicolumn{3}{|c|}{$2^{\text {nd }}$ Floor } & \multicolumn{3}{|c|}{$6^{\text {th }}$ Floor } & \multicolumn{3}{|c|}{$12^{\text {th }}$ Floor } \\
\hline & \multicolumn{2}{|c|}{ Max accel } & \multirow{2}{*}{$\begin{array}{l}\text { Dir. } \\
\text { deg }\end{array}$} & \multicolumn{2}{|c|}{ Max accel } & \multirow{2}{*}{$\frac{\text { Dir. }}{\text { deg }}$} & \multicolumn{2}{|c|}{ Max accel } & \multirow{2}{*}{$\begin{array}{l}\text { Dir. } \\
\text { deg }\end{array}$} & \multicolumn{2}{|c|}{ Max accel } & \multirow{2}{*}{$\begin{array}{l}\text { Dir. } \\
\text { deg }\end{array}$} \\
\hline & g & $\mathrm{cm} / \mathrm{s}^{2}$ & & g & $\mathrm{cm} / \mathrm{s}^{2}$ & & g & $\mathrm{cm} / \mathrm{s}^{2}$ & & g & $\mathrm{cm} / \mathrm{s}^{2}$ & \\
\hline San Fernando & 0.12 & 119.4 & 270 & - & - & - & & 144.3 & 0 & 0.18 & 180.3 & 270 \\
\hline Point Mugu & 0.023 & 22.6 & 180 & - & - & - & 0.029 & 28.7 & 180 & 0.017 & 16.2 & 270 \\
\hline Whittier Narrows & 0.29 & 280.8 & 90 & - & - & - & 0.47 & 457.8 & 90 & 0.27 & 260.7 & 90 \\
\hline Aftershock 1 & 0.14 & 134.8 & 90 & - & - & - & 0.24 & 232.8 & 90 & 0.18 & 174.4 & 90 \\
\hline Aftershock 2 & 0.037 & 36.5 & 90 & - & - & - & 0.045 & 44.5 & 90 & 0.026 & 25.4 & 90 \\
\hline Upland & 0.022 & 21.8 & 90 & 0.049 & 48.3 & 90 & 0.030 & 29.1 & 90 & 0.029 & 28.8 & 360 \\
\hline Sierra Madre & 0.13 & 125.0 & 90 & 0.28 & 269.1 & 90 & 0.17 & 166.3 & 90 & 0.15 & 144.7 & 90 \\
\hline Landers & 0.031 & 30.66 & 90 & 0.057 & 56.3 & 360 & 0.070 & 69.1 & 90 & 0.12 & 119.7 & 90 \\
\hline Big Bear & 0.025 & 24.4 & 360 & 0.037 & 36.3 & 90 & 0.047 & 46.0 & 360 & 0.059 & 58.2 & 360 \\
\hline Northridge & 0.16 & 159.1 & 90 & 0.54 & 526.9 & 90 & 0.244 & 239.4 & 90 & 0.14 & 139.5 & 90 \\
\hline Aftershock & 0.033 & 32.6 & 360 & 0.092 & 90.7 & 360 & 0.035 & 34.1 & 360 & 0.025 & 24.2 & 360 \\
\hline Hector Mine & 0.044 & 43.6 & 90 & 0.065 & 63.6 & 90 & 0.059 & 57.9 & $90^{*}$ & 0.097 & 95.6 & 90 \\
\hline West Hollywood & 0.019 & 18.3 & 90 & 0.046 & 44.8 & 360 & 0.013 & 12.8 & $90 *$ & 0.008 & 8.0 & 360 \\
\hline Compton & 0.008 & 7.7 & 90 & 0.018 & 17.8 & 360 & 0.005 & 5.1 & $90 *$ & 0.003 & 3.2 & 360 \\
\hline Big Bear City & 0.004 & 4.3 & 360 & 0.014 & 13.6 & 360 & 0.004 & 4.0 & $90 *$ & 0.006 & 6.2 & 360 \\
\hline San Simeon & 0.004 & 3.7 & 90 & 0.005 & 4.5 & 90 & 0.013 & 13.2 & $90 *$ & 0.027 & 26.8 & 90 \\
\hline
\end{tabular}

${ }^{*} \mathrm{~N}-\mathrm{S}$ (360) direction channel was non-operational, so maximum shown is for E-W (90) direction only.

Directions of maximum accelerations are determined from headers of processed acceleration files. 
Data processing comments, by earthquake:

1971 San Fernando

Processed by: NGDC or Caltech

ACCELEROGRAM IS BAND-PASS FILTERED BETWEEN 0.125 AND 25.000 CYC/SEC

2285 INSTRUMENT AND BASELINE CORRECTED DATA

Data reference: "Earthquake Strong Motion, Vol.1, USA, Part A", compact disc available from National

Geophysical Data Center, Boulder, Colorado, 1996.

1973 Point Mugu

| Reformatted to SMC format via the V2S (18apr95 version) program on 13Apr2004

| Original station number was 0484 , before $\mathrm{CR}$ installed

| No fixed traces, only one 2-PPS TC trace

| Two minor stalls between 17.2-17.3 sec (12th floor level)

Data reference: National Strong Motion Program (NSMP), U.S. Geological Survey, http://nsmp.wr.usgs.gov/

1987 Whittier Narrows

Processed by: NGDC, Reprocessed 2/2004

Instrument and baseline correction, acausal Butterworth filtering

Data reference: Corrected data from National Strong Motion Program (NSMP), U.S. Geological Survey,

http://nsmp.wr.usgs.gov/. Uncorrected data from "Earthquake Strong Motion, Vol.1, USA, Part A", compact disc available from

National Geophysical Data Center, Boulder, Colorado, 1996.

1987 Whittier Narrows Aftershock of 10/4/87

Processed by: NGDC, Reprocessed 2/2004

Instrument and baseline correction, acausal Butterworth filtering

Data reference: Corrected data from National Strong Motion Program (NSMP), U.S. Geological Survey,

http://nsmp.wr.usgs.gov/. Uncorrected data from "Earthquake Strong Motion, Vol.1, USA, Part A", compact disc available from National Geophysical Data Center, Boulder, Colorado, 1996.

1987 Whittier Narrows Aftershock of 2/11/88

Data reference: National Strong Motion Program (NSMP), U.S. Geological Survey, http://nsmp.wr.usgs.gov/

1990 Upland

ACCELEROGRAM IS BAND-PASS FILTERED BETWEEN .260- .330 AND 25.00-27.00 HZ.

8496 INSTRUMENT AND BASELINE CORRECTED DATA

Data reference: Structural and Earthquake Engineering Consultants, Los Angeles, California.

1991 Sierra Madre

Processed by: Agbabian Associates (digitized first $28 \mathrm{sec}$ ), USGS

Baseline and instrument correction and acausal Butterworth filtering

| Processed using Filmcnv.exe Version 2.0

Digitized by Agbabian Assoc; timebase-corrected version

| Extended past 28 sec by USGS, Jan 2004

Data reference: National Strong Motion Program (NSMP), U.S. Geological Survey, http://nsmp.wr.usgs.gov/

1992 Landers

Baseline and instrument correction and acausal Butterworth filtering

| Digitized and reformated to SMC using V2S (28apr97 version) on Feb 222002

Data reference: National Strong Motion Program (NSMP), U.S. Geological Survey, http://nsmp.wr.usgs.gov/

1992 Big Bear

| vol 1 file named: 0316_BW1.V1,

I which was reformatted to SMC format via the V2S (18apr95 version) 
| program on 21feb2002.

Baseline and instrument correction and acausal Butterworth filtering

Data reference: National Strong Motion Program (NSMP), U.S. Geological Survey, http://nsmp.wr.usgs.gov/

1994 Northridge

Processed by: SEEC (Structural \& Earthquake Engineering Consultants); Maria Todorovska

Digital sampling rate: 244 sps uncorrected (vol. 1), 100 sps corrected (vol. 2)

Number of data points: 32655 uncorr, 13754 corr

Duration: 137.534 sec uncorr, 137.54 corr

ACCELEROGRAM IS BAND-PASS FILTERED BETWEEN .200- .250 AND 25.00-27.00 HZ.

**** INSTRUMENT AND BASELINE CORRECTED DATA

Data reference: Structural and Earthquake Engineering Consultants, Los Angeles, California.

1994 Northridge Aftershock 3/20/1994

Processed by: SEEC (Structural \& Earthquake Engineering Consultants); Maria Todorovska; reprocessed by USGS 2/2004

Number of data points: 16945 uncorr; 7155 corr; 14310 reprocessed

ACCELEROGRAM IS BAND-PASS FILTERED BETWEEN .600- .750 AND 25.00-27.00 HZ.

**** INSTRUMENT AND BASELINE CORRECTED DATA

USGS reprocessing (acausal Butterworth filtering) set low corner at $0.4 \mathrm{~Hz}$ to include structure's fundamental mode

Data reference: Corrected data from National Strong Motion Program (NSMP), U.S. Geological Survey,

http://nsmp.wr.usgs.gov/. Uncorrected data from Structural and Earthquake Engineering Consultants, Los

Angeles, California.

1999 Hector Mine

Baseline and instrument correction and acausal Butterworth filtering

Data reference: National Strong Motion Program (NSMP), U.S. Geological Survey, http://nsmp.wr.usgs.gov/

2001 West Hollywood

Converted using program evt2smc 2002/10/16 14:57:47

| Input file: bl003-0_482-00613.evt

Data reference: National Strong Motion Program (NSMP), U.S. Geological Survey, http://nsmp.wr.usgs.gov/

Comments: Numerous instances of baseline correction noted in headers

2001 Compton

| Converted using program evt2smc 2002/10/16 15:01:57

| Input file: bl008_482-00613.evt

$|<| o c|b|=>12$ th Flr, center<end>

Data reference: National Strong Motion Program (NSMP), U.S. Geological Survey, http://nsmp.wr.usgs.gov/ Comments: Numerous instances of baseline correction noted in headers

Start time from RTC corrected by $+7 \mathrm{hr} 5$ min

2003 Big Bear City

| Converted using program evt2smc 2004/06/30 13:31:35

| Input file: AR039_482-00699.EVT

Data reference: National Strong Motion Program (NSMP), U.S. Geological Survey, http://nsmp.wr.usgs.gov/

Comments: Free-field and structure array recordings have different start times and durations.

2003 San Simeon

Converted using program evt2smc 2004/01/15 14:40:26

| Input file: Cl007_0482-00699.EVT

Baseline and instrument correction and acausal Butterworth filtering

Data reference: National Strong Motion Program (NSMP), U.S. Geological Survey, http://nsmp.wr.usgs.gov/ 
Appendix B - Acceleration, Velocity, and Displacement Time Histories 

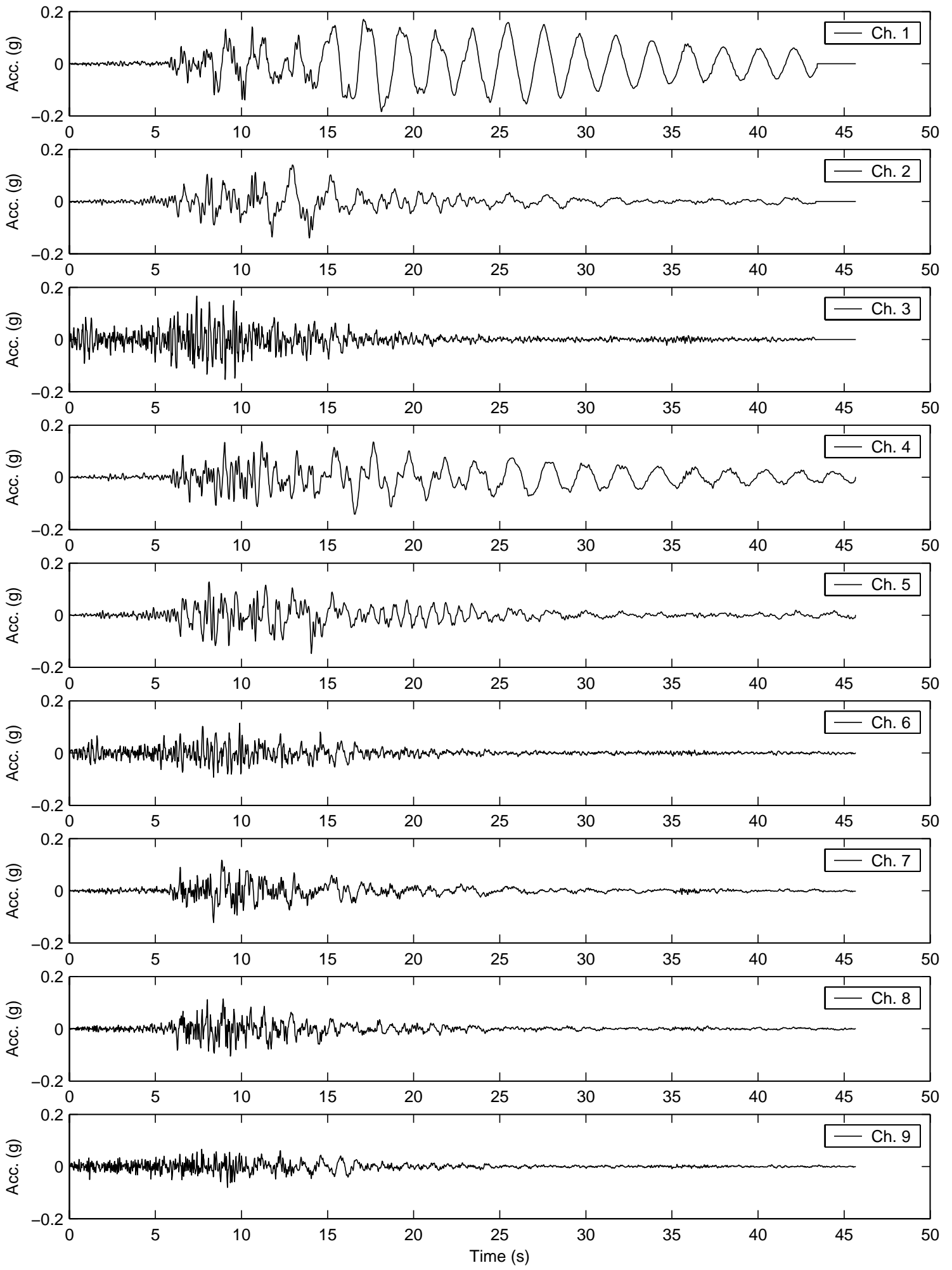

Figure B - 1. 1971 San Fernando earthquake, acceleration 

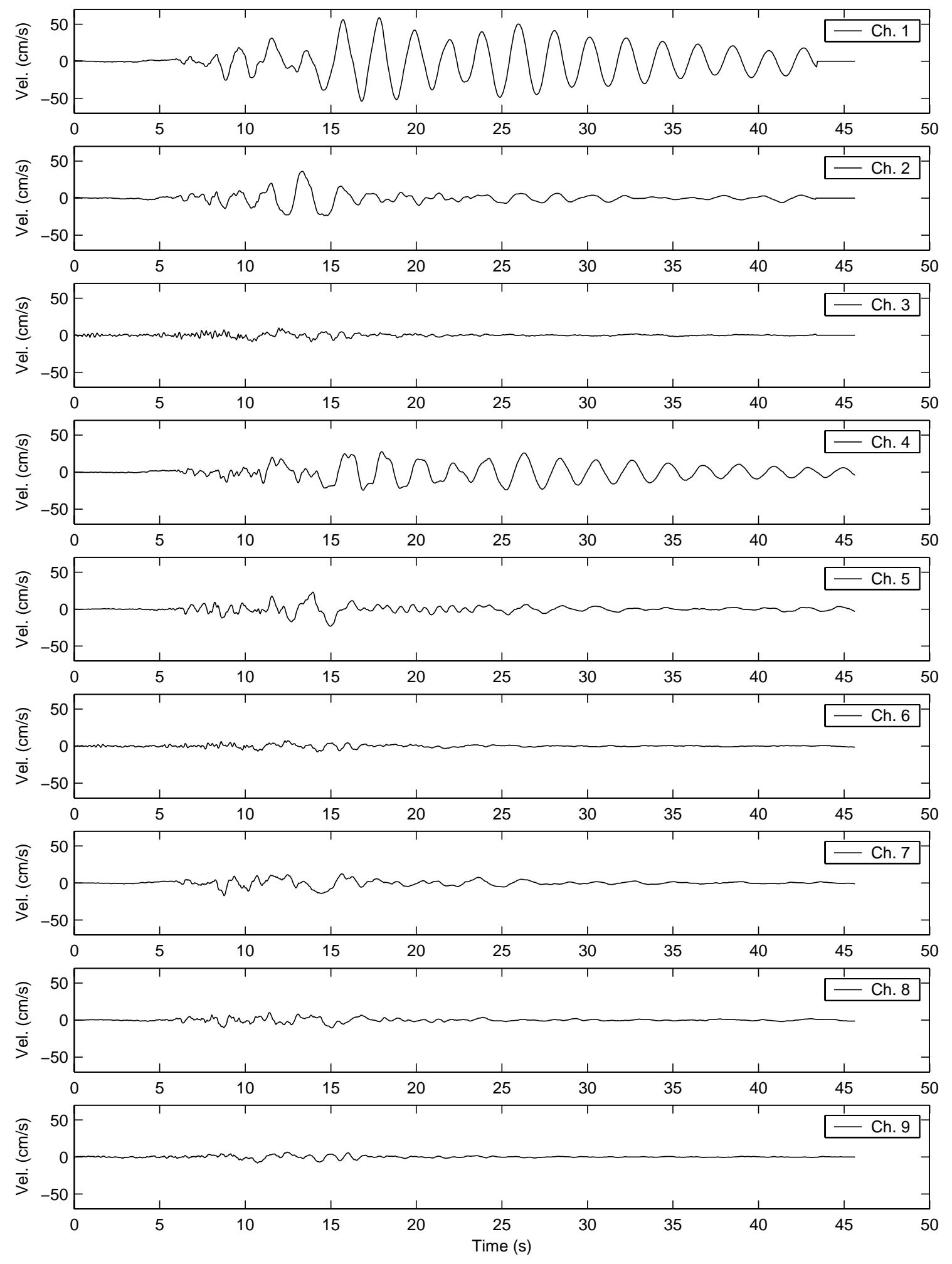

Figure B - 2. 1971 San Fernando earthquake, velocity 

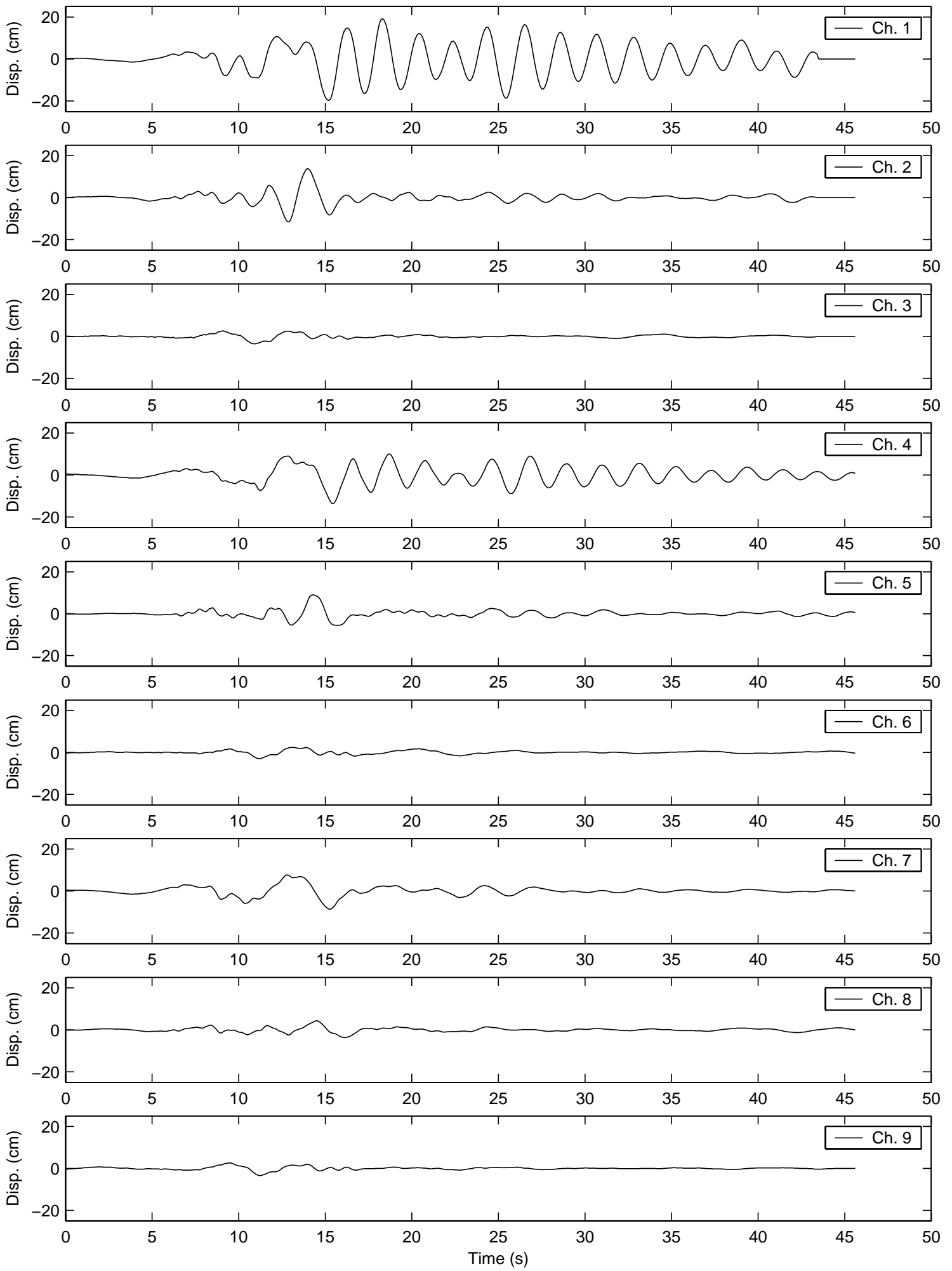

Figure B - 3. 1971 San Fernando earthquake, displacement 


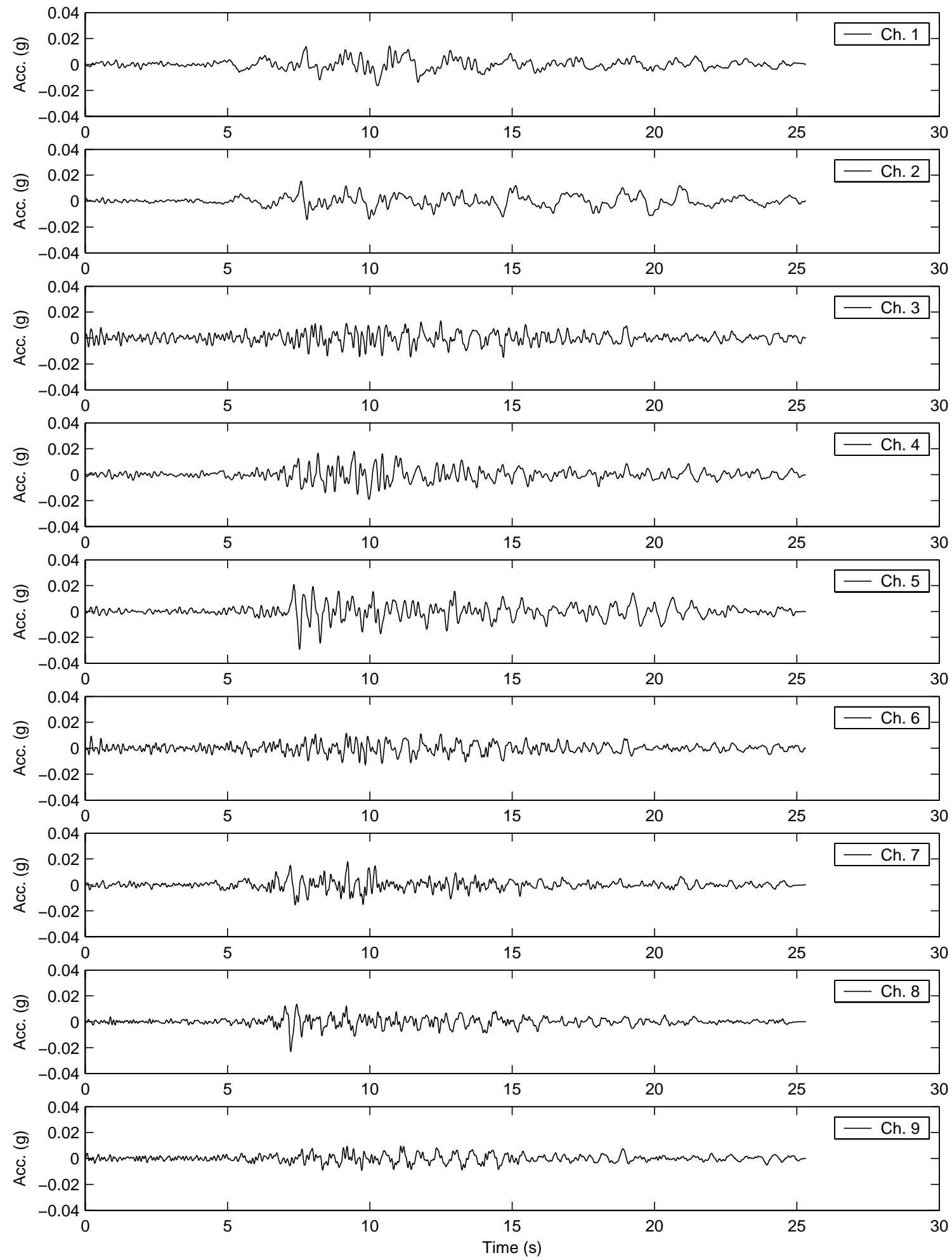

Figure B - 4. 1973 Point Mugu earthquake, acceleration 

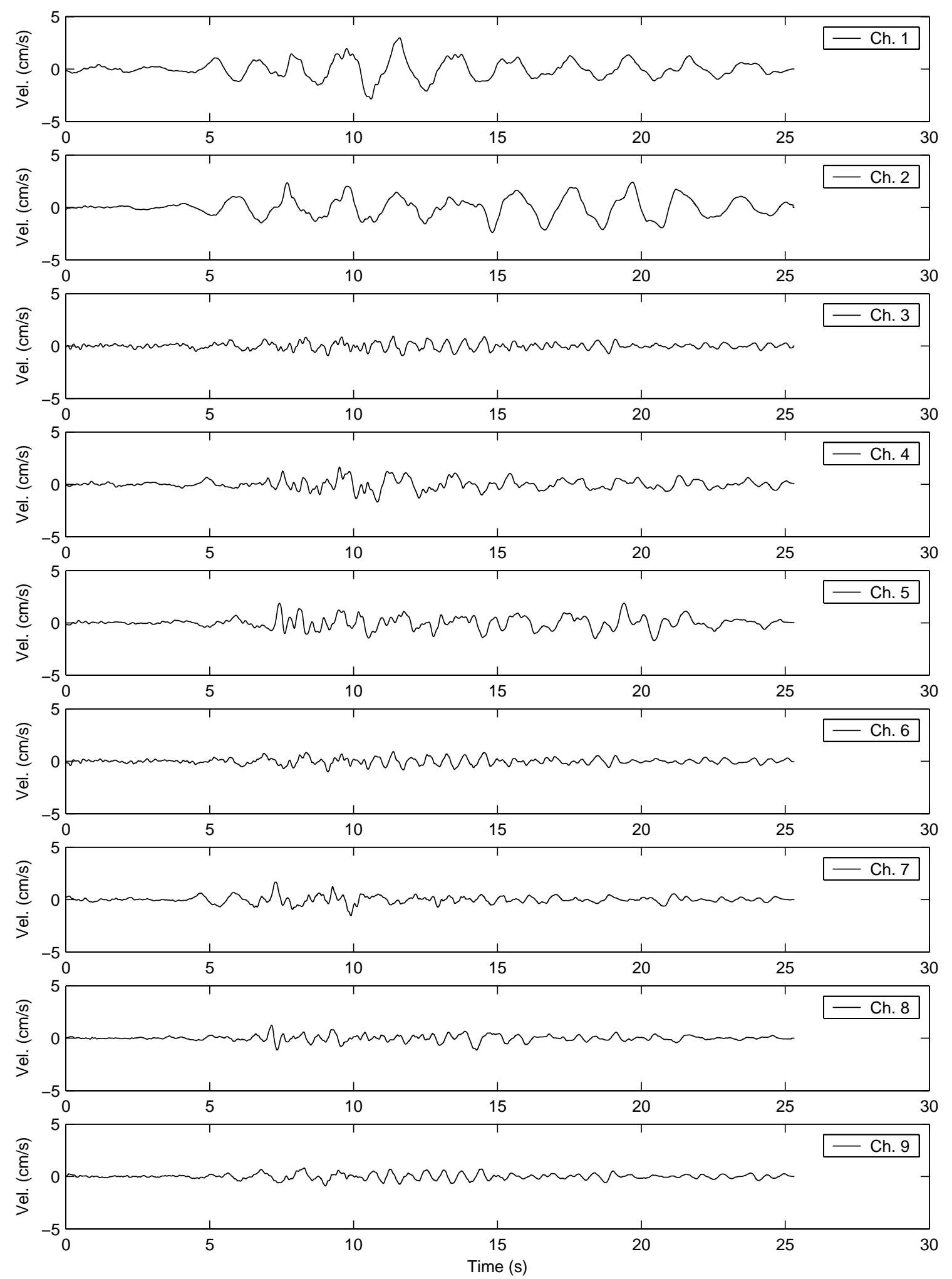

Figure B - 5. 1973 Point Mugu earthquake, velocity 

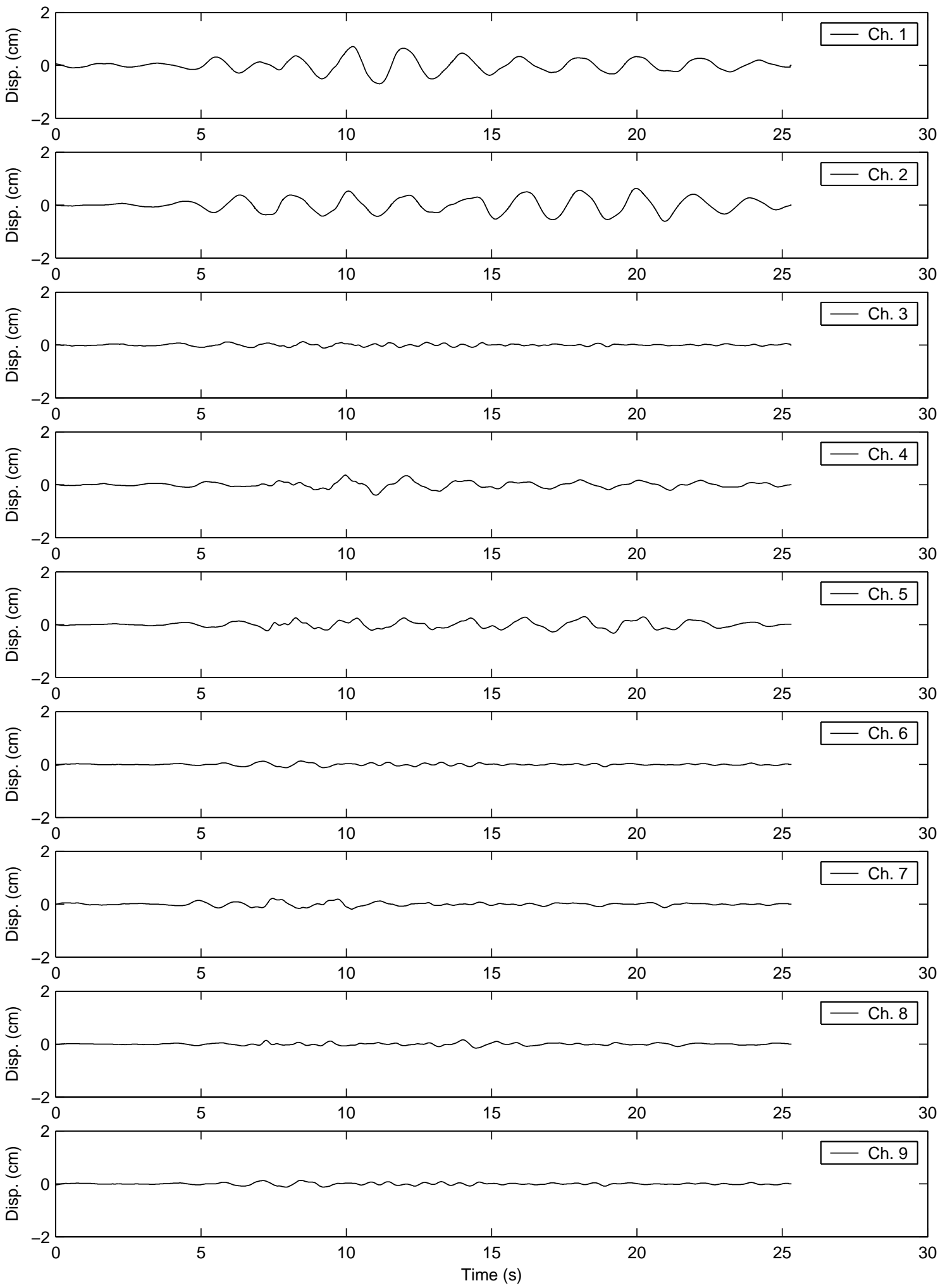

Figure B - 6. 1973 Point Mugu earthquake, displacement 

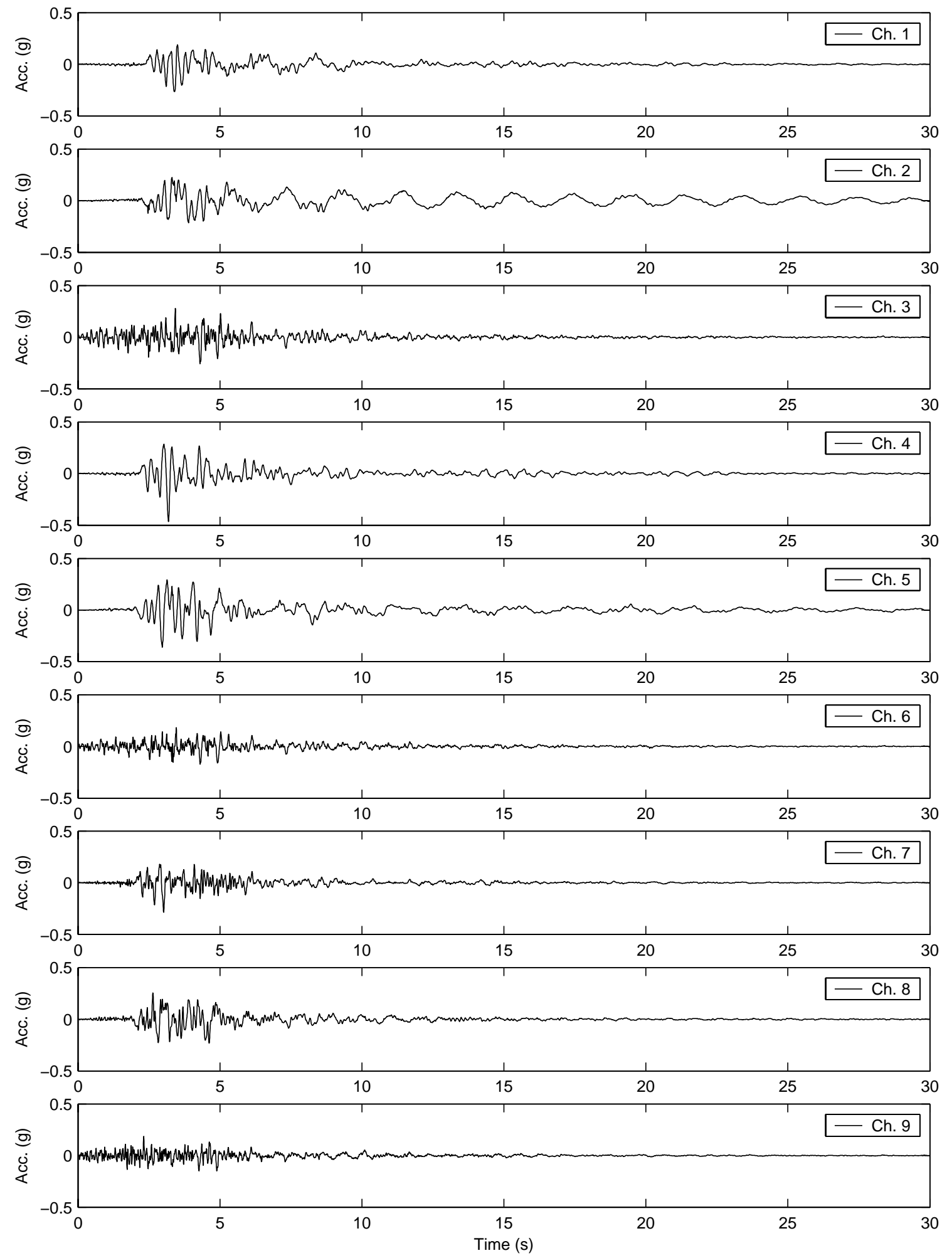

Figure B - 7. 1987 Whittier Narrows earthquake, acceleration 

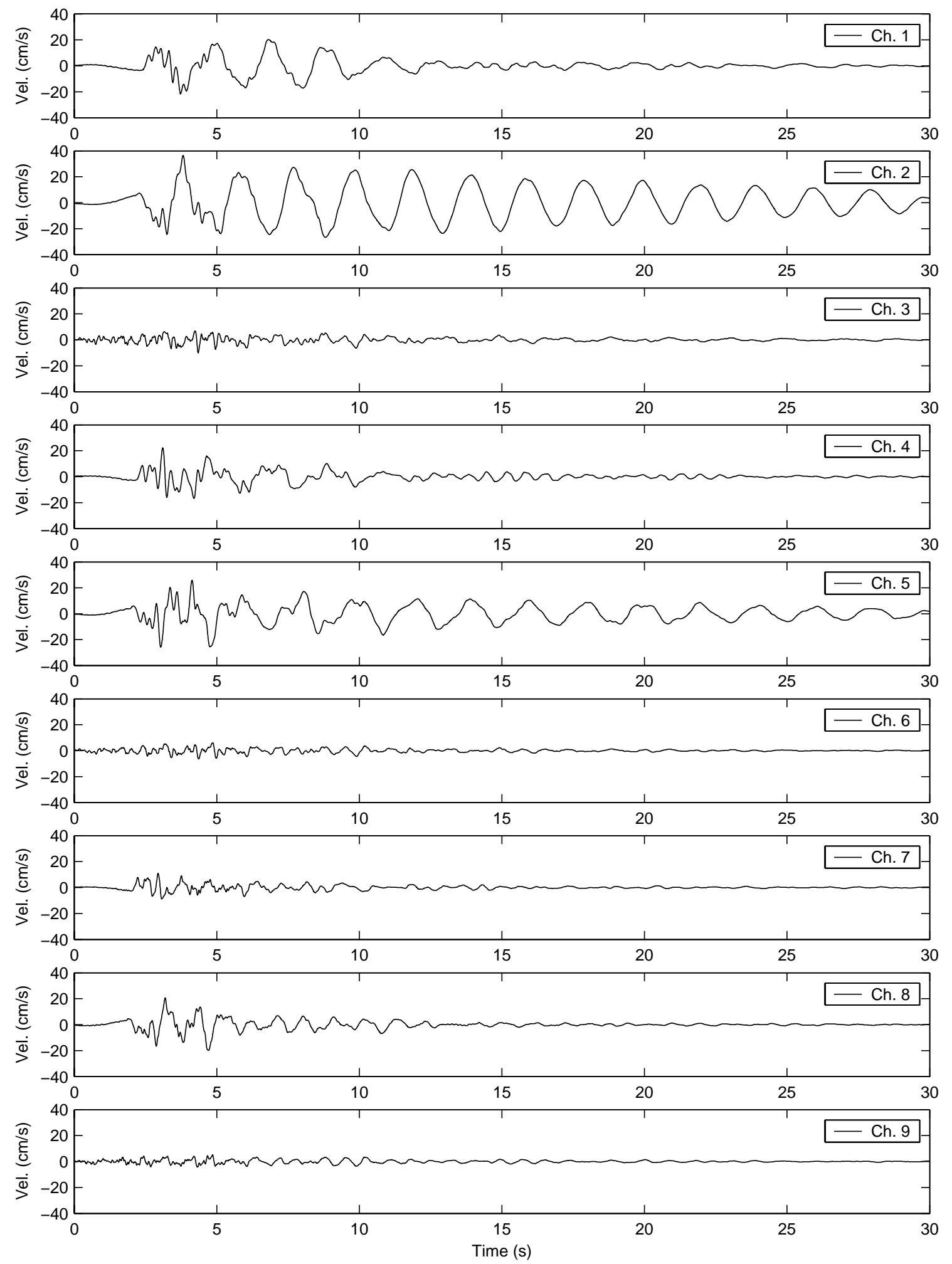

Figure B - 8. 1987 Whittier Narrows earthquake, velocity 

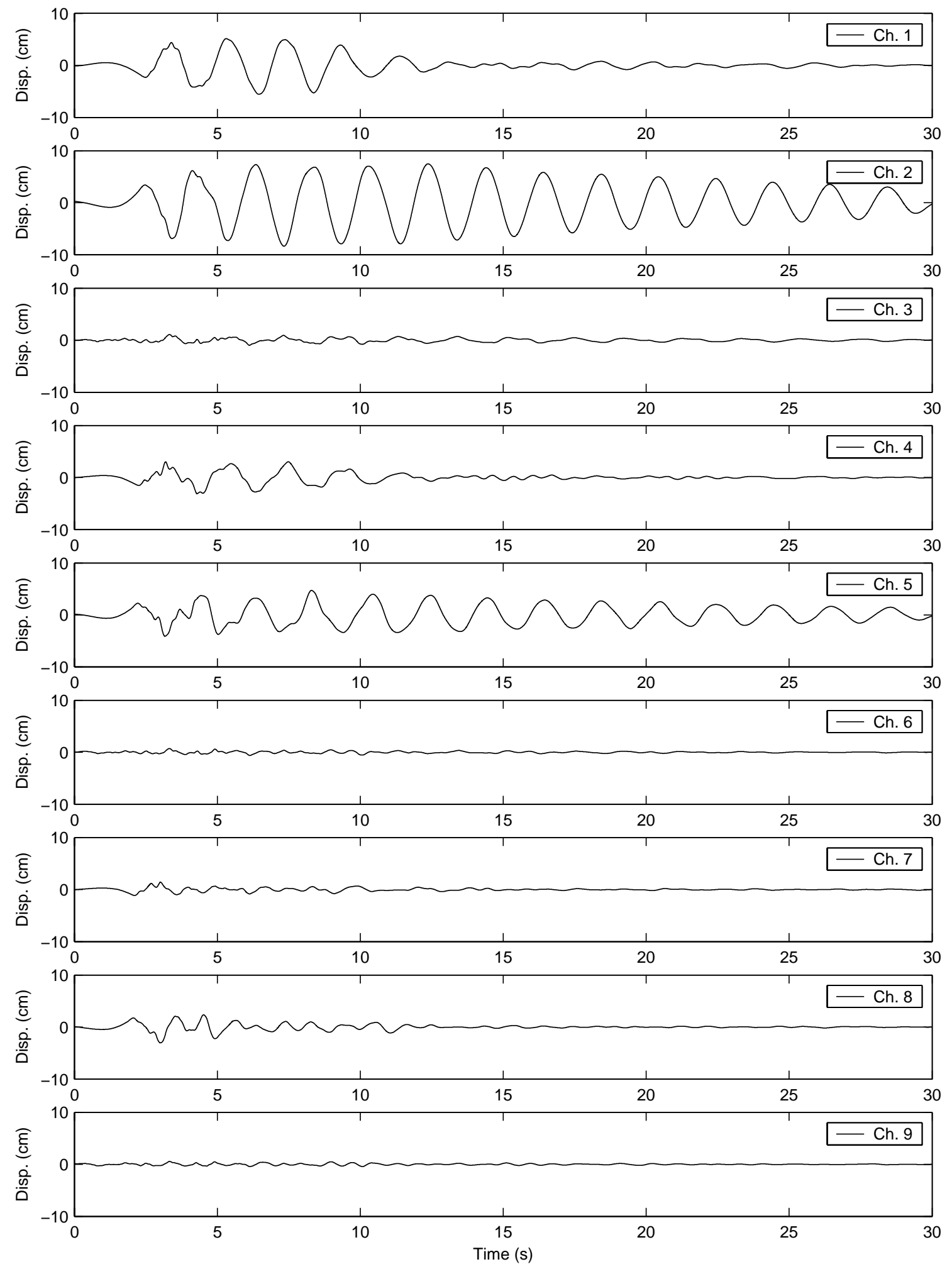

Figure B - 9. 1987 Whittier Narrows earthquake, displacement 

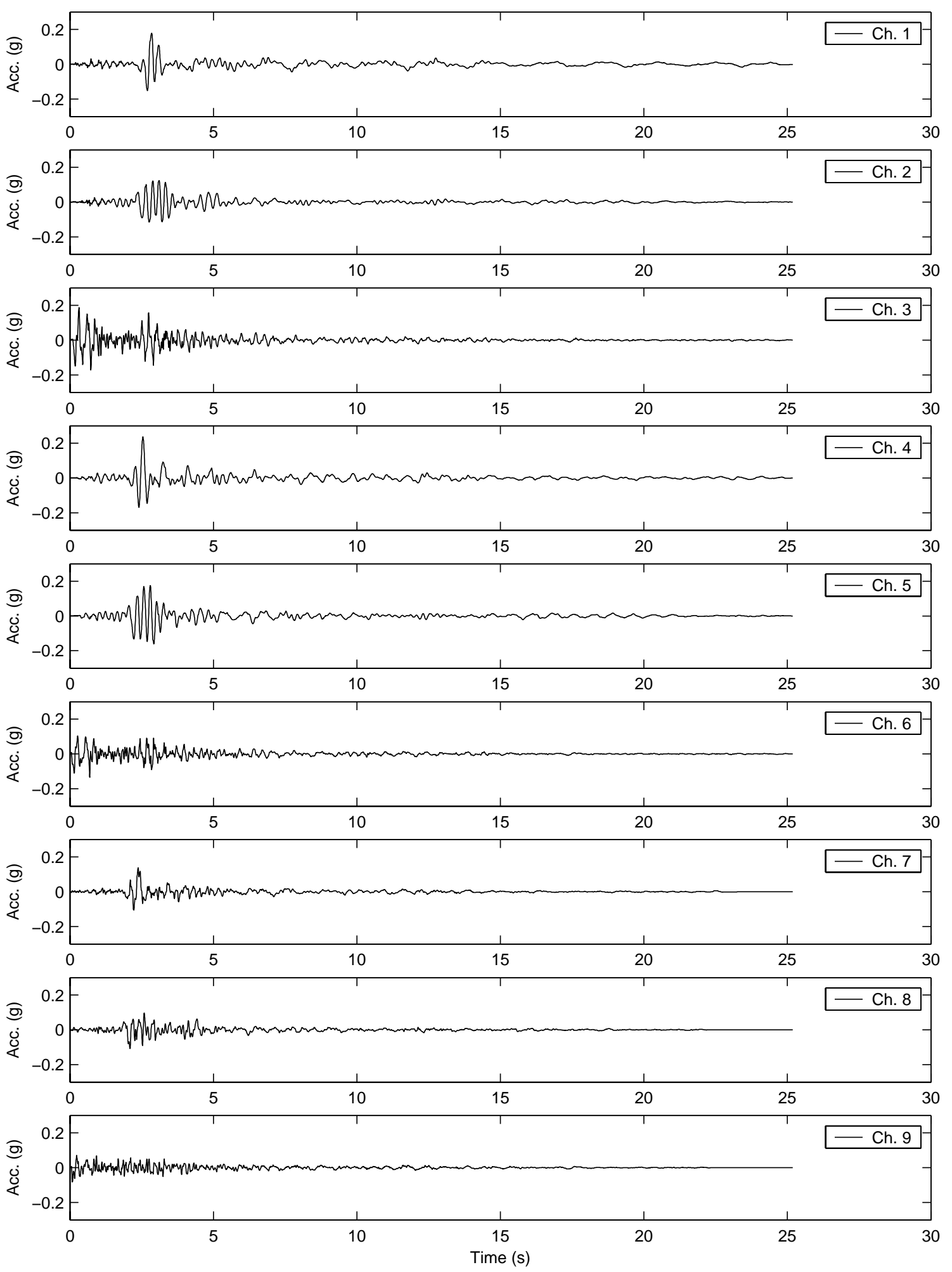

Figure B - 10. Whittier Narrows Aftershock 1, 10/4/1987, acceleration 

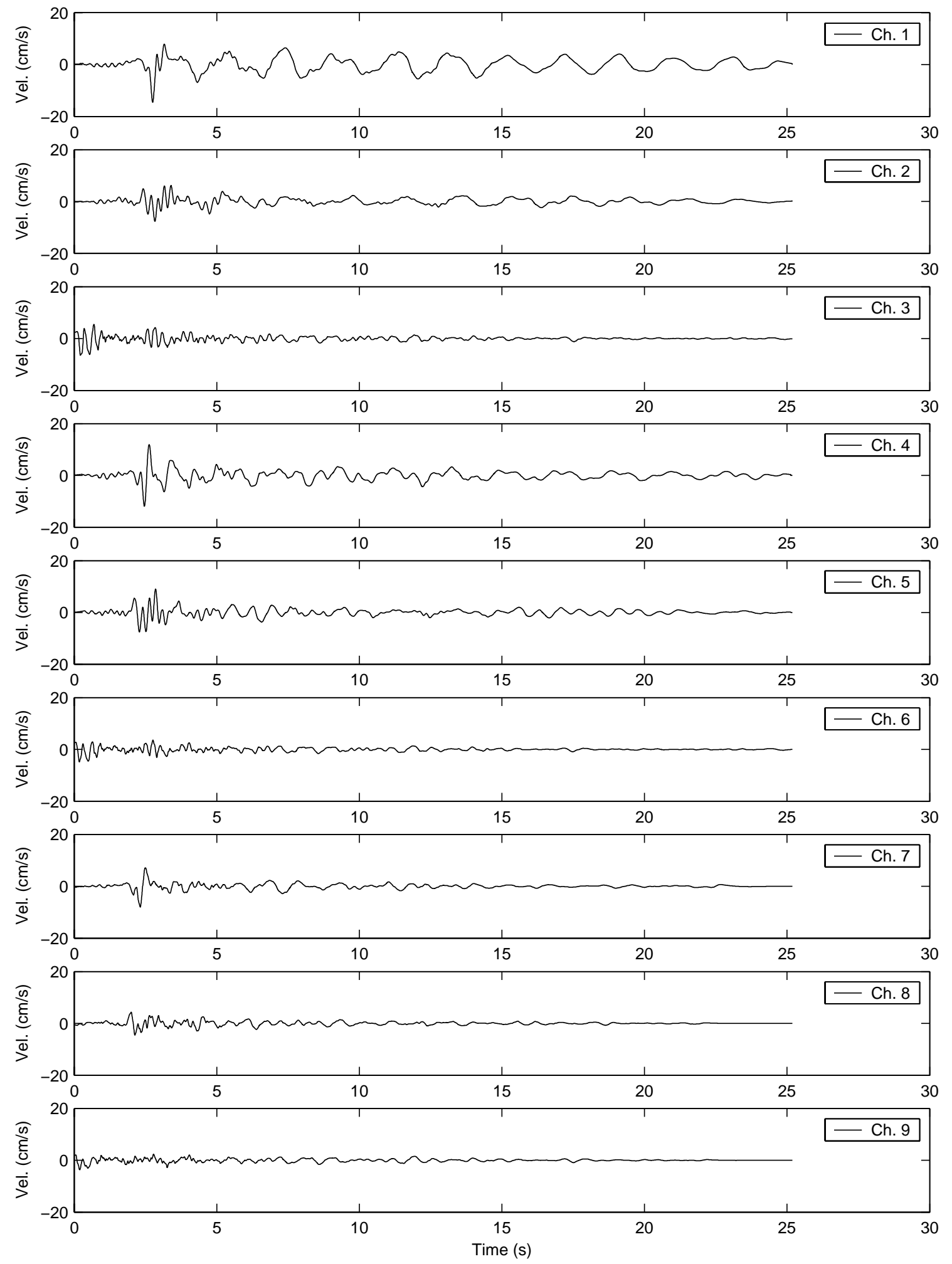

Figure B - 11. Whittier Narrows Aftershock 1, 10/4/1987, velocity 

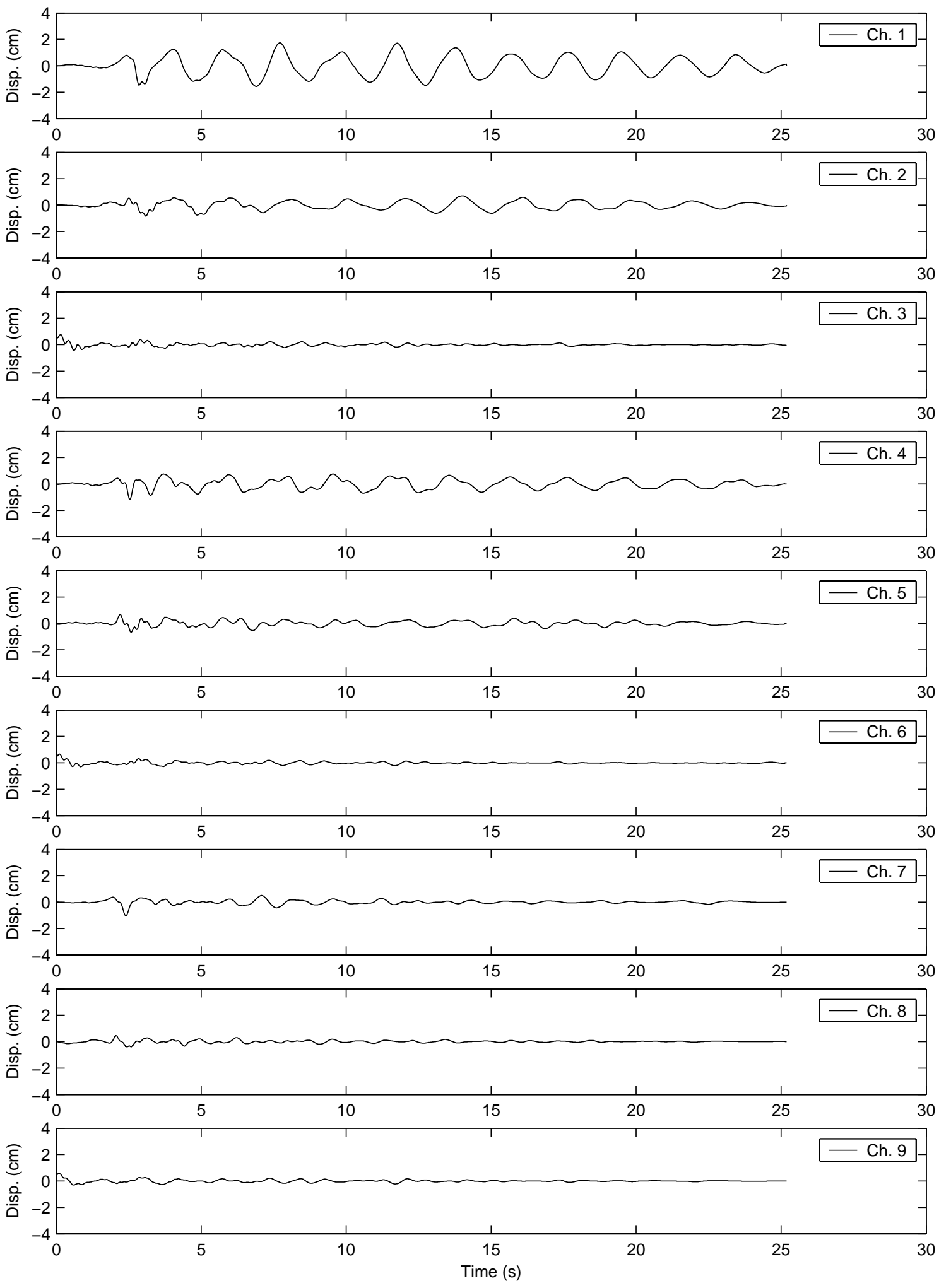

Figure B - 12. Whittier Narrows Aftershock 1, 10/4/1987, displacement 

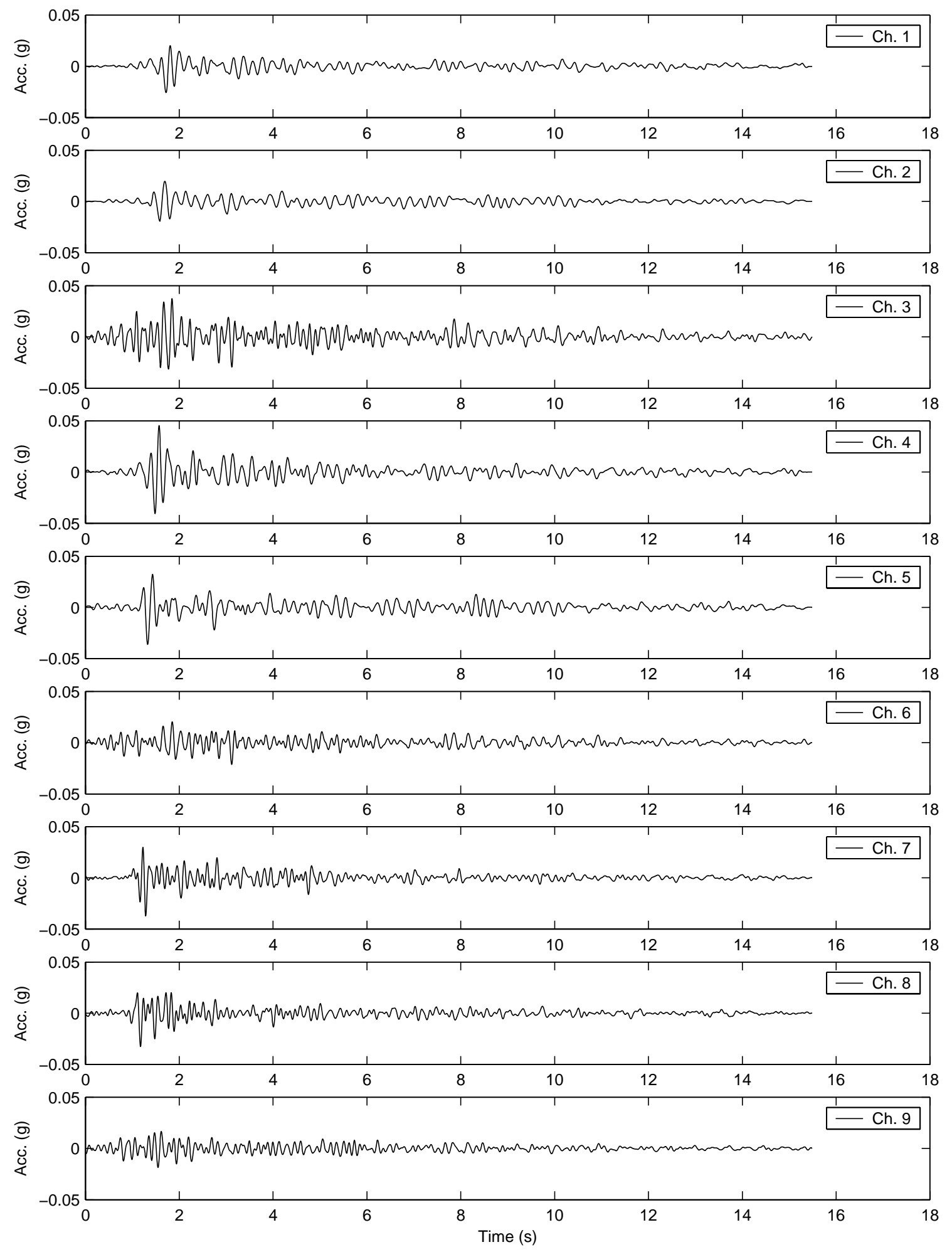

Figure B - 13. Whittier Narrows Aftershock 2, 2/11/1988, acceleration 

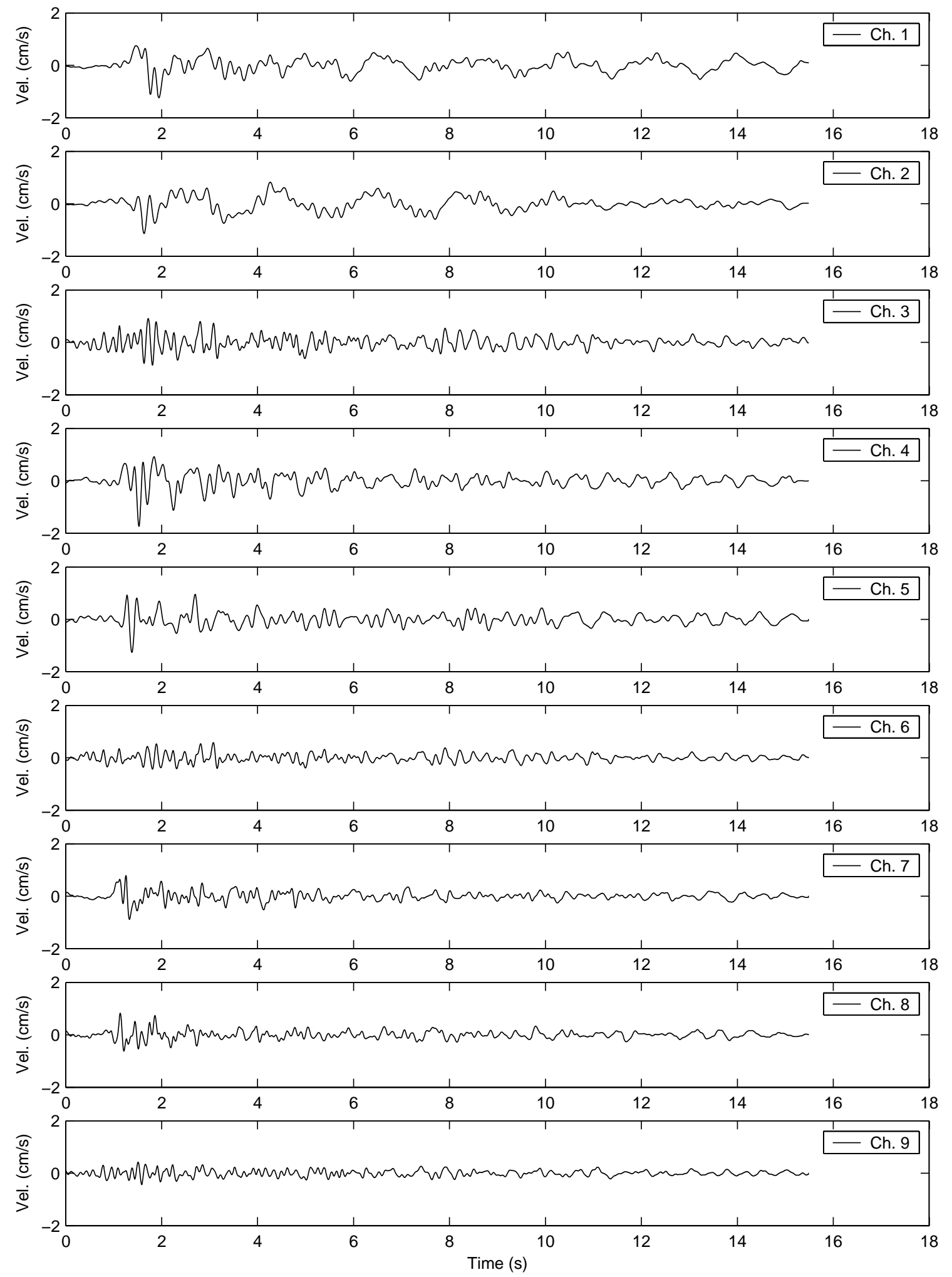

Figure B - 14. Whittier Narrows Aftershock 2, 2/11/1988, velocity 

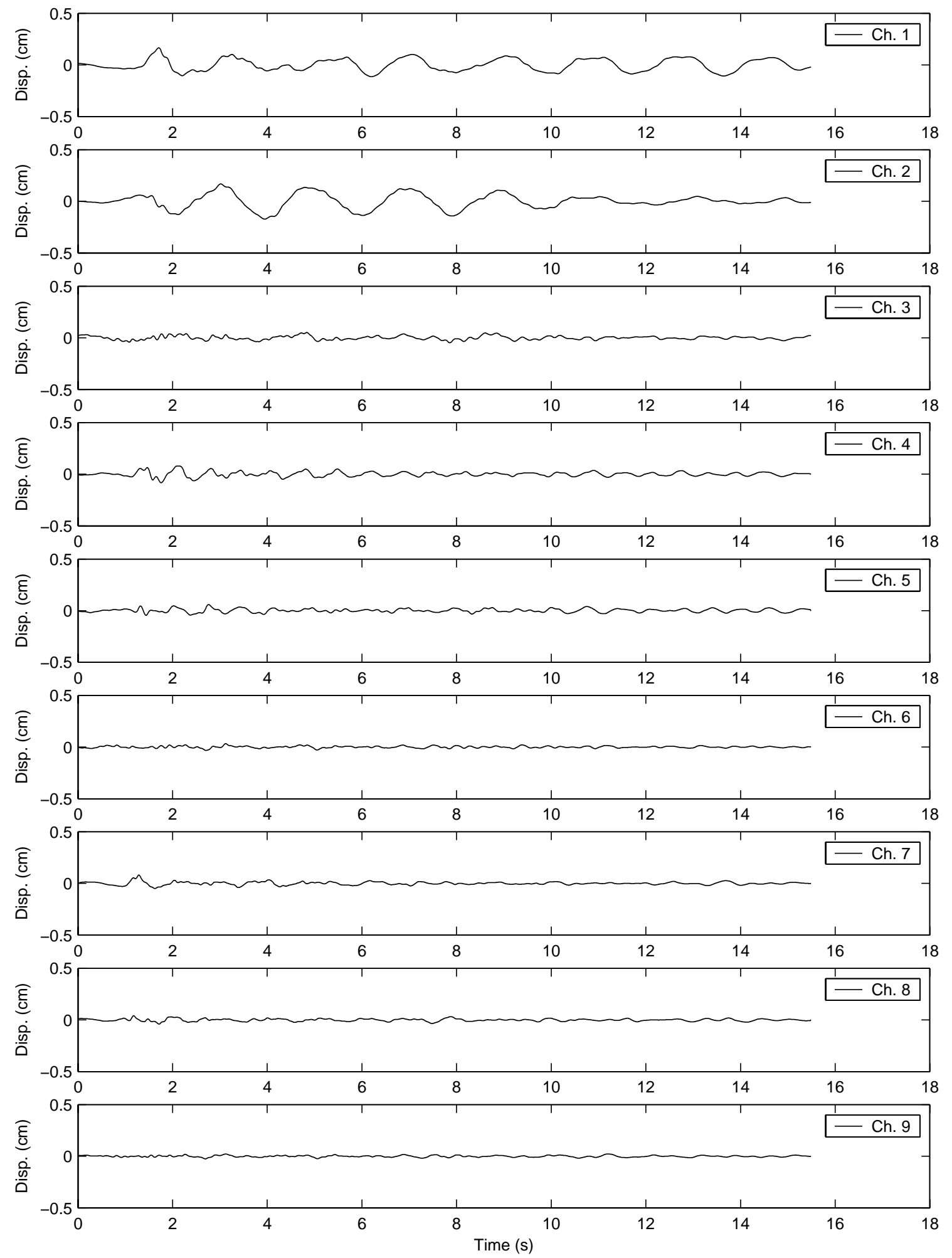

Figure B - 15. Whittier Narrows Aftershock 2, 2/11/1988, displacement 


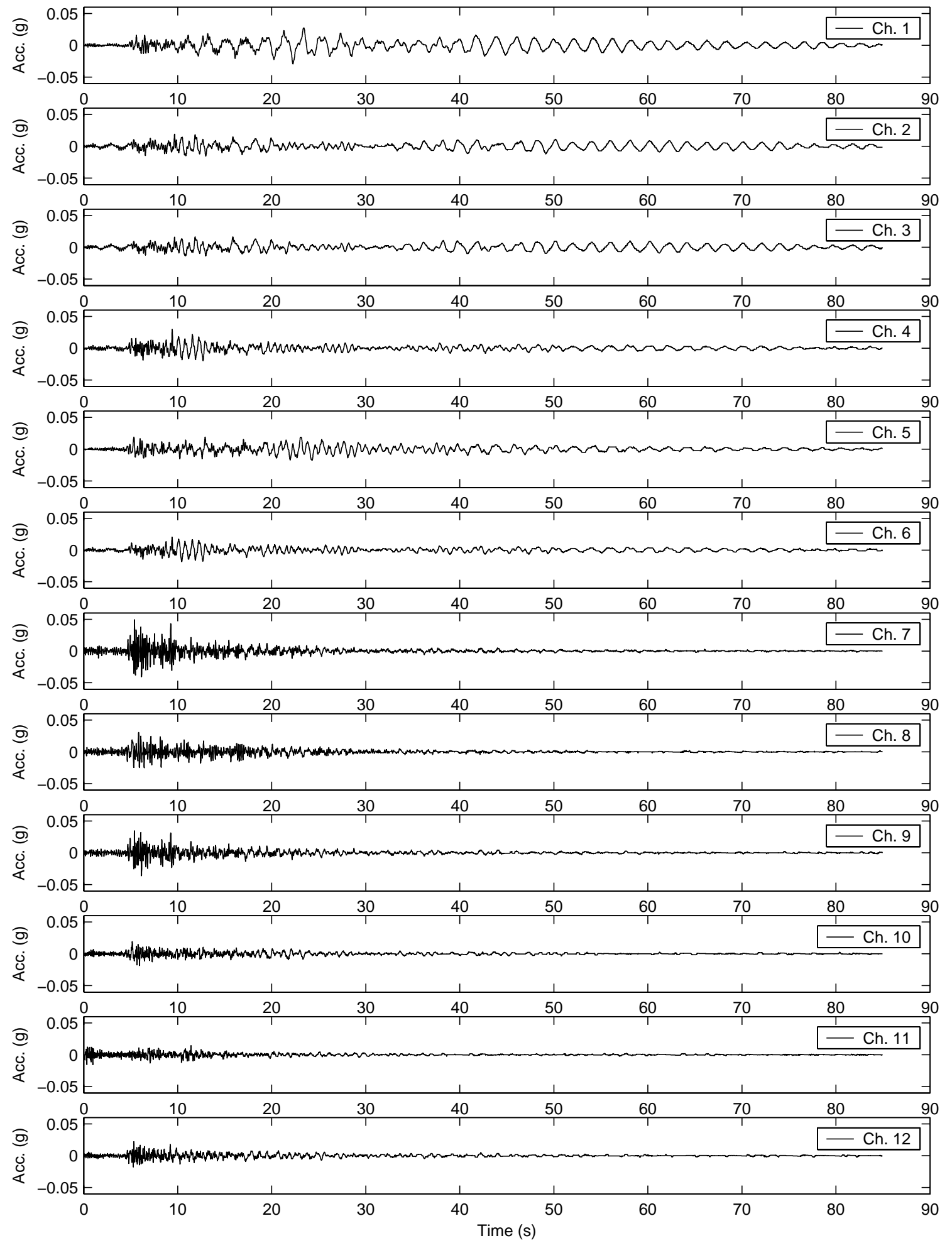

Figure B - 16. 1990 Upland earthquake, acceleration 


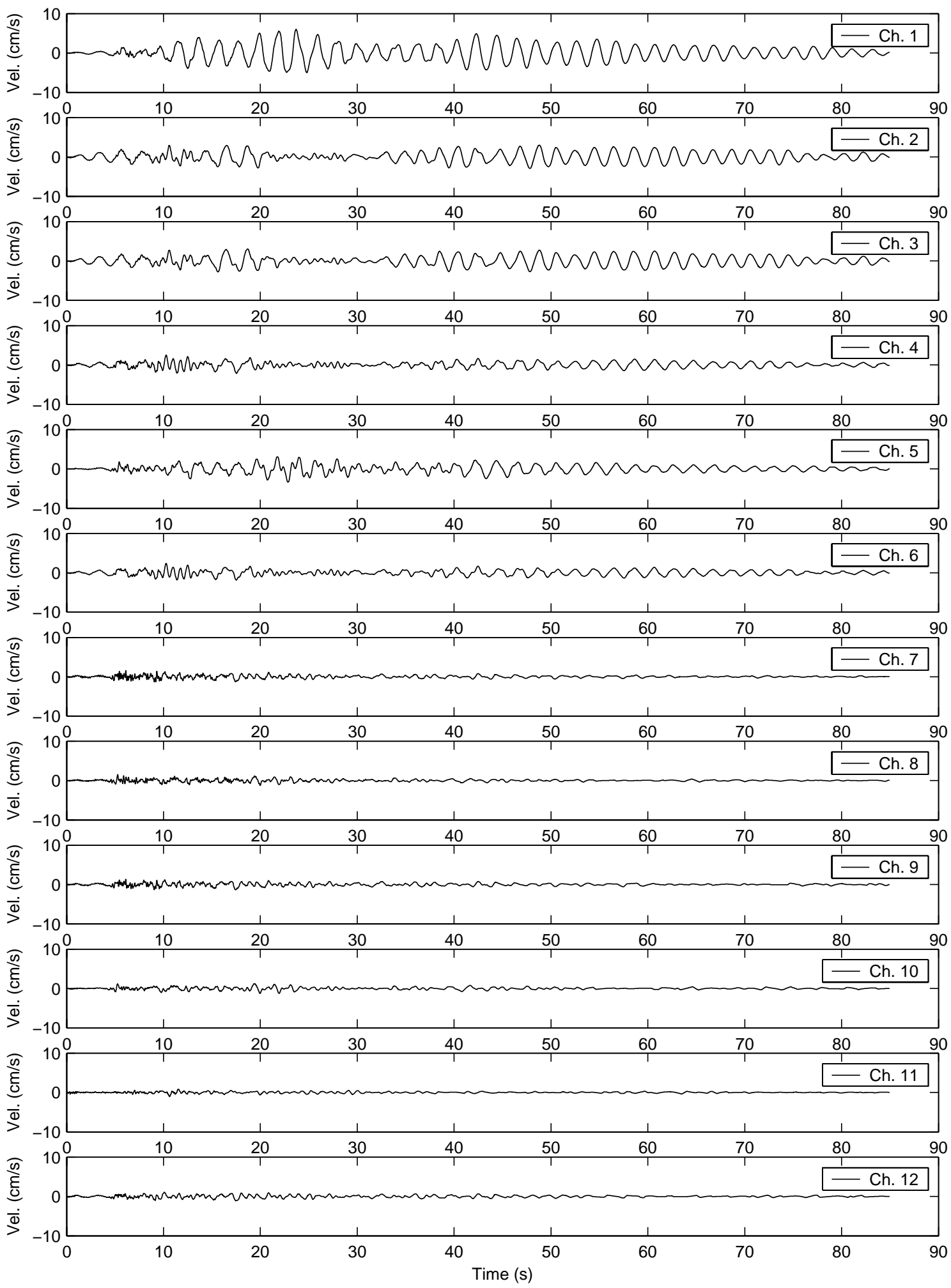

Figure B - 17. 1990 Upland earthquake, velocity 


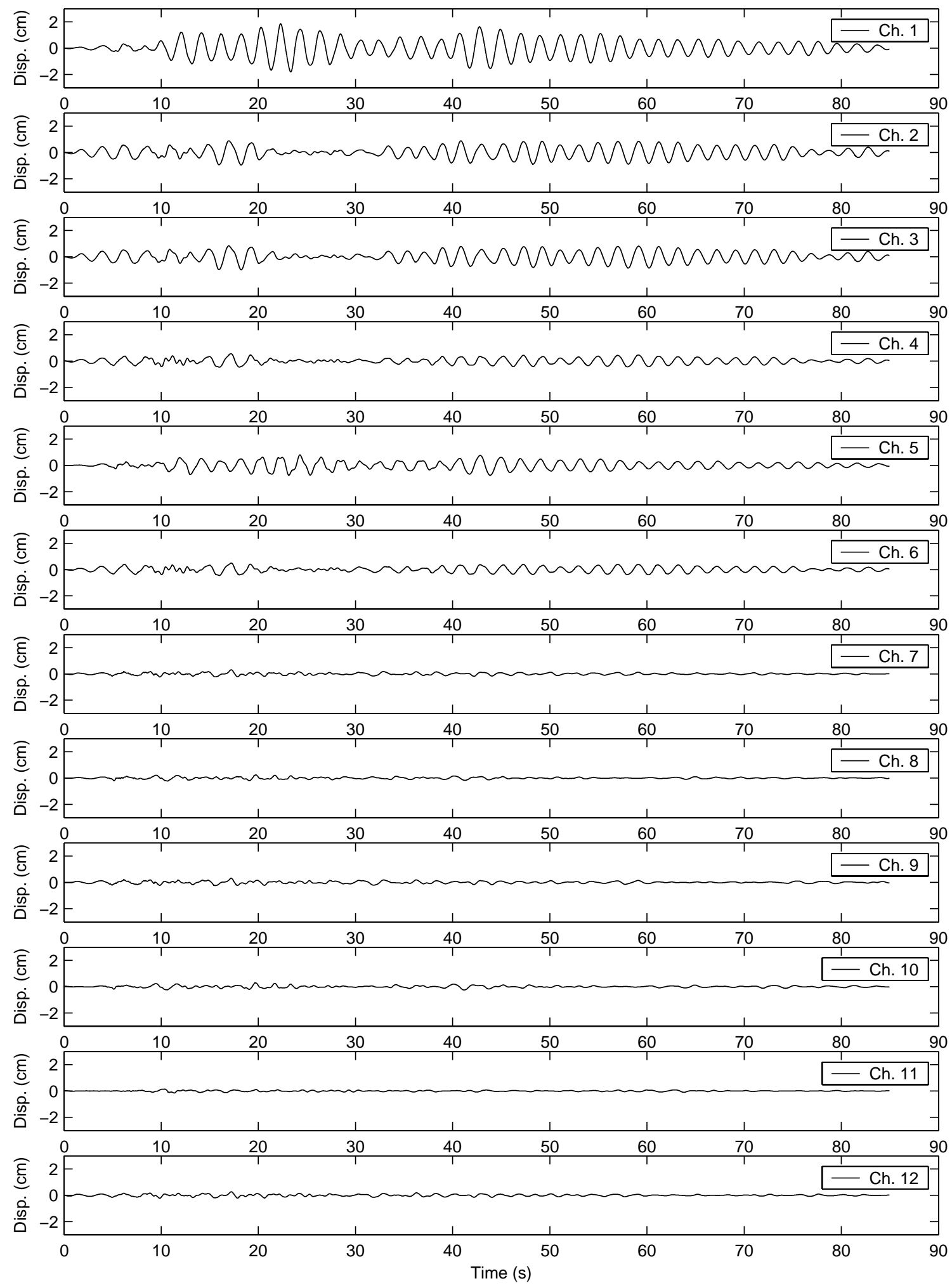

Figure B - 18. 1990 Upland earthquake, displacement 


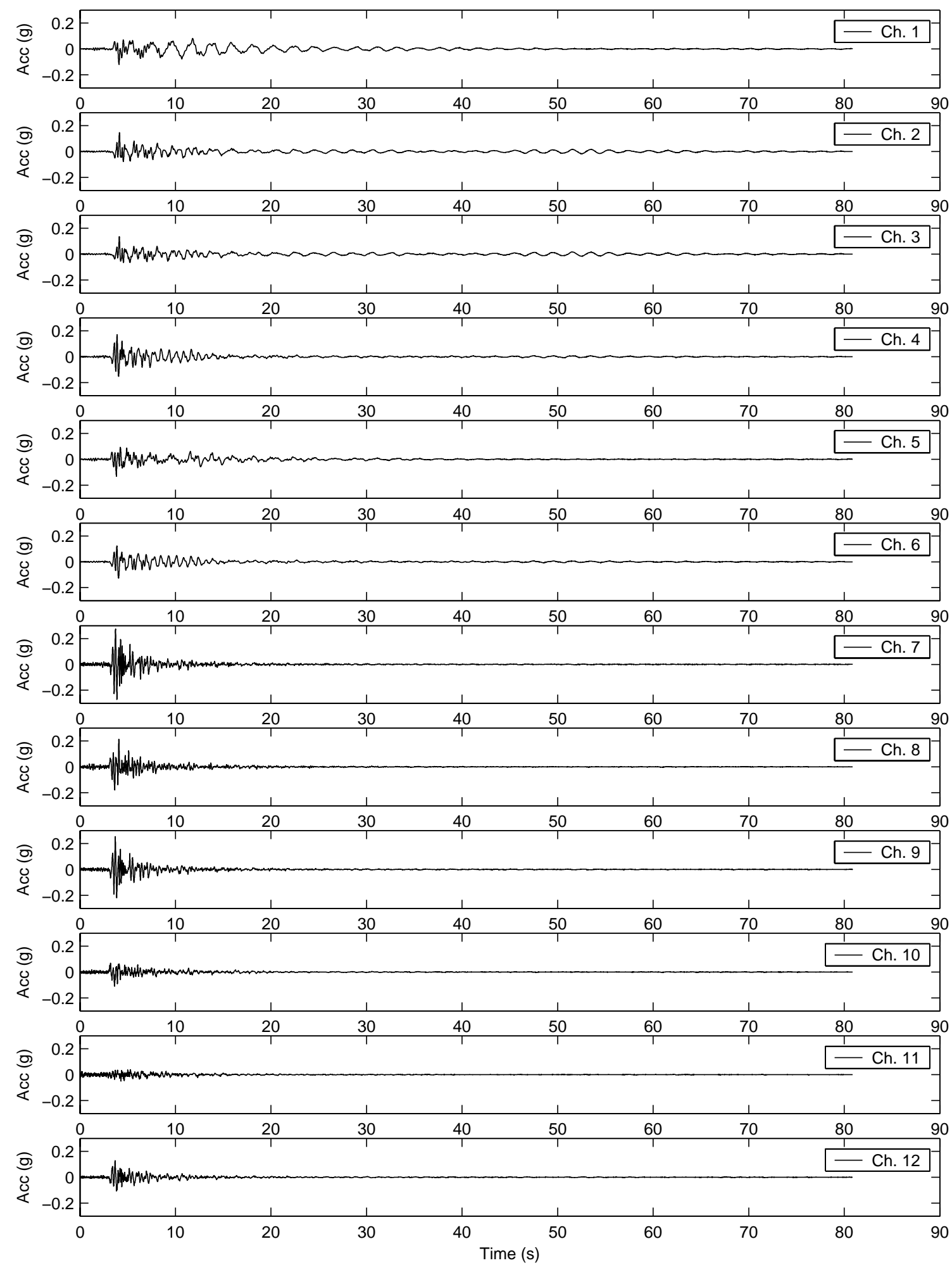

Figure B - 19. 1991 Sierra Madre earthquake, acceleration 


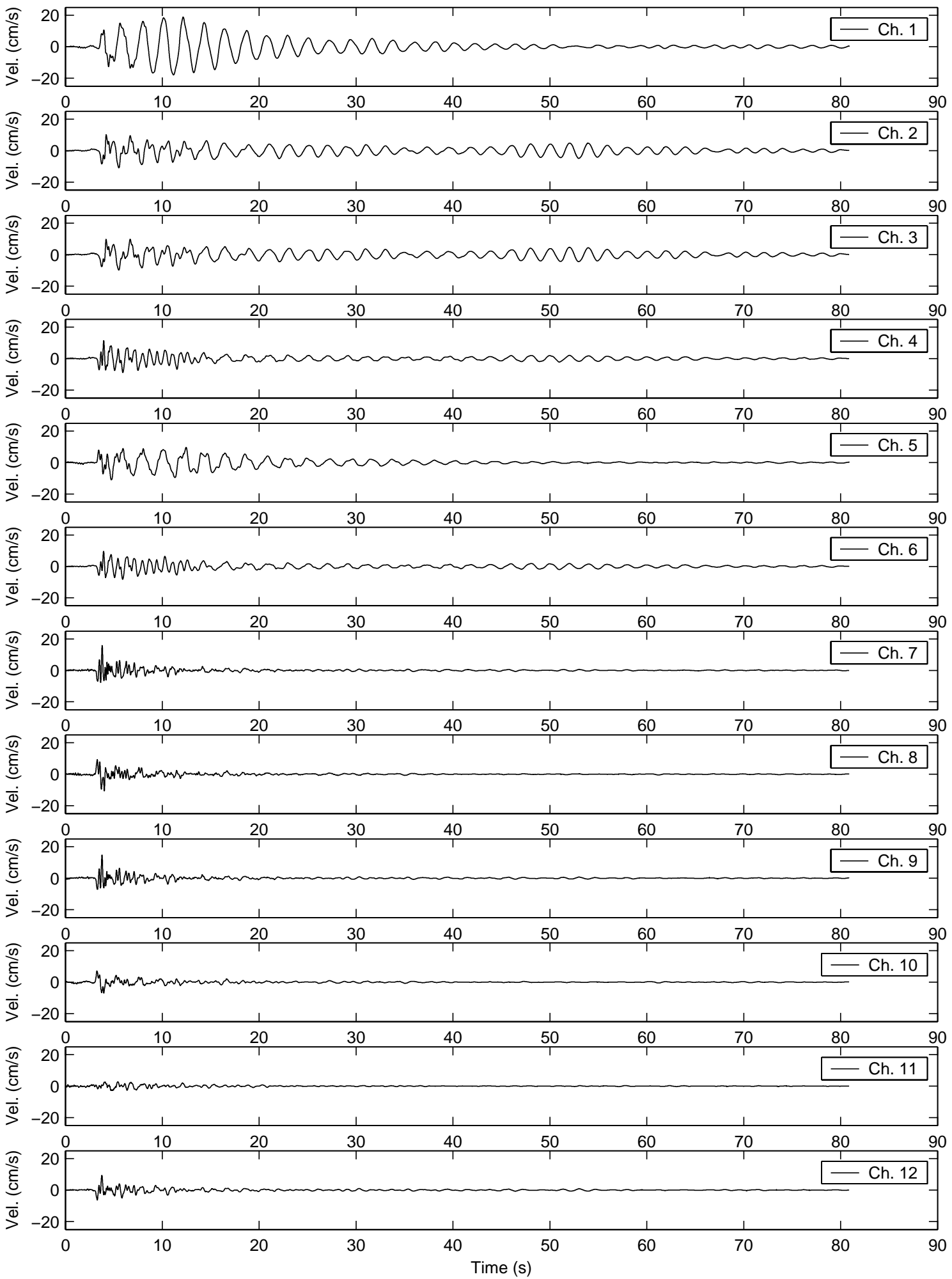

Figure B - 20. 1991 Sierra Madre earthquake, velocity 


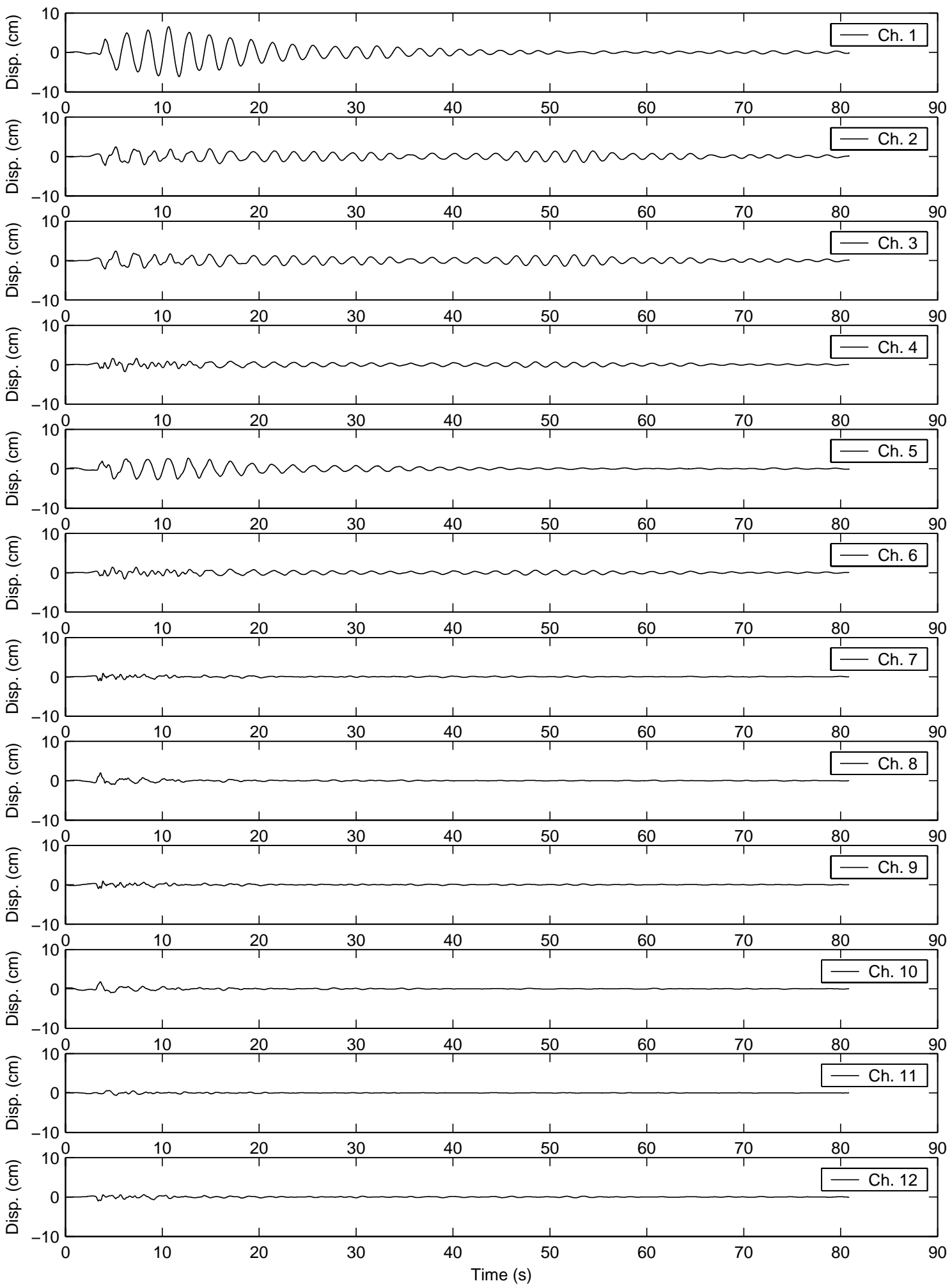

Figure B - 21. 1991 Sierra Madre earthquake, displacement 


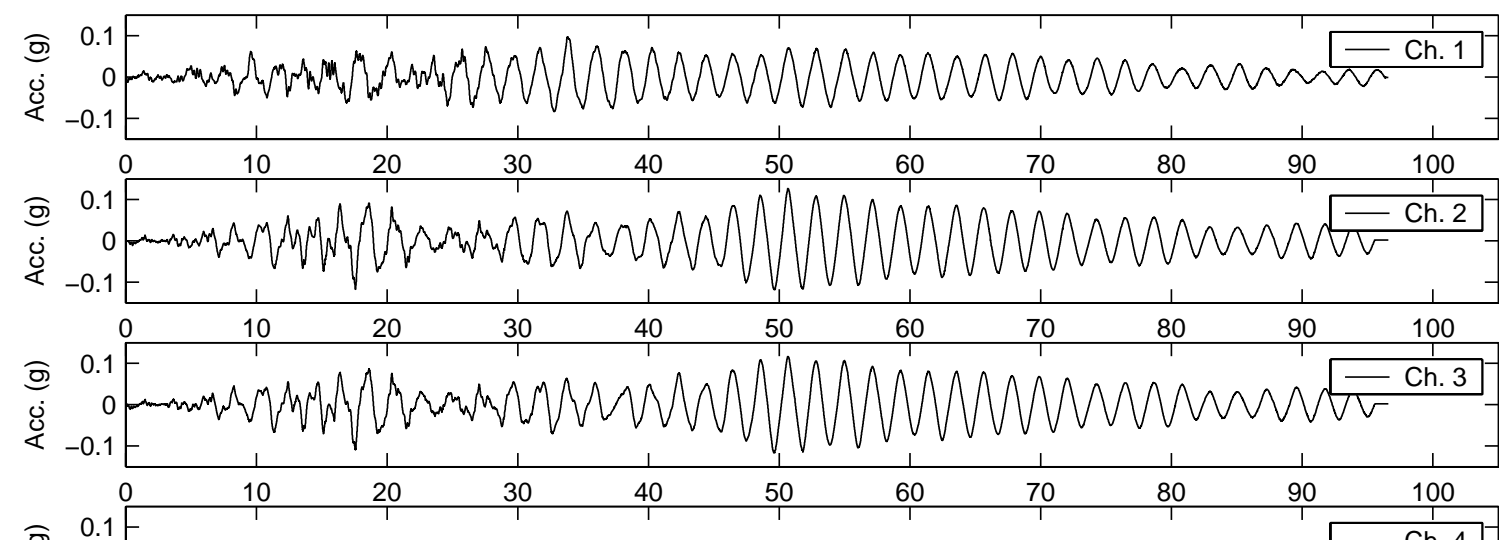

क्ष
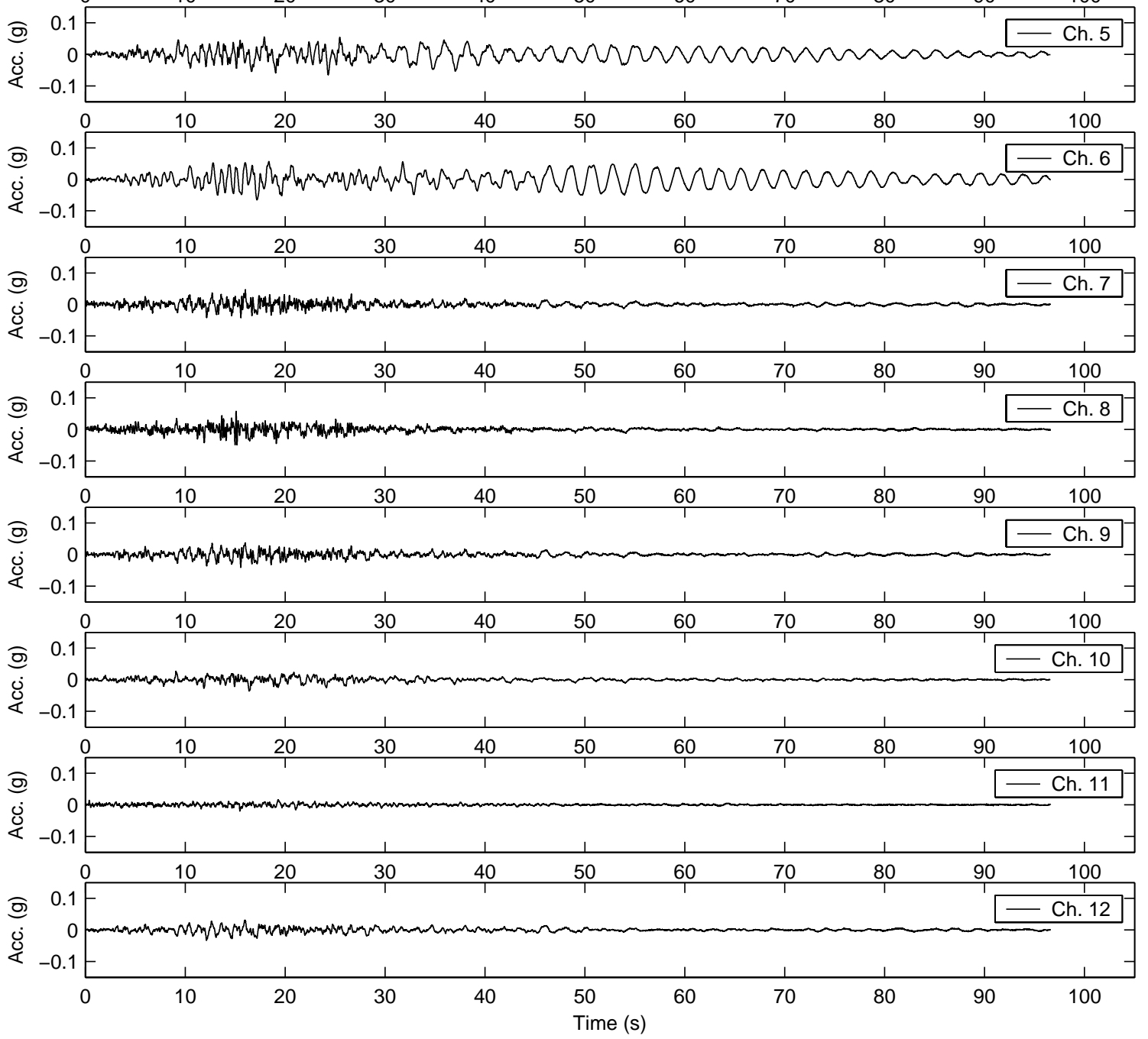

Figure B - 22. 1992 Landers earthquake, acceleration 


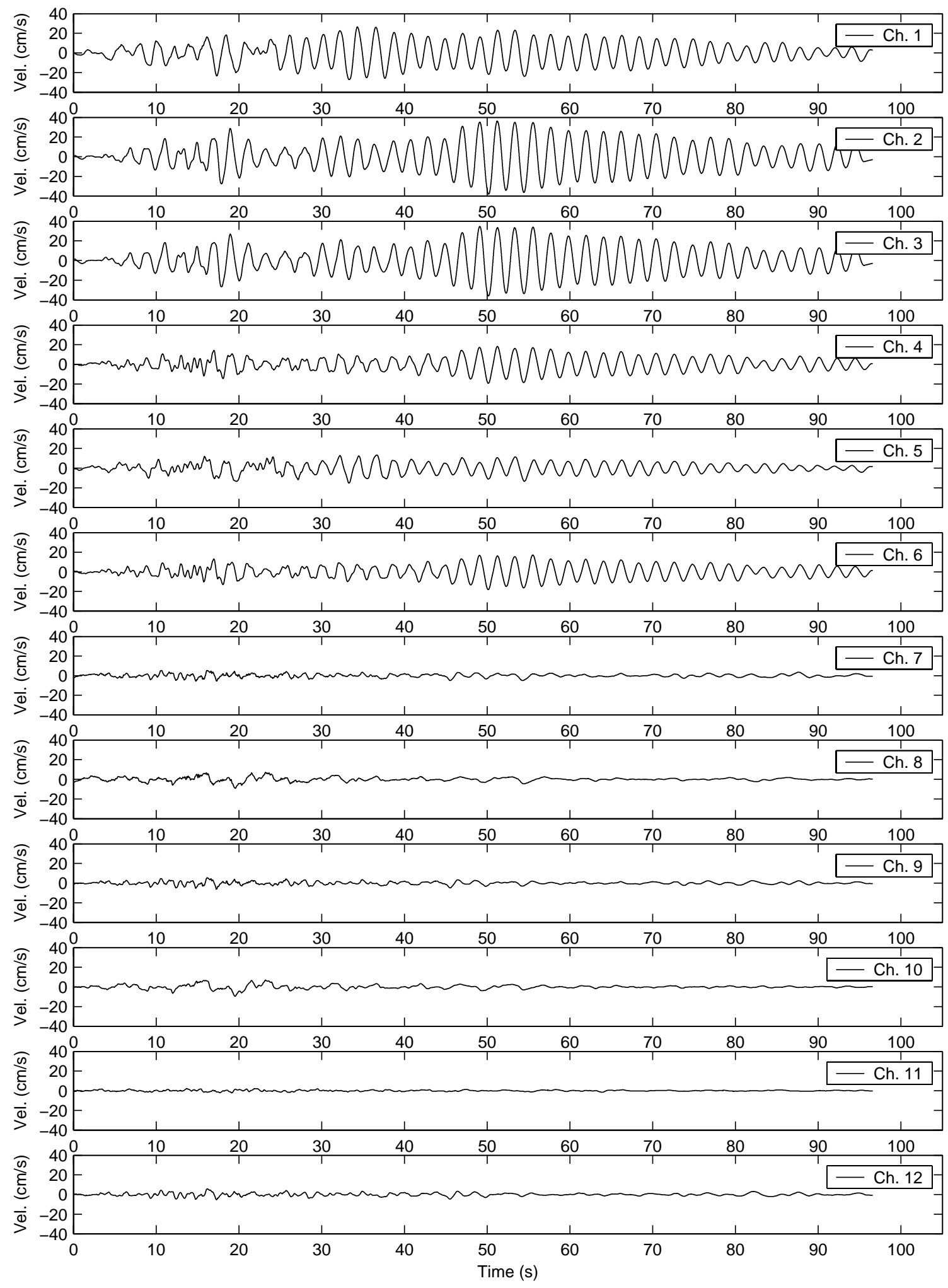

Figure B - 23. 1992 Landers earthquake, velocity 


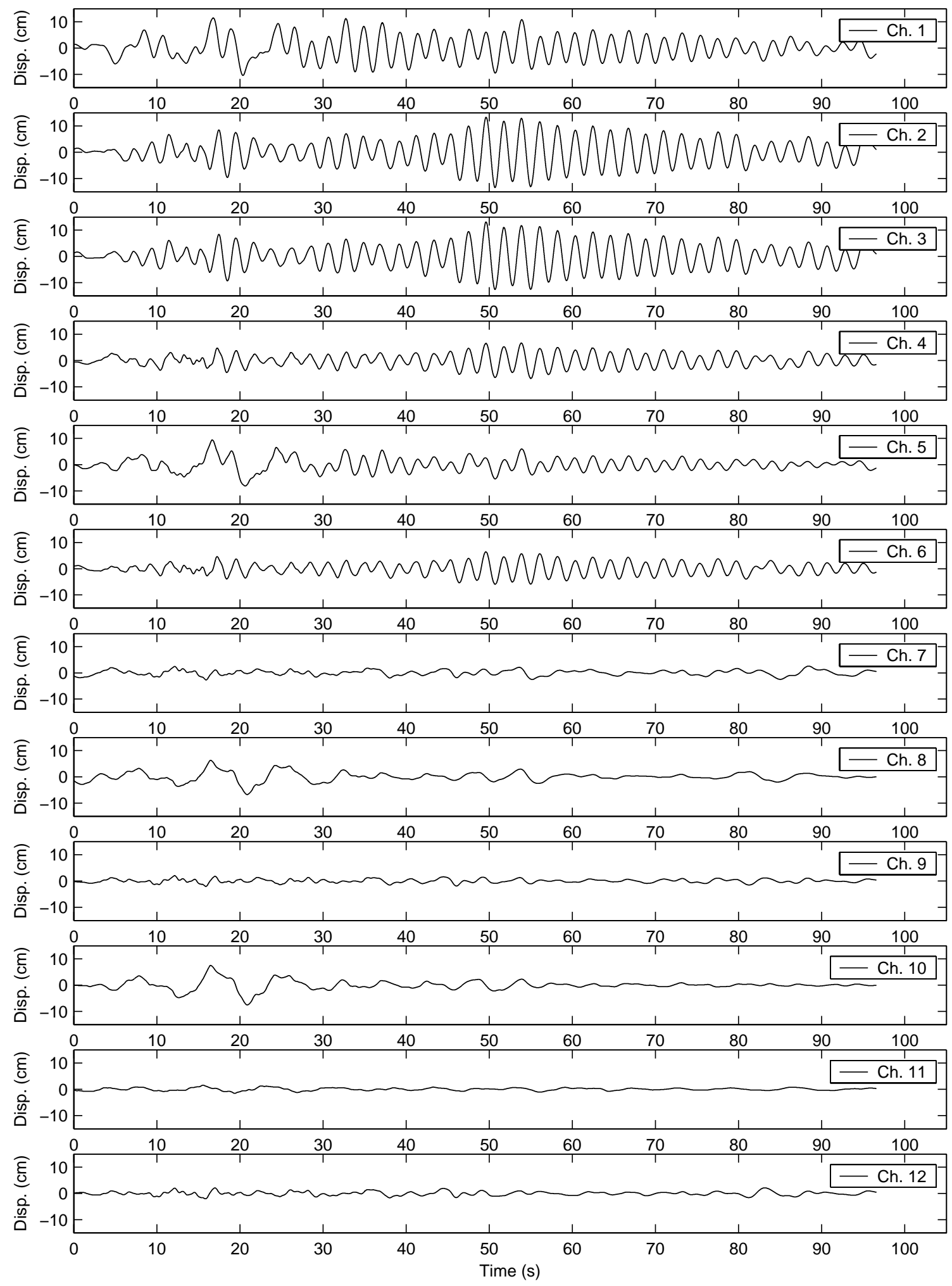

Figure B - 24. 1992 Landers earthquake, displacement 


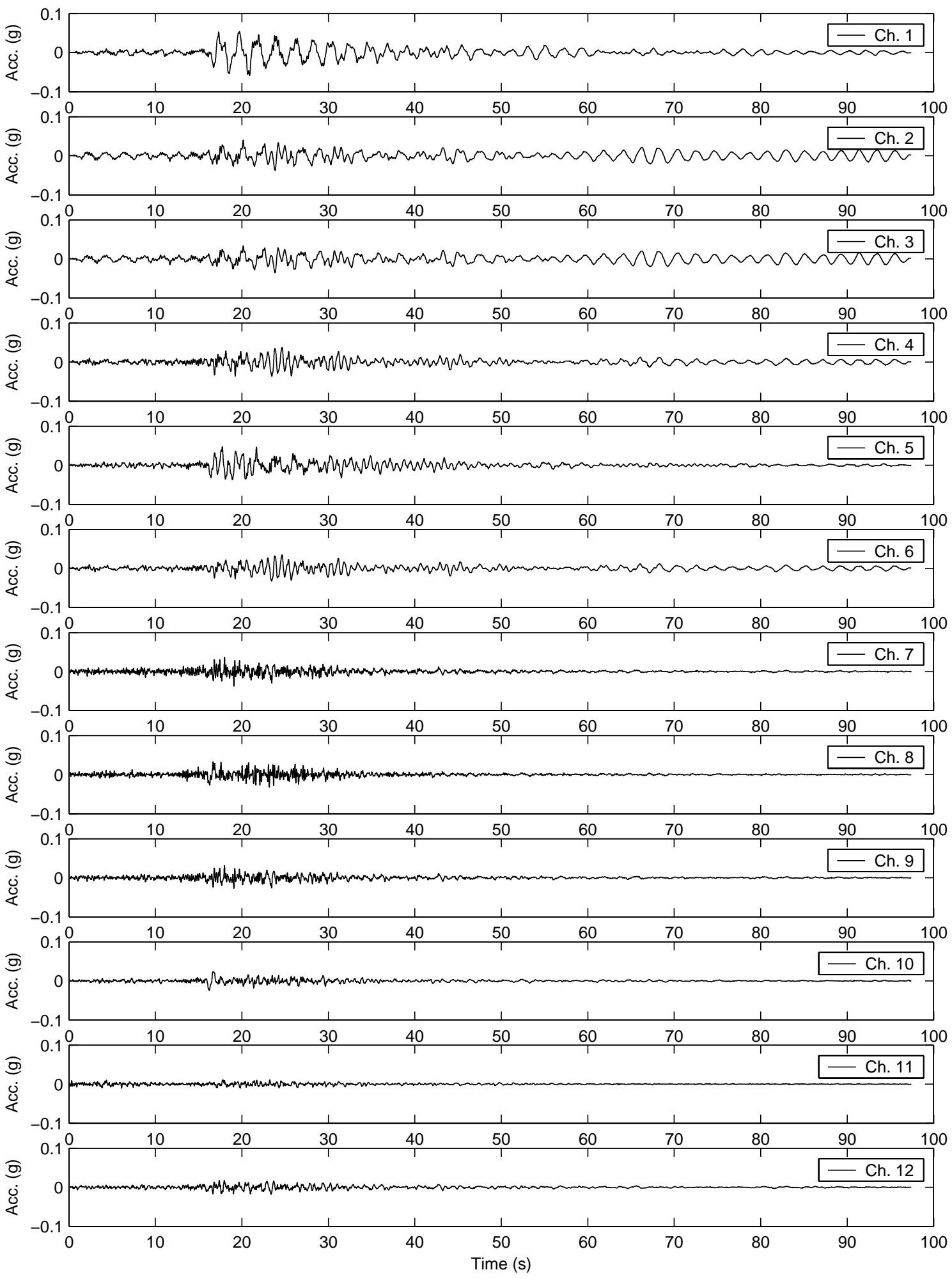

Figure B - 25. 1992 Big Bear earthquake, acceleration 


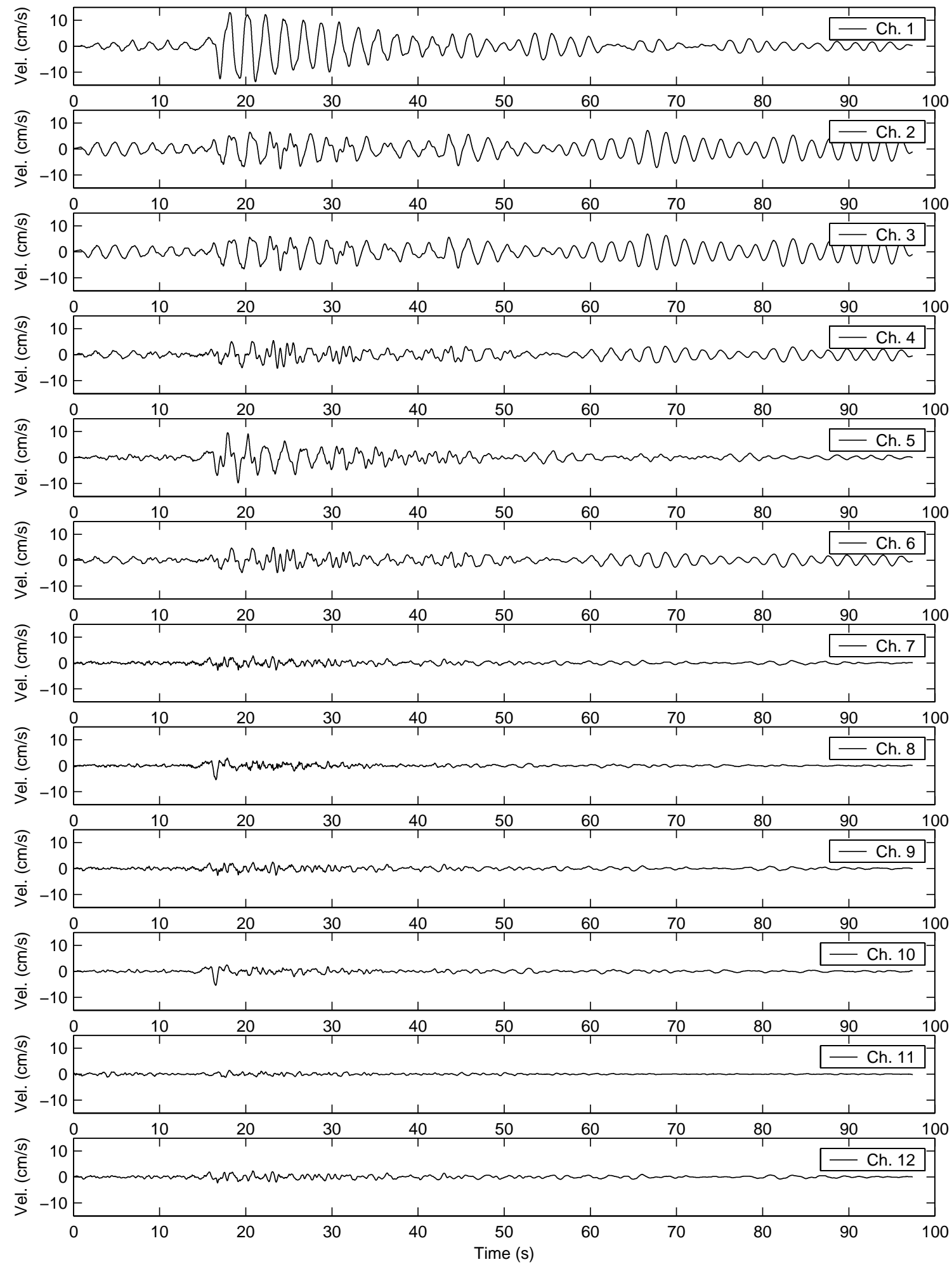

Figure B - 26. 1992 Big Bear earthquake, velocity 


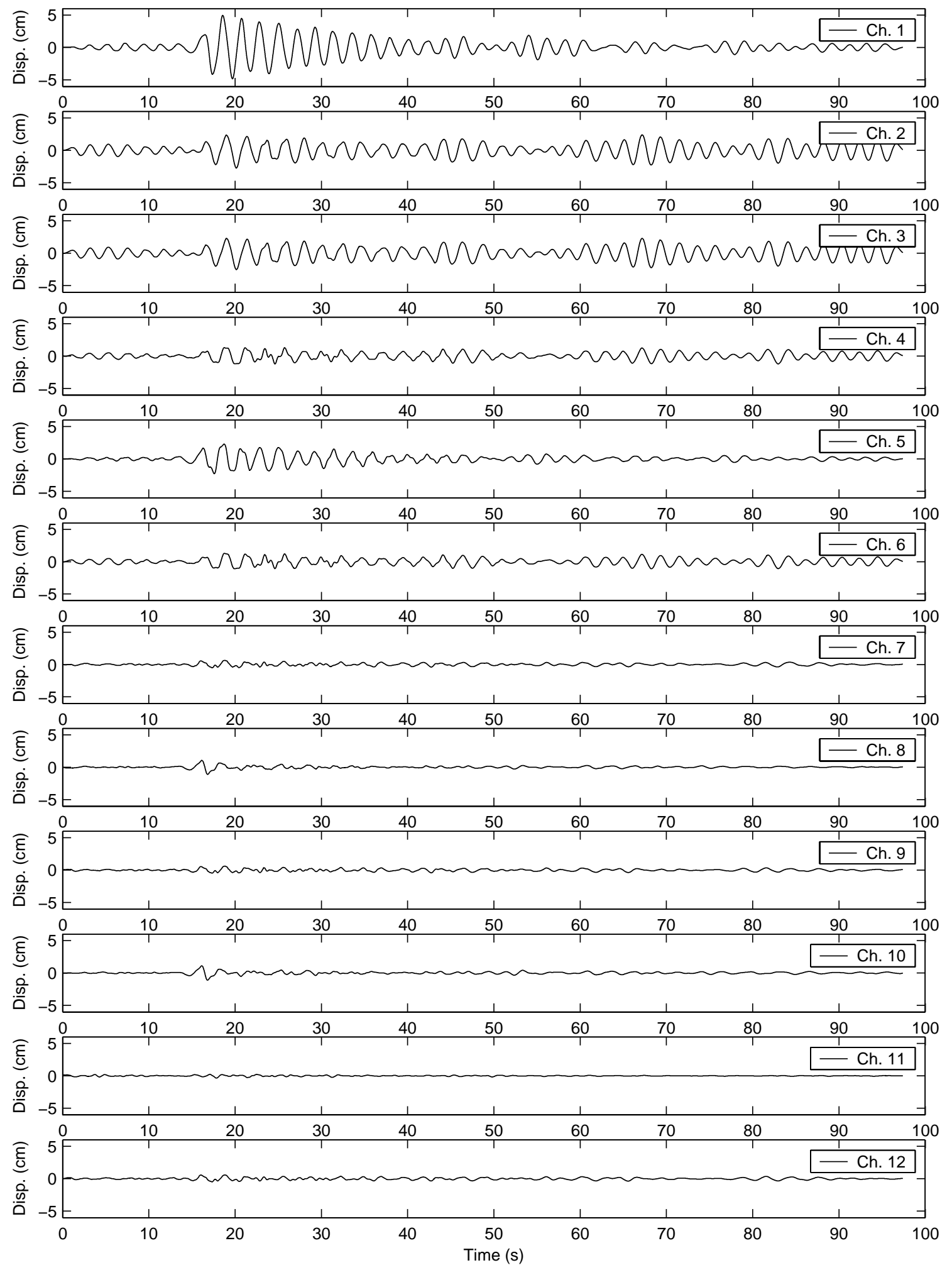

Figure B - 27. 1992 Big Bear earthquake, displacement 


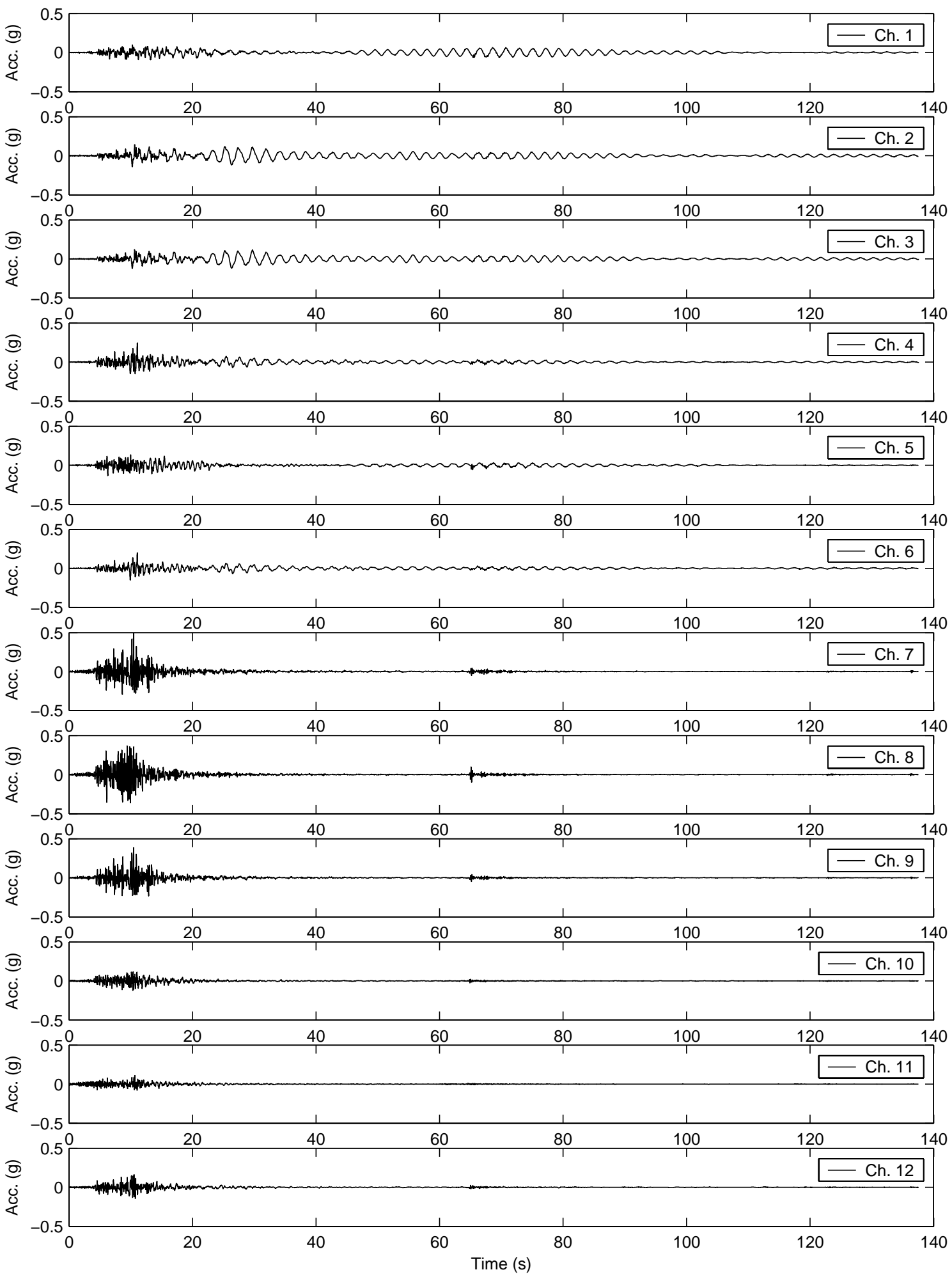

Figure B - 28. 1994 Northridge earthquake, acceleration 


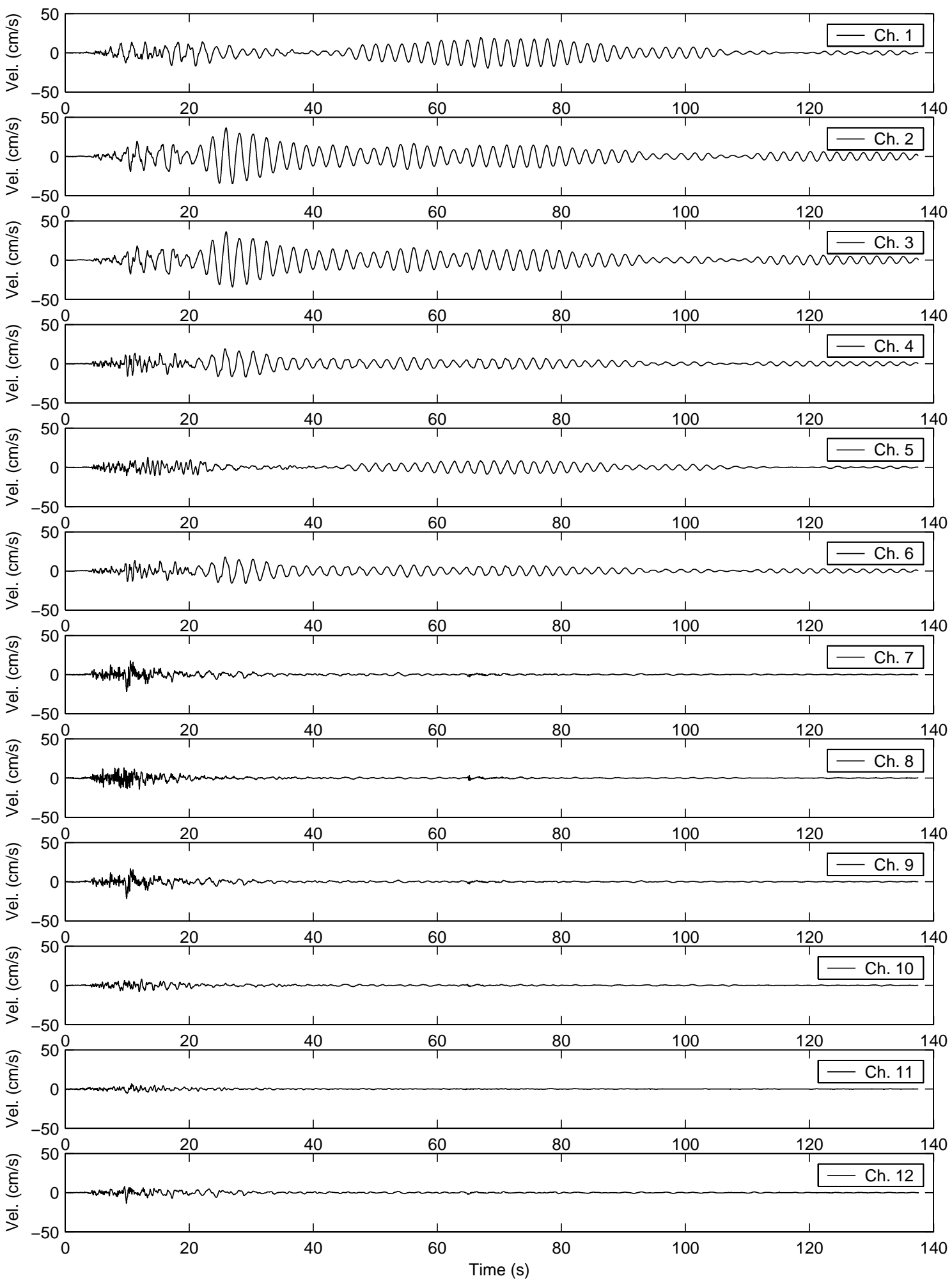

Figure B - 29. 1994 Northridge earthquake, velocity 


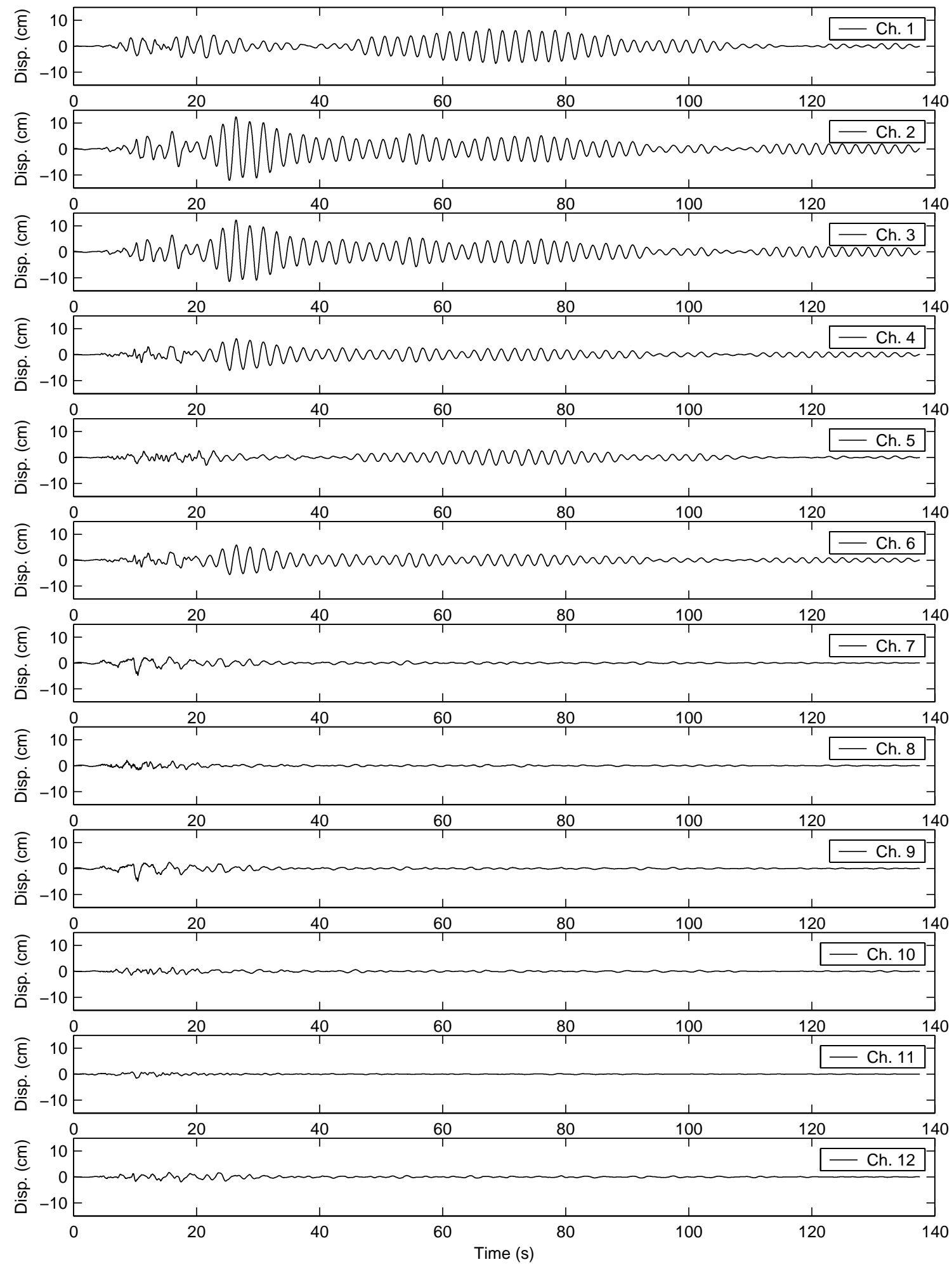

Figure B - 30. 1994 Northridge earthquake, displacement 


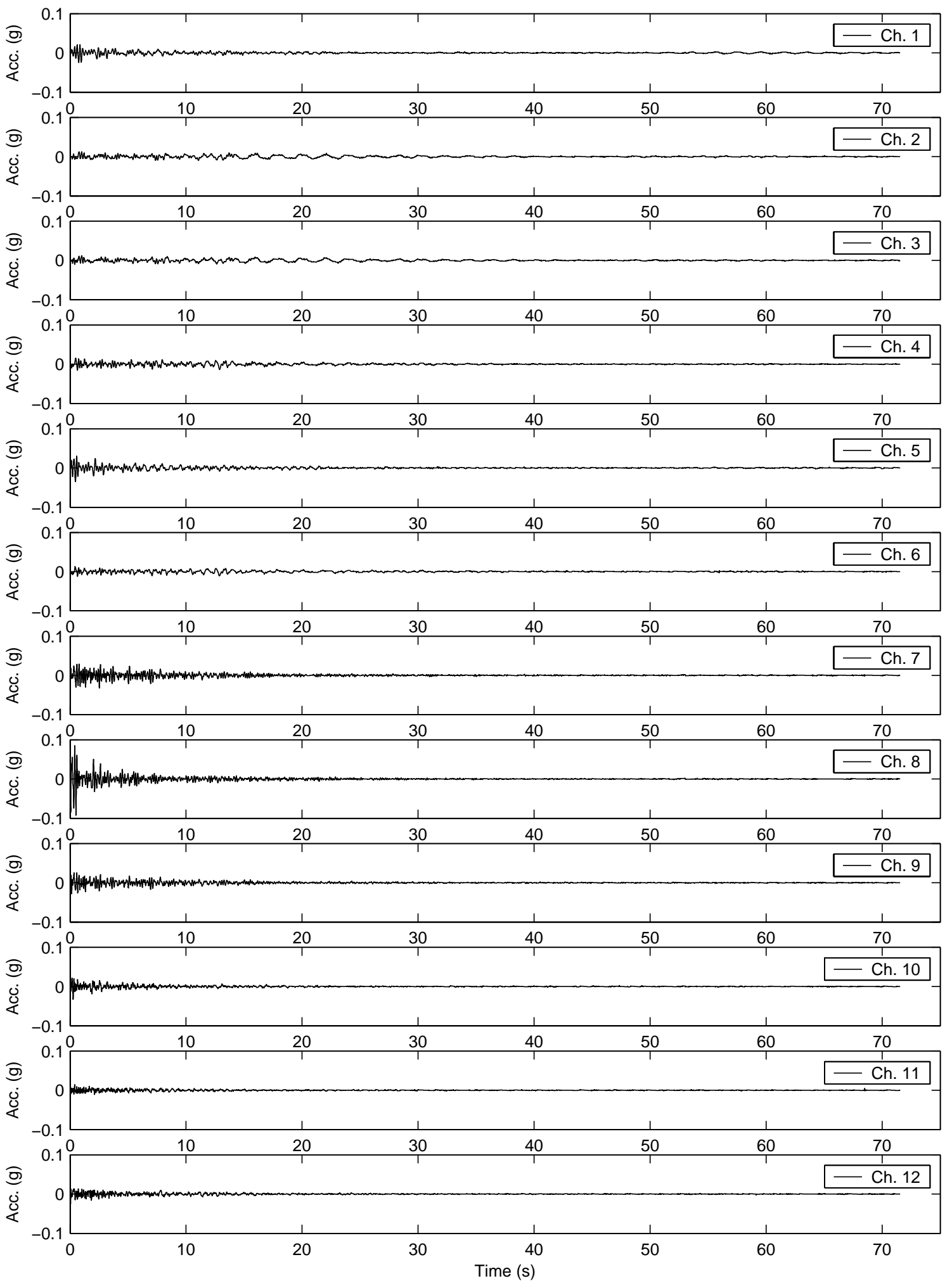

Figure B - 31. Northridge aftershock, 3/20/1994, acceleration 


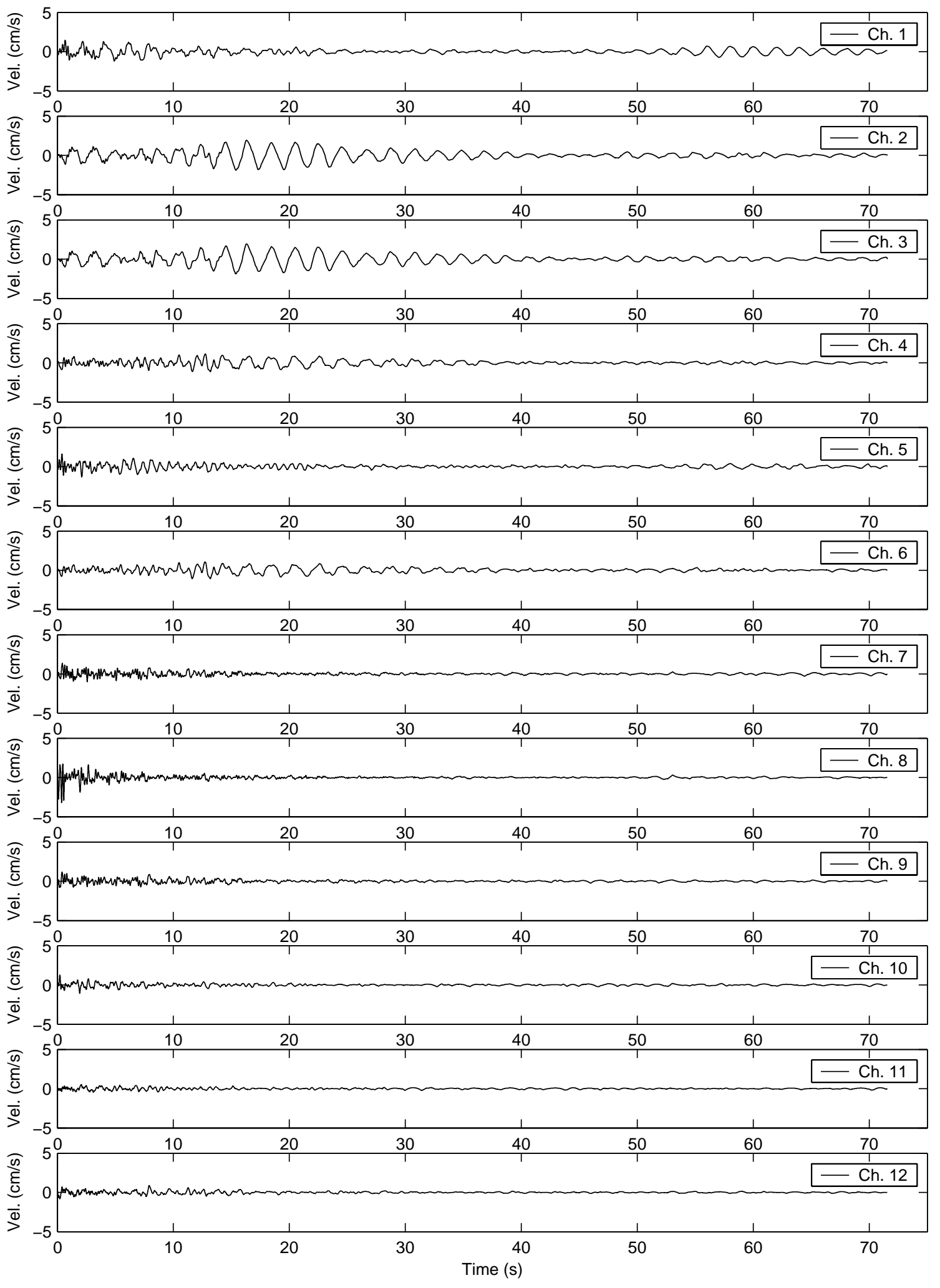

Figure B - 32. Northridge aftershock, 3/20/1994, velocity 


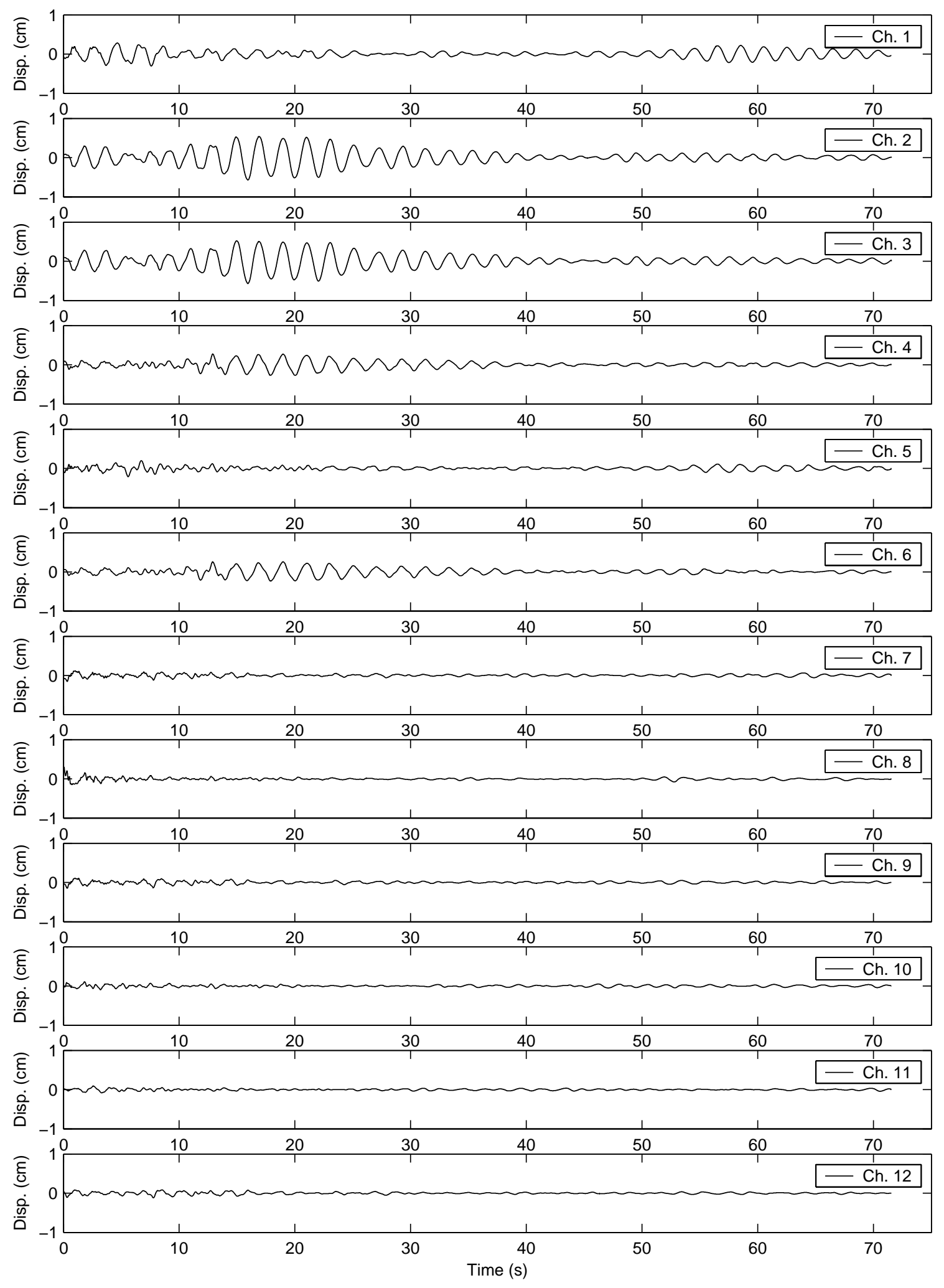

Figure B - 33. Northridge aftershock, 3/20/1994, displacement 

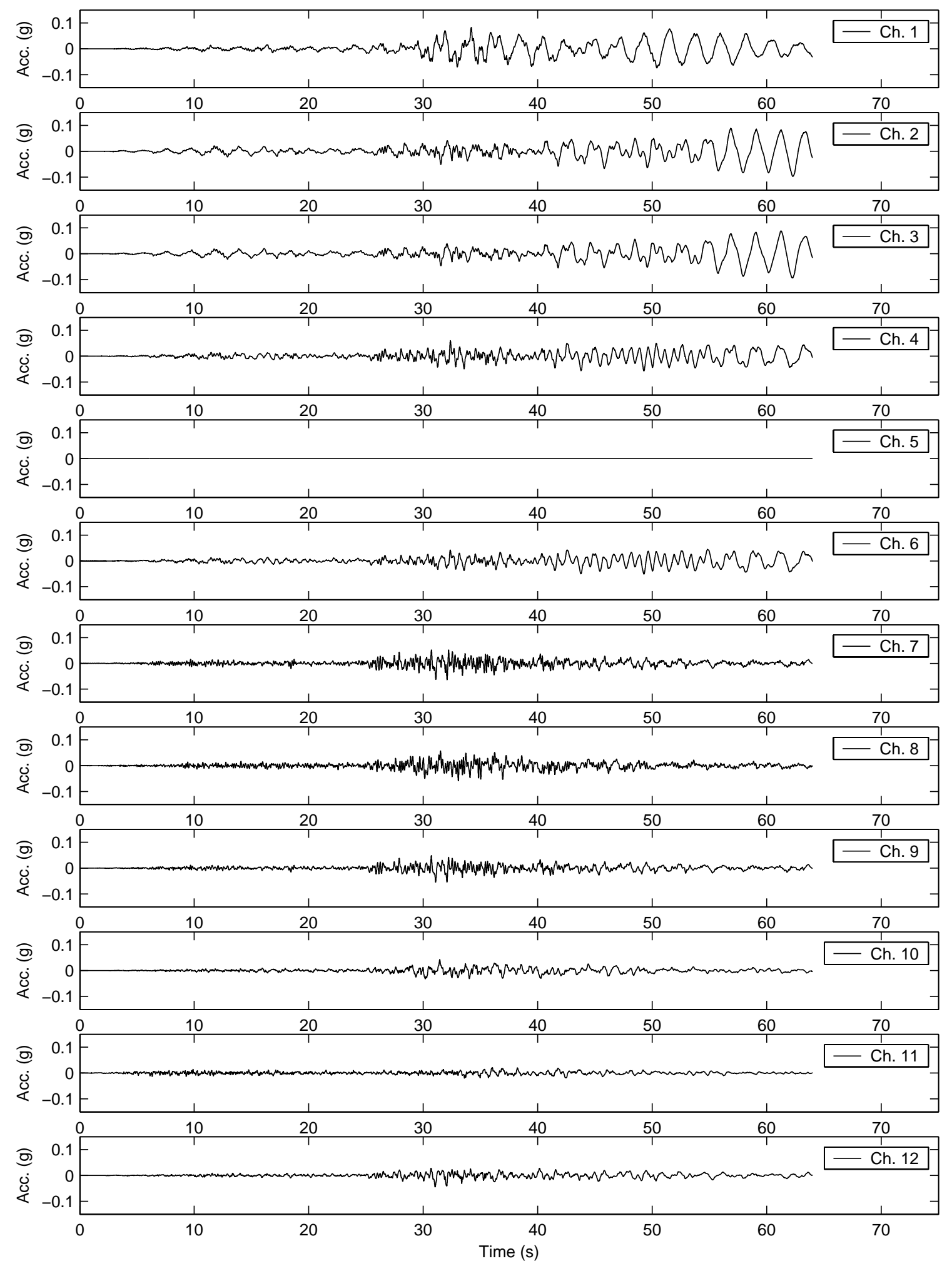

Figure B - 34. 1999 Hector Mine earthquake, acceleration 


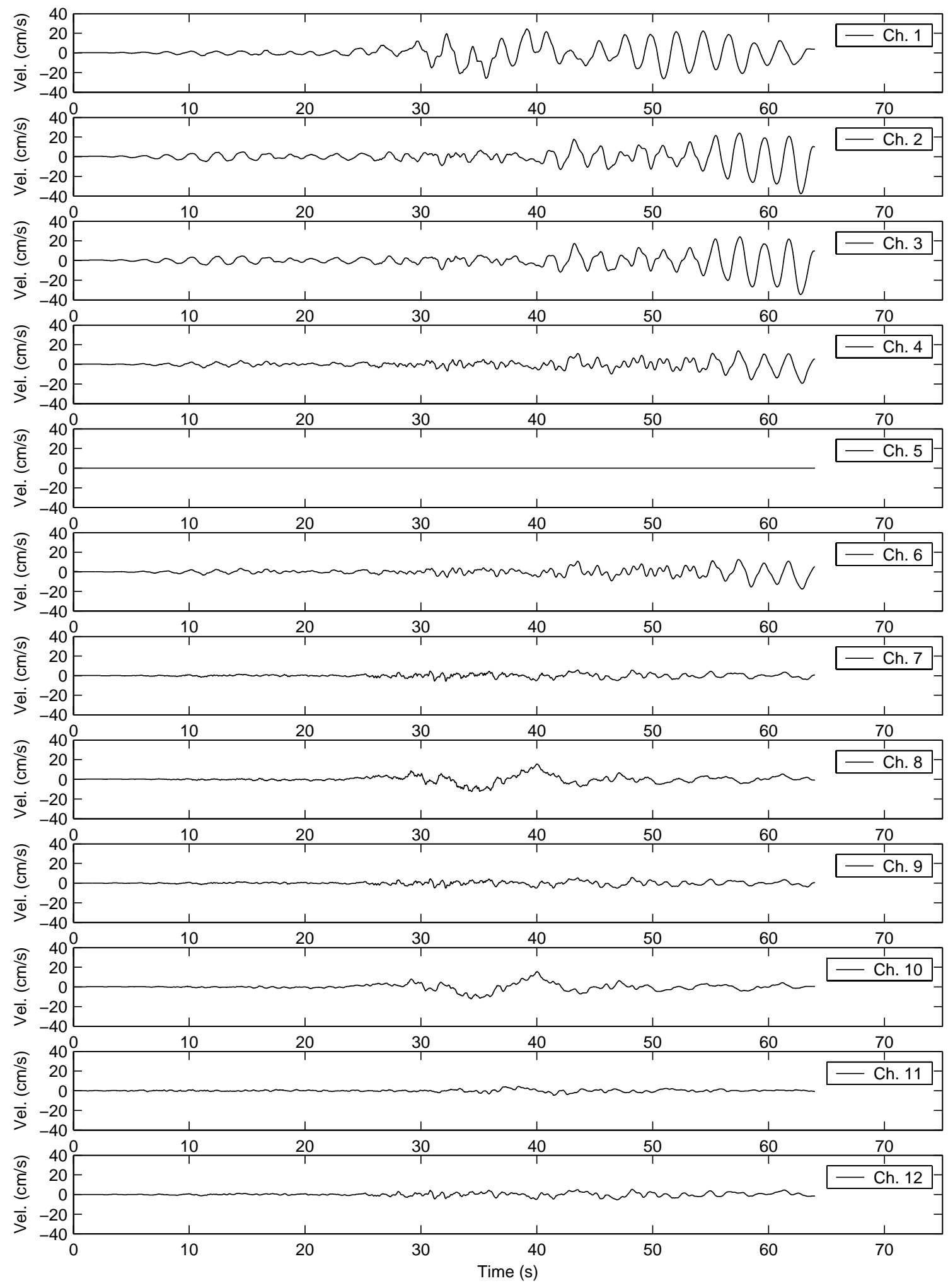

Figure B - 35. 1999 Hector Mine earthquake, velocity 


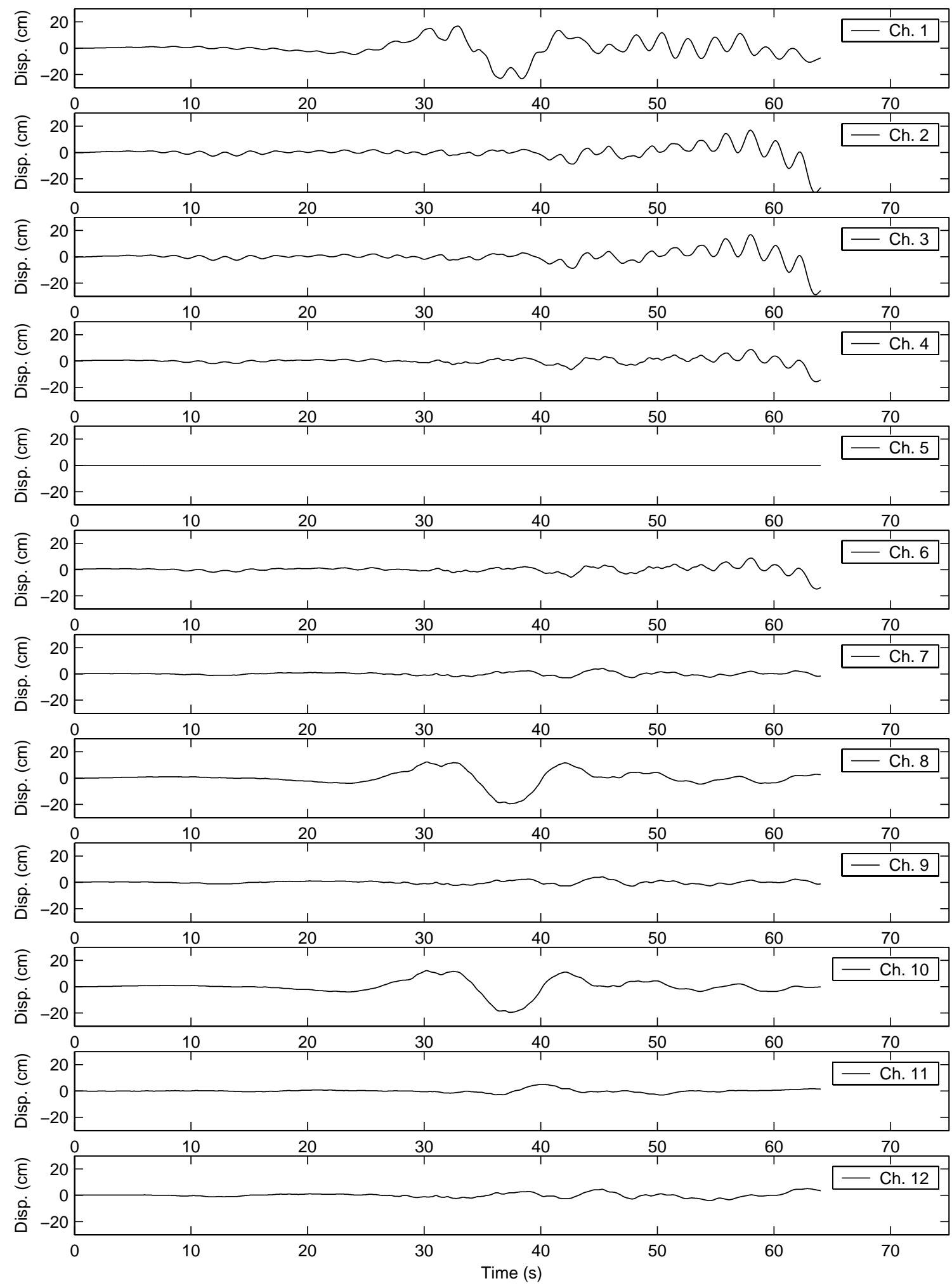

Figure B - 36. 1999 Hector Mine earthquake, displacement 


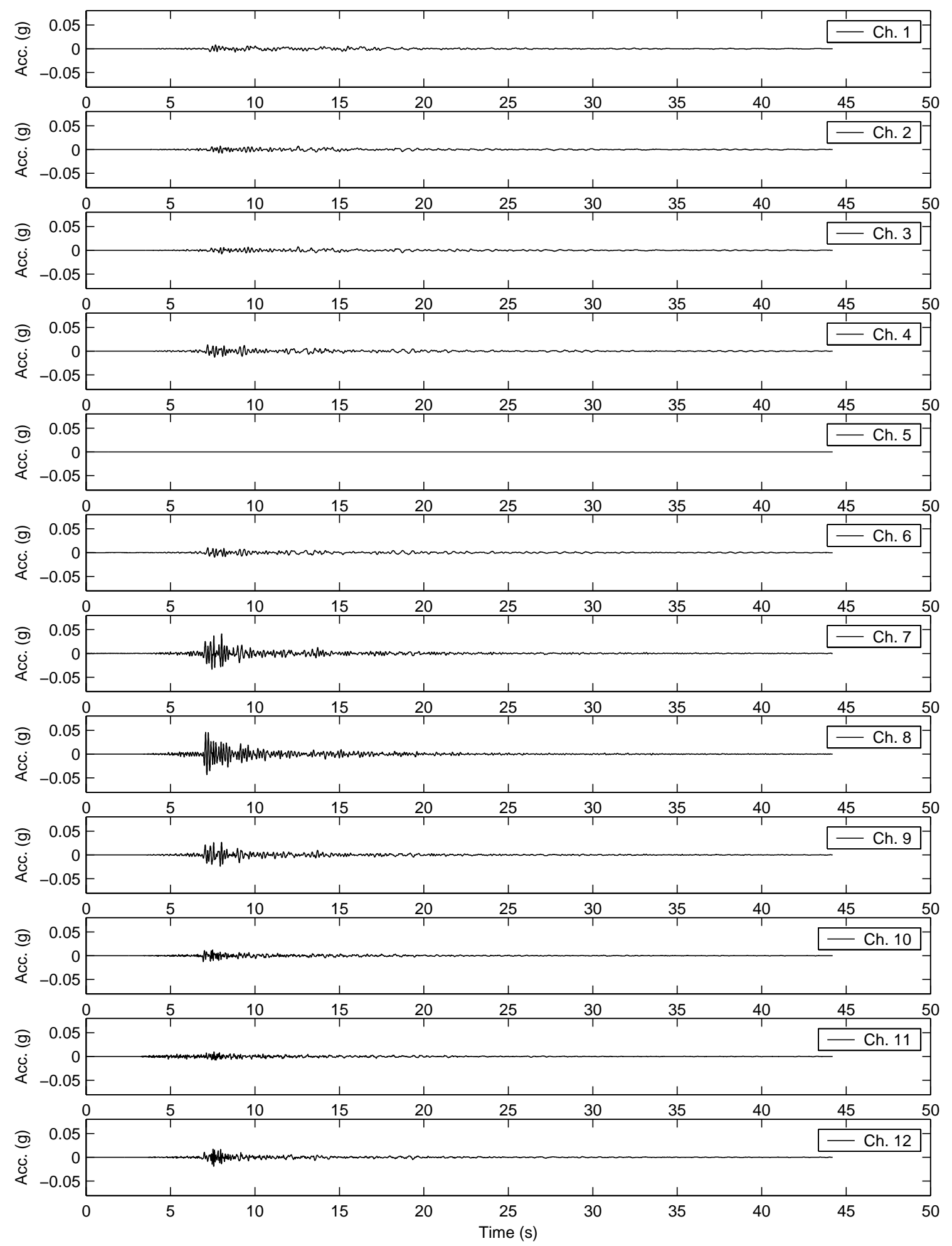

Figure B - 37. 2001 West Hollywood earthquake, acceleration 


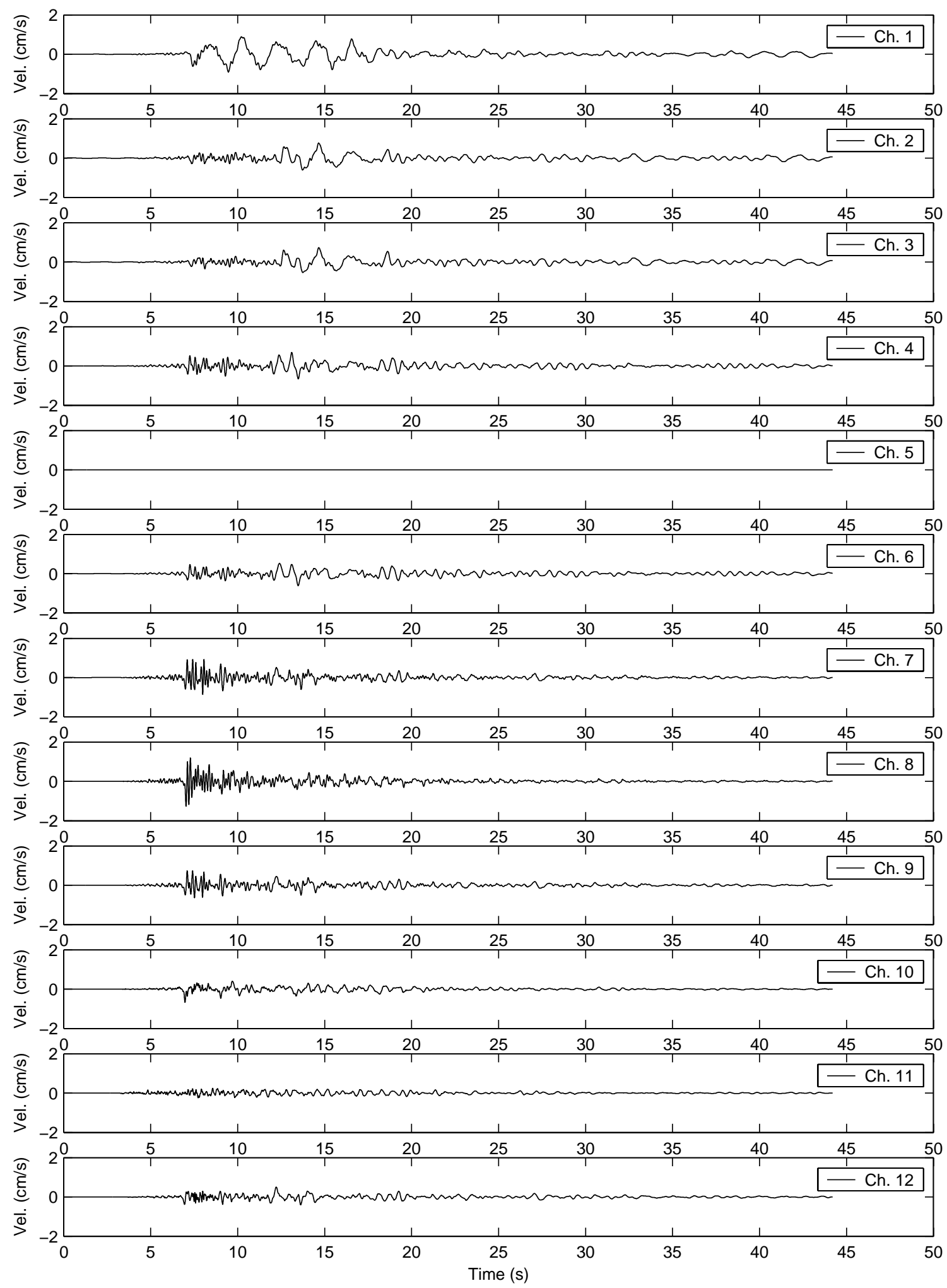

Figure B - 38. 2001 West Hollywood earthquake, velocity 


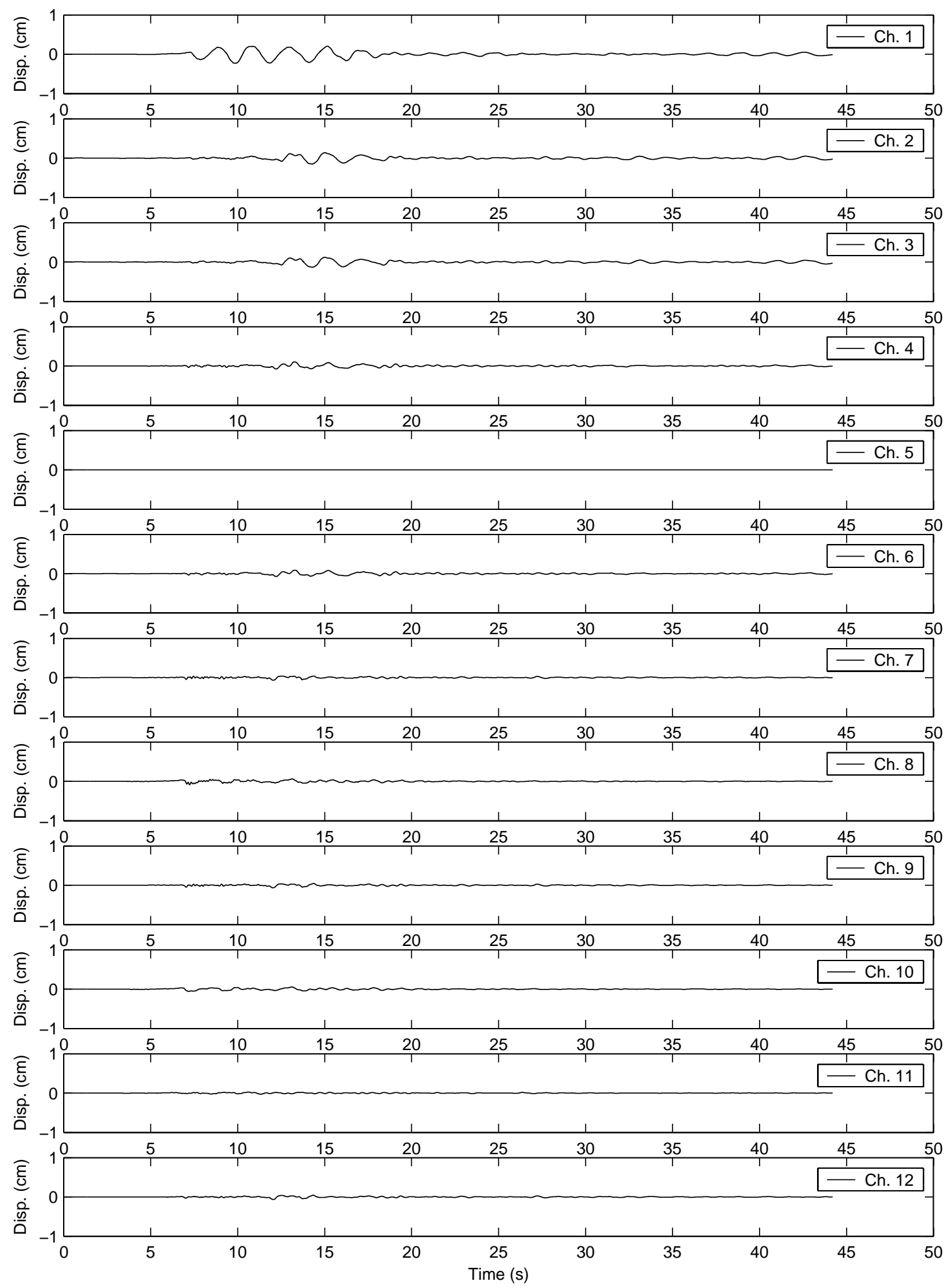

Figure B - 39. 2001 West Hollywood earthquake, displacement 


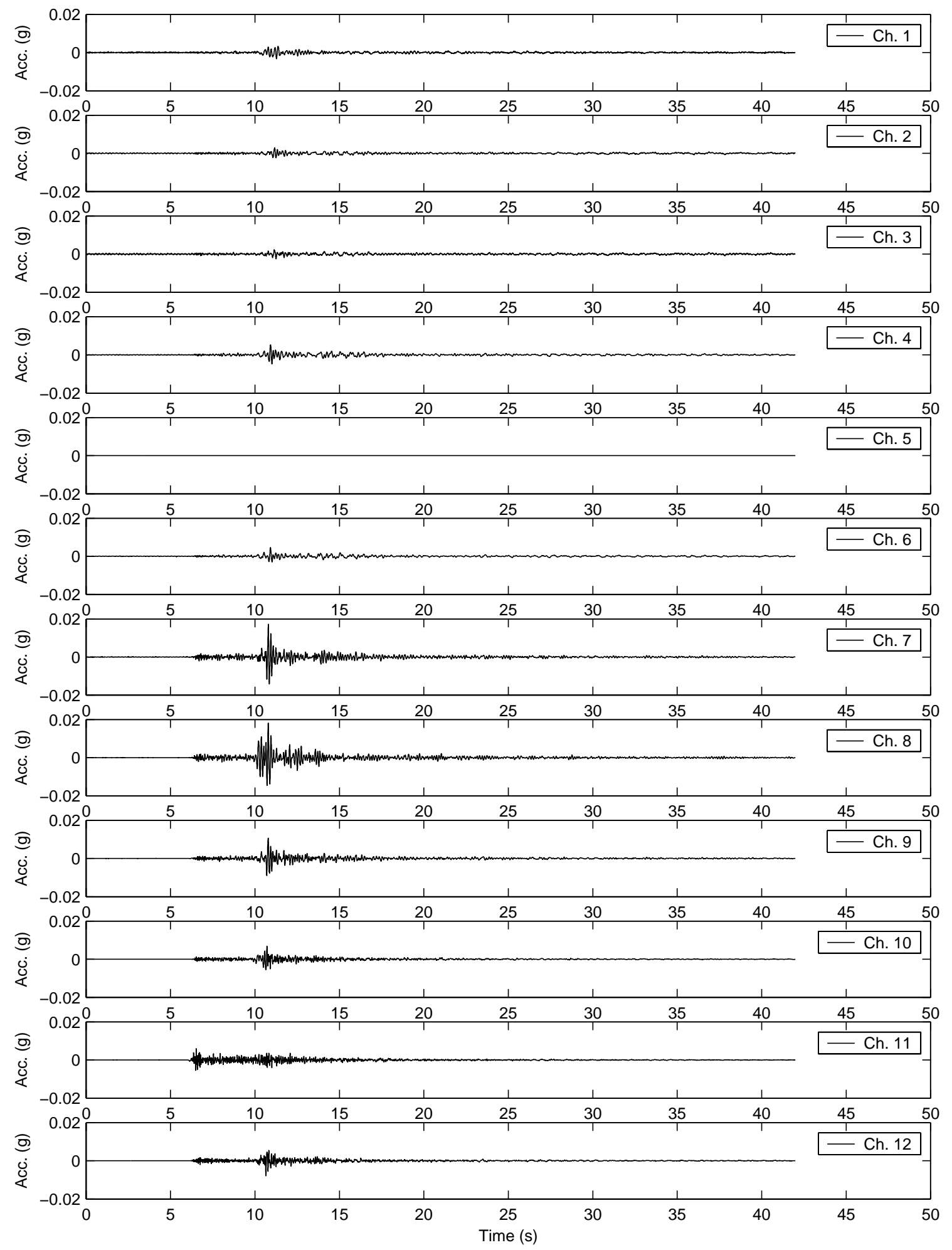

Figure B - 40. 2001 Compton earthquake, acceleration 


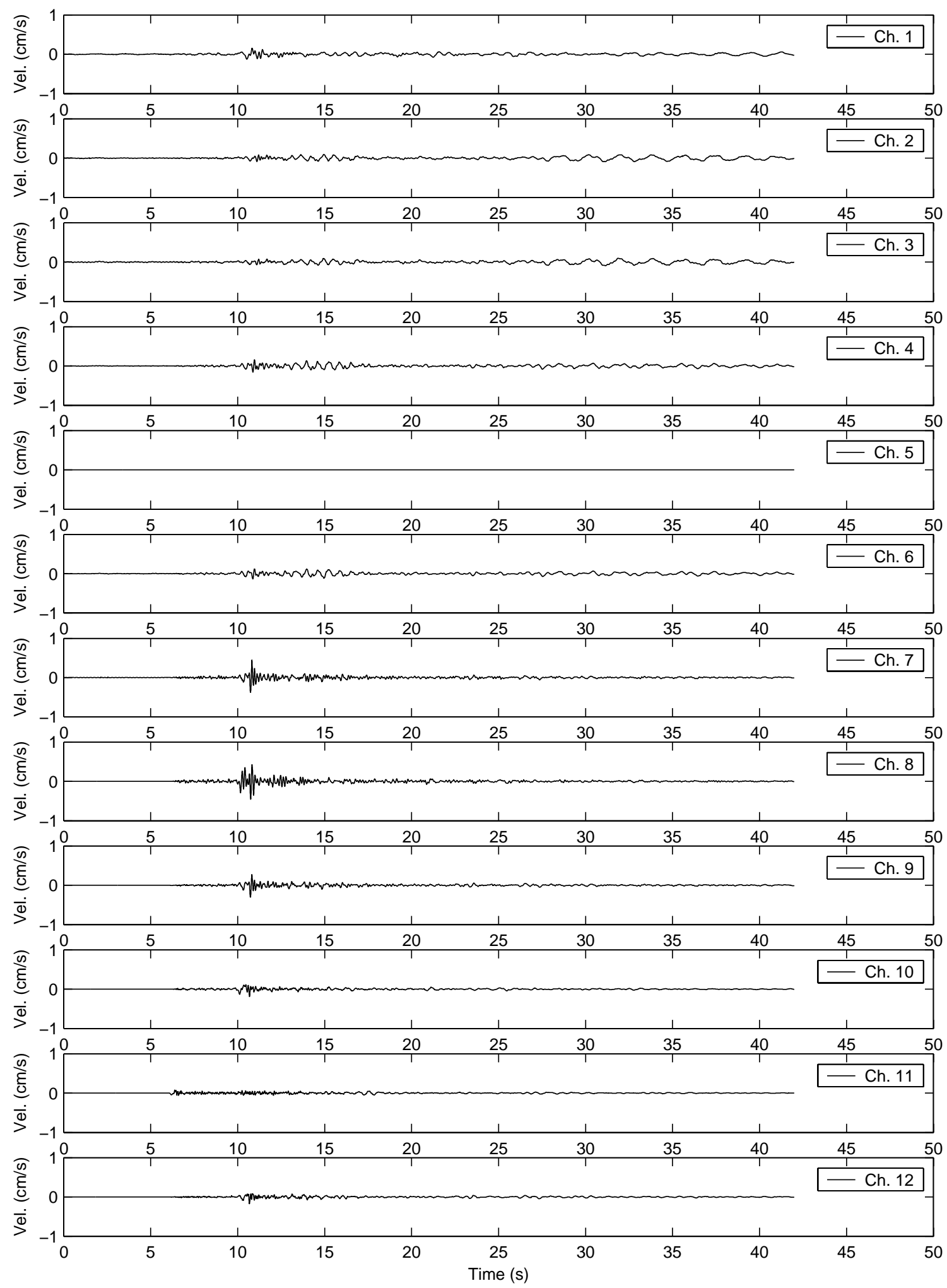

Figure B - 41. 2001 Compton earthquake, velocity 


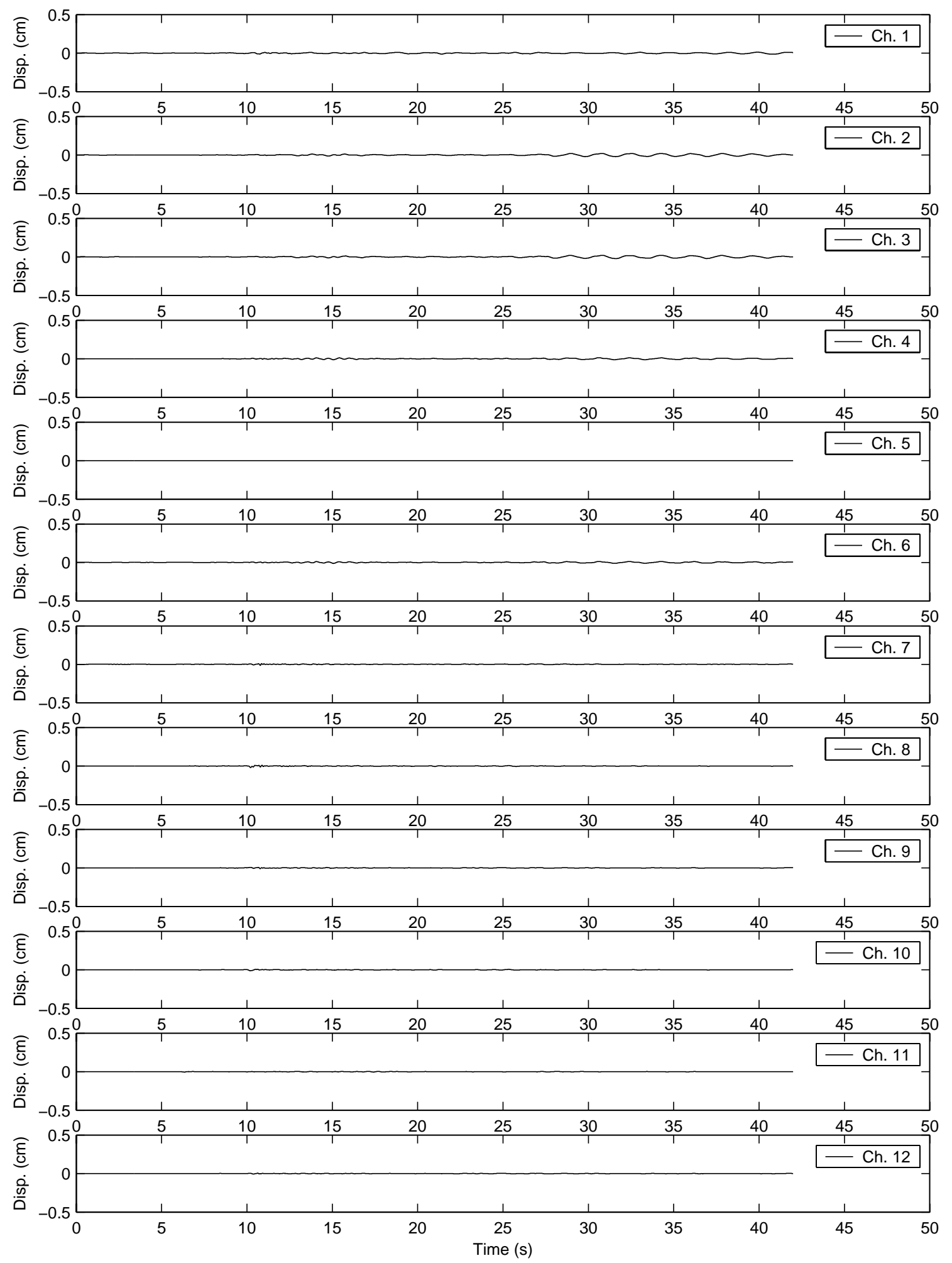

Figure B - 42. 2001 Compton earthquake, displacement 


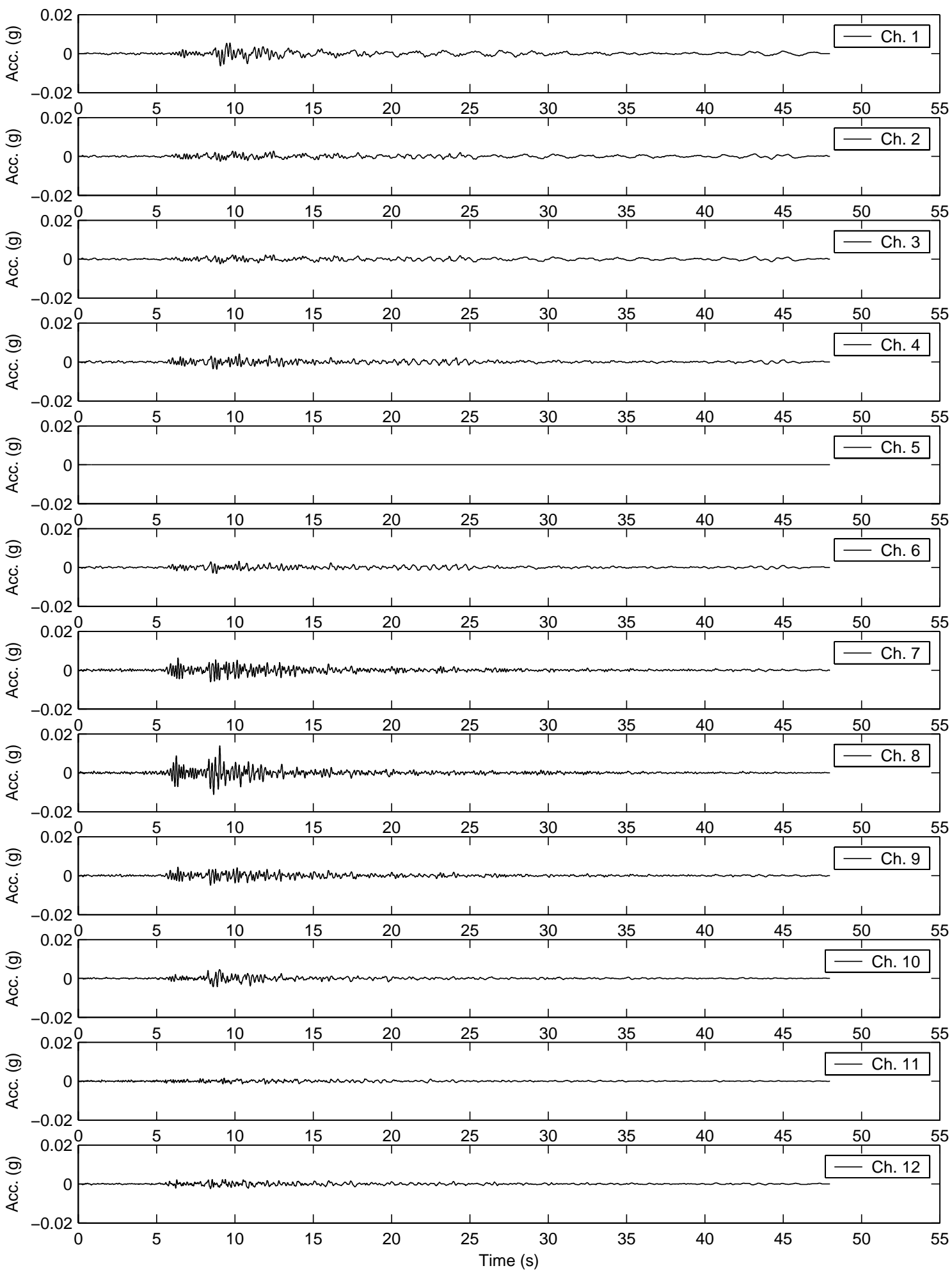

Figure B - 43. 2003 Big Bear City earthquake, acceleration 


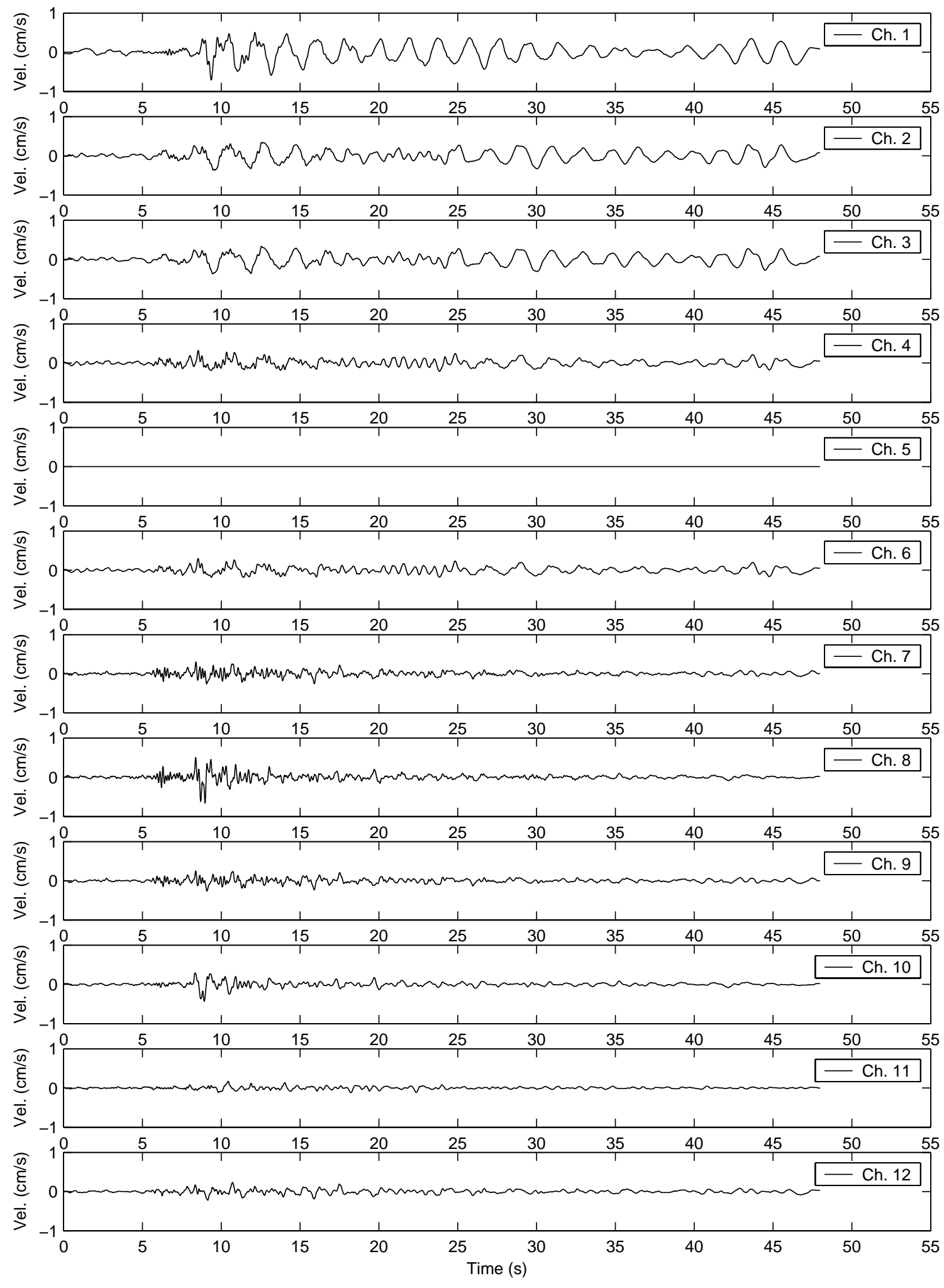

Figure B - 44. 2003 Big Bear City earthquake, velocity 


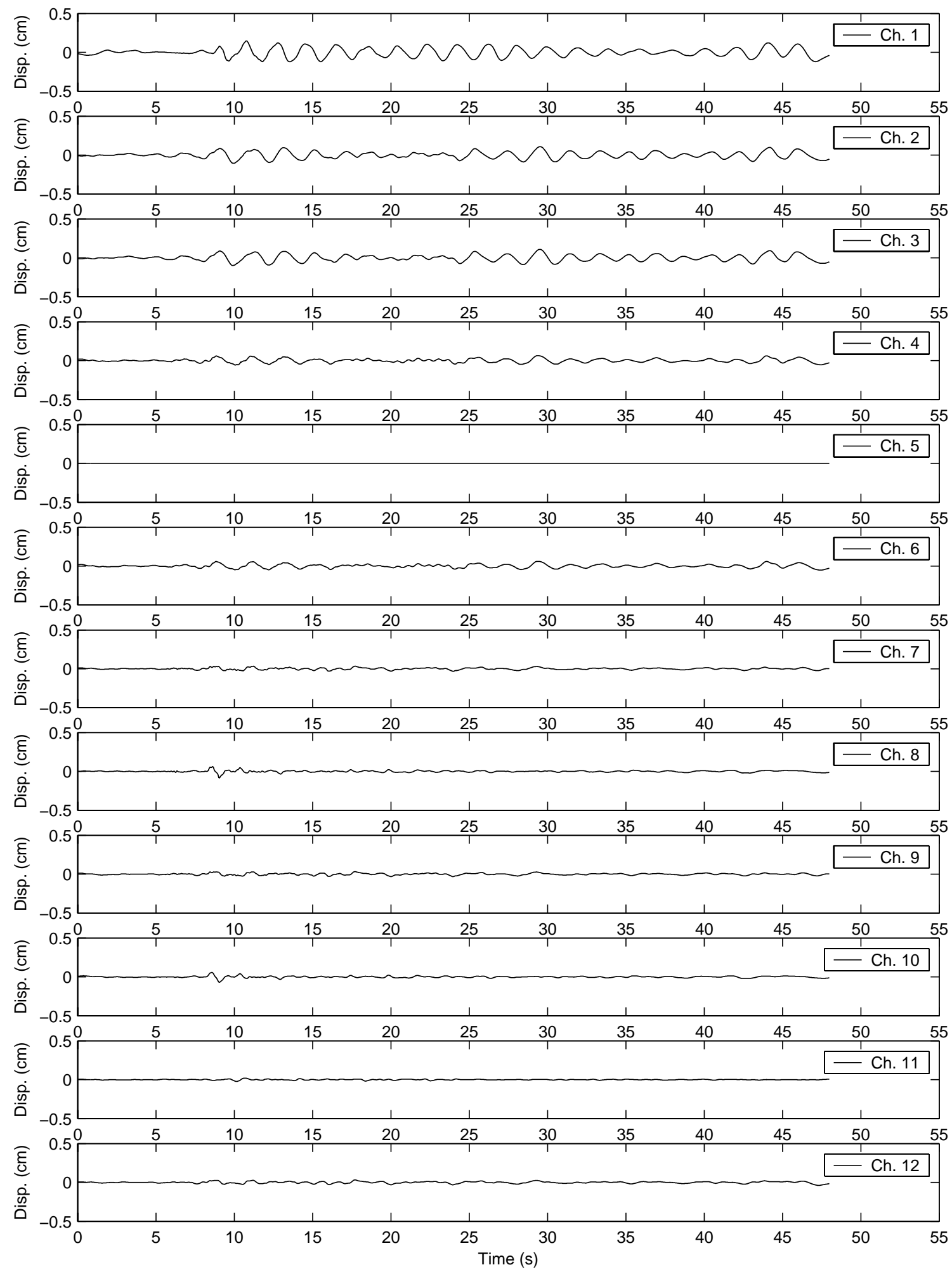

Figure B - 45. 2003 Big Bear City earthquake, displacement 


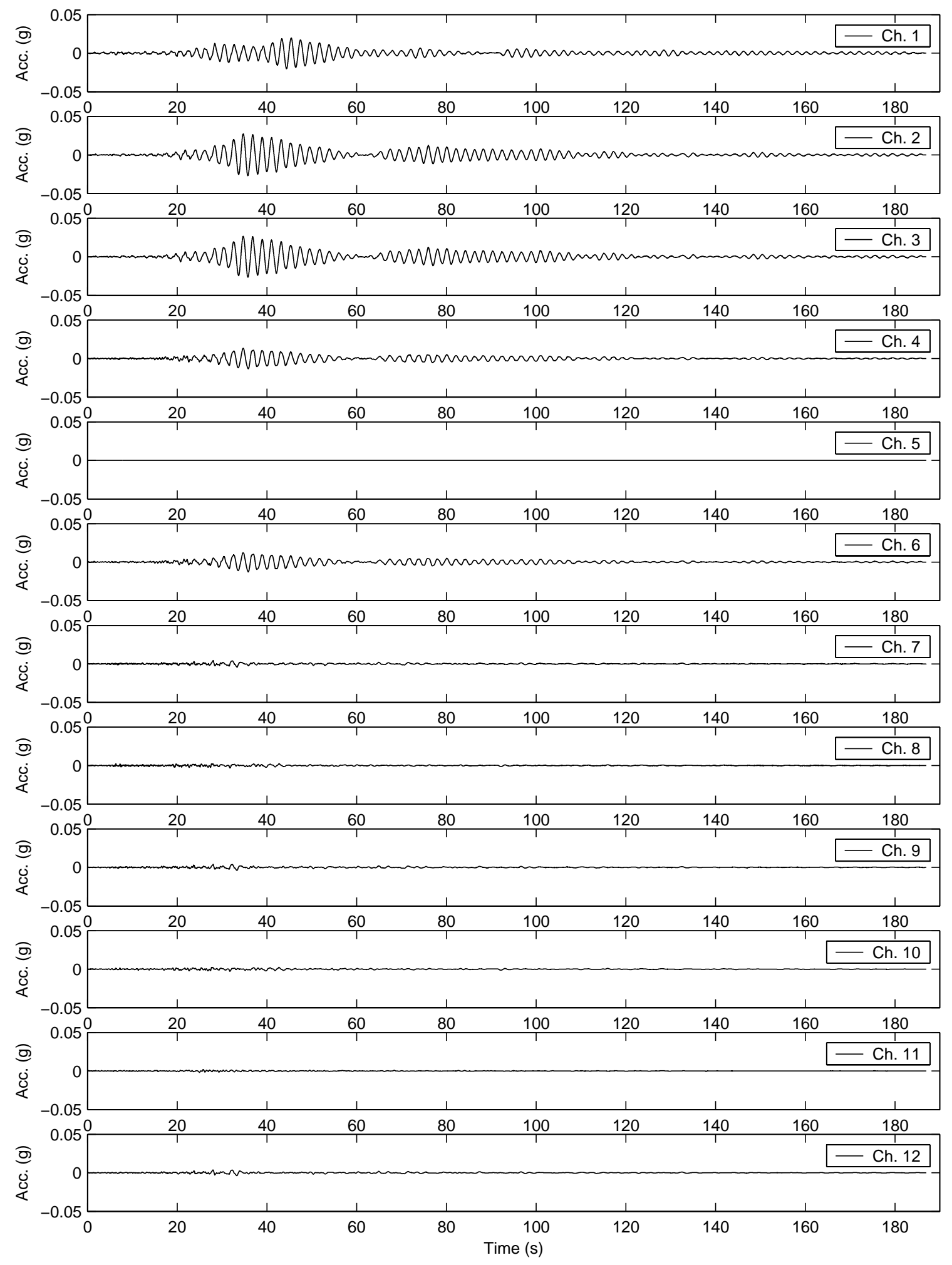

Figure B - 46. 2003 San Simeon earthquake, acceleration 


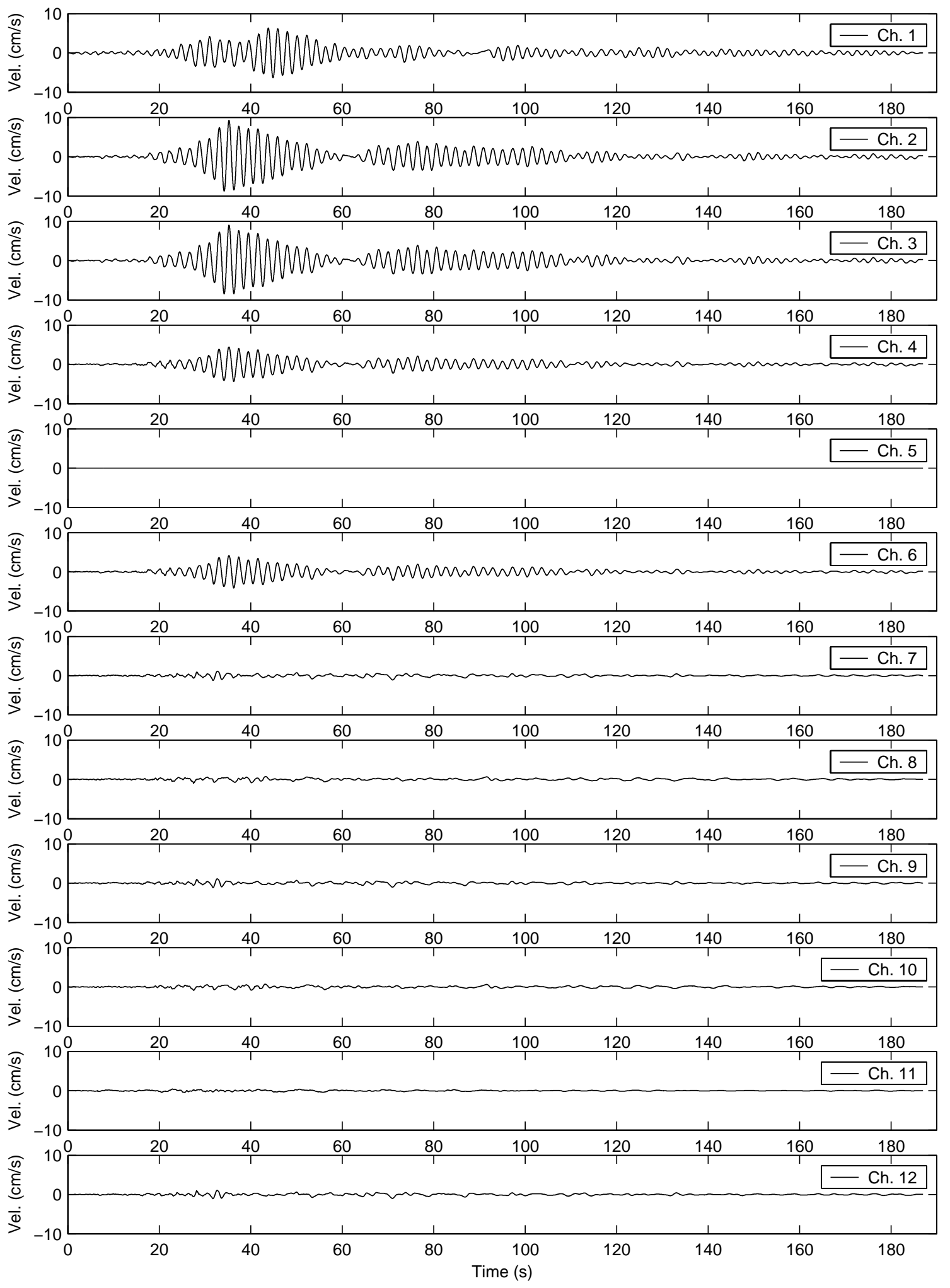

Figure B - 47. 2003 San Simeon earthquake, velocity 


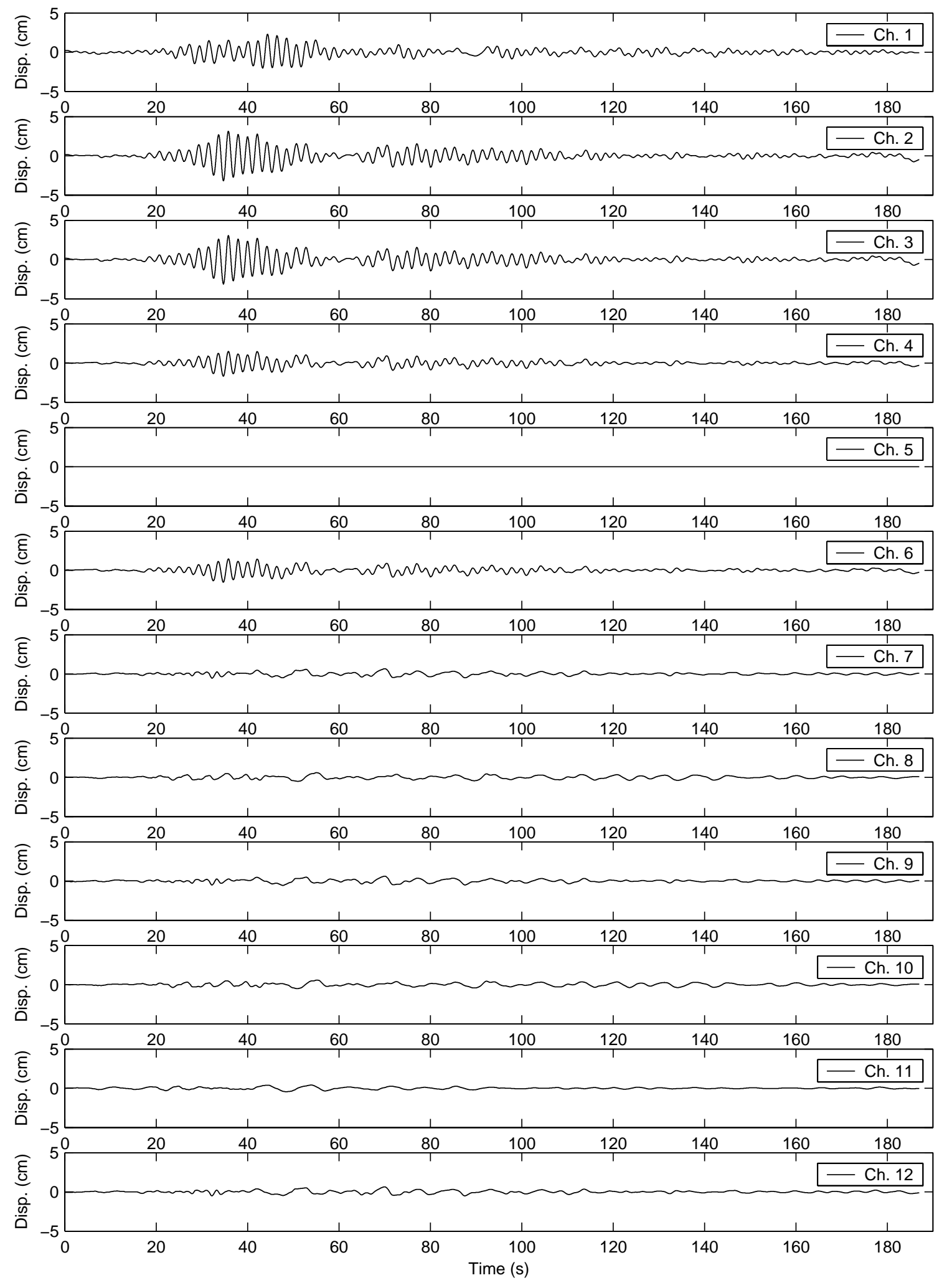

Figure B - 48. 2003 San Simeon earthquake, displacement 


\section{Appendix C - Fourier Amplitude Spectra}



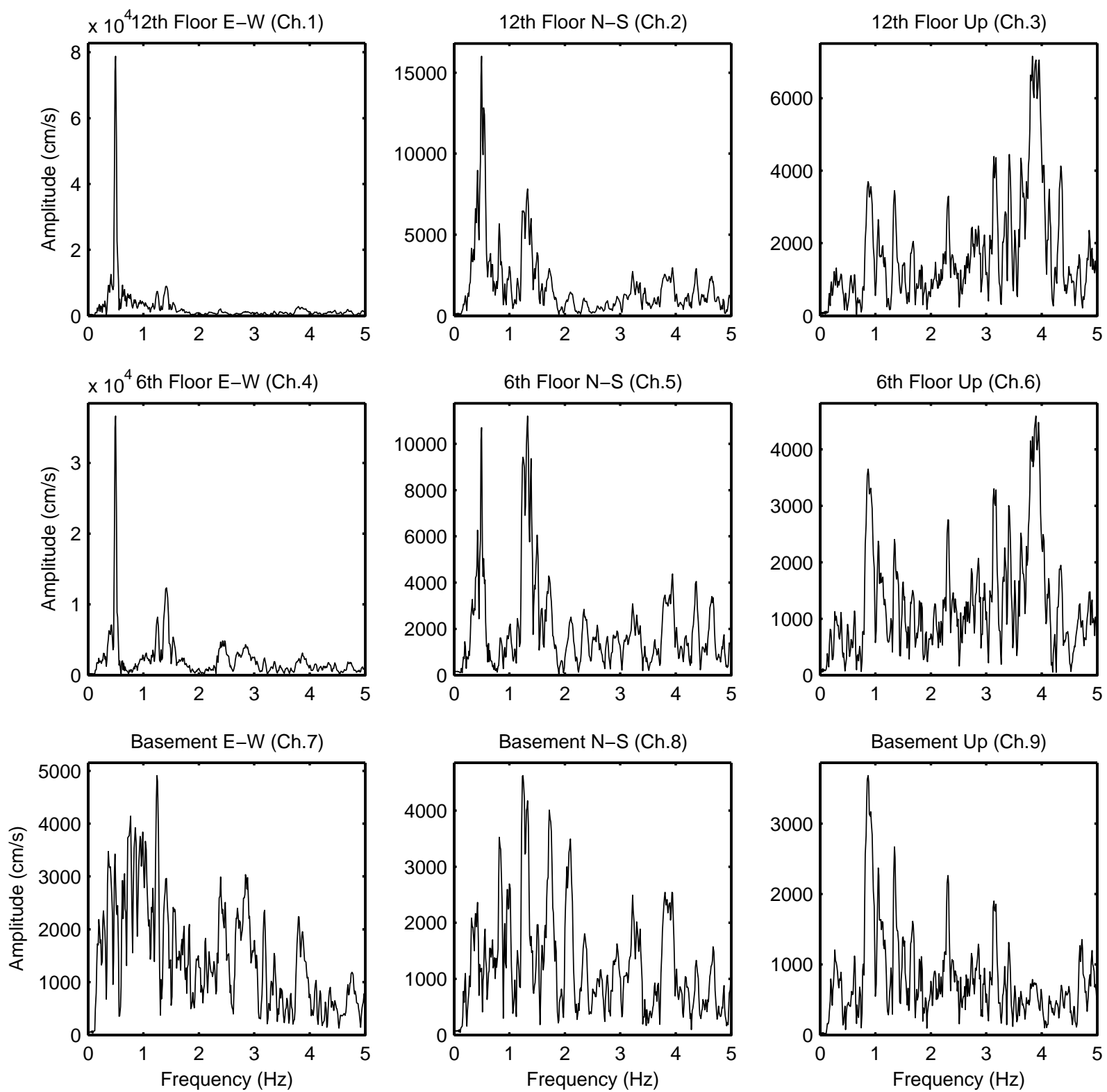

Figure C - 1. 1971 San Fernando earthquake 

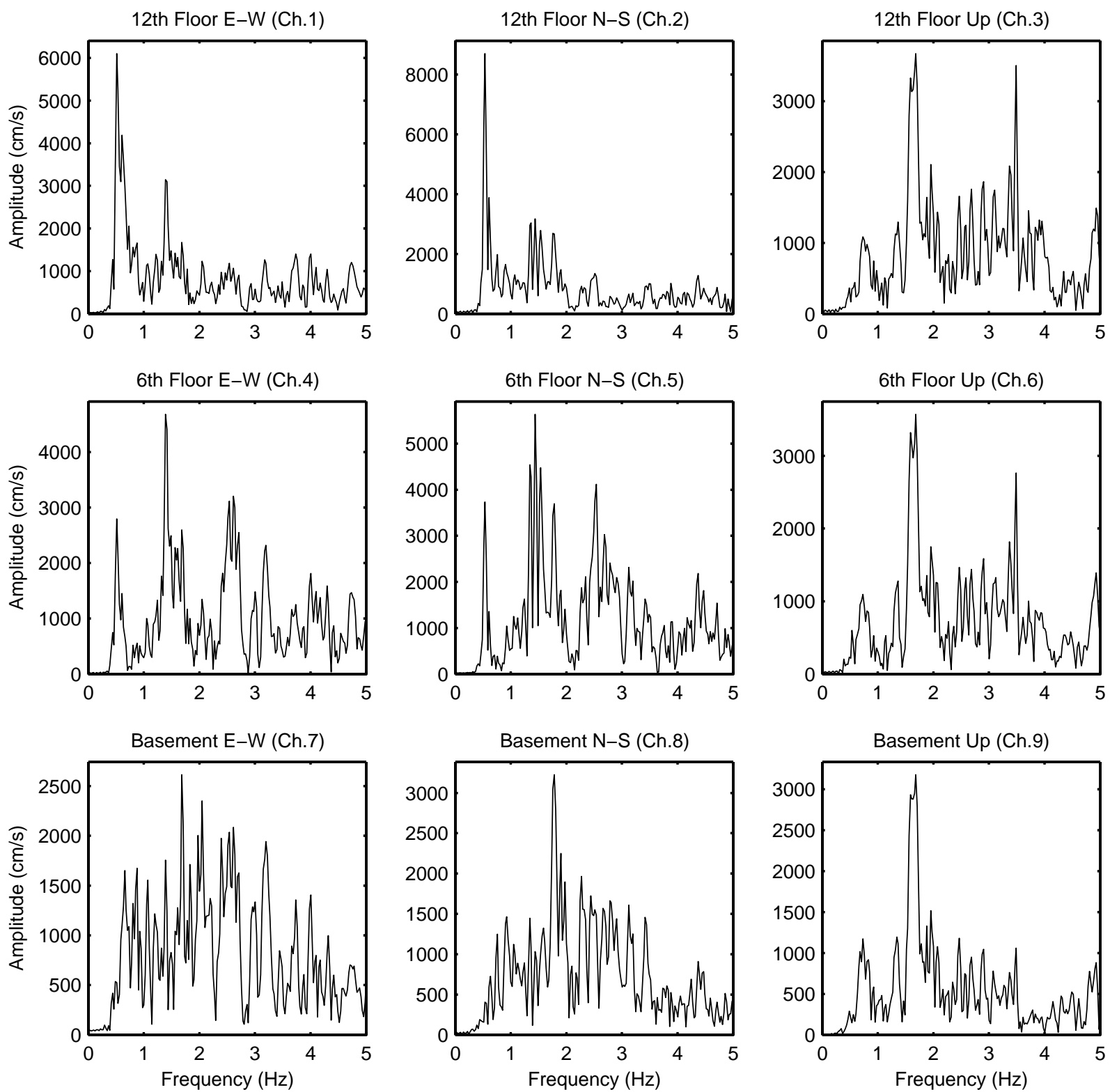

Figure C - 2. 1973 Point Mugu earthquake 

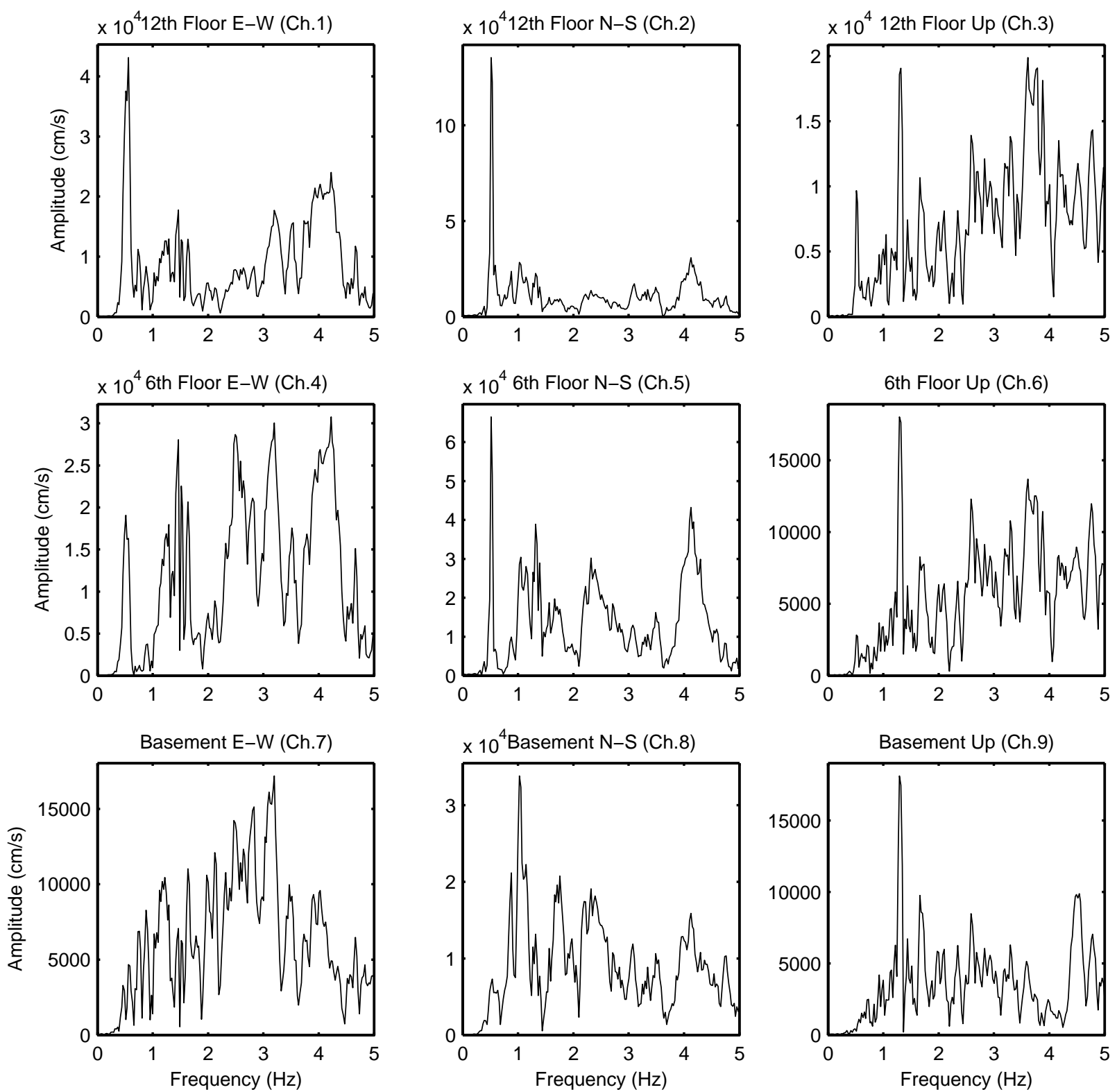

Figure C - 3. 1987 Whittier Narrows earthquake 

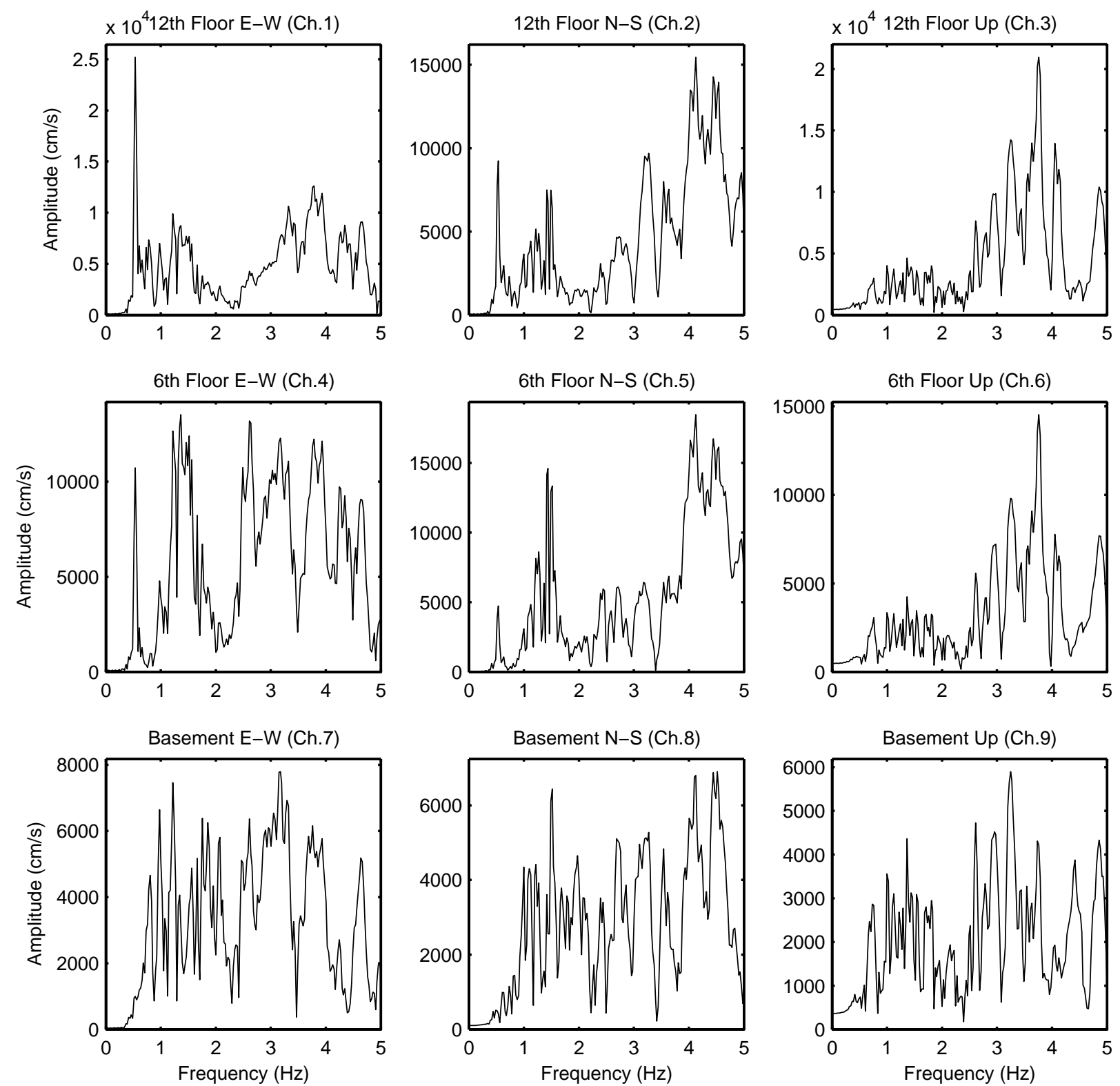

Figure C - 4. Whittier Narrows Aftershock 1, 10/4/1987 

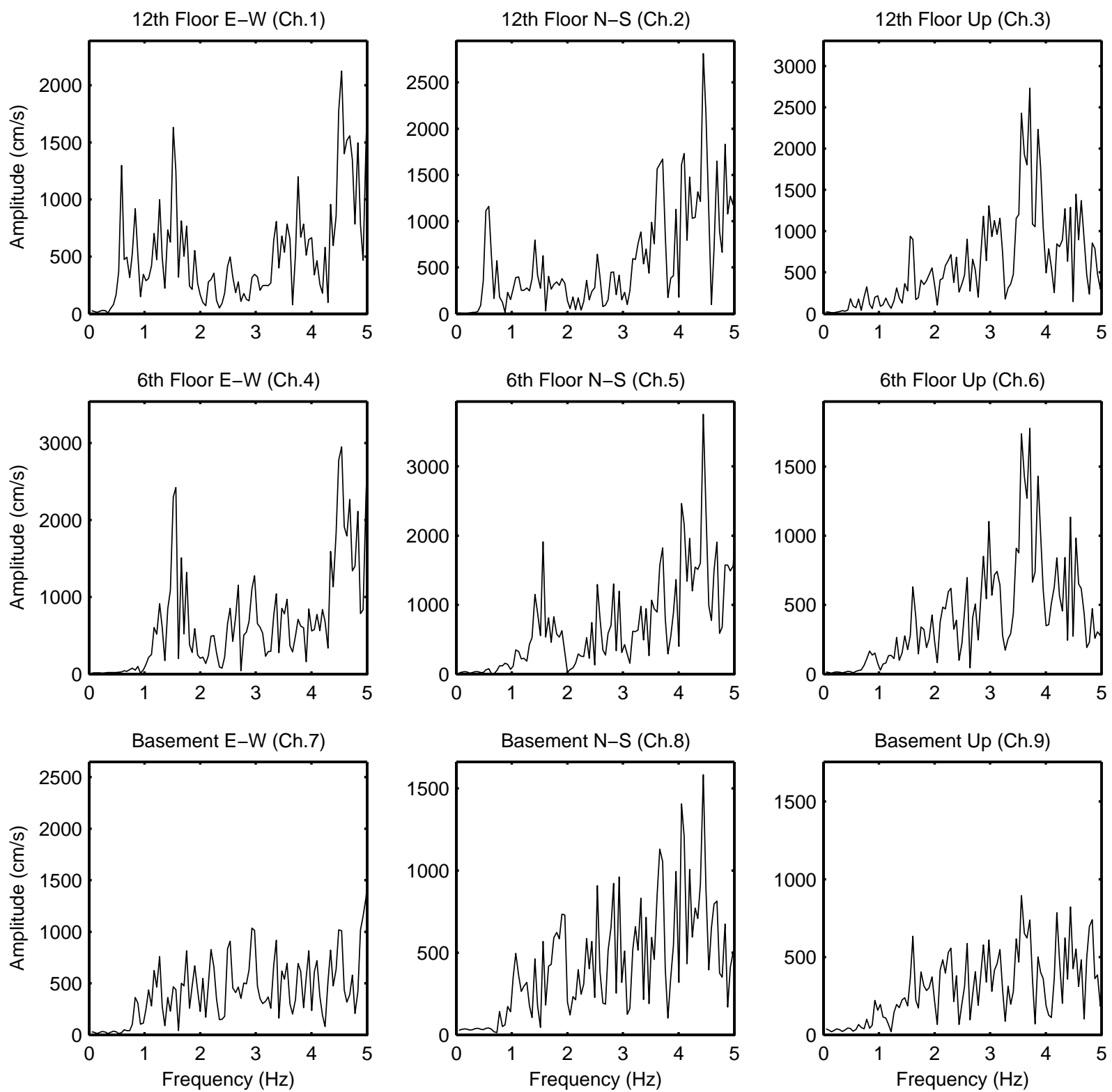

Figure C - 5. Whittier Narrows Aftershock 2, 2/11/1988 

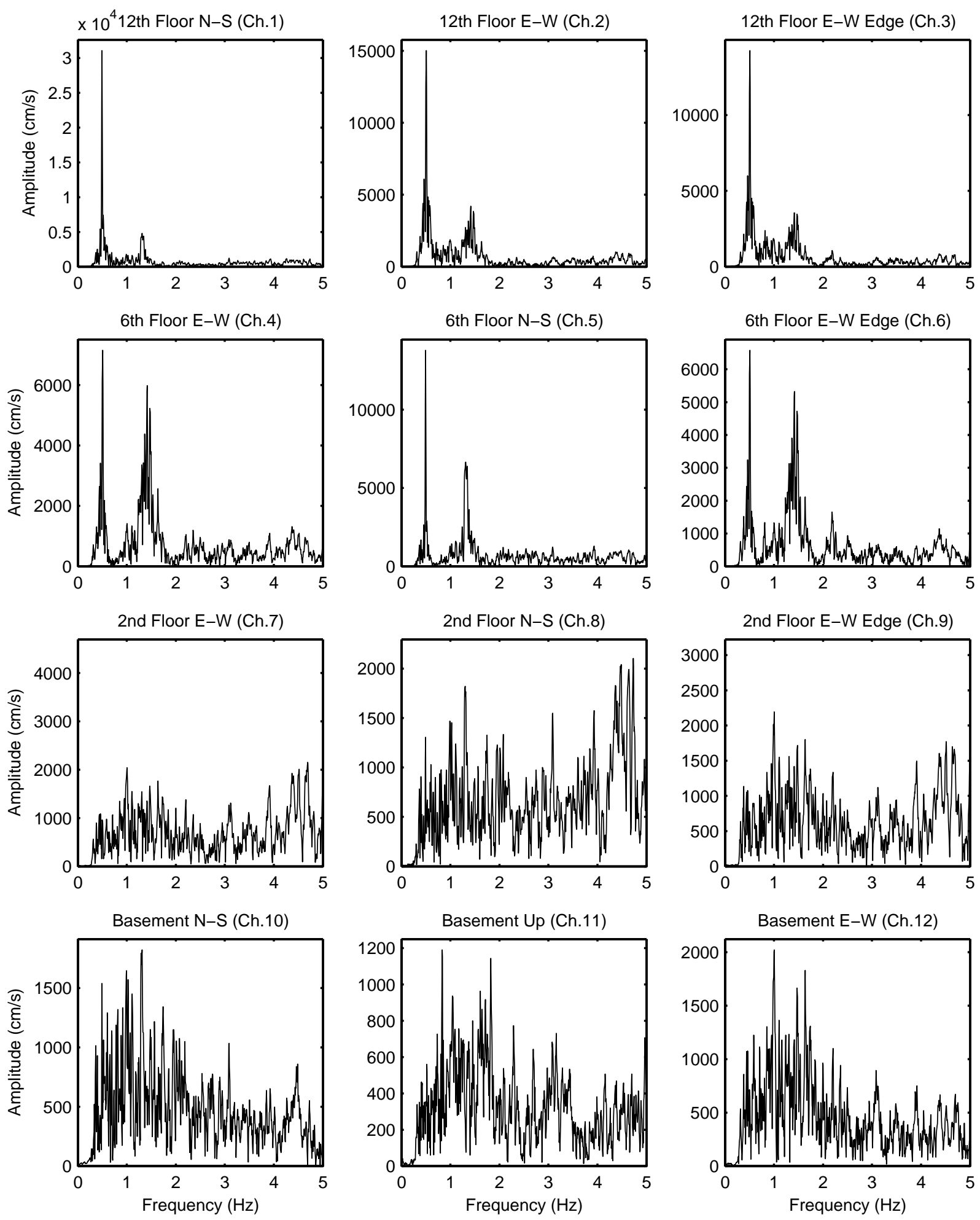

Figure C - 6. 1990 Upland earthquake 

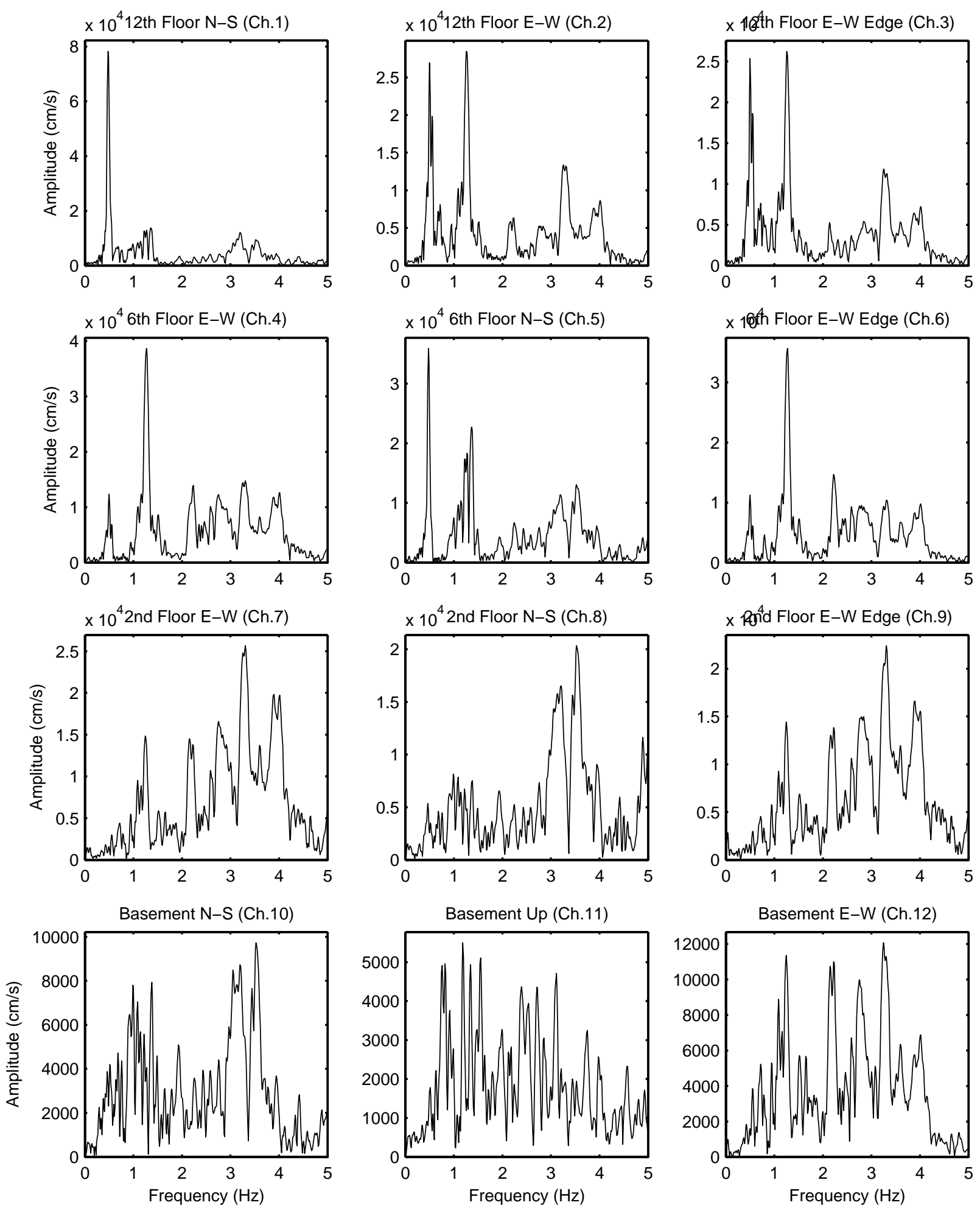

Figure C - 7. 1991 Sierra Madre earthquake 

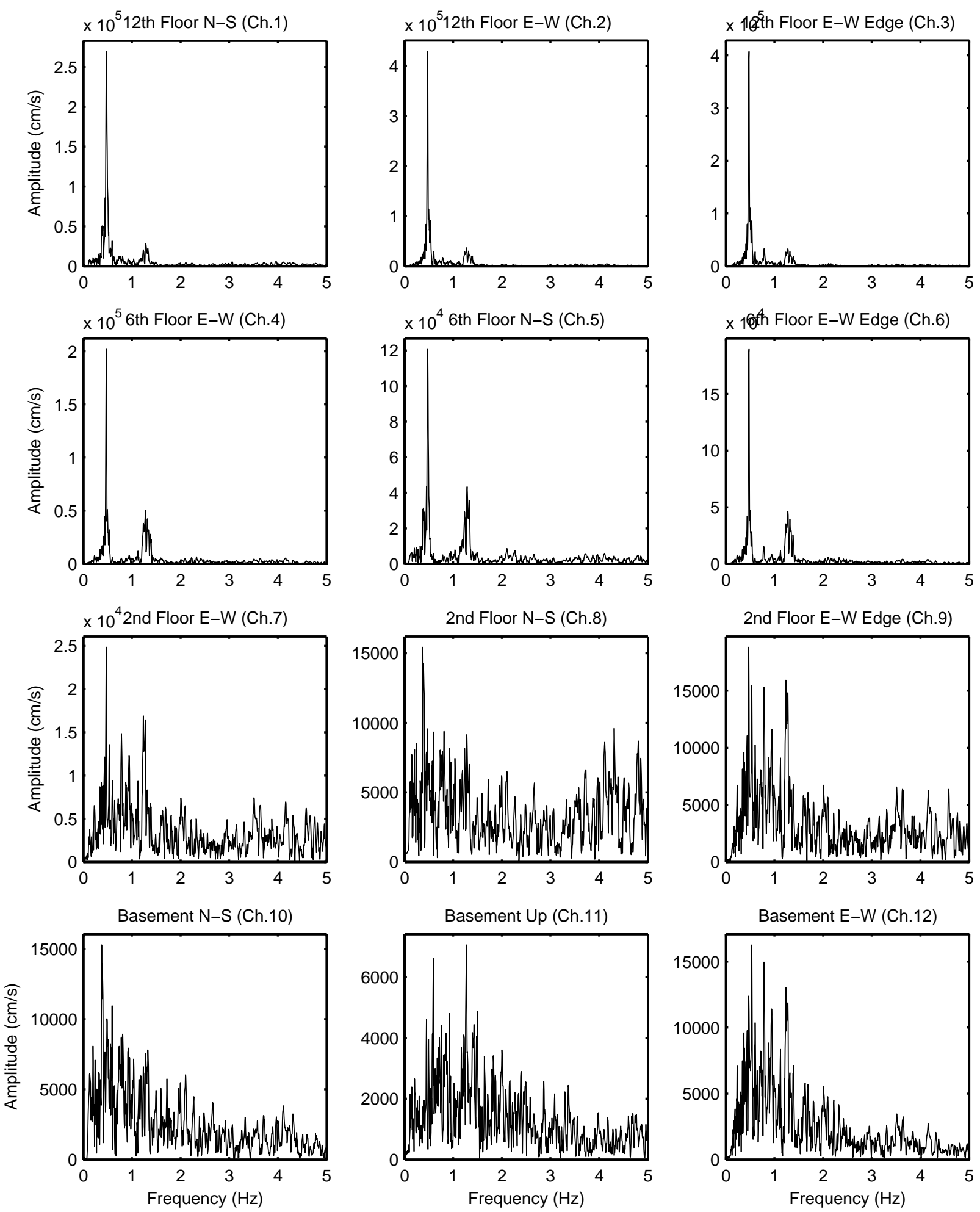

Figure C - 8. 1992 Landers earthquake 

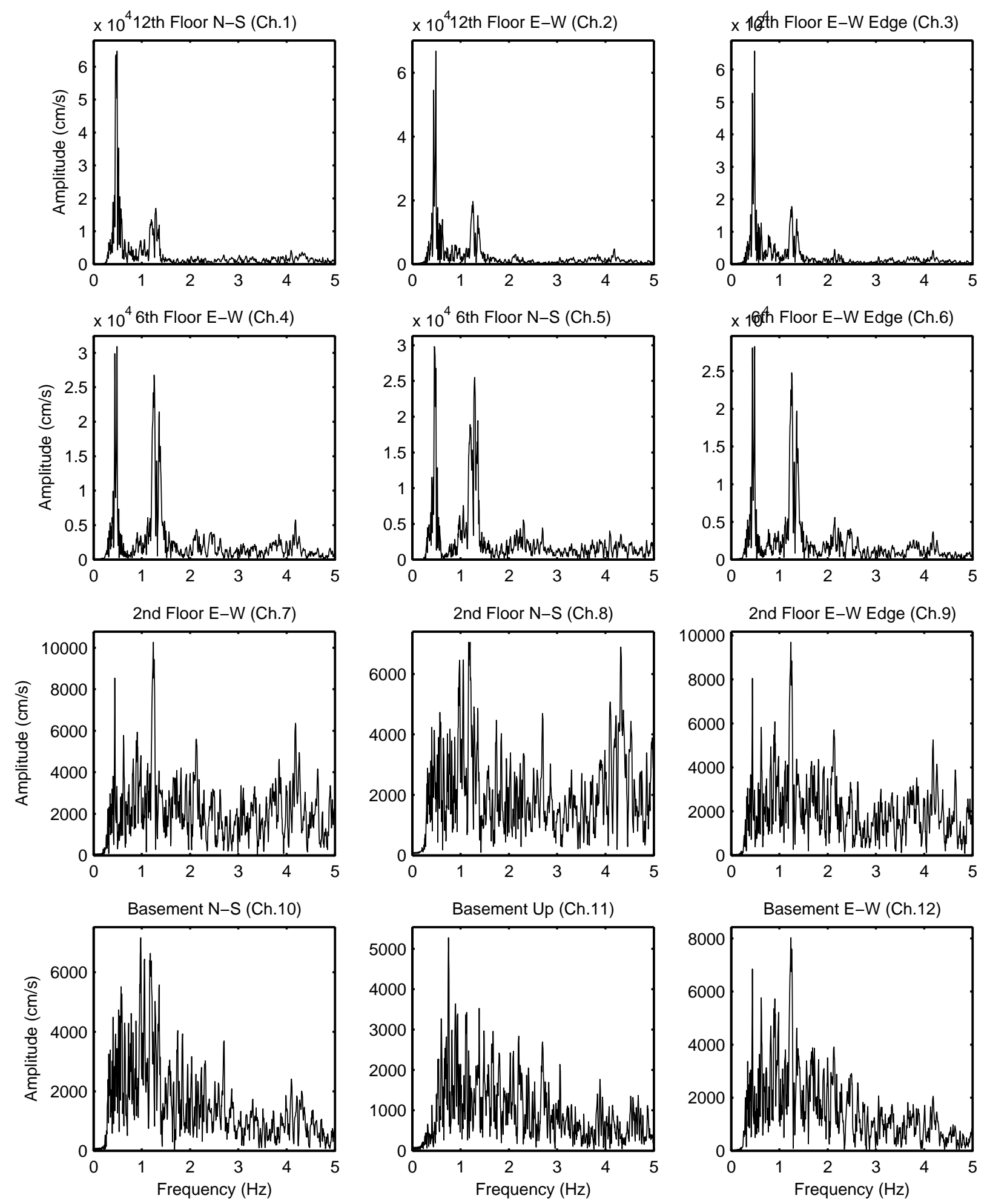

Figure C - 9. 1992 Big Bear earthquake 

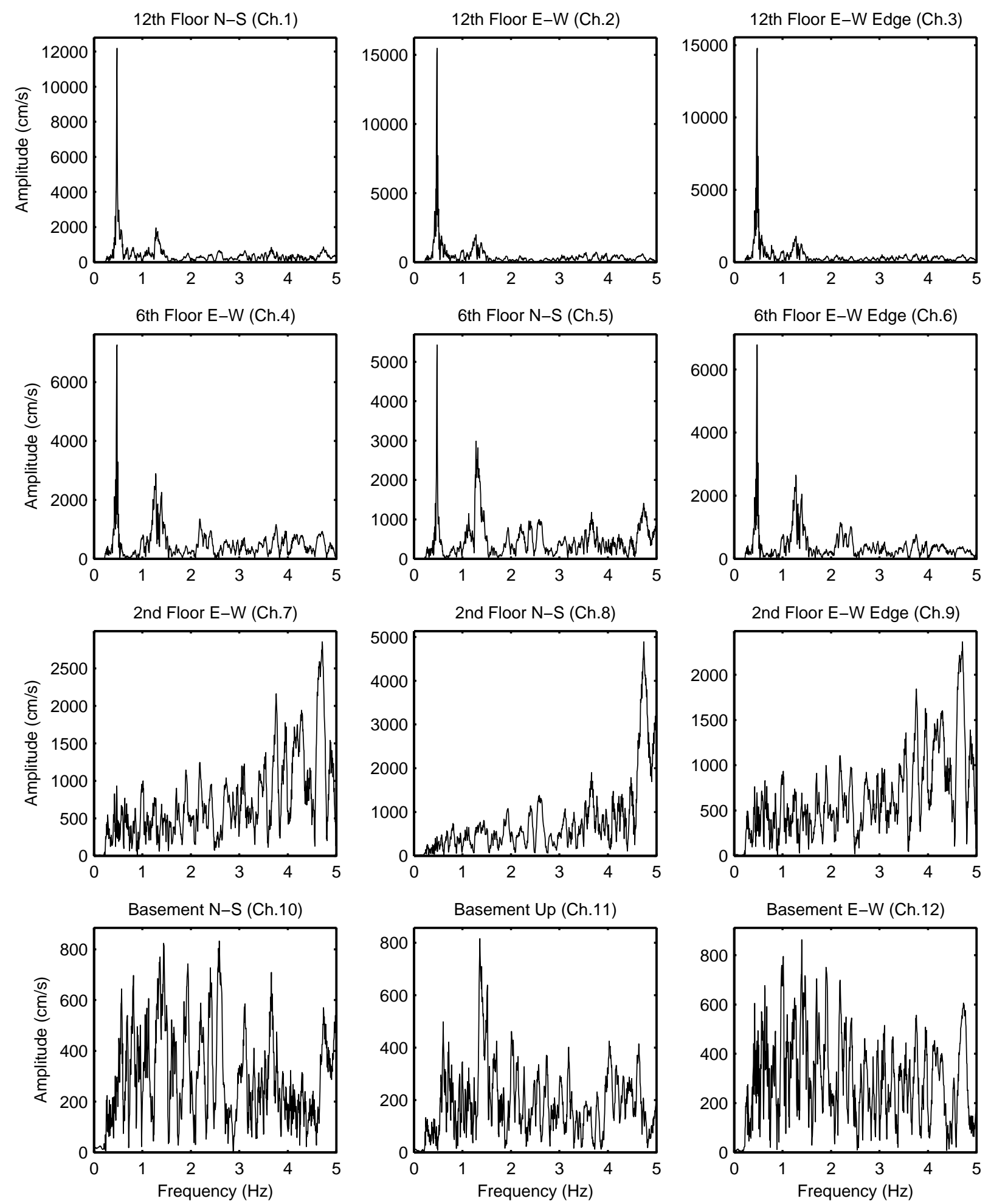

Figure C - 10. 1994 Northridge earthquake 

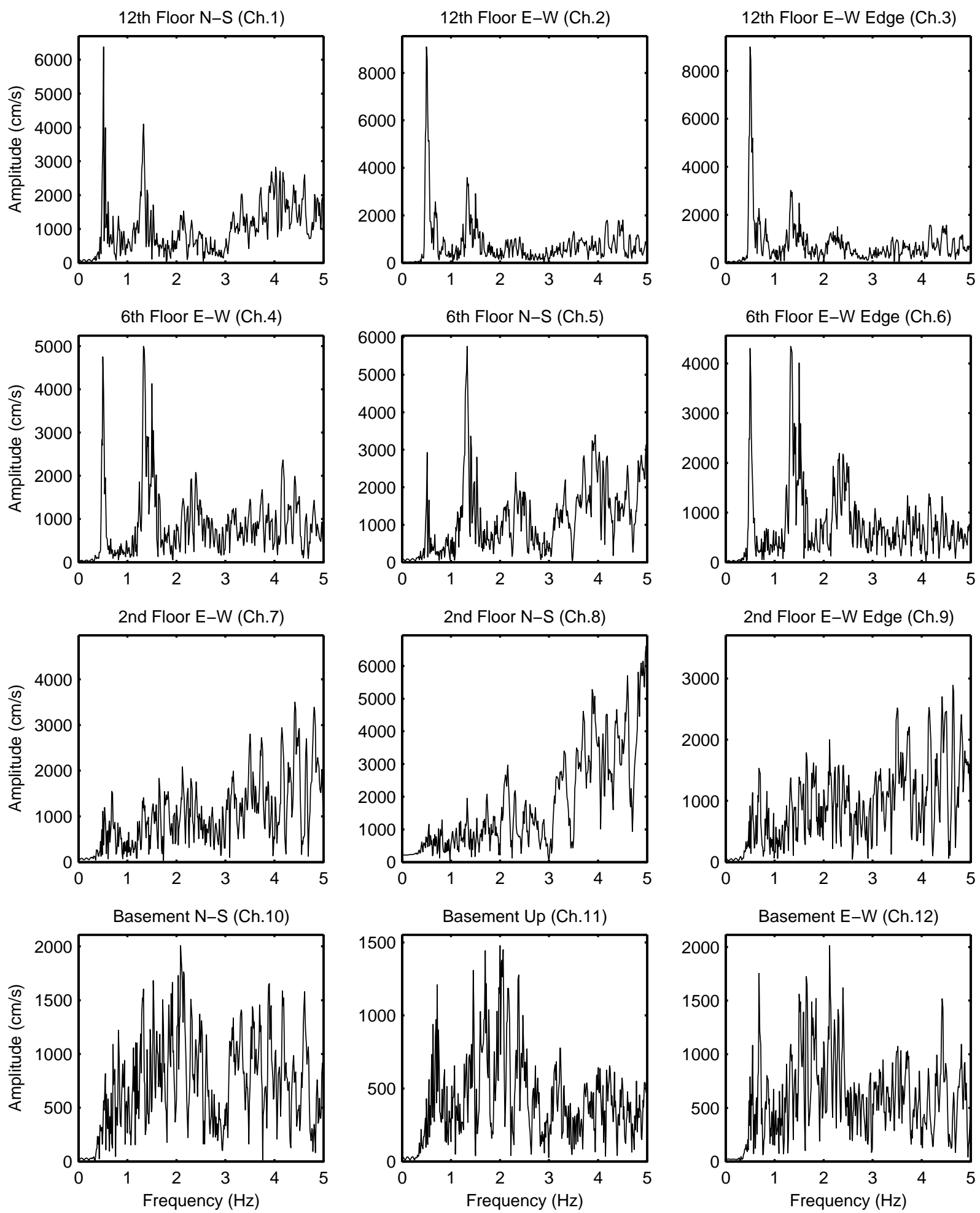

Figure C - 11. Northridge aftershock, 3/20/1994 

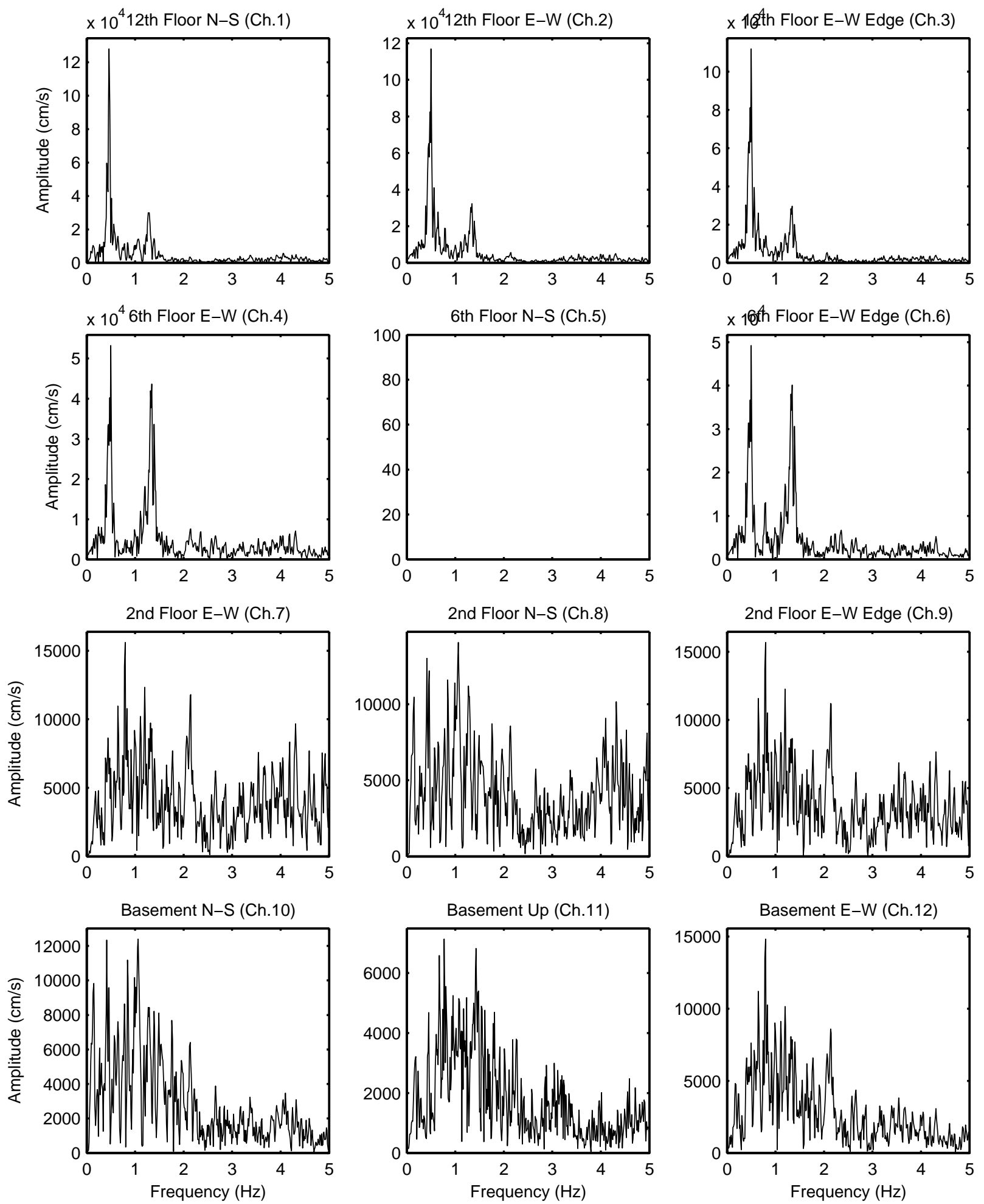

Figure C - 12. 1999 Hector Mine earthquake 

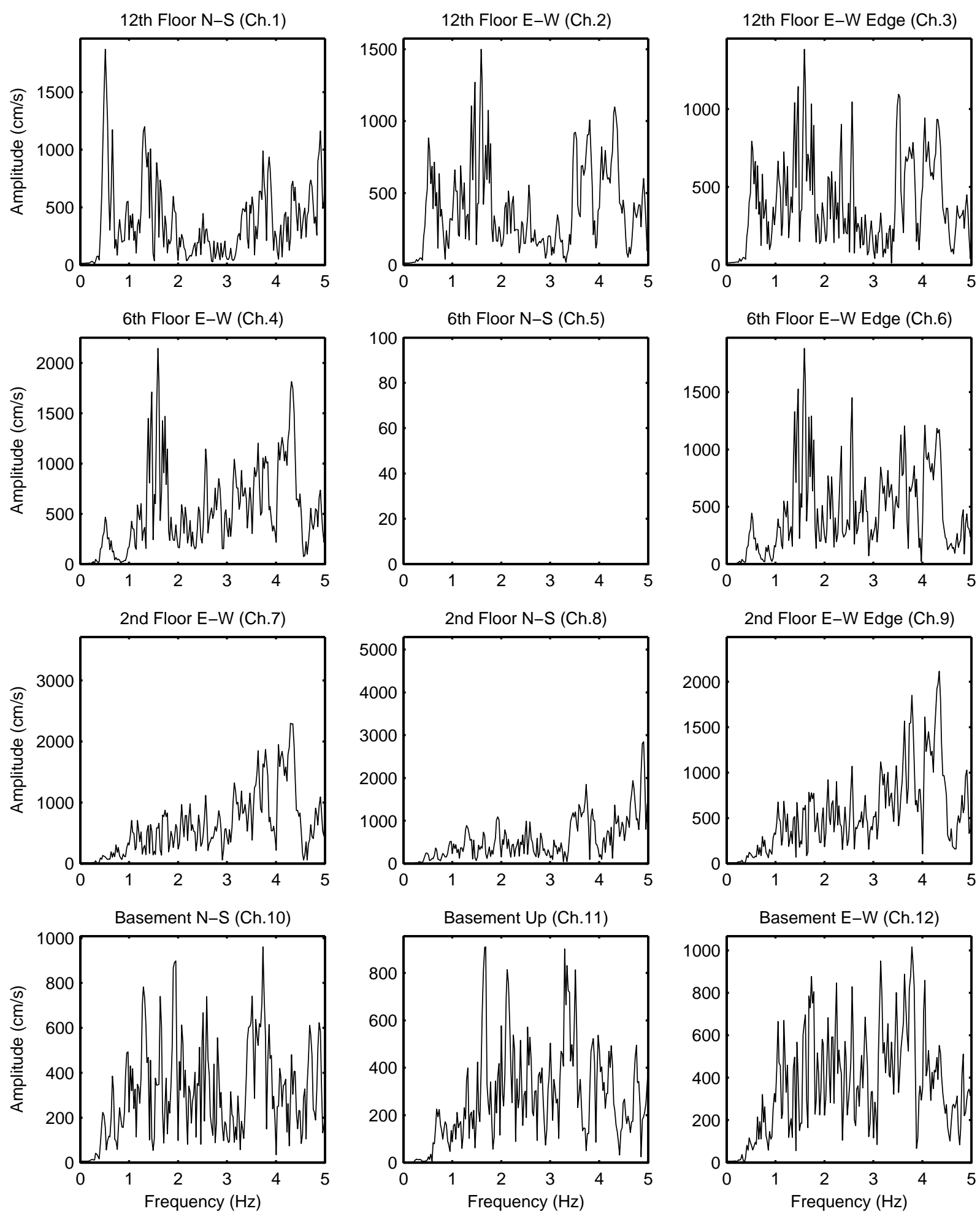

Figure C - 13. 2001 West Hollywood earthquake 

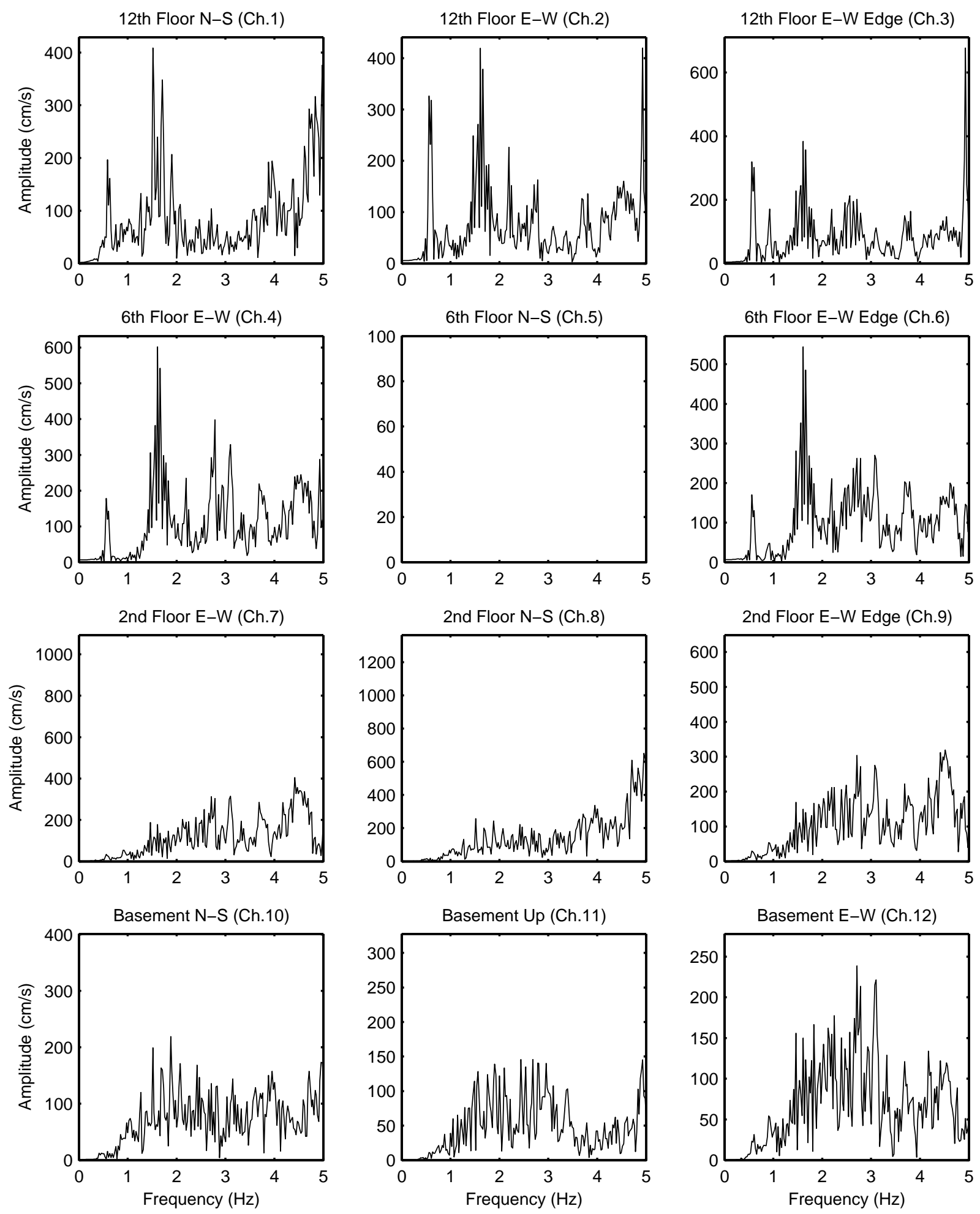

Figure C - 14. 2001 Compton earthquake 

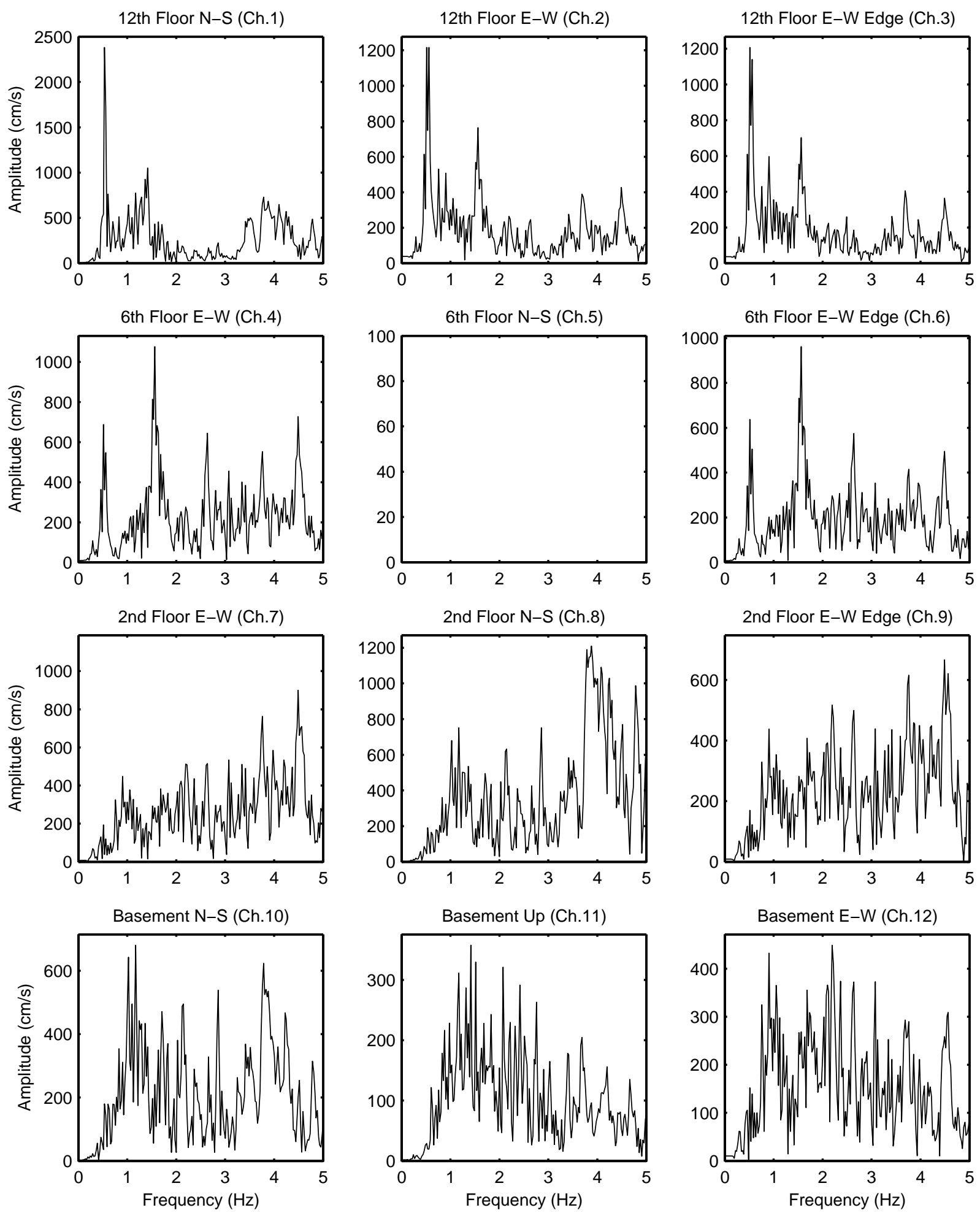

Figure C - 15. 2003 Big Bear City earthquake 

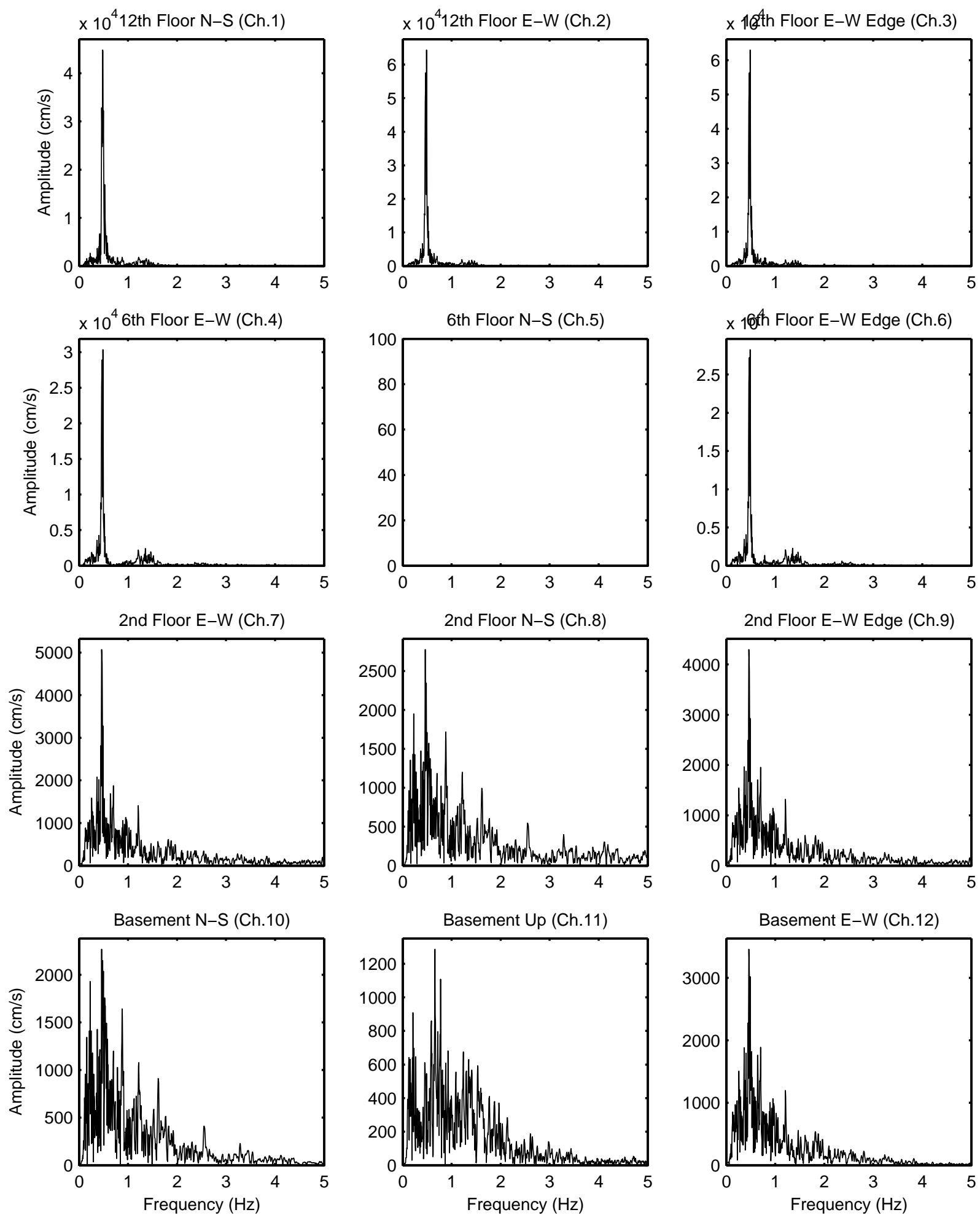

Figure C - 16. 2003 San Simeon earthquake 
Appendix D - Spectral Analysis of Selected Channel Pairs 

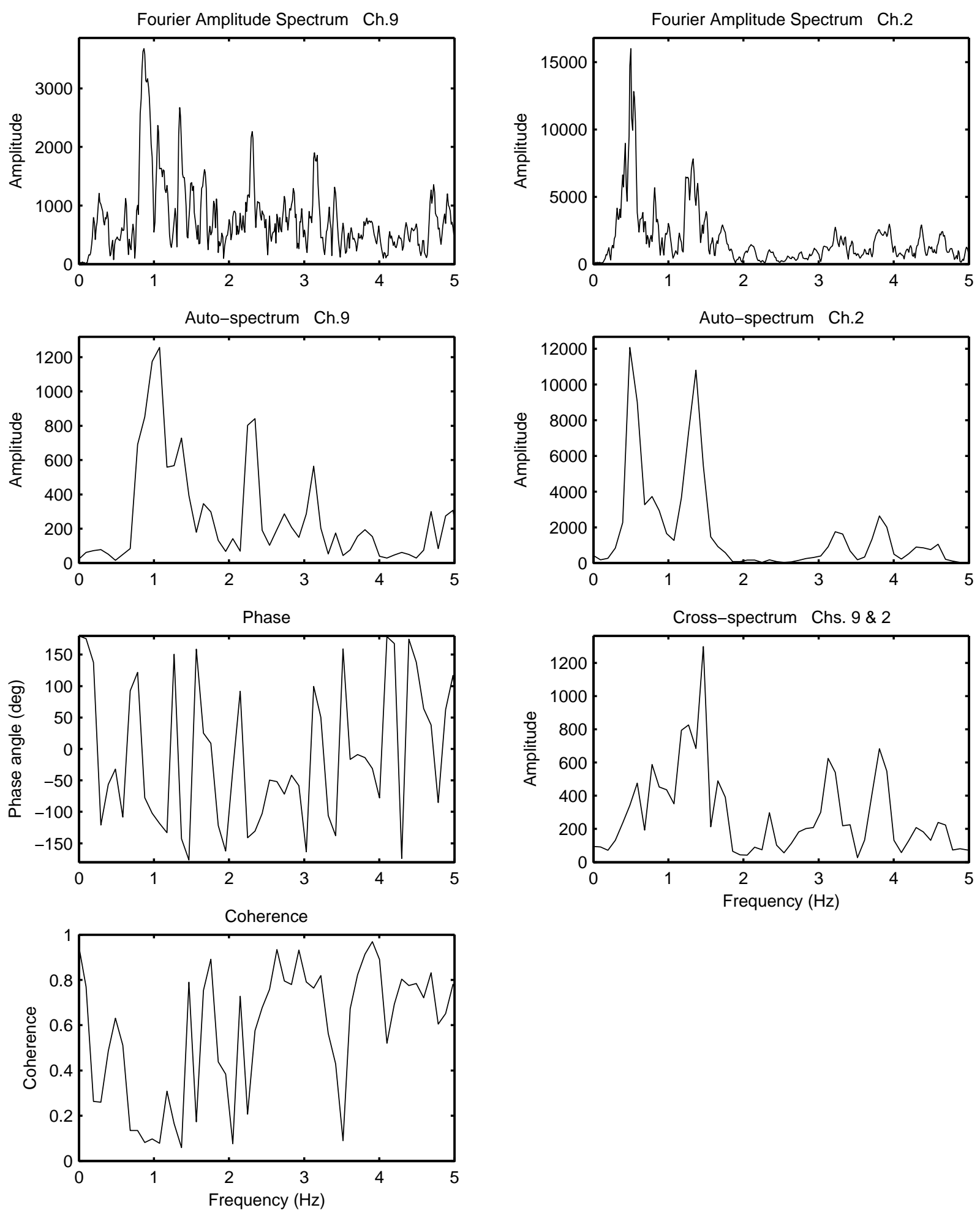

Figure D - 1. 1971 San Fernando earthquake, basement up (Ch.9) and 12th floor N-S (Ch. 2) 

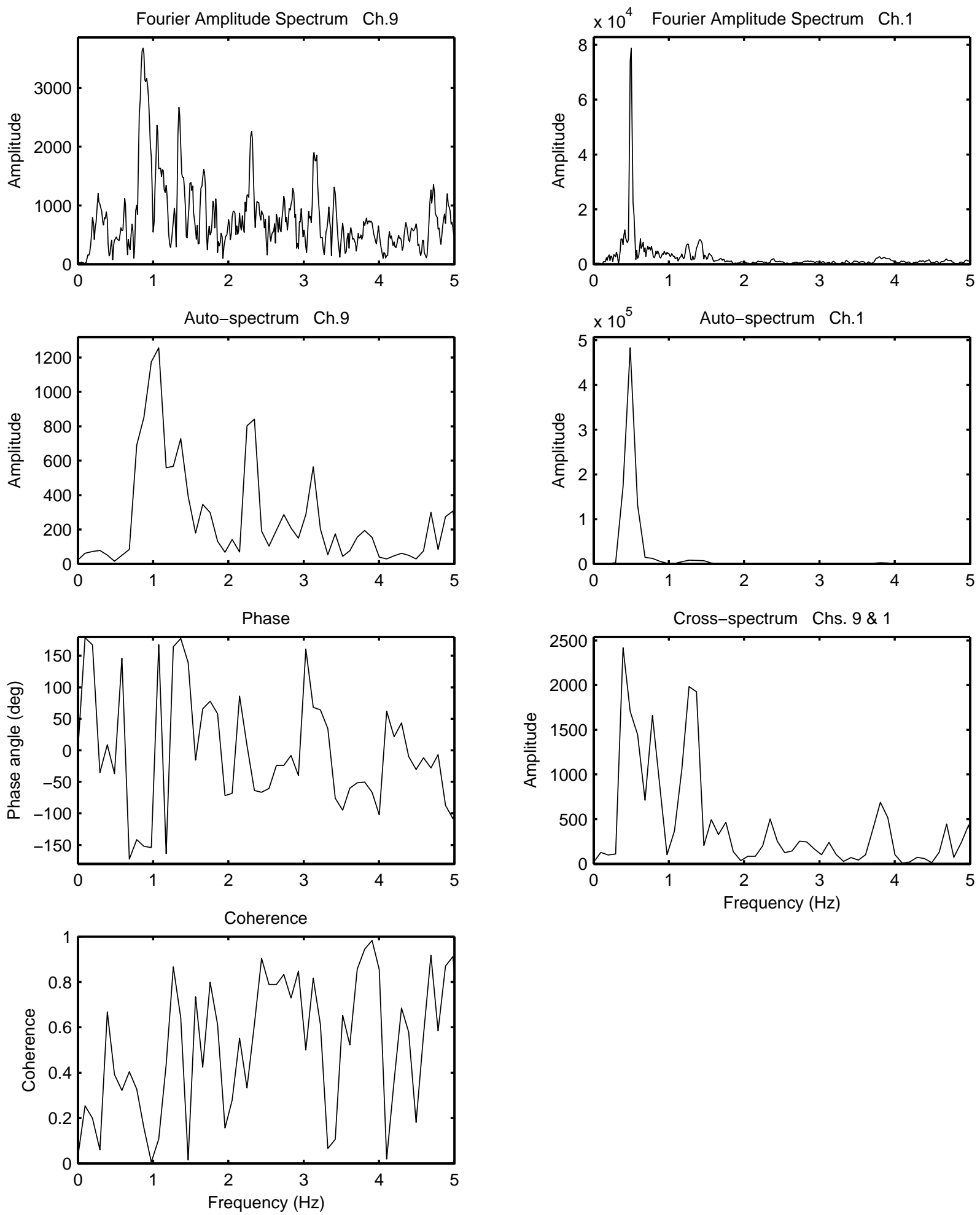

Figure D - 2. 1971 San Fernando earthquake, basement up (Ch.9) and 12th floor E-W (Ch. 1) 

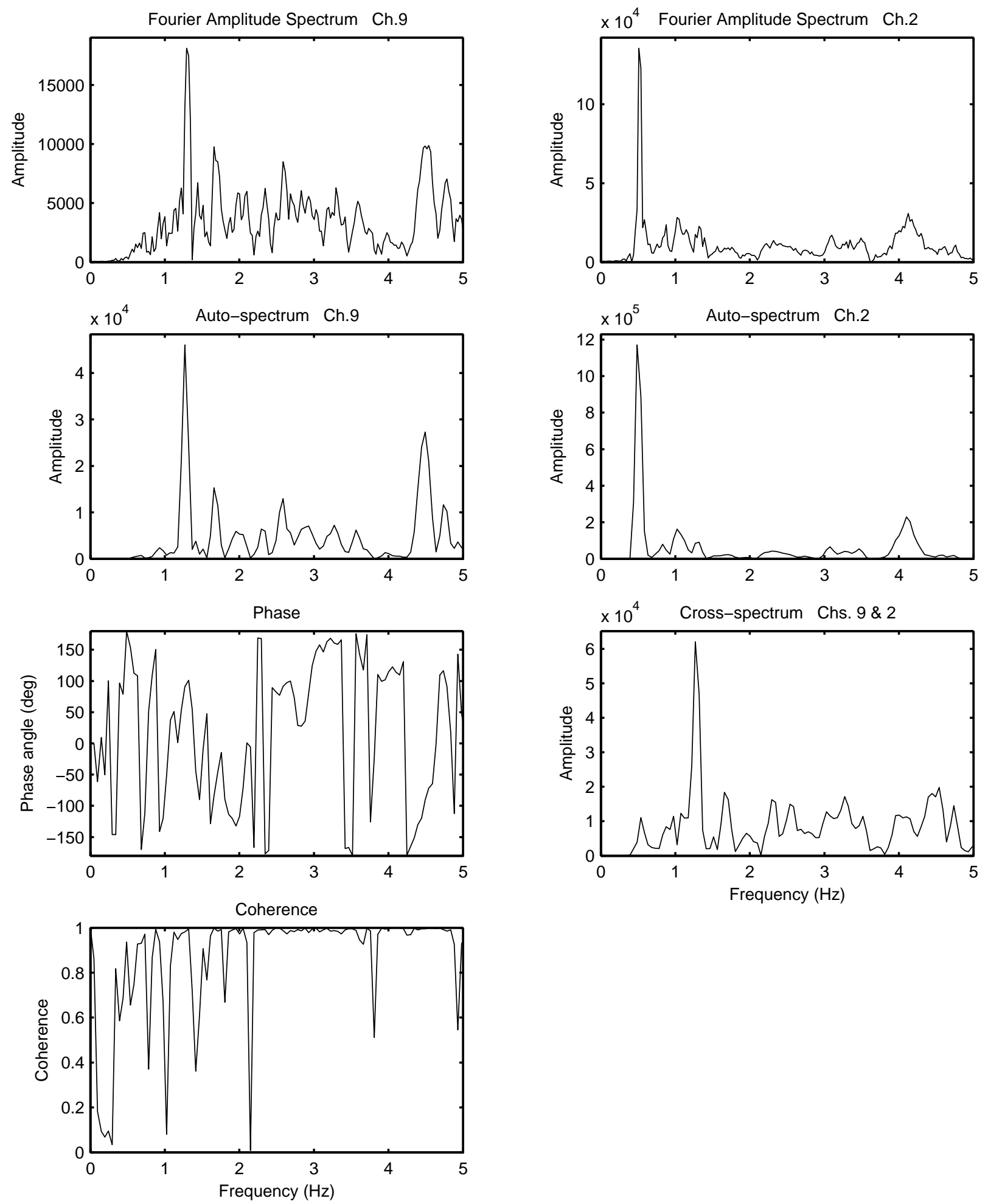

Figure D - 3. 1987 Whittier Narrows earthquake, basement up (Ch.9) and 12th floor N-S (Ch. 2) 

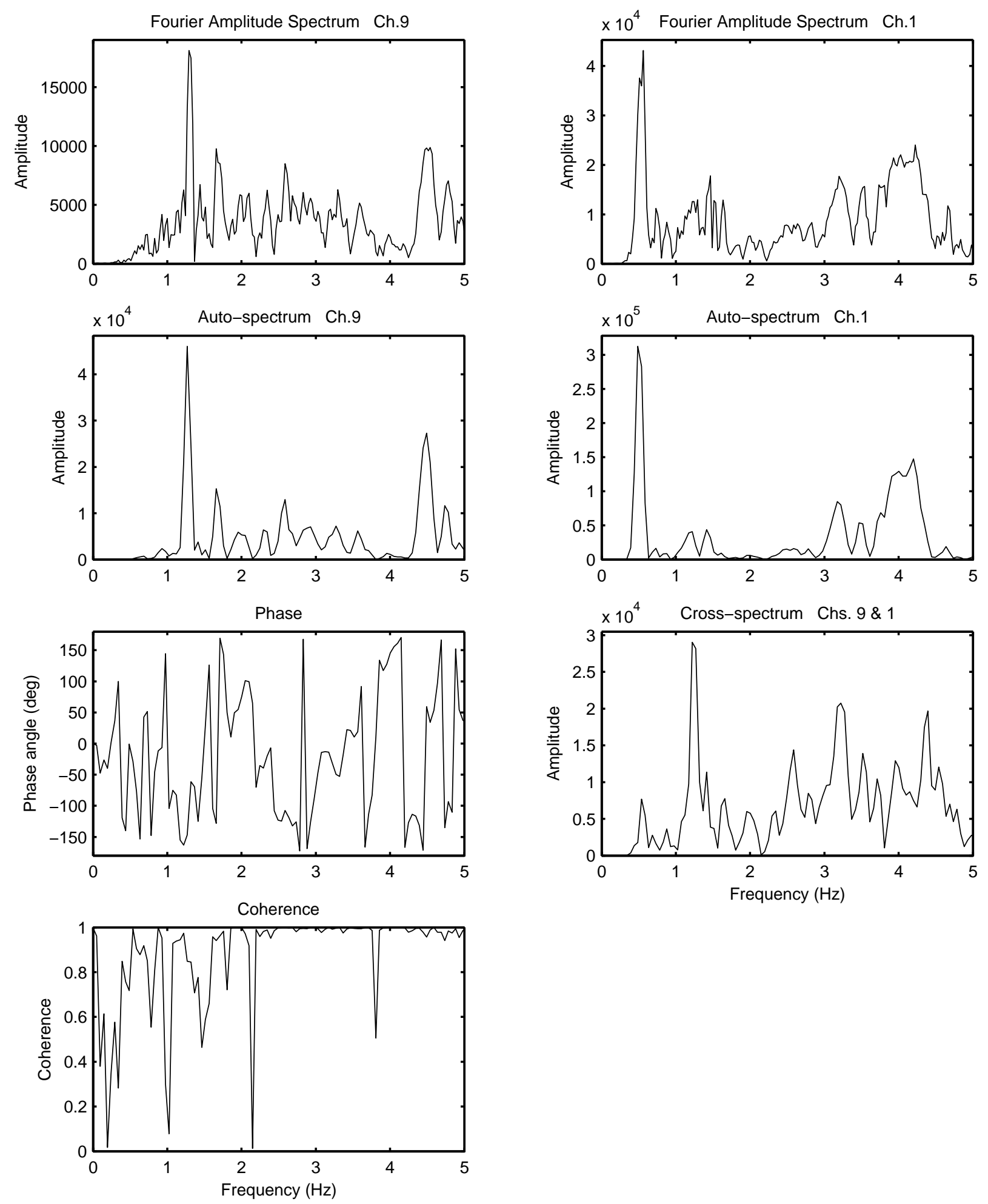

Figure D - 4. 1987 Whittier Narrows earthquake, basement up (Ch.9) and 12th floor E-W (Ch. 1) 

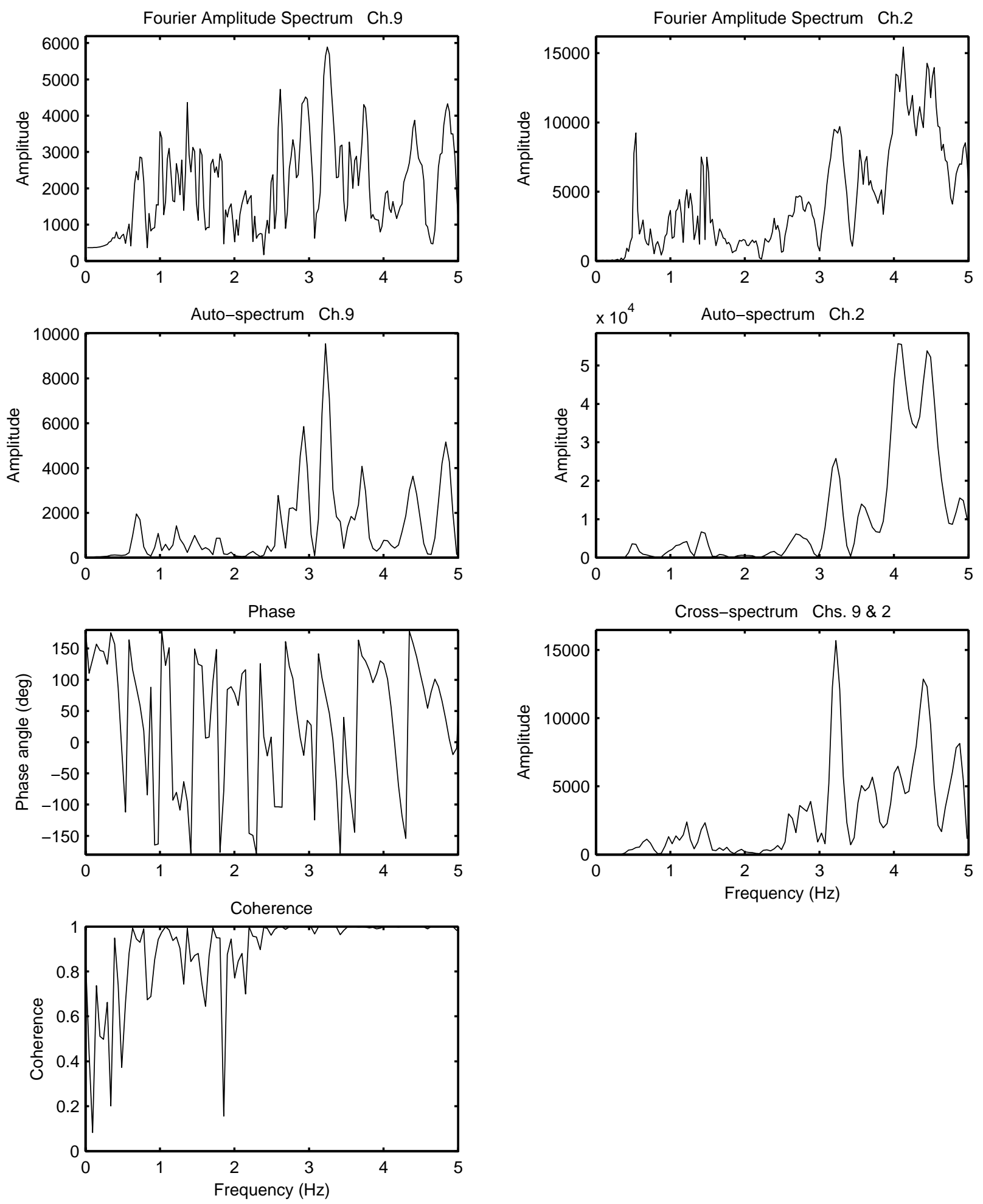

Figure D - 5. Whittier Narrows Aftershock 1, 10/4/1987, basement up (Ch.9) and 12th floor N-S (Ch. 2) 

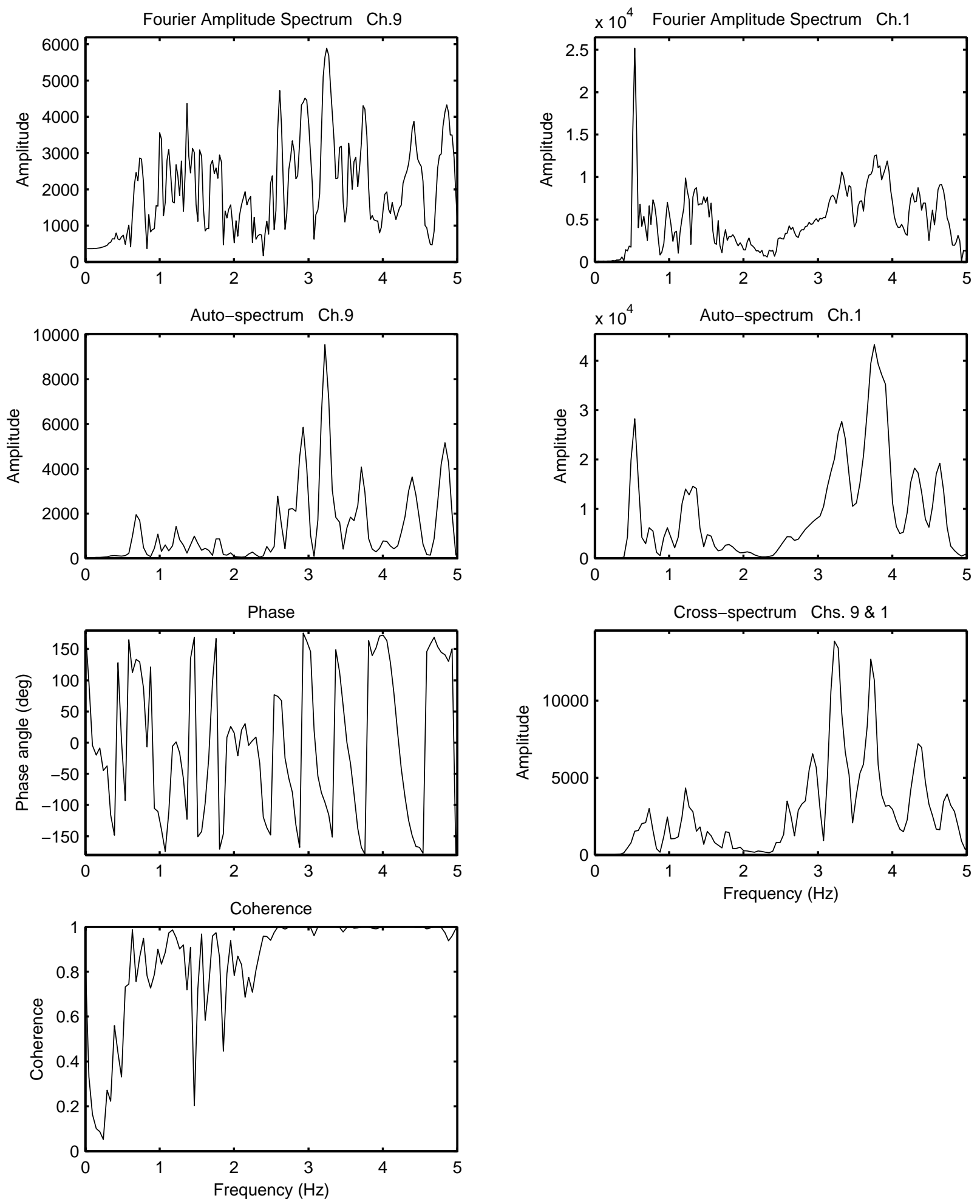

Figure D - 6. Whittier Narrows Aftershock 1, 10/4/1987, basement up (Ch. 9) and 12 th floor E-W (Ch. 1) 

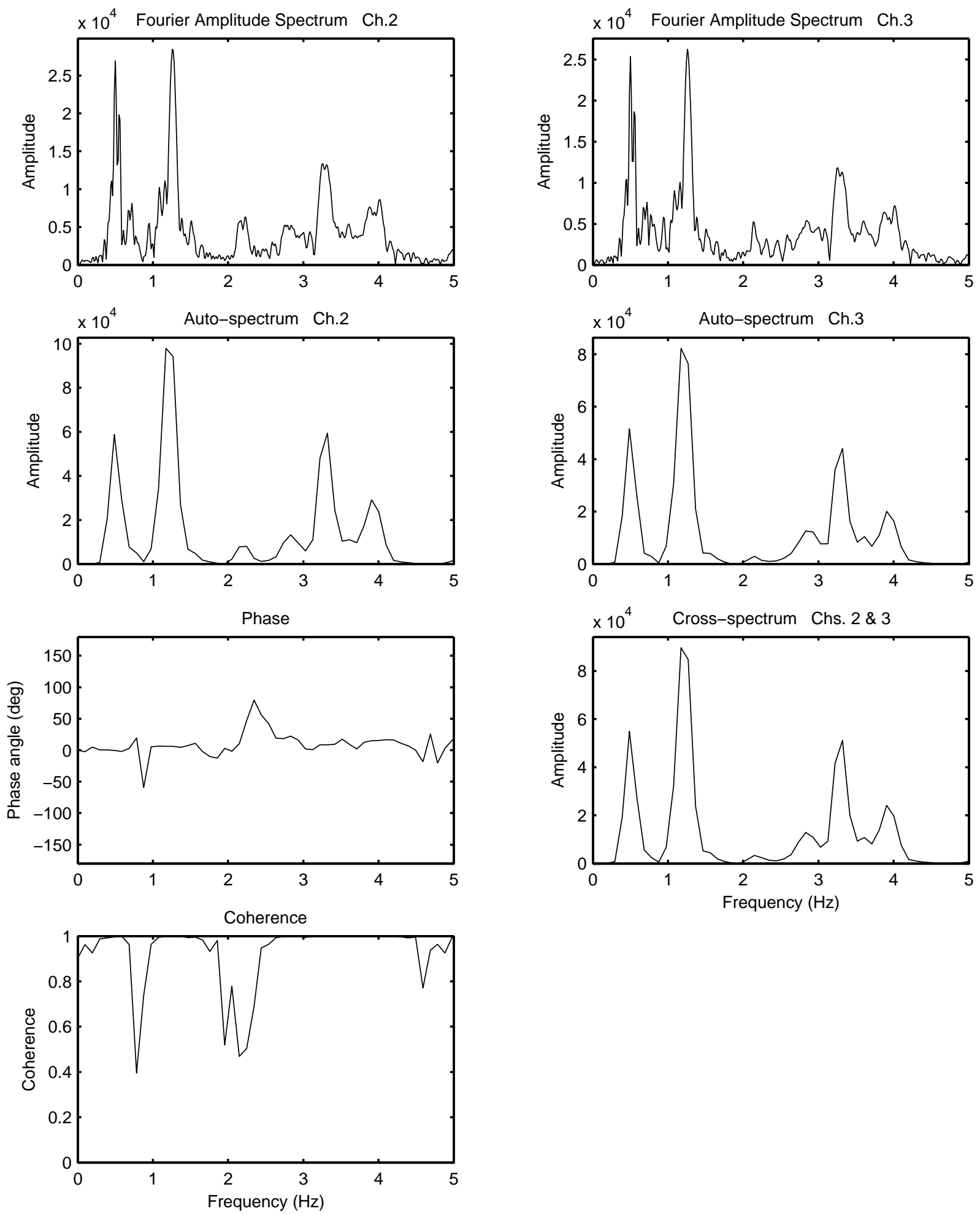

Figure D - 7. 1991 Sierra Madre earthquake, 12 th floor E-W center (Ch. 2) and edge (Ch. 3) 

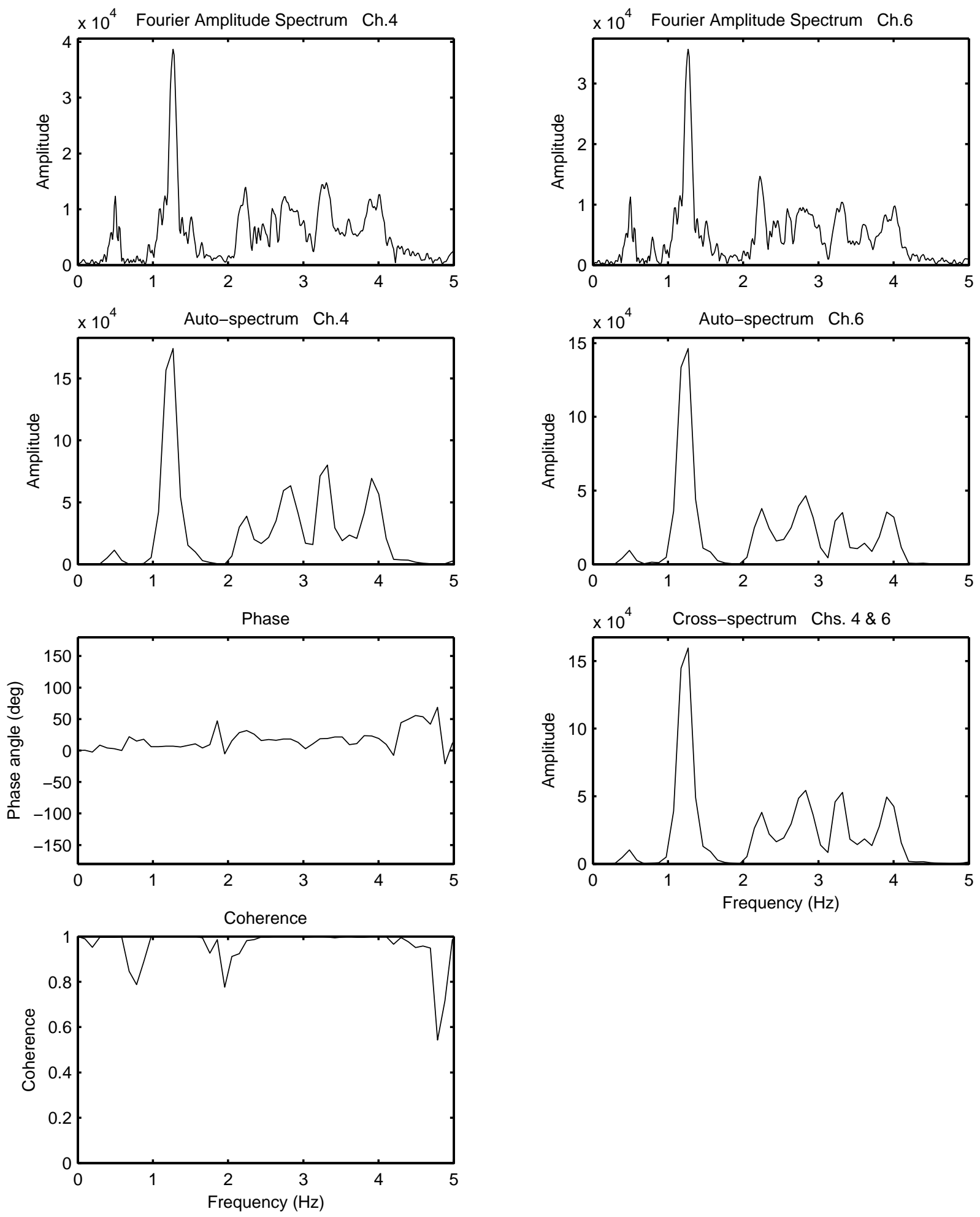

Figure D - 8. 1991 Sierra Madre earthquake, $6^{\text {th }}$ floor E-W center (Ch. 4) and edge (Ch. 6) 

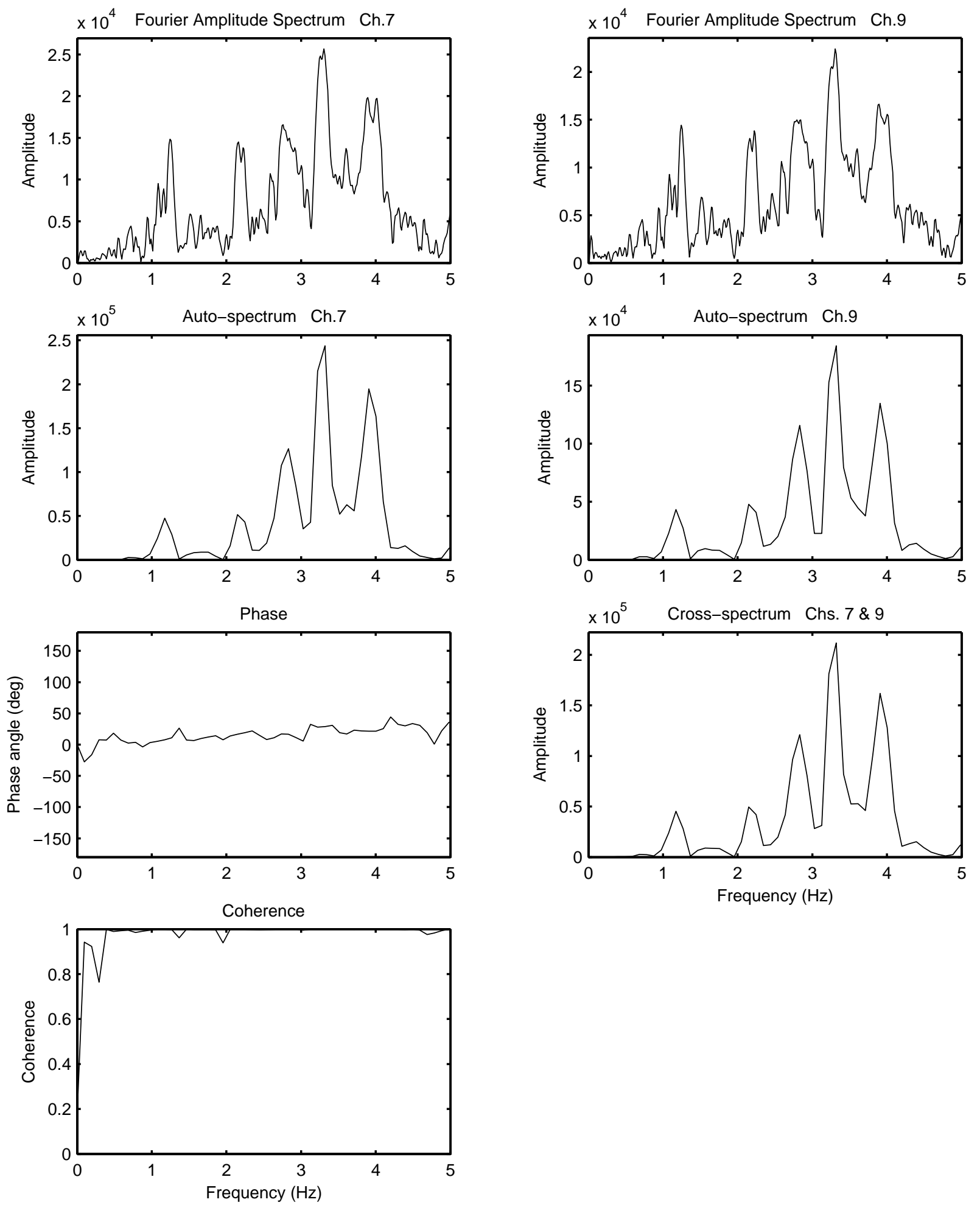

Figure D - 9. 1991 Sierra Madre earthquake, 2nd floor E-W center (Ch. 7) and edge (Ch.9) 

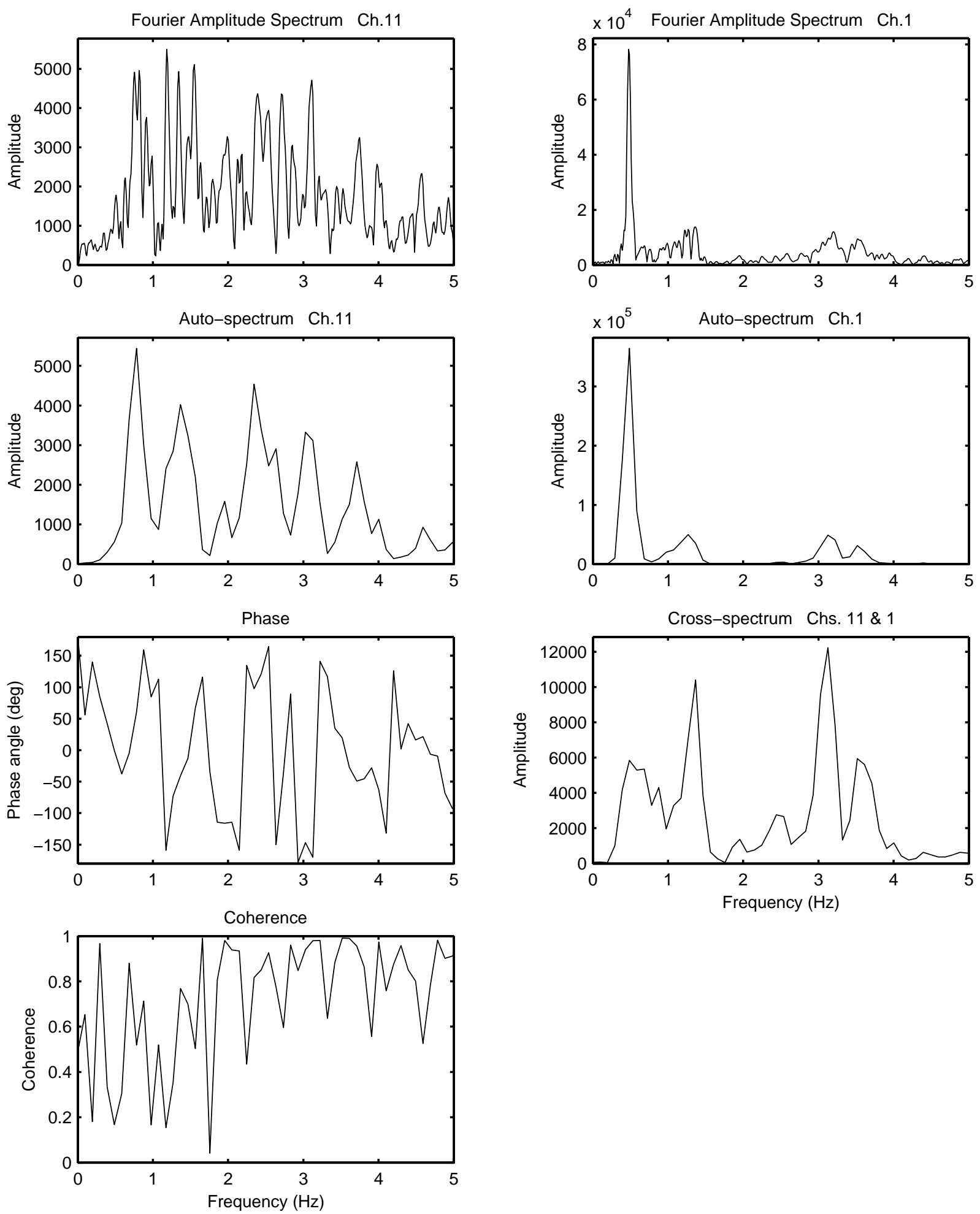

Figure D - 10. 1991 Sierra Madre earthquake, basement up (Ch.11) and 12 th floor N-S (Ch. 1) 

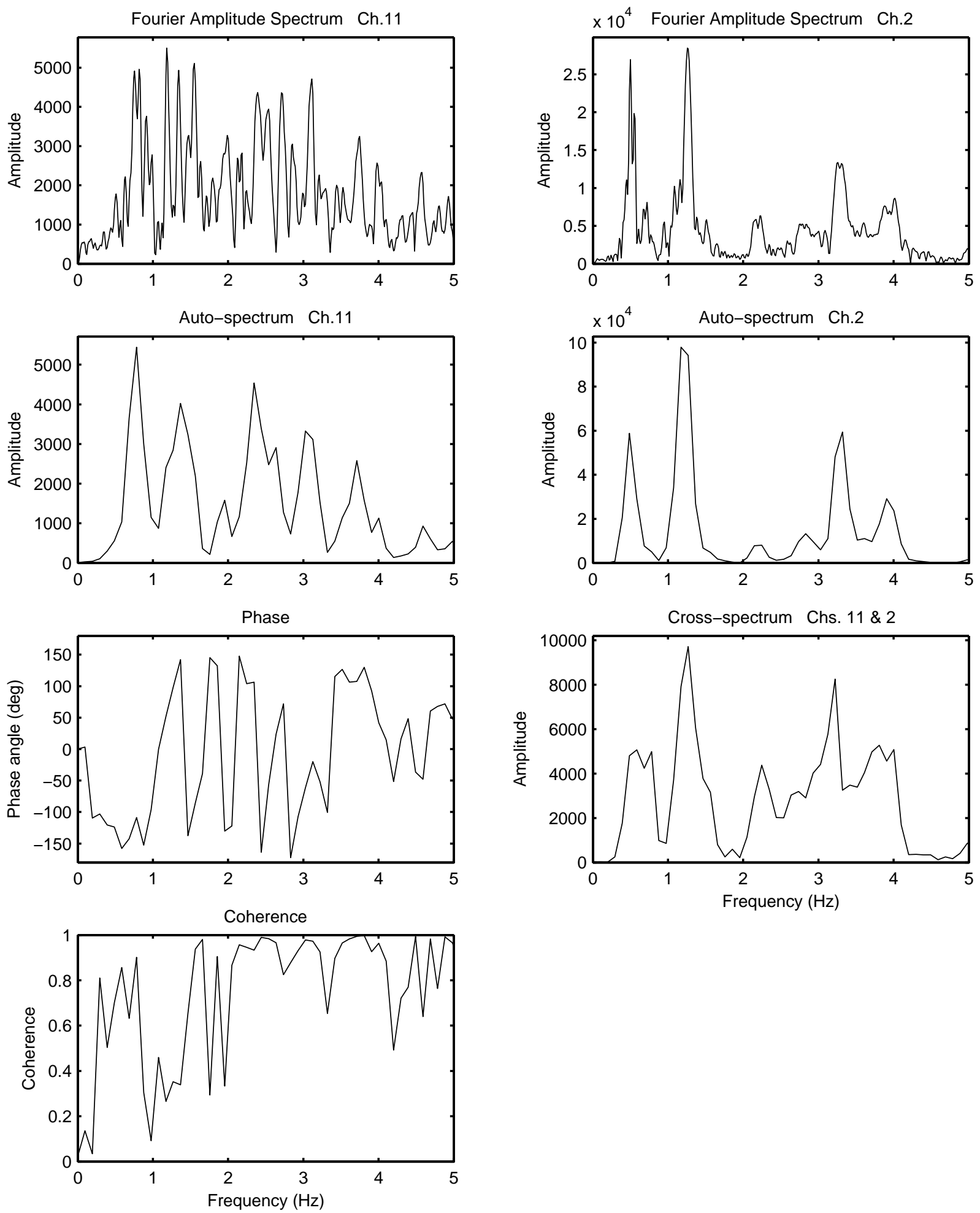

Figure D - 11. 1991 Sierra Madre earthquake, basement up (Ch.11) and 12 th floor E-W (Ch. 2) 

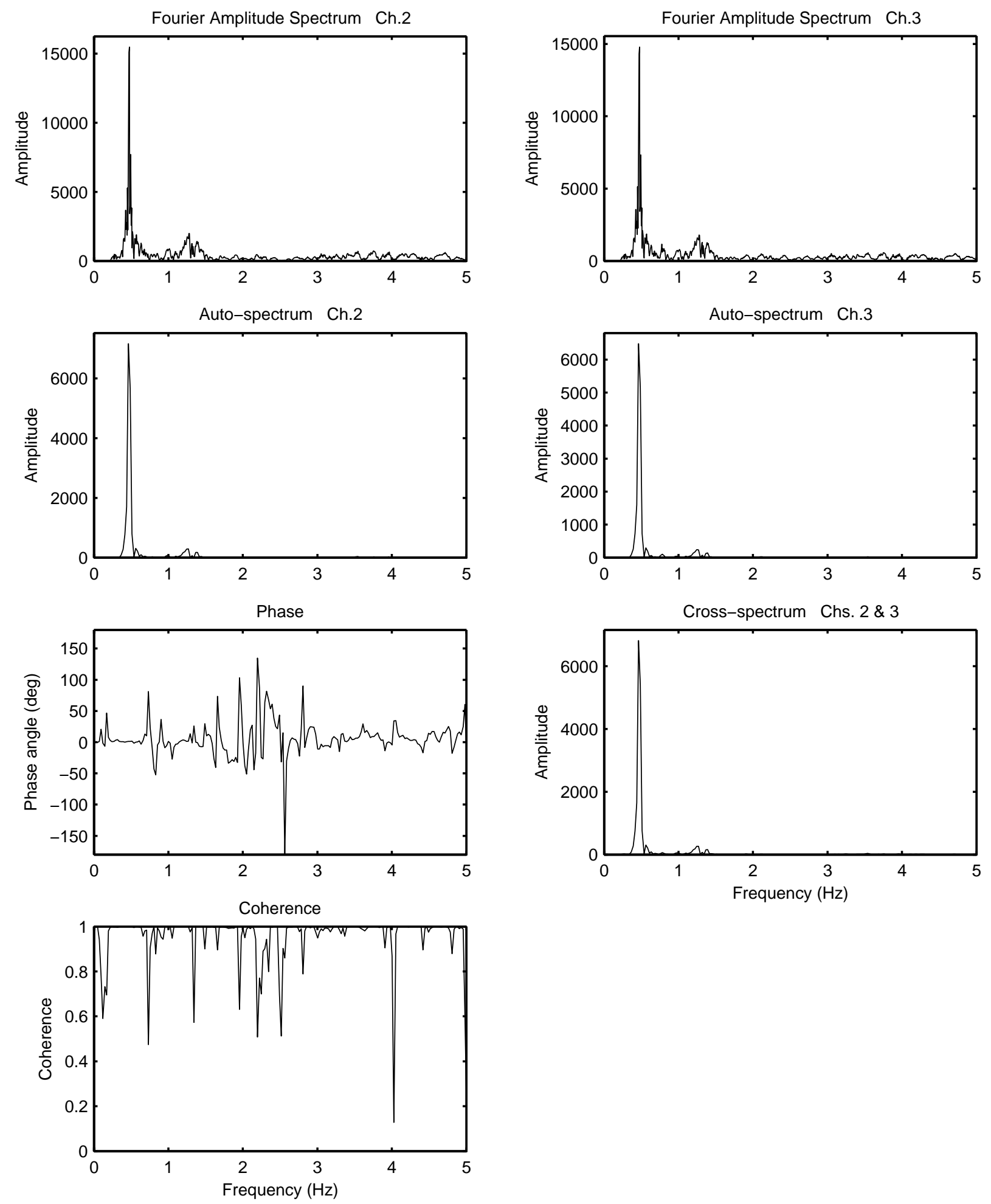

Figure D - 12. 1994 Northridge earthquake, $12^{\text {th }}$ floor E-W center (Ch. 2) and edge (Ch.3) 

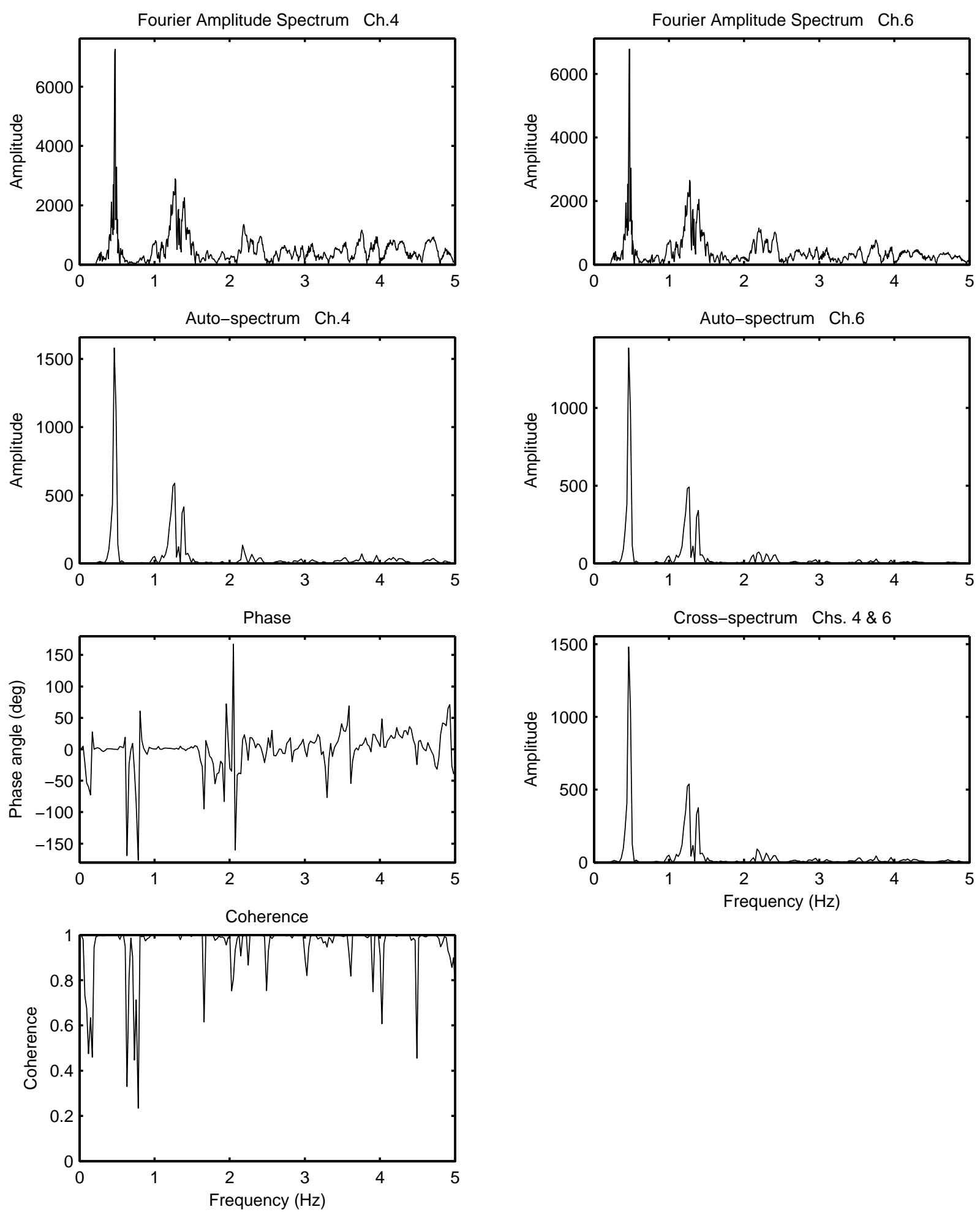

Figure D - 13. 1994 Northridge earthquake, 6th floor E-W center (Ch. 4) and edge (Ch.6) 

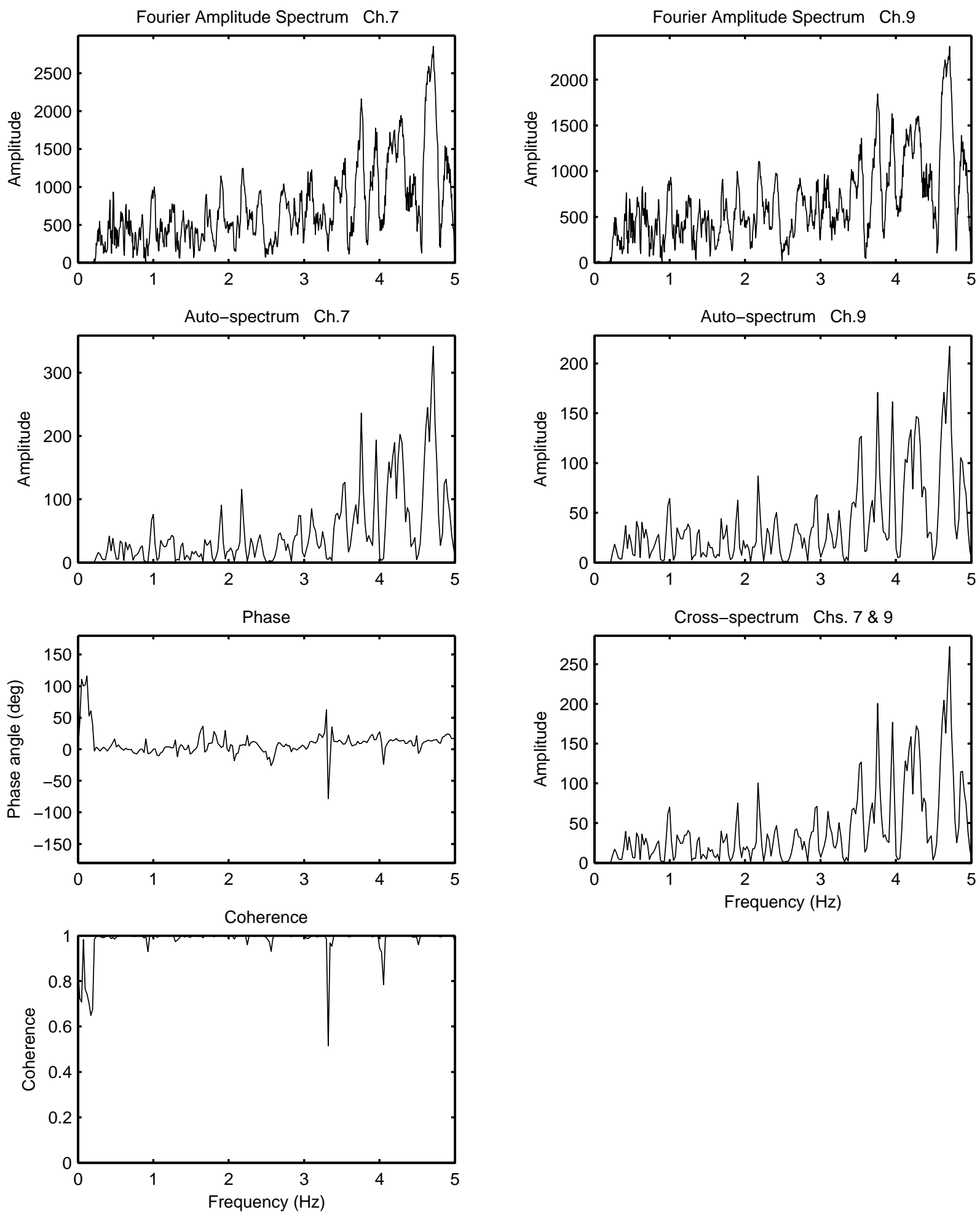

Figure D - 14. 1994 Northridge earthquake, $2^{\text {nd }}$ floor E-W center (Ch. 7) and edge (Ch.9) 

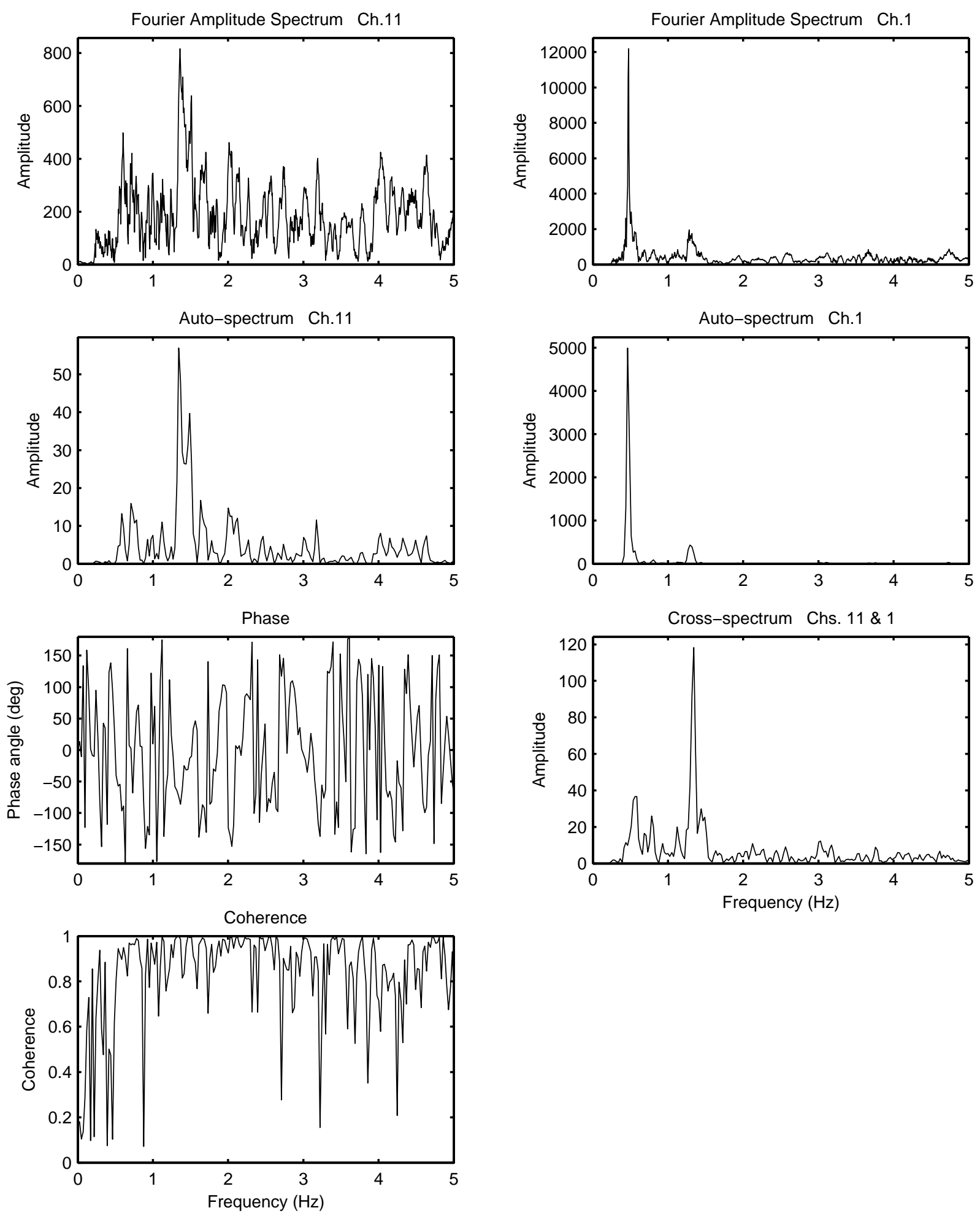

Figure D - 15. 1994 Northridge earthquake, basement up (Ch.11) and 12th floor N-S (Ch. 1) 

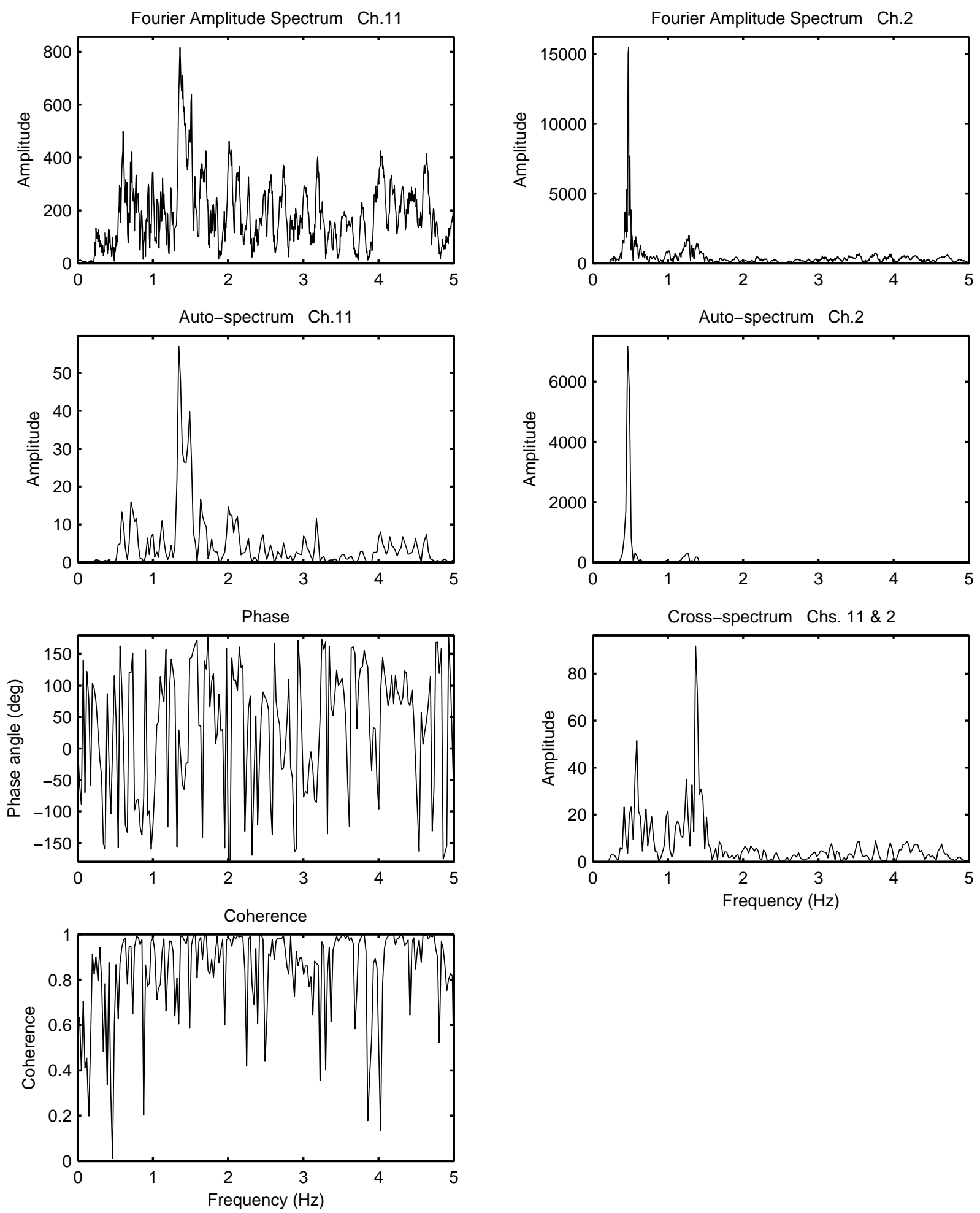

Figure D - 16. 1994 Northridge earthquake, basement up (Ch.11) and 12th floor E-W (Ch. 2) 

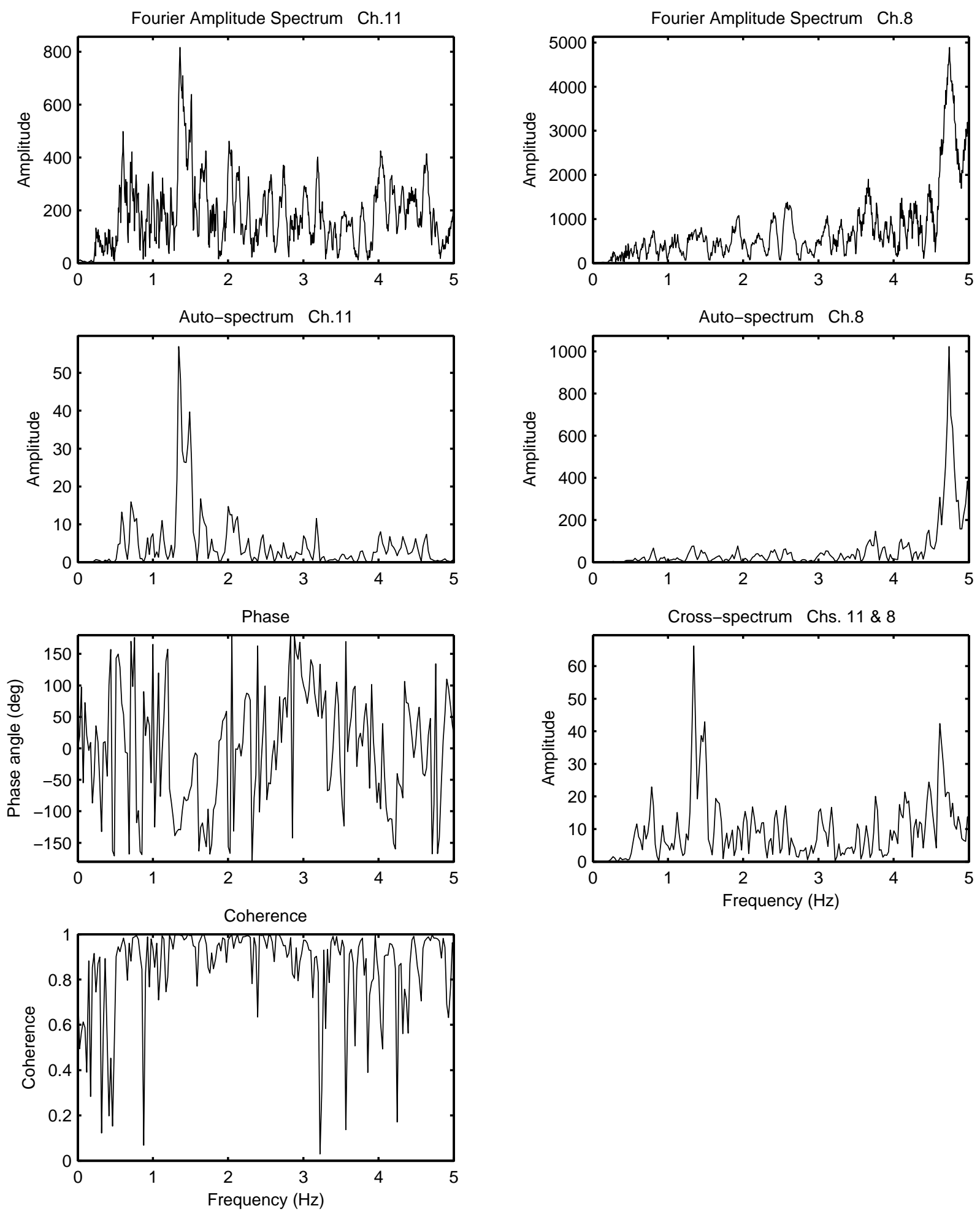

Figure D - 17. 1994 Northridge earthquake, basement up (Ch.11) and 2nd floor N-S (Ch. 8) 

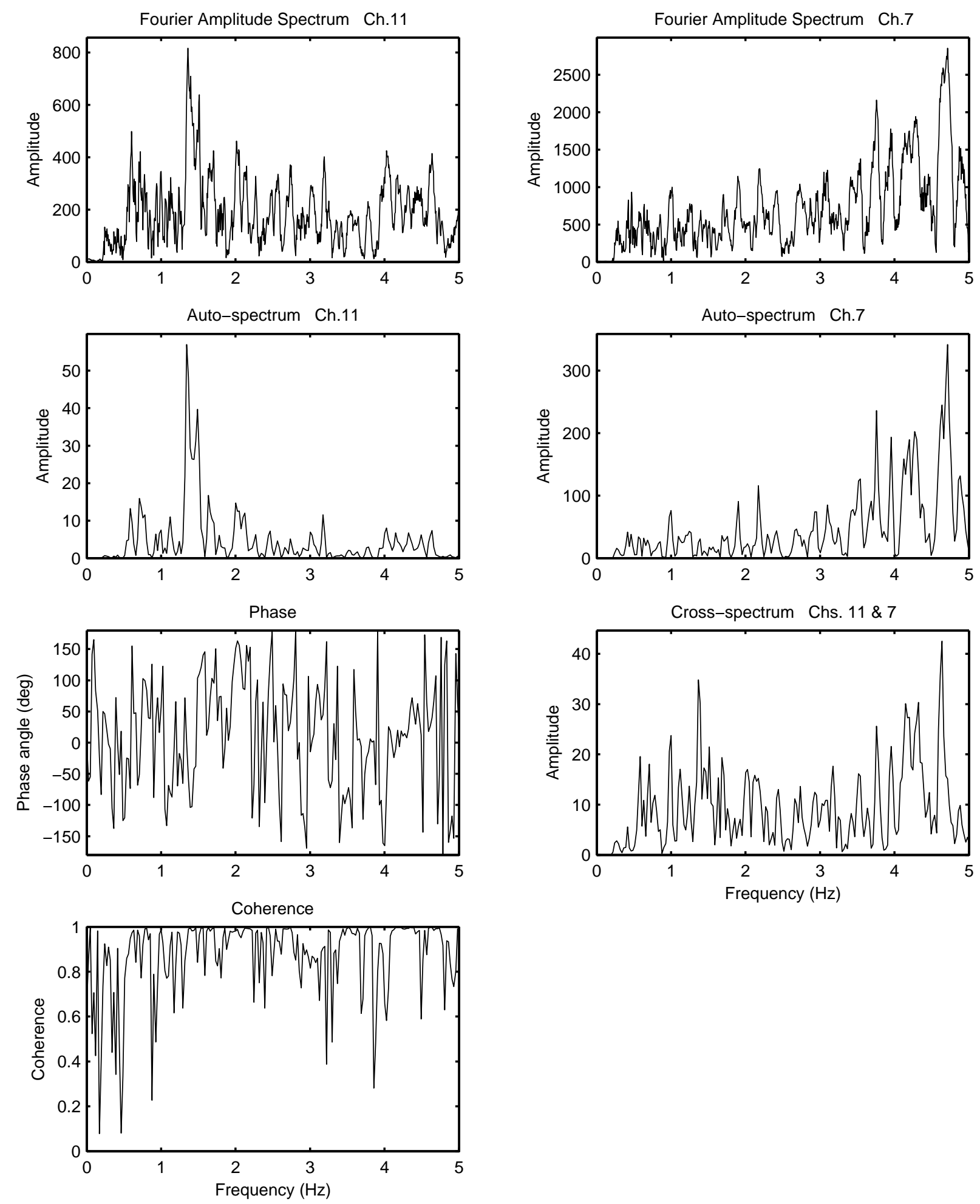

Figure D - 18. 1994 Northridge earthquake, basement up (Ch.11) and 2nd floor E-W (Ch. 7) 


\section{Appendix E - Joint Time-Frequency Analyses for Selected Channels and Earthquakes}



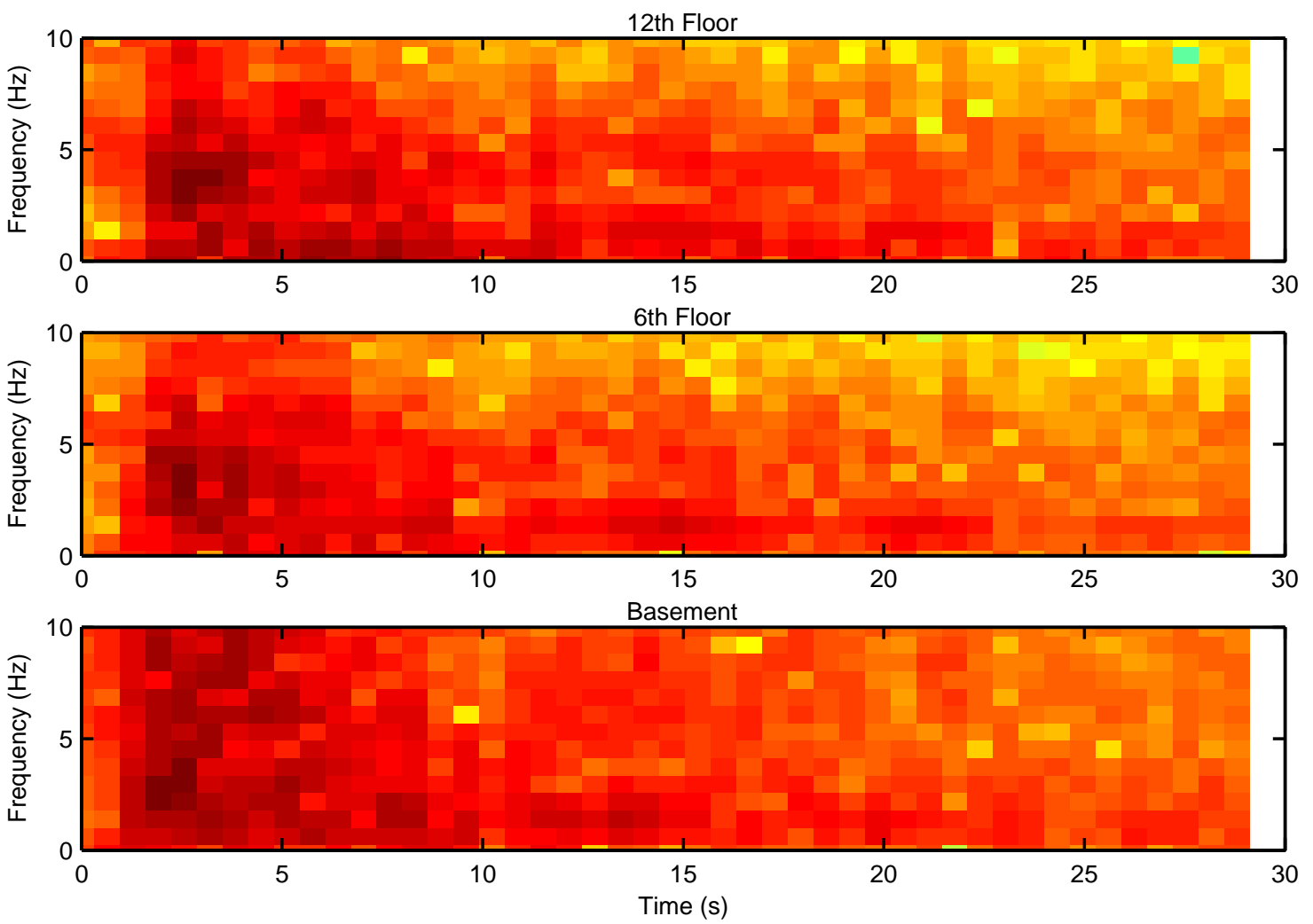

Figure E - 1. 1987 Whittier Narrows earthquake, E-W direction, window size 256 points 

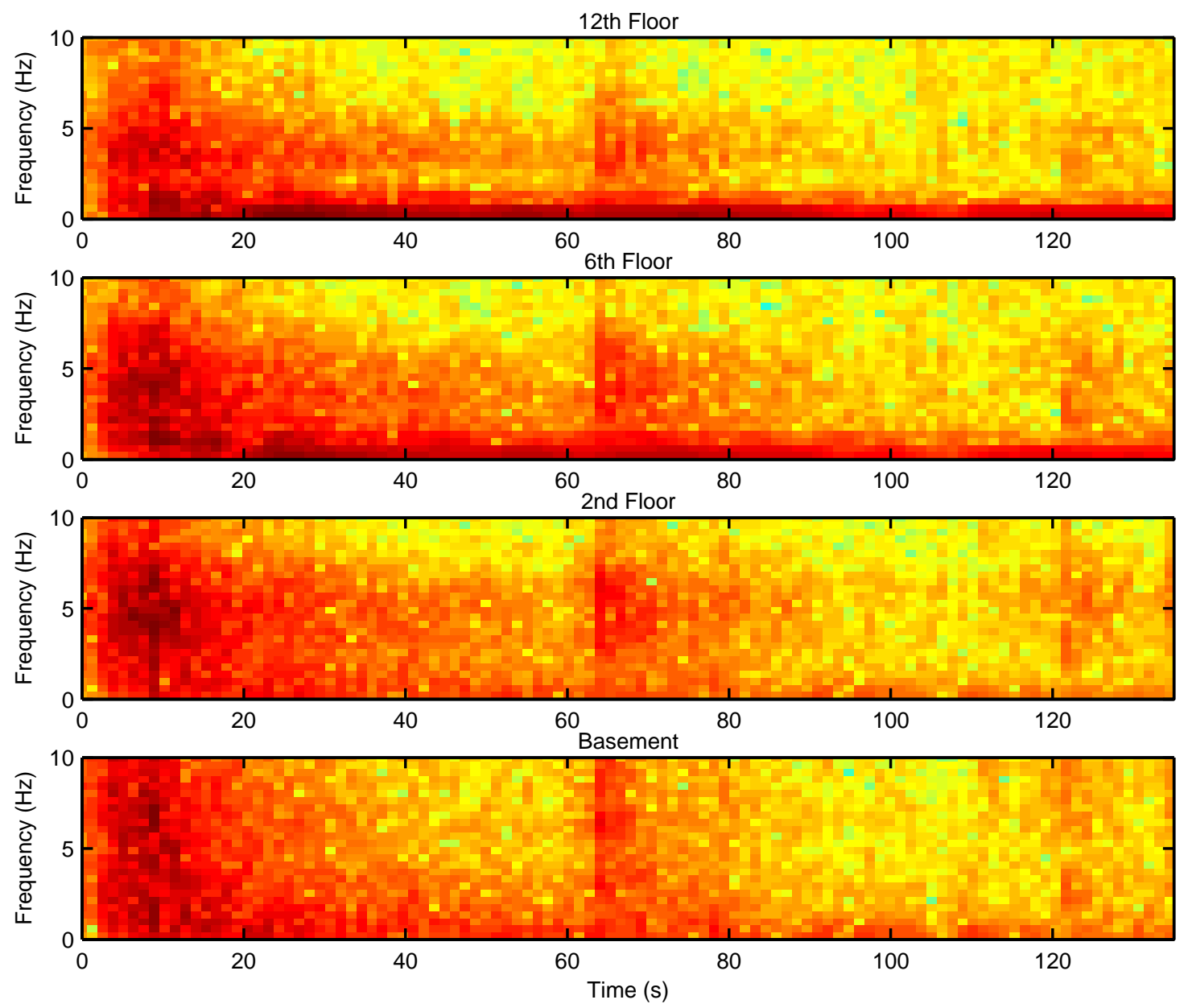

Figure E - 2. 1994 Northridge earthquake, E-W direction, window size 256 points 

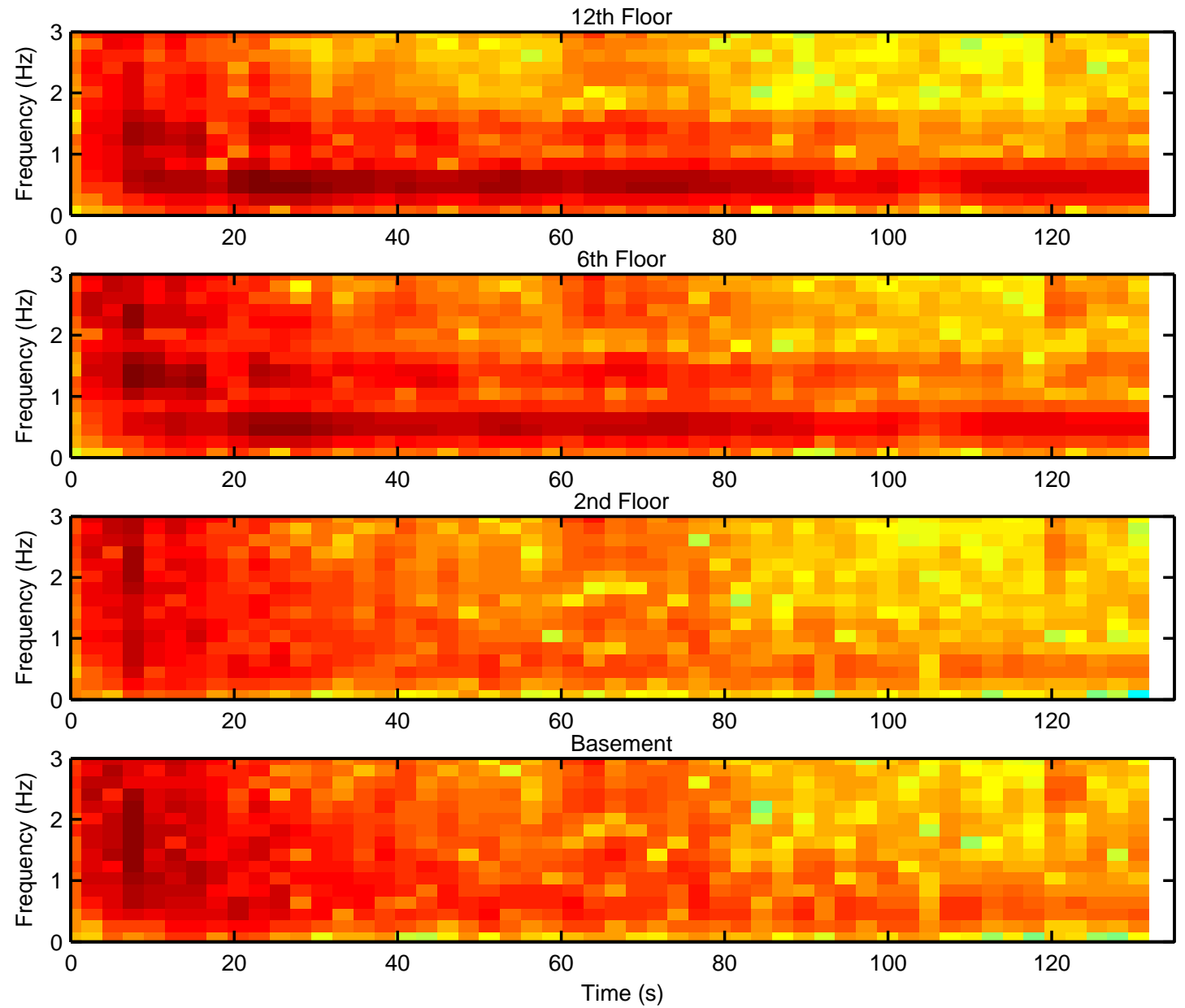

Figure E - 3. 1994 Northridge earthquake, E-W direction, low-frequency region, window size 512 points 


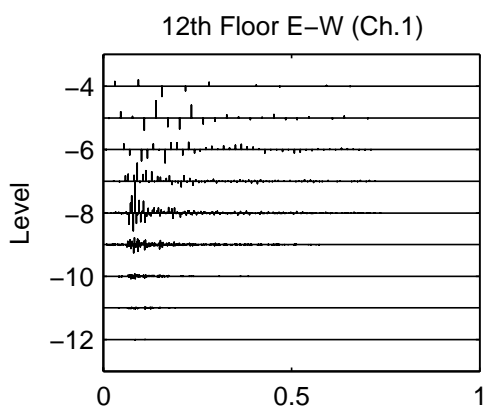

6th Floor E-W (Ch.4)
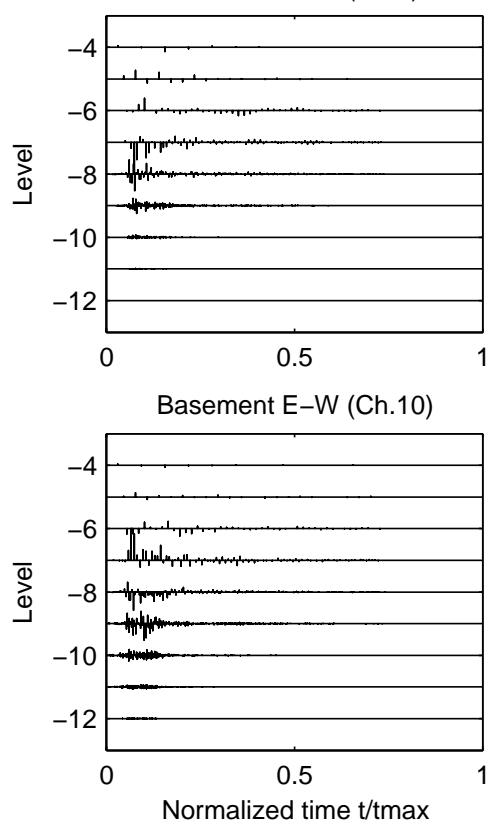

12th Floor N-S (Ch.2)

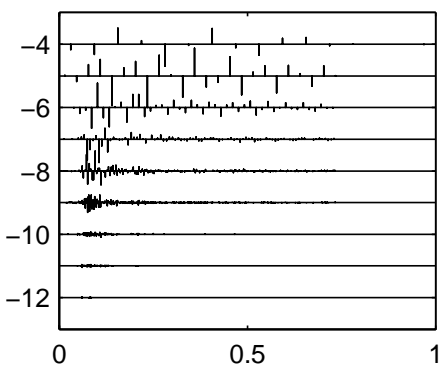

6th Floor N-S (Ch.5)

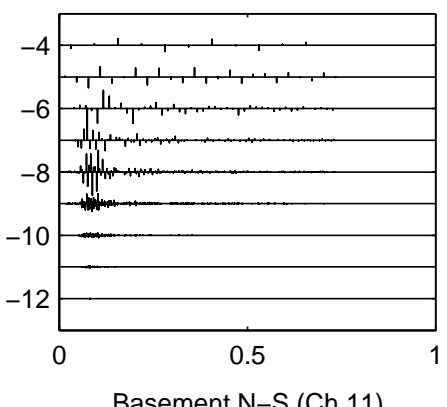

Basement N-S (Ch.11)

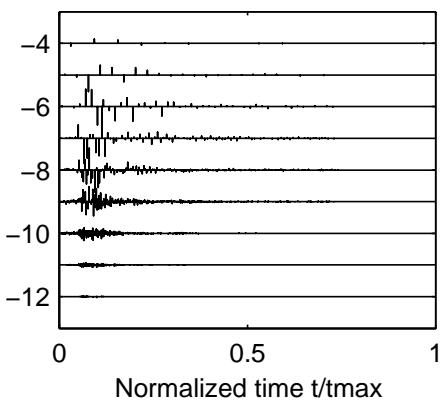

12th Floor Up (Ch.3)

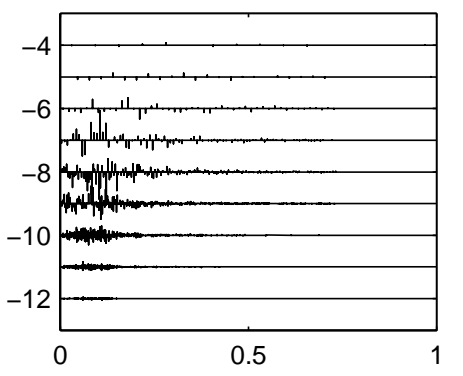

6th Floor Up (Ch.6)
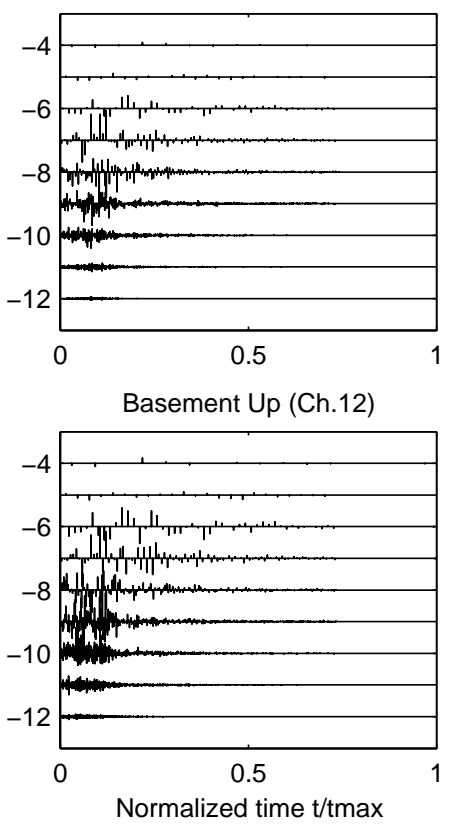

Figure E - 4. Spike plots of wavelet coefficients, Whittier Narrows earthquake, Daubechies D4 wavelet. Each spike represents the amplitude of the wavelet coefficient at that time location. Level refers to level of wavelet decomposition as is expressed in terms of powers of two related to the scale. Broadly, high frequency content increases with increasingly negative powers of two (smaller scale). The precise form of the relationship between scale and frequency depends on the mother wavelet used. 

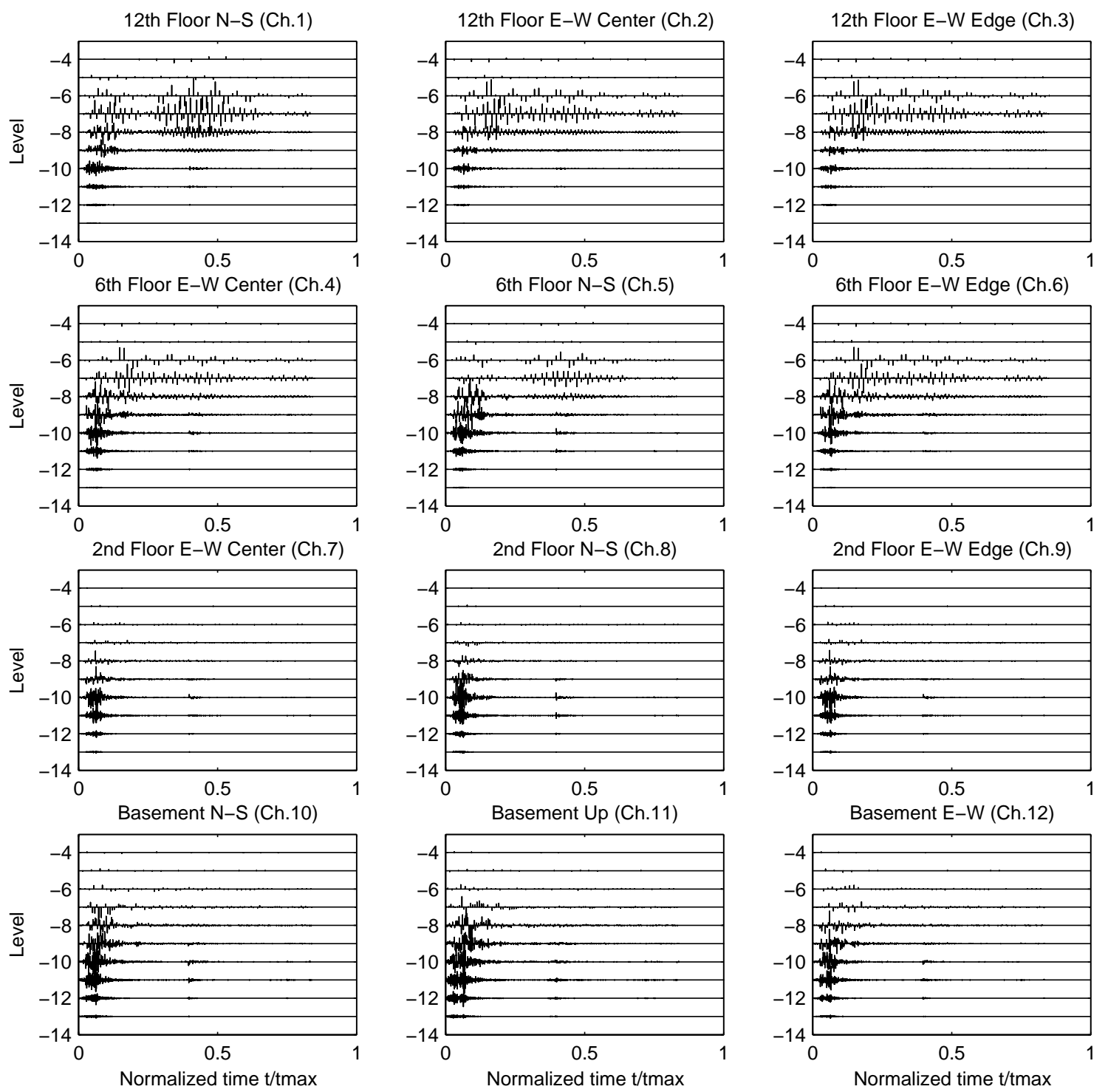

Figure E - 5. Spike plots of wavelet coefficients, Northridge earthquake, Daubechies D4 wavelet. The aftershock arrival at 0.4 tmax $(\sim 65 \mathrm{sec})$ is clearly visible in the $2^{\text {nd }}$ floor transforms. The $12^{\text {th }}$ floor records show significant lower frequency response, as well as beating, which is indicated by a pattern similar to amplitude modulation in the wavelet coefficients. 